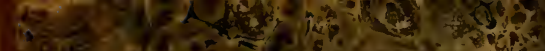

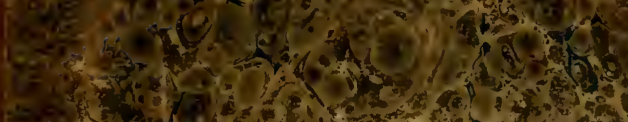

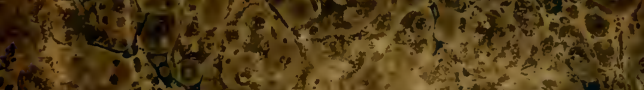

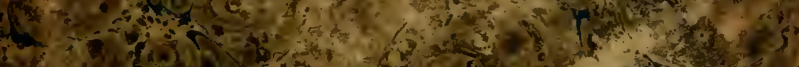

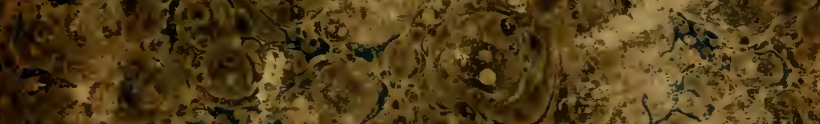
- is and

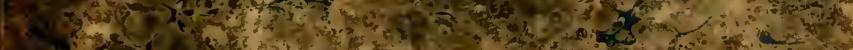

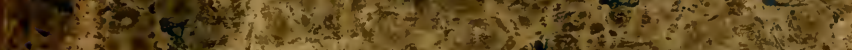

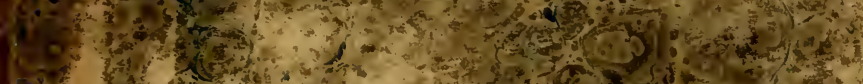

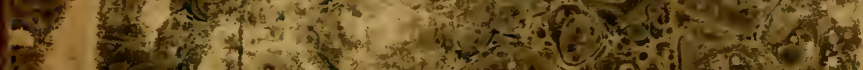

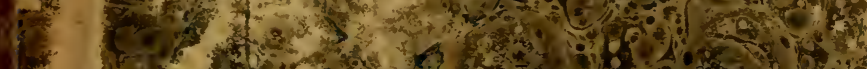

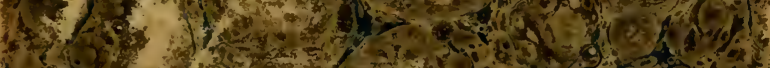

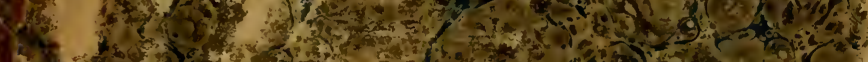
1.4.

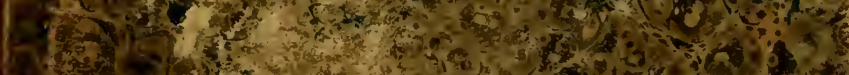
(6)

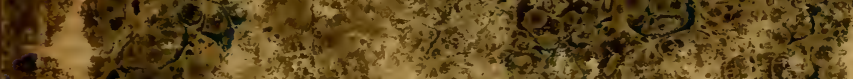

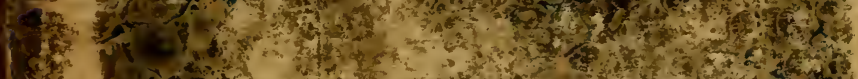

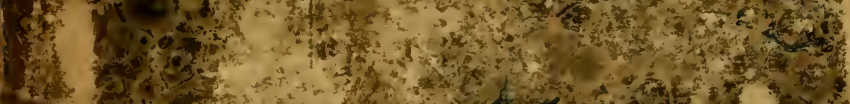

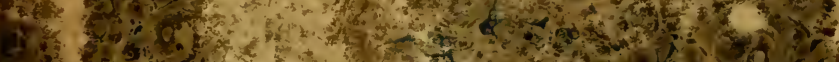

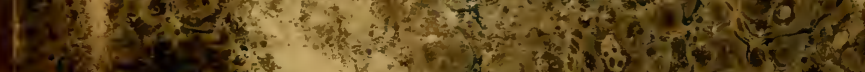
W.

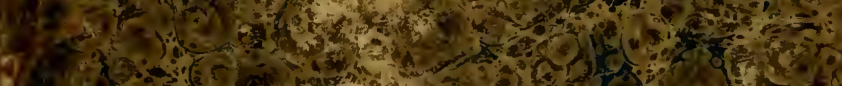
Q10 3 a

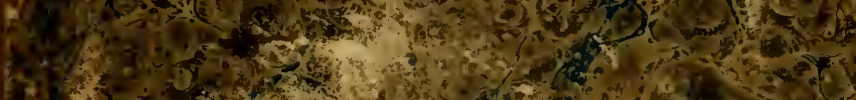

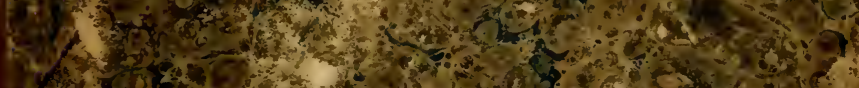

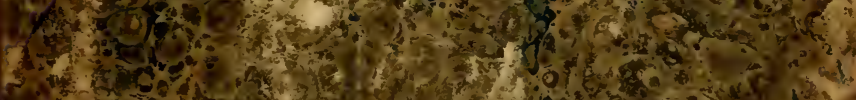

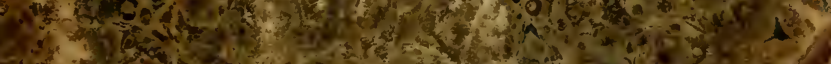

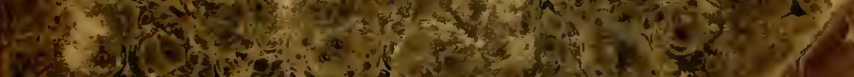




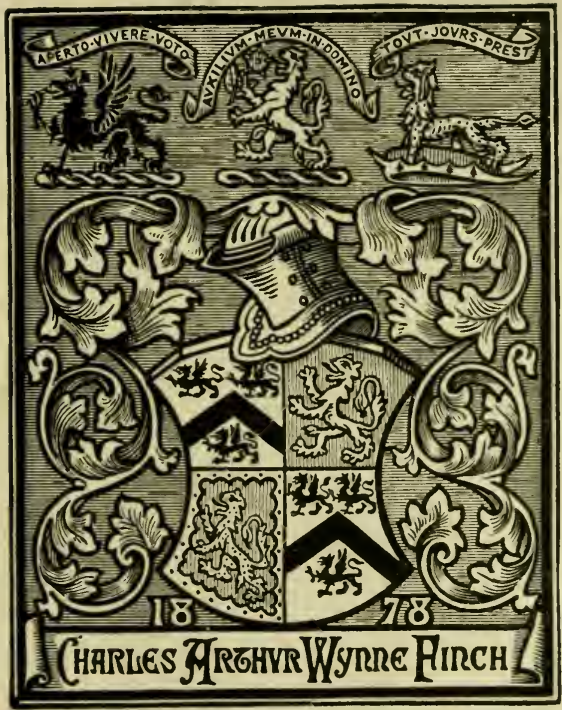




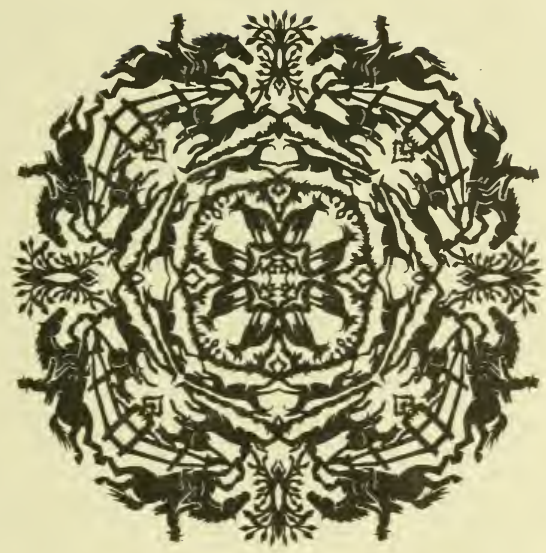

JOHN A.SEAVERNS 








$$
\begin{aligned}
& \text { Frounet view of the } \\
& \text { Finternal miencite Jool? }
\end{aligned}
$$

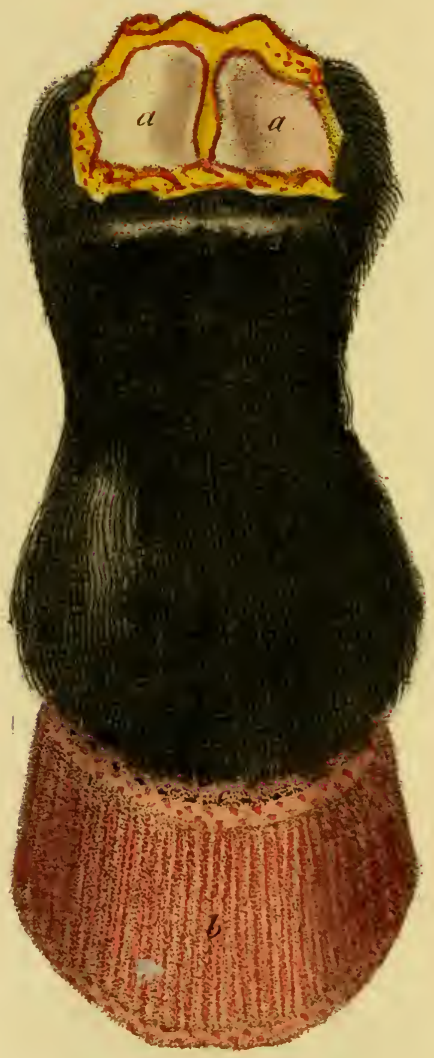




\title{
C.G.Whane. 1226.
}

\section{A TREATISE}

ON

\section{VETERINARY MEDICINE;}

\author{
CONTAINING
}

A COMPENDIUM OF THE VETERINARY AR'T:

$$
\text { OR, AN }
$$

Accurate Description of the Diseases of the Horse, and theif Mode of Treatment;

The Anatomy and Physiology of the Foot; and

The Principles and Practice of Shoeing.

$$
\text { ULUSTRATED BY PLATES': }
$$

With Observations on Stable Management, Feeding, Exercise, and Condition.

$$
\begin{gathered}
\text { BY JAMES WHITE, } \\
\text { OF EXETER, }
\end{gathered}
$$

LATE VETERINARY SURGEON TO THE FIHST OR POYAE DRAGOORS.

$$
\begin{gathered}
\text { Dedicated, by Permission, } \\
\text { тo - }
\end{gathered}
$$

HIS ROYAL HIGHNESS THE DUKE OF YORK.

THE EIGHTH EDITION, CONSIDETALLX ENLATIGID

$$
\text { LONDON: }
$$

PRINTED FOR J. JOHNSON, ST. ALL'S CHLRCHYARD ; AND LONGMAN, HURST, REES, AND ORME, paternoster-roh, - 1807. 
minute detail of symptoms and of a more varied plan of cure is considered. The only addition to the article of shoeing is an improved method of shoeing flat and convex feet. For this the author is indebted to the Honourable New ton Fellowes of Eggsford, whose reputation as a sportsman is equalled by his accurate knowledge of the general management of the horse. The liberal support which the Author has experienced from this gentleman, during his residence in Devonshire, claims his warmest acknowledgements. The patronage with which the public have honoured him will erer be remembered with gratitude, and stimulate him to continue his exertions in contributing to improve the condition of the most useful of animals.

Fetcrinary Establishment,

Exe Island, Exeter. 


\section{C.W.C.W \\ A \\ COMPENDIUM \\ OF THE}

VETERINARY AR'T, \&C.

CHAPTER I。

\section{Introduction.}

THERE is scarcely a disease to which the Horse is liable, that will not appear, upon it strict examination, either to consist in, or to be a consequence of inflammation, which, when it attacks any of the internal organs, gives rise to his most dangerous diseases: thus an intiammation of the lungs, bowels, or any of the internal parts, will produce that kind of derangement in the systen which is termed a fever, the violence of which will be proportioned to the degree and extent of the inflammation, and the importance of the inflamed organ in the VOL, I, 
animal economy. It appears necessary therefore, as an introduction to this work, to give a sketch of the anatomy of those internal organs, and to point out the various functions they perform; after which it will be proper to give a general description of inflammation, with its different modes of termination.

We sometimes, howerer, meet with diseases which seem to originate in clebility; but many of these will be found, if carefully attended to at the commencement, to begin with some degree of increased action of the system; and though bleeding may be improper, a mild purgative will generally prove very beneficial.

In the former editions of this work, scarcely any notice was taken of these diseases: we shall, in the present, therefore, describe particularly, under the head Fever, their symptoms, causes, and most effectual mode of treatment.

STRECTURE AND FUNCTIONS OF THE INTERNAL ORGANS.

The hollow part of the body is divided into two carities by a strong muscular partition 
termed the diaphragm or midriff; the anterior part is named the thorax or chest: and the posterior the abdomen or belly. The thorax contains the lungs and heart; the abdomen the stomach, intestines, liver, spleen or milt, pancreas or sweetbread, kidncys, and bladier.

\section{Of the Lungs.}

In describing the lungs, it is necessary to begin with the trachea or windpipe, which is a cylindrical cartilaginous tube, extending from the throat to the chest. The trachea is not made up of one entire cartilage, but of several cartilaginous rings, which are united by strong membranes; and such is the elasticity of these cartilages, that the tube is enabled to preserve its cylindrical form, even when it receives considerable pressure, and thereby affords free ingress and egress to the air in respiration. The membranes also are elastic, so that the windpipe may be either elongated, shortened, or bent, in some degree. The upper part of the trachea is composed of stronger cartilages than the other parts of the tube, and is termed larynx; to this is connected 2 B 2 
curious kind of valve, called epiglottis, which. is always open, except in the act of swallowing: it is then forced down upon the larynx, so as to prevent food, or any thing which may be passing over the throat, from falling into the windpipe. Where the trachea joins the chest, it divides into numerous branches, which gradually becoming smaller, at length terminate in minute cells: the lung's, indeed, are made up of the ramifications of the trachea and blood-ressels; the interstices being flled with a cellular membrane, which serves not only to unite them, but likewise to give a uniform and homogeneous appearance to the whole mass. The lungs are covered with a fine delicate membrane called the pleura, which also covers the internal surfice of the ribs and diaphragm, and, by stretching across the chest from the spine to the breastbone, divides the thorax into two cavities; this part of the pleura is therefore named mediastimum. On every part of the pleura an aqueous fluid is secreted for the purpose of preventing a cohesion of the parts; and when this is produced too abundantly, it constitutes the disease terned hydrothorax, or dropsy of the chest. The pleura, though so fine a membrane, is impervious to air; whinh may be proved on tiee 
dead animal, by rupturing one or more of the small branches of the windpipe, and then blowing into the lungs. The air which is forced in will then escape through the ruptured parts, and be diffused in the cellular membrane*, so as to make the lungs appear muca laryer than they were before. When the air is at length forced to the surface of the lungs, it will be prevented from escaping by

* The cellular membrane is that which connects the various parts of the body witu can otiner, it nut only win tis the sirin to

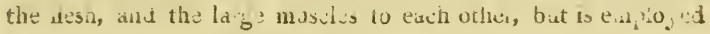

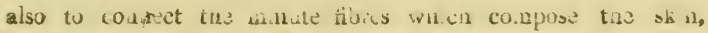

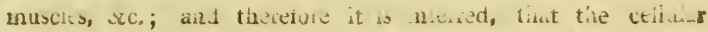
memorane exists in evely part of tis boay, nuwerer niande; and is in sone putts so fin , as to un in inatin, whic i.t others, at

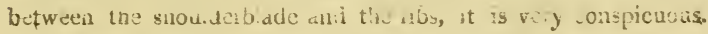
The ceilular wembrdne is comproca of celts o. ranows sices, which comminicate ireely with exch other, so that it a blow pipe be put into ons of the cels, and air forced through it, all the neightouring parts will be blown up to á conorauabre size. A familiar examsle $\mathrm{o}_{2}$ this is the practice among butchers of blowing up the cellular menbrane of a slouldur of real. It sometimes happens in the case of a fracture : rib, that one end of the bone is forced into the lungs, so as to wound the branches of the windpipe and the pleura; the air which is inspired will then escape; and, as the wound communicntes with the cellutar membrane between the muscles of the riks, the air gradually diffuses itself through all the contiguous parts; and we have sometimes seen the whole borly, and even the celtular menbrane about the eye, inflated from this cause. 
the pleura, which will be blown up, and appear like an inflated bladder on the surface of the lungs. If this be punctured, the air will soon escape, and the lungs will return to their original size. This circumstance is noticed, as it is supposed to happen sometimes in the living animal, and to be the cause of broken wind. (See Broken Wind and Chronic Cough.) The lungs are divided into two parts, or lobes, one of which is situate in each cavity of the thorax: this division seems to have been provided in case of accidents, it having been proved, that when one lobe is incapable of performing its function in consequence of injury or disease, the other has been found adequate to the support of life.

The lungs are the organs of respiration or breathing; but they do not appear to be actively concerned in the performance of this office: when the diaphragm and the muscles of the belly and ribs contract, the cavity of the thorax is considerably diminished, and the lungs so compressed, that all the air contained in them is forced out through the windpipe; when this has been effected, the muscles relax, and the thorax returns to its original size. There would now be a vacuum between the in- 
ternal surface of the ribs, and the external surface of the lungs, did not the air rush in through the windpipe, and so distend its branches and cells as to make the lungs completely fill the carity. Thus are the lungs constantly employed in inspiration and expiration; and this process, which we call breathing, is carried on by the combined action of the diaphragm, and the muscles of the ribs and abdomen. It is supposed that the elasticity of the lungs, or rather of the branches of the windpipe, materially contributes to this in?portant action, in the same manner as a bottle of elastic gum, or Indian-rubber, fills itself either with air or water, from its great elasticity. If a small pipe or quill be tied to the mouth of one of - those bottles, and the air pressed out by the hand; as soon as the pressure is removed, the bottle will resume its original form, and consequently be filled with air again. If the mouth of tile bottle or the pipe be put into water after the air has been pressed ont, on removing the pressure, the bottle will be filled with water. 


\section{Of the Heart.}

'The heart is placed nearly in the middle of the thorax: it is rather conical in its form; the apex inclining towards the left side; its base attached to the bones of the back and ribs: it is loosely invested with a membrane or sac, termed pericardium, vulgarly heart-bag. This sac always contains a small quantity of fluid, which serves to lubricate its internal surface, as well as the surface of the heart, to prevent their cohesion, and suffer them to more freely upon each other. Sometimes this fluid accumulates, from a diseased action of the vessels which form it, to a considerable degree. This kind of dropsy generally accompanies that of the chest. The heart is clivided into two carities, termed ventricles, each of them having a small hollow appendage, which, from a slight resemblance it bears to a dog's ear, is named auricle. The blood-ressels proceed from these cavities, the arteries from the ventricles, the veins from the auricles; the former serving to carry the blood from the heart to every part of the body, for the purposes of nourishment, secretion of the various juices, and stimulating the system to action, as well as for fur- 
nishing the various parts with the vital principle; the latter conveying back the blood, thus deprived of its essential parts, to the heart, that it may be renovated by circulating through the lungs, as we shall now describe more particularly. When the left ventricle is full of blood, it contracts so powerfully as to force its contents into the aorta or grand artery, by which the blood is distributed all over the body; it is then taken up by the veins, and conveyed by them into the right auricle, whence it flows into the right ventricle; this also, when it is sufficiently distended, contracts upon its contents, and propels the blood into the pulmonaryartery, by which it is conveyed to every part of the lungs. The pulmonary veins then receive it, and convey it to the left auricle, whence it is propelled into the left ventricle, that it may again be distributed by the aorta to every part of the body.

The blood is thus continually circulating through the body; and this process may be considered as one of the most important actions that is performed in the animal machine. If it be stopped for a few seconds, all motion is suspended; and if it be prevented a longer time 
from going on, vitality is destroyed. The function of the lungs is of equal importance in the animal economy, and cannot be stopped even for a short time, without suspending or totally destroying animation. Ancient physiologists had a very imperfect iclea of the manner in which these organs so essentially contributed to the support of life: the moderns, however, have been more successful in their researches; they have discovered that the blood derives from the air, which is taken into the lungs, the most inportant properties, without which it would be a useless rapid mass, totally inadequate to the purposes for which it was designed. If we examine the blood in the left ventricle of the heart, and in the arteries, it will be found of a bright scarlet colour, and replete with those properties which render it capable of nourishing the body, and stimulating the whole system to action: in the reins it becomes of a much larker colour; and when it arrives at the right ventricle is nearly black, and destitute of those enlivening qualities which it possessed when in the left ventricle: had not the Deity then provided some means for its renovation, it would have been quite unfit for a second circulation, and the duration of life must have beeu short 
indeed; but from the right ventricle it is conveyed by the pulmonary artery to the lungs, at the moment they are distended with air: here the blood undergoes a wonderful alteration, it resumes its bright scarlet colour, and is returned by the pulmonary veins to the left side of the heart, with all its original and essential qualities restored to it. It is proper to observe, that there are valves placed in such situations, as effectually prevent the blood from taking a retrograde course. Were it not for this contrivance, the blood would as readily be forced into the left auricle as into the great artery, when the left ventricle, which lies between them, contracts, or shrinks up; and so of the other paits.

Hence we may learn how important are the functions of respiration and the circulation of blood, how essential to the life of animals, and how dependent they are on each other.

\section{Viscera of the Abdomen.}

Having finished our description of the thoracic viscera, we proceed to notice those of the abdomen, or belly; the first and most important of which is the stomach. Whaterer this organ 
receives is conveyed to it by a long muscular tube, named asophagus, or gullet. The œsophagus originates in the throat, where its size is considerable, but it suddenly diminishes into a small tube, and is continued of the same size to the stomach: the upper part has been thought to resemble a funnel in its form, and is distinguished by the term pharynx.

The pharynx is situate immediately behind the larynx, or beginning of the windpipe; but is not, like it, composed of strong cartilage or gristle : it is formed of membrane with a muscular corering, which by contracting forces the masticated food down the gullet, or œsophagus. As it is absolutely necessary to breathing that the larynx should be always open, it is therefore composed of strong cartilage, which cannot easily, or by moderate pressure, be squeezed together and shut up: but this structure is not requisite in the pharynx, as it only requires to be opened occasionally; and then the muscles of the tongue are able to force food or water into it, while its own muscles continue to force the food or water downward, through the gullet, into the stomach. We have before observed, that, while the food or water is passing over the 
tongue into the pharynx, it cannot fall into the windpipe, on account of its being covered by the valve epiglottis, which is forced down upon the windpipe by the food, as it passes into the pharynx, so as to shut it completely. If at this instant the animal happen to cough, that is, throw out air with considerable force from the lungs, the valve is for a moment opened by it, and a little of the food or water is liable to get into the windpipe, whence it is soon expelled by violent coughing.

The œsophagus, having passed along the throat and back part of the chest, penetrates through the diciagm, and terminates in the stomach.

The œsophagus of a horse has on its internal surface an insensible membrane, which stretches into the stomach, and lines nearly one half of its surface: this peculiarity enables us to account in sonse measure for the inactivity of many violent poisons when given to the horse. In the human resophagus, this membrane does not exist, the whole of its internal surface, as well as that of the stomach, being exquisitely sensible.

If two grains of emetic tartar be swallowed by a man, they soon occasion violent vomiting; 
whereas two hundred times that quantity would produce no sensible effect upon the horse. At the cardiac orifice, or that part where the cesophagus enters the stomach, its internal coat is so loose as to be thrown into folds, appearing as if it were designed as a valve to prevent the regurgitation of the contents of the stomach; from this cause, as well as from the insensibility of the membrane, with which great part of the stomach is lined, a horse very rarcly vomits; but the opinion that he is totally incapable of that action, is certainly not true, as I have once seen a horse vomit considerably. This romiting came on spontaneously, and soon ceased. There is no medicine we are acquainted with capable of producing this action in the horse's stomach; and its occurrence is very rare, this being the only case I ever saw: but I have been informed of two similar cases.

When we examine the throat, another valvular structure may be observed, (which is peculiarly large in the horse) formed by the epiglottis or valve of the windpipe, and a membranous substance that hang's from the back part of the roof of the mouth : this is termed selum pendulum palati. These bodies form 
a very complete valve, which opens downward only, thereby preventing the return of any thing through the mouth, either from the lungs or stomach: thus we find that a horse breathes only through his nose, except in coughing, by which the valve is so deranged as to allow the air, so thrown out from the lungs, to pass through the mouth.

In the case of romiting I have just mentioned, the contents of the stomach were at first observed to pass through the nose; at length, by a violent cough, the valve was deranged, and a considerable quantity of fluid, mixed with masticated hay and oats, was evaculated by the mouth.

That part of the stomach where the œsophagus terminates is called the cardiac orifice; and that where the intestines begin is termed pylorus.

The intestines or bowels consist of one very long tube, which terminates at the anus.

In the horse the intestines measure nearly thirty yards; but being convoluted in order to adapt them to the cavity in which they are placed, they have the appearance of several distinct parts.

The internal surface of a horse's intestines 
are not lined with that insensible membrane which is found in the osophagus and upper part of the stomach; on the contrary, it is endued with a high degree of sensibility, and appears to be more susceptible of irritation than that of most other animals. From this irritability of the intestines it is, that many horses have been destroyed by the administration of strong purgatives, and hence arises the necessity of using these medicines with skill and caution.

The intestinal tube is not, throughout its whole extent, of a uniform size; that part next the stomach is rather small, and continues for about twenty yards nearly of the same diameter; it then becomes very large, but again diminishes before it's termination at the anus.

Anatomists, in describing the intestinal canal, divide it into two parts, viz. the small and the large intestines; these are subdivided, the former into duodenum, jejunum, and ileum; the latter into cacum, colon, and rectum.

All the internal surface of the intestinal tube is covered with a mucous substance, for the purpose of defending it from the action of acrimonious bodies. The various convolutions of the intestines are held together by a mern- 
brane called mesentery, which not only serves this purpose, but affords also a bed for the lacteals, or those small vessels by which the nutritious parts of the food are conveyed to the heart, to be converted into bloci. Before we proceed to a particular description of these vessels, it will be necessary to explain the process of nutrition.

When food is taken into the mouth, it is broken down by the teeth, and so mixed with saliva, as to be in a proper state for entering the stomach; it is then, by the united action of the tongue and muscles of the throat, forced into the nophagus, whence it passes into the stomach. In this organ it undergoes a considerable alteration; for here Nature has provided a curious liquid called gastric juice. which has the property of dissolving every thing that is taken into the stomach, and of converting it into a soft pulpy mass, of a uniform and homogeneous appeurance. When the food has been thus altered, the mass is forced by a contraction of the stomach into the duodenum, or first part of the intestinal canal; this mass, however, does not consist wholly of nutritive parts, or such as are fit for the formation of blood; and another operation is ne. 
cessary in order to separate them from such as are useless; this seems to be effected by the bile and pancreatic juice*

There is a peculiarity, however, in the stomach and intestines of the horse, which it is proper here to describe. The stumach of the horse is small in proportion to his general bulk, and has nearly half of its inner surface covered with a strong insensible membrane of a white colour. This is the part to which botts are generally attached, which explains why these worms so often exist in the stomach without doing any mischief. This insensible membrane is supposed also to enable the stomach to press upon the solid food it may contain, and assist the gastric juice in reducing it to a soft mass: but digestion is far from being perfect in the stomach of the horse, and appears to be completed in the large intestines, cacum and colon. This contrivance seems absolutely necessary in the horse, when we consider the wonderful speed and exertion of which he is capable, and for which Nature appears to have designed him.

* This opinion has been proved by the experiments of Mr. Astley Cooper, lecturer on anatomy and surgery, and assistnit surgeon of St. Thomas's Hospital. 
The ox, the sheep, and other ruminant animals, have four large stomachs, the smallest of which, eren in the sheep, is as large as that of the horse. These animals take in a large quantity of food at once, and digest it at their leisure, from which they feel no inconvenience: but the horse, even in a state of natu, e, is differently employed. Rapidity of motion and strength are necessary to his preservation; and in his domesticated state it is more particularly required. Hence, he is formed with a small stomach, which requires frequent supplies, and is no impediment to his exertions. From this will appear the absurdity of keeping a horse a considerable time without food or water, and then suffering him to take in a large quantity : incurable and even fatal diseases have arisen from this management. In the ox and sheep, digestion is completed in the fourth stomach: the first stomach is very capacious; and, when filled with food which is swallowed hastily, and without much mastication, is stimulated to contract upon its contents, and is perhaps assisted by the efforts of the animal; that opening of the stomach which communicates with the nesophagus and mouth, being considerably larger than that which leads 
to the second stomach; and the food being so gross and imperfectly masticated, that it cannot easily pass through a small orifice, it necessarily follows that a contraction of the stomach will force the food through the largex opening, and cause it to return to the mouth, where it undergoes a more complete mastication, and is rendered so soft and pulpy, by the addition of saliva, as to pass readily through the smaller orifice into the second stomach.

The horse, in a state of nature, is almost constantly feeding; and the food which he takes in, is retained but a short tinc in the stomuch; dinestion seems to ba going on nearly through the whole of the intestines, and appears to he chicfly effected in the cœcum, or blind grut, which in the horse is re. markably large and capacious. From these curious contrivances, the horse's stomach is never so loaded with food as to hinder the action of the lungs, and impede his relocity. It must be confessed, however, that this does sometimes happen; not from the natural inclination of the animal, but from the folly, negligence, or cruclty of lis keeper. I have been the more particular in describing the stomach, as the subject is connected with, 
and will tend to elucidate, some important diseases.

The bile is formed by the liver, a large glandular body, divided into several lobes, and situate immediately behind the diaphragm, to which it is firmly attached. The form of the liver is too well known to require a particular description; we have only to observe, therefore, that the bile, which it secretes, is conveyed by the hepatic duct into the duodenum, within three or four inches of its origin. In man, and the greater part of quadrupeds, all the bile does not flow immediately into the intestine, there being a small vessel connected with the hepatic duct, which conveys a certain portion into a sac that is attached to the liver, and called the gall-bludder, whence it is occasionally expelled: but this does not exist in the horse, although Mr. Taplin, in his 'Stable Directcry,' has aftempted to give an accurate description of its situation and diseases!

From what we have just said of the peculiarity in the digestive organs of the horse, the reason of his having no gall-bladler will readily appear. In man, and many animals, the food is retained a considerable time in the stomach; during which, the bilious fuid, of 
gall, is not wanted; therefore Nature has provided a reservoir, the gall-bladder; for as the bile is constantly forming by the liver, so would it be as constantly flowing into the first intestine, were it not for the gall-bladder, which would have occasioned a great waste of this useful fluid. During the time of digestion, the food is shut up in the stomach, the pylorus being closed, and the first intestine empty. The orifice of the duct which conveys the bile into this intestine, being without its usual stimulus, the digested food, becomes torpid ; and, as the action of the whole duct depends upon its orifice being stimulated, the bile, instead of passing through it, flows into the gallbladder, where it, remains until the digestive process is so far completed, that the food begins to flow from the stomach into the intestine. The biliary duct is then stimulated to action; the gall-bladder partakes of the irritation, and, assisted by the pressure of the distended intestine, contracts upon its contents, and forces the bile through the duct, into the intestine, where it mingles with the digested food, and causes a separation of the chyle, or nutritious parts.

It must be obvious, that, as the horse is 
almost constantly feeding, and as digestion is continually going on in his stomach and intestines, that a constant flow of bile is necessary, and therefore that a gall-bladder would be useless, perhaps injurious.

The pancreas is also a glandular body, and secretes a fluid somewhat resembling saliva, which is conveyed by the pancreatic duct into the duodenum, at the same place where the hepatic duct enters. When these fluids (the bile and pancreatic juice) are poured into the intestine, they mingle with the mass of digested food which has been expelled from the stomach, and separate from it all those essential parts which are fit to be converted into blood; this process is termed chylification. We have before observed, when describing the mesentery, or that membrane by which the intestines are held together, that an immense number of small delicate vessels are spread over its surface, named lacteals, from their containing a fluid which in its appearance resembles milk. This fluid consists in fact of the essential parts of the food proceeding to the heart, in order to be converted into blood. All the lacteals open into the intestines, and cover the whole of their internal surface, where they are always dis- 
posed to absorb the nutritious parts of the food in its passage through the intestinal canal. Some physiologists suppose, that the mouths of the lacteals have the power of selecting such parts of the food as are fit to be converted into blood, that no previous separation takes place, and that the bile serves. only as a natural purgative, constantly stimulating the intestines, thereby keeping up a small degree of motion in them, and promoting the expulsion of the feculent parts of the food.

It will probably be asked, how it is that the mass of food passes through the intestines, since they are so convoluted that it cannot possibly be effected by the power of gravity? but if we exanine their structure, this phrnomenon may be readily explained. The intestines are composed, in great measure, of muscular fibres, some of which run in a circular, and others in a longitudival direction: when the circulur fibres contract, the ditmeter of the canal is diminished; and when the longitudinal fibres are in action, it becomes shorter; and, by the combined action of these fibres, the food is gradually propelled through the whole length of the intestinal canal. The motion thus excited may be distinctly seen in an animal re- 
cently killed, and in some it continues a considerable time after death. The intestine, however, is not entirely composed of muscular fibres; its internal surface is lined with a fine nervous and muscular membrane, which is endued with exquisite sensibility, and has the power of forming on its surface a mucous substance, which serves to protect it from the action of acrimonious bodies. Beside the muscular and nerrous coat, there is another which enters into the composition of the intestine: this is a thin membrane called peritoncum. The peritonæum not only forms the third and external coat, it likewise cnvelops all the organs contained in the abdomen, forming their external coat, and is closely connected with them, and is then so reflected as to form a kind of sac, in which they are all inciosed. Thus are the intestines composed of three coats, which are closely in contact with each other; the peritonæal, the muscular, and the nervous coat.

IVe have yet to describe the course of the lacteals, or those ressels which take up the chyle or nutritious parts of the food. We have before observed that they are spread upon the mesentery, whence they pass on TOL. I. 
towari the spine, bccoming larger and less numerous in thcir progress; at length they terminute in a large tube, which ruas along the spine, and is named the thoracic duct; this pours its contents into a large rein near the ineart, to which part it is immediately after coinveyed, and converted into blood.

The lidneys are two glandular bodies, situate within the loins; their office is to separate urine from the blood. The urine, thus separated, is conreyed by two tubes of considerable length, termed ureters, into the bladder, which is composed of three coats, like those of the intestine; and when it has received a sufficient quantity of mine to stimulate its muscular fibres into action, it contracts upon the urine, and forces it out through the methra or minary canal. We have now finished our sketch of the abdominal an 1 thoracic riscera; which has been given with a view to render the description we are ahout to give of internal diseases more intrlligible to those readers who are unacquainted with anatomy, than it would otherwise have fech. 
CHAPTER II.

Influmation.

ITwas supposed by the celebrated Boërhave, and other physiologists of his time, that inflammation depended on a viscidity of the blood, which rendered it unfit for circulating in the finer ressels; and that hence arose obstructions, and those appearances by which the disease is characterised. This opinion, however, has obtained very little credit with modern physiologists, and is now universally rejected; it having been proved, that blood drawn from an animal labouring under inflanmation is more fluid, and remains fluid longer, than that which is taken from the same animal when in health.

The most prevailing opinion at present respecting infiammation is, I believe, that it consists in an increased action of the heart and arteries, when general; whereby the blood circulates with unusual velocity, throwing the whole system into derangement; and

C 2 
when local, or existing in a particular part*, the increased action is in like mamner confined to the vessels of that part.

When a part is inflamed, there arises in it an unusual degree of heat, generally attended with considerable tension and swelling; the sensibility and irritabiity are always increased, and produced by it in parts where it did not before exist. In bones and tendons, for example, scarcely any sensibility can be perceived when they are in a state of health;

* In local inflammation, though the larger arteries of the part lave their action increased, it is probable that their small branches, whlich from their minute size are termed capillary arteries, are in a state of debility, and distended with blood, which they are incapable of getting rid of; the larger arteries; acting with unusual $x$ trength and quickncss, will of course force a grcater quantity of illood than usual into these delicate vessels, so as to stretch them beyond their tone, and render them incapable of contracting upon their contents. This accounts for swelling, heat, and redness of an inflamed part, and slows the utility of bleeding by leeches on such occtasions; as these worms attack only the capillary arteries, drawing off' the superiluous bluod, and enabling tleen to recover their strength, and contract as before. This doctrine points out also the efficacy of general bleeding, and purging, in local infammation, which tend to muderate the action of the larger arteries, and cause thein to pour 100 more blocel into their minute branches than they are capable of forcing into their terminations---the veins. We thought it poper to say thus much of the theory of inlanmation, as it may lead to a better practice than is commonly adopted in treating the inflammatory complaints of horses. 
but, when inflamed, it is roused to an alarning degree, and the most dangerous consequences may ensue from it.

Inflammation has four modes of termination: the first is termed resolution; that is, when the disease, after going a certain length, gradually disappears again: the second, suppuration; that is, when matter is formed, or an abscess produced: the third is named effision, which implies an extravasation either of blood, - coagnlable lymph, or serum: and the fourth, gangrene or mortification, by which is meant the death of the inflamed part.

Inflammation of the external parts is generally occasioned by some mechanical injury, such as wounds, braises, \&c.: somctimes, however, it arises from interiul infammation, or symptomatic ferer, and is then to be considered as an effort of nature to cure the internat disease. Thus we sometimes find in fevers abscesses taking place on the surface of the body, whereby the fever is considerably diminished, and, in general, terminates favourably.

Inflammation is often produced by plethora, or redundancy of blood in the body; in which 
case it is sometimes gene' a', the whole arterial system haring its action increased: this also may be considered as an effort of nature to get ind of the superfiuous blood, and in such cases she nust be assisted by copious bleeding. It more commonly happens, howerer, that the rediundant blood is determined to some particular part, occasioning local infiammation; very frequentiy falling upon some of the internal organs, and the lungs are peculiarly liable to suffer; from this source, indeed, their most dangerous fevers arise. The eyes also are very apt to suffer when a horse becomes plethoric, to which cause, I believe, almost all the diseases of that delicate organ may be attribuțed.

In the treatment of external inflammation, we should endeavour to bring it to the most fuvourable termination, that is, resolution; unless when it arises from an effort of nature to cure some internal discase; - it is then desirable to bring it speedily to suppuration. The remedies to be employed for resolving inflammation are, local or general bleeding, (see Index, Bleeding) purgatives, fomentations, poultices, or the saturnine lution, made warm; 
sometimes, in leed, I have seen cold applications used with success, such as sal ammoniac dissolved in rmegar, goulari, \&c.**

When inflammation takes place in tendinous parts or joints, tine saturnine poultice has been found an usetul remeily, and in the latter case I have often found biisters extremely efficacious. As in these cases the inflammation generally proves more troublesome, and as the pain which it occasions is often so considerable as to produce symptomatic ferer, it becomes necessary to employ, without loss of time, the most prompt and efficacious means for its reduction; with this riew we excite artificial inflammation in the contiguous skin and cellular membrane, which are parts of far less importance in the animal economy than joints or tendons, and capable of bearing a considerable degree of inflammation, withont much inconvenience to the animal: this is done by means of rowels and blisters, and the inflammation, thus excited, will tend in a considerable degree to diminish that which is going on in the inore important part. Should we fail in our cndearours to resolve inflammation, it will probably terminate

* Since writing the above, I have often employed cold remedics, in local infammation, with great adrantage. 
in suppuration; and when it appears that the lisease does not abate by the use of the remefies we have recommended, an assiduous application of fomentations and poultices will expedite the suppurative process, and afford great relief to the animal. When the inflammation, or rather the swelling which it occasions, arrives at this state, it is termed an abscess, in which, when the suppuration is complete, and it contains matter, a fluctuation may be felt, upon its being pressed by two fingers alternately. This point being ascertained, an opening is to be made with a lancet or knife, in such a way that the matter may be completely evacuated, and a future accumulation prevented: it is then to be dressed with digestive liniment or ointment. Should the wound appear indisposed to heal when this treatment has been pursued for a short time, discharging a thin offensire matter, and wanting that red appearance by which the healing process is indicated, the detergent lotion will soon remove these unfarourable appearances; the discharge will become whiter and thicker, and red granulations of new Hesh will sprout up. Should these granulations, however, become luxuriant, constituting what is commonly 
termed proud flesh, they are to be kept down by means of the caustic poivder. It sometimes happens, that when a part is inflamed and swollen, instead of going on to suppuration, it degenerates into a hard and almost insensible tumour: this depends on the inflammation having terminated in effusion of coagulable lymph, and is to be removed by stimulating embrocations or blisters.

When inflammation runs very high, as is sometimes the case in viclent bruises, or deep and extensive wounds of the lacerated kind, it may terminate in gangrene or mortification, which is generally attended with danger: in this case, the matter discharged, instead of being white and thick, consists of a dark-coloured fluid, of a peculiar offensive smell; the constitution is generally affected, the pulse becoming quick, weak, and sometimes irregular; the appetite goes off; and there is a great degree of debility. Should the inflammation terminate in this nay, if it arise from a wound, let it be dressed with digestive liniment, oil of turpentine, or camphorated spirit of wine; the diseased parts should be scarified, and fomentations applied almost incessantly, until the mortified parts appear to c 5 
separate, and the matter loses in great measure its offensire smell, appearing whiter and more thick. When the horse is weakened by the disease, and loses his appetite, particularly if there be a copious discharge from the wound, one or two of the following cordial balls are to be giren daily:

\section{No. 1.}

Ycllow Peruvian bark, $\quad 1 \mathrm{oz}$.

Ginger, powdered, - 2 drams.

Opium, - - - 1 dram.

Oil of carraways, - - 20 drops.

Syrup enough to make a ball for one dose.

\section{No. 2.}

Yellow Peruvian bark, $\frac{\mathrm{x}}{2} \mathrm{oz}$.

Powdered snake root, 2 drams.

Powdered cassia, - $\quad 1^{\frac{1}{2}}$ dram.

Oil of clores, - 20 drops.

Syrup enough to form a ball for one dose.

Remark.-The opium, in the ball No. 1, is to be omitted when the horse is costive, or if it appear to take off his appetite; but when the disease is accompanied with a purging, it is extremely useful. 
When any of the internal parts are inflamed, a fever is generally produced, the violence of which will depend upon the importance of the inflamed organ, as well as upon the extent of the inflammation; some of the internal parts being more essential to life than others, and, when inflamed, occasioning of course greater derangement in the system. The only farourable terminations, to which internal inflammation can be brought, are resolution and effusion; and as the first is by far the most desirable, the most vigorous measures should be adopted in order to effect it. The most important remedy in these cases is copious bleeding, and the earlier it is employed the more effectual will it prove: the next remedy is external inflammation, artificially excited by means of rowels and blisters. The ferer powder, and occasional clysters, are of considerable service. 


\section{CHAPTER III.}

\section{Fever.}

'THE fevers of horses bear very little analogy to those of the human body, and require a different treatment. Writers on farriery have described a great variety of ferers, but their observations appear to have been drawn from the works of medical authors, and their reasoning seems entirely analogical. I can distinguish only two kinds of ferer, the one, an idiopathic or original disease, and therefore properly termed simple; the other dependent on internal inflammation, and very justly denominated symptomatic ferer. For example, if the lungs, bowels, or stomach were inflamed, the whole system would be thrown into disorder, and a symptomatic fever produced: but if a collapse of the perspiring ressels happen to take place, the blood will accumulate in the interior parts of the body; and 
though inflammation is not produced by it, the unequal distribution of the blood alone will occasion that derangement in the system which constitutes the simple fever. The simple fever does not occur so frequently as the symptomatic, nor is it by any means so formidable in its appearance; yet it is necessary to give it the earliest attention, for unless nature receives timely assistance, she will be sometimes unable to get rid of the load which oppresses her; and the blood will accumulate in the interior part of the body, until inflammation in some of the viscera is produced, and a dangerous disease established. The following are the symptoms of simple fever:- shivering, succeeded by loss of appetite, dejected appearance, quick pulse, hot mouth, and some degree of debility: the horse is generally costive, and voids his urine with difficulty. The disease is often accompanied with quickness of breathing, and in a few cases with pain in the bowels, or symptoms of colic.

As soon as a horse is attacked by this disease, let him be bled freely; and if costiveness be one of the symptoms, give a pint of castor oil, or the oil of olives; and let a 
clyster of warm water-gruel be injected*. After the operation of the laxative, the fever powder is to be given once in twetre hours, and continued until its diuretic effect becomes considerable. Warm water and mashes are to be frequently offered in small quantities; warm clothing, frequent handrubbing, and a liberal allowance of litter are also necessary ; and when the ferer runs high, it is advisable to insert rowels about the chest and belly, in order to prevent internal inflammation from taking place. When the disease appears to be going off, the horse looking more lively, and the appetite returning, let him be led out for a short time in some warm situation, and give now and then a malt mash for the purpose of recorering his strength.

* I have lately found the following drink a very useful laxative on these occasions :

Take of Barbadoes aloes powdered, - 3 drams.

Prepared kali, - $\quad$ - $\quad$ - 1 dram and $\frac{5}{2}$

Castor oil, - - - - 4 oz. to 6 oz.

Simple mint water and pure water, of each, $4 \mathrm{oz}$.

Mix for one dose. 


\section{FEVER POWDER.}

No. 1.

Powdered nitre, - $\quad$ - $1 \mathrm{oz}$.

Camphor and tartarised antimony, of each $-\quad\} 2 \mathrm{dr}$.

Mix for one dose.

$$
\text { No. } 2 .
$$

Powdered nitre, - $\quad$ - $1 \mathrm{oz}$.

Unwashed calx of antimony, $2 \mathrm{dr}$.

Mix for one dose.

No. 3.

Antimonial porder, - $\quad$ - $3 \mathrm{dr}$.

Camphor, - - - $1 \mathrm{dr}$.

Mix for one dose.

The additions made by the author to this subject may be found in the Appendix.

\section{Symptomatic Fever.}

The symptomatic fever is generally occasioned by high feeding, close stables, and a 
want of proper exercise: sometimes, however, a sudden transition from a cold to a hot temperature is evidently the cause of it. In this respect it is different from the simple fever, which, as before observed, sometimes arises from exposing a horse suddlenly to cold air, when he, has been accustomed to a warm stable. Horses that are taken from camp or grass, and put sudklenly into warm stables, are extremely liable to those internal inflammations on which symptomatic fever depends, and many thousands fall victims to this kind of treatment.

When a fever is symptomatic, it is not preceded by shivering, nor is it so sudden in its attack as the simple fever: but when it is not subdued by an early application of remedies, the symptoms gradually increase in violence, until they present a very formidable appearance. When the disease, however, is occasioned by great and long continued exertion, it generally comes on suddenly; and the complaint has a very clangerous ippearance in its earliest stage.

The symptomatic fever lias many symptoms in common with the simple ferer, which are, loss of appetite, quick pulse, dejected appear- 
ance, hot mouth, and debility; and if to these be joined difficulty of breathing, and quick working of the flanks, with coldness of the legs and ears, we may conclude that an inflammation of the lungs is the cause of the fever. If the borse hang down his head in the manger, or lean back upon his collar with a strong appearance of being diowsy, the eyes appearing watery and inflamed, it is probable that the fever depends upon an accumulation of blood in the vessels of the brain, and that the staggers are approaching: in this case, however, the pulse is not always quickened; sometimes, indeed, I have found it unusually slow.

When the symptoms of ferer are joined with a yellowness of the eyes and mouth, an inflammation of the liver is indicated. Should an inflammation of the bowels be the cause, the horse is violently griped. An inflammation of the kidneys will also produce ferer, and is distinguished by a suppression of urine, and an inability to bear pressure upon the loins. When inflammation of the bladder is the cause, the horse is frequently staling, voiding only rery small quantities of urine, and that with considerable pain. Extensive 
wounds, and particularly those of joints, will also produce symptomatic ferer. Sometimes several of the internal parts are inflamed at the same instant; and indeed when inflammation has existed for a considerable length of time, it is seldom confined to the oroun in which it originated; the disease spreals to other viscera; and when more than one organ is inflamed, thelsymptoms will generally be complicated: still, however, the cossential remedies aré the same, that is to say, cupious and early bleeding, with rowels and blisters.

Having now given a gencral description of symptomatic fever, I shall proceed to treat of those cases separately to which above I have brietly alluded.

\section{Inflammation of the Lungs.}

This is a very dangerous disease, and one to which horses are extremely liable: the frequency of its occurence is occasioned by improper management, and not by any natural defect in the constitution of the animal: it may therefore be prevented by proper attention in the groom. Medical writers make a 
distinction between inflammation of the lungs, and that of the pleura, or the menbrane which covers those organs, calling the former peripneumony, and the latter plturisy: this distinction, however, is not necessary in veterinary nosology, since we never find these parts affected separately in the horse. The progress of this disease is often very rapid; and unless proper remedies are empioyed at an early period, it frequently terminates fatally.

Its approach is inilicated by the following symptoms:-loss of appetite, an apperance of duiness and disiulination to motion, unusual quickness in the motion of the lanks, hot mouth, and sometimes a cough. If the discase, by adopting an inert or improper mode of treatment, be suffered to procecd, all these symptoms will increase; respiration will,become extremely quick and laborious, the pulse more frequent, and at the same time weak. A striking appearance of uneasiness and anxiety may be observed in the animal's countenance: the nostrils expanded, the cyes fixed, and the head inclining downwgrd; the legs and ears become cold, and the debility is so considerable, that he is incapable of moving in the stall without great difficulty; he 
never lies down, unless so much weakened as to be incapable of standing. The disease, however, is not always so rapid in its progress as we have here described it, and not unfrequently a considerable remission may be observed, which is occasioned probably by an effusion of serum or water having taken place in the chest; and this remission is sometimes so conspicuous, that we are led to give a favourable prognosis, the horse beginning to feed again, and the pulse becoming less frequent. But this flattering appearance often proves fallacious, the disease soon returns with accumulated force, and puts a period to the animal's life. I have seen cases, where bleeding has not been performed with sufficient freedom, in which the inflammation being checked in some degree, at length terminated in a plentiful effusion of water in the chest; when this happens, the horse returns to his food, looks more lively, and, in short, the symptons of fever in a great measure disappear. There remains, notwithstanding, an unusual quiclness in respiration, generally accompanied with a cough; the hind legs swell, and the horse very rarely lies down; a rough unhealthy appearance may also be observed in 
the cont, the skin feeling as if stuck to the ribs; and the animal continues in a state of weakness. After some time the inflammation generally returns, and then speedily ends in death. It sometimes happens that the inflammation terminates in suppuration; in this case also the fever is in some degree lessened, and the horse begins to feed a little; but he still remains in a very feeble state, has a weak cough, and discharges fetid matter from his nostrils; at length the disease again becomes violent, and soon puts a period to his sufferings.

The first thing to be done, when this dangerous disease is observed, is to bleed copiously, even till the horse begins to faint from loss of blocl. I have seen six quarts drawn at one operation, and with the best effect; sometimes indeed the disease will be completely subdued by thus bleeding freely at its commencement. Should the horse be costive, or even if the bowels be in a natural state, it will be arlvisable to give a pint of castor oil, and inject a clyster of water-gruel. It will then be necessary, in order to divert the inflammation from this important organ, to insert rowels about the chest and belly, and to blister the 
siles extensively. Let the legs be kept warm by alnost constant hand-rubbing; and warm clothing must never be omitted. Nothing is more pernicions in this complaint than compeling the animal to breathe the impure air and stimulating vapours of a close stable; this is indece so obvious a truth, that it would be mmecessary to mention it, were it not a constant practice with grocms on this occasion to stop every arevice they can find, by which pure sir nigit be admitted, and the noxious.exlialations suffered to escape.

If the disease do not appear to abate in twelve hours aftur the bleeding, particularly if it have become more violent, let the operation be repeated, and with the same freedom as at first. We need not be apprehensive, at this carly period of the disease, of any dangerous devility ensuing from the loss of so much blood: on the contrary, it will tend to reestablish strength, by subduing the inflammation on which the fever depends. It has rarely been found necessiry to bleed several times, and that very plentifully; but ii must lie recollected, that when the fever has existed for some time, and has nearly exhausted the liurse's strength, bleeding seldom does good, 
and in some instances, I believe, has been the means of hastening death. When suppuration takes place in the lungs, though there is little probability of saving the animal, his life may be prolonged by giving frequently good watergruel and infusion of malt. Opium, salt of hartshorn, and other cordiais, will also be of service. I have generally given the following ball on these occasions; and though I hare never seen a horse recorer after suppuration had taken place in the lungs, yet these remedies have certänly afforded considerable relief.

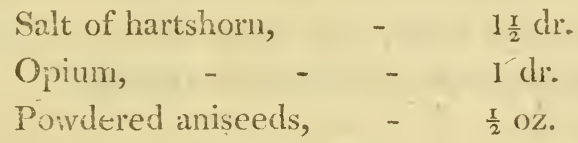

Syrup enough to form a ball for one dose.

When the mode of treatment here recommended is adopted before the disease has gained much ground, it will generally succeed completely. Considerable weakness will of course remain after the fever has been removed, but this also will "gradually go off, if proper attention be paid to the horse's diet and exercise. When the appetite begrins to return, it will be advisable to give small quantities of . 
oats that have been steeped in boiling water; good water-gruel will also be found serviceable in recruiting his strength; the sweetest parts should be selected from the hay, and given frequently in small quantities. Malt is an excellent restorative on these occasions, but must not be given too freely. When the weather is favourable, let the horse be led out for a short time every day; or if a small paddock can be procured, and the season of the year will admit of it, he may be turned out for a few hours every day, while the sun shines, trking care that he is well clothed during that time; by these means he will gradually recover his original strength.

\section{Inflammation of the Bowels.}

This disease is not so frequent as the preceding, though equally dangerous, and generally more rapid in its progress. Inflammation maly attack either the peritonæal coat of the intestine, or that delicate membrane which forms the internal or villous coat. In the former case the disease will be attended with custiveness, but in the latter a violent purging is the most conspicuous symptom; but which 
ever of these coats is first attacked, the inflammation, in a short time, generally spreads to the other.

The peritonæal inflammation begins with an appearance of dulness and uneasiness in the horse; the appetite is considerably diminished, or is entirely lost, and the pulse becomes more frequent; the pain and febrile symptoms gradually increase; he is continually pawing with his fore feet, and frequently endearours to kick his belly; he lies down and suddenly rises again, and looks round to his flanks, strongly expressing by his countenance the violence of the pain he suffers; this urine is commonly high coloured, and in small quantity, and sometimes voided with considerable pain; he is generally costive, and the pulse remarkably small and quick; the legrs and ears become cold, respiration is very much disturbed, and sometimes, from the violence of the pain and the animal's struggling, profuse perspiration breaks out; at length mortifcation takes place, and is quickly succeeded by death. Sometimes the progress of this disease is remarkably rapid; in one instance I have seen a complete mortification take place in the course of twelve hours, and that very extensively.

VOL. I. 
When only the internal coat of the intestines is inflamed, there is generally a violent purging, accompanied with febrile symptoms; these however are seldom so considerable as in peritonxal inflammation, nor does the animal appear to be in so much pain. This disease is commonly produced by the improper use of physic, or by neglecting a horse during the operation of a purgative.

In the treatment of peritoneal inflammation, early and copious bleeding is the most importunt remedy. The efficacy of artificial inPammation on the surface of the body is remarkably conspicuous in this disease; and I have seen even the actual cautery applied to the shin of the abdomen with manifest advantage. As a substitute for this severe remedy, I would recommend covering the back with fiesh sheep-slins, which will soon excite, and l. eep up for a considerable time a copious perspiration on the part; the whole of the abdomen or belly should have the mustard embrocation assiduously rubbed upon it, the stimulating effects of which may be promoted by covering the part afterward with sheep-skins, (3) wam clothing. Rowels also way be insorted about the elest and be!ly, putting into 
them blistering ointment instead of turpentine, or the common digestive, which is usually employed for the purpose. Should the horse be costive, which, as we have before observed, is almost always the case, give a pint or twenty ounces of castor oil, and let clysters of fine water-gruel be injected. He should be allowed to drink plentifully of warm infusion of linseed, or wann water alone; while hand-rubbing to the legs, with a liberal allowance of litter, should not be forgotten. If the disease do not abate in six hours after the bleeding, the operation must be repeated; and if the costiveness be not removed ten or twelve hours after the oil has been taken, give another dose, and repeat the clyster. If the clisease continue, and increase in violence, after all these remedies have been properly applied, there will be but little probability of recovery; particularly if the pulse have become so quick, weak, and fluttering, as to be scarcely felt; or if there appear to be a remission or cessation of pain, or the horse become delirious. These are always fatal symptoms, denoting that mortification is taking place, which is the certain harbinger of death; but should the pain continue after the above remedies have 
been fairly tried, the anodyne clyster may be injected.

With respect to the causes of peritonxal inflammation, the most usual appears to be high feeding and want of exercise; it is not unfrequently occasioned, howerer, by putting a horse suddenly into warm stables when taken from camp or grass. The fatal consequences of this mantagement were often experierced in the amy, I believe, though a different cause was assigned before the reterinary art had made sufficient progress to point out its impropriety and danger.

In some instances the disease appears to have been prodtuced by the distension which the intestines bave suffered in flatulent colic or gripes, where this complaint has been neglected or improperly treated, or where the spasm has been so violent as to resist the operation of every remedy.

An inflammation of the villous or internal coat of the intestine, we have before observed, is commonly occasioned by giving too strong physic, or by inattention during its operation, and is grencrally accompanied with profuse purging: in this case a different treatment is required from what we have recommended for 
peritonaal inflammation, and bleeding must not be enployed, unless the pulse is much accelerated and the febrile symptoms considerable: the oil also must be omitted. Here the mustari embrocation, and sheep-skins to the back and belly, are eminently useful.

It is of consequence to make the horse drink freely of fine warer-grnel, or linseed tea, which, if he refuse to drink, must be given with a horl. If the disease contime, notwitistanding these remedies have been carefully employed, let the anodyne clyster be injected; and if this fail, give the anolyne or the restringent draught. It sometimes happens when a horse has taken physic, that gropes and violent sickness occur before the purging takes place: in this ease, by means of a clyster, a plentiful exhibition of thin water-gruel, and exercise, we shall produce an eracuation, and relieve the animal. Peritouæal inflamnation has sometimes been mistaken for flatulent colic or gripes, but their appearances are very different, and they may easily be distinguished by referring to the annexed table, in which their symptoms are contrasted. 
RESTRINGENT DRAUGHT.

Opium, - $\quad$ from $\frac{1}{2}$ to $1 \mathrm{dr}$. Plepared chalk, - - - $1 \mathrm{oz}$.

Compound powder of tragacanth, $1 \mathrm{oz}$. Mint water, - $\quad$ - $\quad$ - 1 pint.

ANODYNE DRAUGHT.
Opium,
$-$

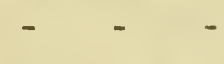
$1 \frac{x}{2} \mathrm{dr}$.
Water-gruel,

Mix for one dose.

\section{MUSTARD EMBROCATION.}

Camphor, - $\quad$ - $\quad$ - 1 oz.

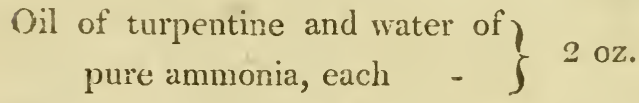

Flour of mustarl, - $\quad$ - $8 \mathrm{oz}$.

To be made into a thin paste, with water, and subbed for a consiclerable tine on the part.

ANODYNE CLYSTER.
Opium,
$\begin{array}{lll}- & - \\ - & -\end{array}$
- $\quad \frac{5}{2} \mathrm{OZ}$.
TVater-gruel
3 pints.

Mix for one injection. 


\section{A TABLE,}

SHOWING THE DIFFERENCE BETWEEN

\section{FLATULENT COLIC, OR GRIPES,}

AND

Inflammation of the Boxels*.

symptoms of Infiammation of Symptoms of Flutulent Colic. the Bowels.

1. Pulse very quick 1. Pulse natural, tho' and small. sometimes a little quickened.

2. Lies down and sud- 2. Lies down and rolls denly rises again, upon his back. seldom rolling upon his back.

3. Legs and ears ge- 3. Legs and ears generally cold. nerally warm.

4. In general, attacks 4. Attacks suddenly, gradually, is com- is never preceded, monlypreceded, ind and seldom accom-

* The additions to this subject will be found in the Appendix, under the head Diserses of the Bowes, which includes both the iufammitory and fiatuent colic, and some other disorders. 
always accompanied by symptoms of toms of fever. fever.

3. No intermissions 3. There are frequently can be obscried. short intermissions.

\section{Infammation of the Stomach.}

The stomach, like the intestines, may be inflamed either on its external or internul surface. When the external coat is the seat of the disease, the symptoms are nearly the same as those by which peritonæal infammation of the intestines is indicated, and the same treatment is required; the only difference observable in the symptoms is, that in this case the pain seems to be more acute and distressing than in the other: the same difference may be observed between the large and small intestines, the latter being possessed of more sensibility than the former.

When inflammation attacks the peritonæal coat of the stomach, it very soon diffuses itself to the small intestines and neighbouring riscera; or if the small intestines be its original seat, it frequently spreads to the stomach, and sometimes to the large intestines also. In 
examining horses, therefore, that have died of these diseases, we seldom find the inflammation confined to one particular organ; it more commonly happens, indeed, that the whole of the abdominal viscera will exhibit morbid appearances, but in different degrees; those most contiguous to the part first diseased haring suffered considerably, while such as are more remote from it are perhaps scarcely altered; for we can generally distinguish the original seat of the inflammation.

An inflammation of the internal or villous coat of the stomach is not a very comnon disease, and is generally occasioned either by poisons or strong medicines that have been swallowed, or by that species of worms termed bots. When poisons, or strong medicines incautiously given, are the cause, it will of course cone on suldenly; the pulse will be extremely quick, and so weak that it can scarcely be felt; the extremities will becone cold, and there will be a peculiar dejected appearance in the animal's countenunce; respiration will be disturibed; sometimes there will be a cough, and always a nght degree of debility. The treatuent of chis ciisease consists in giving oily or mucilaginous liquus freelyx

D 5 
such as decoction of linseed, gum arabic dissolved in water, \&c.; and at the same time medicines that are capable of decomposing or destroying the poison; for which purpose I believe the sulphurated kali is useful in doses of half an ounce, provided the poison be either mercurial or arsenical. Clysters are to be injected; and if the disease be accompanied with purging, they should be composed of strong linseed decoction or water-gruel. I saw five cases of inflamed stomach at one time, all occasioned by poison. The above treatment was pursued, and four out of the fire perfectly recovered.

That inflammation which bots produce in the stomach is indicated by symptoms somewhat different from those just described: indeed it may more properly be considered as vilceration of the stomach than inflammation, since, upon examining horses that have died of this complaint, I have always found uicers of considerable size. This disease gencrally comes on gradually: the horse becomes hide-bound, has a rough unhealthy coat, gradually loses flesh and strength, though he continues to feed well, and has a frequent and troublesome cough. The disease 
perhaps will continue in this state for sume time, and no serious consequences are apprehended; its cause and seat are seldom suspected; medicines are given to remove the cough, with common alteratives for the purpose of improring his condition.

In some instances these insects are spontaneously detached, and expelled through the intestines: in such cases, if the stomach have not been much hurt by them, it will gradually recover, and the horse be restored to his origimal strength and condition. When this does not occur, these worms produce so much mischief in the stomach, as to throw the whole system into disorder. The lungs are particularly liable to sympathise with the stomach in this case, and frequently become inflamed in consequence. The inflammation thus produced in the lungs is extremely obstinate; and though it may be checked in some degree by bleeding, and the other remedies we have recommended for that disease, yet as the cause cannot often be removed, it generally, I believe, terminates fatally. This symptomatic inflammation of the lungs may be distinguished from the idiopathic or original, by the following criterion:- It is generally preceded by an 
unhealthy appearance in the coat, and a troublesome cough; the animal seldom bears bleeding wel!, the loss of any considerable quantity causing a rapid diminution of strength ; whereas, in the idiopathic inflammation of the lungs, the strength of the pulse, as well as the whole system, is often increased by bleeding. (See Worms, Bots, and Diseases of the Stomach.)

\section{Inflammation of the Kidneys.}

This disease does not occur very frequently, and is generally occasioned, I believe, by an immoderate use of strong diuretic medicines. At the first attack of this complaint the horse constantly stands as if he wanted to stale, sonetimes voilling a small quantity of highcoloured or bloody urine. When the inflammation becomes more consilerable, a suppression of urine and fever generally take place; if the loins be pressed upon, the animal shrinks from the tunch, and appears to feel great pain. In the first place, bleed freely, then give a pint or twenty ounces of castor bil, throw up clysters of wirm water, and 
cover the loins with sheep-skins, having previously rubbed upon them the mustard embrocation. Should these remedies fail of procuring relief, repeat the bleeding; and should not the oil have operated suficiently, let another dose be given. All diuretic meuhicines are to be carefiully avoiled. (See Bloody Urine, Suppression of Urine, Appendix.)

\section{Inflammation of the Bladder.}

When the bladder is much inflamed, its mritability is so increased, that it becomes incapable of containing any urine, contracting upon every drop almost that passes into it from the kidneys. In this complaint, then, the horse is attempting almost constantly to stale, but voids only a few drops of urine, and that with consilerable pain: it is generally attended with quick pulse, and other symptoms of fever. Nothing is more beneficial in this disease than calusing the horse to drink largely of linseed decoction, or any other muciagninats liquei, and throwing up frequently clysters of the sane: vlecding, and a dose of castor oil, are likewse highly necessary. After the oper- 
ation of the oil, let the following ball be given every sixth hour. Should no relief be obtained by these means, the horse continuing to roid his urine frequently, in small quantities, and with pain, give one dram of opium twice a day, and omit the ball. Costiveness tends very much to aggravate this complaint; and, whenever it occurs, let a clyster be injected, and a dose of oil given.

\section{THE BALL.}

$\begin{array}{llll}\text { Powdered nitre, } & - & - & \frac{\mathrm{I}}{2} \mathrm{oz} . \\ \text { Camphor, } & - & - & 1 \mathrm{dr} \text {. } \\ \text { Liquorice powder, } & - & - & 3 \mathrm{dr} \text {. }\end{array}$

Honey suficient to form a ball for one dose.

(See Diabetes, Bloody Urine, Stoppage of Lrine, Stone.)

\section{Infammation of the Liver.}

This disease is indicated by a yellowness of the eyes and mouth, red or dark-coloured urine, great weakness, and ferer, generally a*companied with diambea or purging, and sometimes witi costiveness; the horse has a very languid appearance, and is almost constantly fying down. Sometines the progress 
of this complaint is very rapid, speedily terminating in death: at others it proceeds more slowly, the animal lingering for a considerable time. In this case it not unfrequently terminates in dropsy, or inflammation of the bowels. A case I recently met with terminated in this way. It is often complicated with other internal diseases, causing some variety in the symptoms.

Bleeding can be employed with safety only at the commencement of this disease: afterward it generally does harm, by inducing a dangerous degree of debility. The sides should be blistered; and if there be no purging, the ball No. 1 given, once in twelve hours, until it occasions moderate purging; but if the bowels be already in a lax state, the ball No. 2 or 3 will be better adapted to the complaint, and is to be given in the same way.

\section{THE BALL.}

$$
\text { No. } 1 .
$$

$\begin{array}{llll}\text { Calomel, - } & - & - & \text { half a dr. } \\ \text { Barbadoes aloes, } & - & - & 1 \mathrm{dr} . \\ \text { Castile soap, } & - & - & 2 \mathrm{dr} . \\ \text { Rhubarb, - } & - & - & \text { half an oz. }\end{array}$

Sirup enough to form a ball for one dose. 


\section{No. 2.}
Opium, ' - - $\frac{\mathrm{I}}{2} \mathrm{dr}$. to $1 \mathrm{dr}$.
Calomel, - - $\quad$ - $1 \mathrm{dr}$.
Castile soap, - - $2 \mathrm{dr}$.

Sirup enough to form a ball for one dose.

$$
\text { No. } 3 .
$$

Opium and calomel, of each, $1 \mathrm{dr}$.

Emetic tartar, - $\quad$ - $2 \mathrm{dr}$.

Liquorice powder, - $3 \mathrm{dr}$.

Sirup enough to furm a ball for one dose.

It is necessary to promote the horse's strength, by a diet thac is nutritious and easy of digestion, such as malt, arrow-root, carruts, \&c., indulging him in any kind of green foul which he shows a particular inclination for; taking care, huwever, not to give him too much at once. Besicie the above medicines, those of a tonic kind should be given, such as bark, steel, \&c. (See Tonics in the Veterinary Materia Medica.) 


\section{Stiangles.}

This disease gentrally attacks young horses between the third and fifth year of their age, and consists in an infammation of the membrane of the throat and nose, and swelling of the glands under the throat, accompanied with cough, and a discharge of white thick matter from the noctrils; sarretinies there are likewise a soreness of the throat, and diffirulty in swallowing. The infiamed glanls commonly suppurate in a short time, and burst, discharging a large quantity of matter. When this has taken place, the cough and other symptoris senerally go off, the sore gradually heals, and the horse speedily recovers. In some cascs the strangles assume a more formitable appearance, are attended with a considerable degree of fever, and the throat is sometiases so much infinst, that the horse is incapable of swallowing either food or water; but howerer riolent the attack may be, I have aiways found that, by adopting a proper mole of treatment, every unpleasant symptom may be easily renoved, and a speedy recurery effected. It is not a very uncommon circumstance for the straugles to attack young 
horses while at grass; and then they are frequently not perceived until nature has nearly effected a cure.

The approach of strangles may be known by a dulness of countenance, watery eyes, cough, and a slight degree of swelling in the glands under the jaw. As soon as they are discovered, let the hair be carefully clipped off from the inflamed glands and contiguous parts of the throat; let a large poultice be then applied to the throat, in doing which it is necessary to take care that it is so secured as to be constantly in contact with the throat; for unless this is attended to, the poultice will be but of little service. I have generally found, that by rubbing a small quantity of some stimulating ointment on the inflamed glands, previous to the application of each poultice, suppuration has been considerably promoted : for this purpose the following formula will be found useful :
Camphor,
$-2 \mathrm{dr}$.
Cil of origanum,
$1 \mathrm{dr}$.
Spermaceti ointment,
$20 \%$ mix.

When matter is completely formed in the glands, which may be known by the tumous 
becoming larger, and by the skin feeling tense and somewhat elastic, an opening should be made with a lancet, and its contents evacuated: this plan is certainly preferable to that of waiting until it bursts spontancously, as the animal is instantly relieved by it, and the cure more speedily effected. To evacuate the matter perfectly, it is necessary to use moderate pressure with the fingers; and when this has been done, let a piece of lint, dipped in digestive liniment, be inserted, for the purpose of keeping the lips of the wound open, and allowing the matter to escape freely; the poultice is to be continued until the swelling is perfectly reduced. When strangles attack the initernal parts of the throat so as to render the horse incapable of swallowing, and particularly if the external swelling be not considerable, it will be advisable to apply a blister, and keep the bowels open with clysters. It is very necessary, in every case of strangles, to steam the head well, that is, to put hot bran mashes into the manger frequently, so that the horse may inhale the vapours.

It is of consequence to distinguish cases of incipient strangles from common colds. In the latter, bleeding is a useful remedy; but in the 
former I believe it does much harm, by interrupting a process of nature. I cunnot, by any argument, show why bleeding should be improper in the strangles; indeed, if our practice were guided by theory only, we should be led to consider it as a case of comnion infammation, and consequently adopt that mole of treatment which would tend to remove it most expeditiously, and prevent suppuration; and with this view we shoull hare recourse to blee ling an i purgatives : experitnce, however, certainly sanctions a different treatment, and has, I think, fully proved the propriety of using every means for encomraging suppuration. I have secu several hundrel cases in which this plan has besn pursued, and not one of thein terninated unfarourably. Should the inflammation, howerer, spread to the lungs, occasioning great diffoulty of breathing and ferer, and particularly if the horse be past the age of five, bleeding rnust not be omitted; and if a laxative drink can be given, it will be fonnd of great service. A rowel in the chest will also do good.

Should a congh or any unpleasant symptom remain after the strangles are healed, let the following alterative ball be given every morn- 
ing, until moderate purging is produced; and if it be found necessary, let it be repeated after an interval of four or five days. It is almost superfluous to add, that great attention must be paid by the groom; the head, neck, and chest, as well as the body, should be clothed; warm water should be given frequently in small quantities; a large quantity of litter should be allowed; and hand-rubbing to the legs should never be onitted.

ALTERATIVE B.ALL.

Barbadoes aloes, - $\quad 1 \frac{\mathrm{x}}{2} \mathrm{dr}$.

Emetic tartar and Castile?

soap, of each, - $\} 2 d$.

To be made into a ball for one dose.

\section{Catirrh, or Cold.}

It would be superfluous to give a particular description of this complaint, since it is so well known, and its appearances so generally understood, that scarcely any one can be at a loss to distinguish it from other diseases. It consists in an inflammation in the mucous membrane, which lines the internal part of the nose, throat, \&c., sometimes attended with a slight degree of 
fever: hence arise the cough and discharge from the nostrils, which are the principal symptoms of catarrh. On the first attack of this complaint, bleeding will grenerally be found an effectual remedy; but if it be neglected until a considerable discharge has taken place from the nostrils, it seldom proves beneficial. The following laxative, however, will be found a very useful remedy, and may be repeated after an interval of a few days, should it appear necessary: it will generally prevent those obstinate and eren incurable coughs which so often remain after a cold, and which not unfrequently terminate in broken wind.

\section{LAXATIVE BALL.}

\begin{tabular}{|c|c|c|}
\hline Barbadoes aloes, & & \\
\hline Emetic tartar, & $=$ & - \\
\hline Castile soap, & 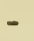 & - \\
\hline
\end{tabular}

Sirup enough to form a ball for one close.

A dose of fever powder is to be given every morning and evening, until the symptoms abate, or a consiclerable diuretic effect is produced, and then every second or third day only.

Somctimes a swelling takes place in the 
parotid glands, which are, situate immediately beneath the ear. Should no unusual heat or tenderness be observed in these swellings, apply the stimulating ointment recommended for strangles; but it they feel hot, be painful, and appear to be in a state of active inflammation, a poultice is the best remedy. If the eyes be inflamed and watery, a rowel should be inserted under the jaw; and if the inflammation in the throat be so considerable as to render swallowing painful and difficult, a blister will afford great relief. Hot bran mashes should be given frequently, which will not only serve to keep the bowels open, bui will act as a fomentation to the inflamed membranes, since the horse will be constantly inhaling the rapour which escapes from them. Should he be costive (which is not likely to happen while he is taking bran mashes), let clysters be injected occasionally. The head anil chest, as well as the body, should be well clothed, the legs frequently hand-rubbed, and a large quantity of litter allowed; by these means he will soon be restored to health. Should a cold be attended with a considerable degree of fever, or should the appetite go off, and the flanks work quicker than usual, it is 
necessary to make some alteration in the treatment. (Vide Ferer and Inflammution of the Lungs.) It is necessury to observe, before I conclude this subject, that the strangles on their first attack are sometimes mistaken for a cold. This may be productive of mischief, since bleeding is generally improper in that complaint: if, therefore, a cold be accompanied with a swelling of the giands under the jaw, if they feel hot and be painful, and particularly if the horse be young, - we may conclude that the strangles are approaching, and treat it accordingly.

Should the cough remain after the other symptoms are gone off, give the laxatire again ; and if necessary, repeat it after a short interval. If the cough continue after this, let the folluwing ball be given every morning for a week.

\section{TIIE RALL.}

Powdered squills, - - $1 \mathrm{dr}$.

Gum ammoniac, - $\quad 3 \mathrm{dr}$.

Opium, - - - $\frac{\mathrm{x}}{2} \mathrm{dr}$.

Sirup enough to form a ball. 


\section{Chronic Cough*.}

W'e have already noticed this complaint as one of the symptoms of a cold, but did not at that time gire any particular direction for its treatment, because it-generally ceases as soon as its cause (the cold) is remored. It sometimes happens, howerer, that the cough continues, although every other symptom is gone off.This complaint, which, from its long continuance, is distinguished by the term chronic, may be readily accounted for, when it is recollected that what is called a cold consists in an inflammation of the membrane which lines the nose and throat; and that this membrane also forms the internal surface of the windpipe and its branches. When the cold, therefore, has been violent and improperly treated, the inflammation is liable to extend to the windpipe, or even to its branches, causing an effilsion of coagulable lymph from the membrane, which proves a constant source of irritation. It is probable also that the inflammation may sometimes render the membrane so rery

* See Cough in the Appendix.

VOL. I. 
irritable, or so alter its secretion, as to keep up a constant irritation and cough, without any effusion having taken place. When a. considerable quantity of coagulable lymph has been effused, it obstructs the passarge of the air in respiration in some degree, causing that sonorous kind of breathing which is termed thickness of üind, or roaring. A blister to the throat has sometimes been found useful in the chronic cough. One of the following alterative balls is to be given every morning until moderate purging is produced; and this, if assisted by proper atterition to exercise, liet, and grooming, has oíten effected a cure.

The chronic cough is frequently occasioned by worms in the bowels or stomach, and is then to be treated accordingly. (See Worms.)

\section{BALLS.}

No. 1.

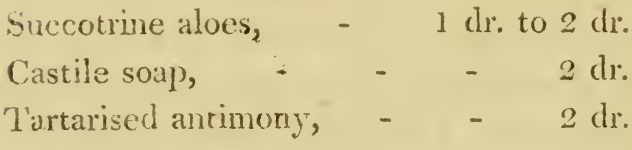

Sirnp enough to form a ball for one close.

Should the disease not submit to this remedy, try the following. 


\section{No. 2.}

Gum ammoniacum, - $\quad 3 \mathrm{dr}$.

Powdered squill and opium, of each $1 \mathrm{dr}$.

Camplior, - - - - 1 df.

Sirup enough to form a ball for one dose.

This is to be given every moruing, and continued five or six days. A stable, properly ventilated, should be chosen, and the vapours of foul litter carefully avoided.

\section{Inflammation of the Eye*.}

When the eye is inflamed, it loses part of its beautiful transparency, appearing then as if covered with a film; the lids are partially closed, and the haws become more visible. should the inflammation have been brought on by some external injury, and particularly if it be not very considerable, the eye lotion will be sufficient to remove it; but in more violent cases it will be necessary also to bleed moderately and give a laxative ball. By these means, inflammation arising from external injury may generally be cured in a short time.

* See Appendix, Anatomy and Diseases of the Eyes. 
The eyes often become infamed in consequence of cold and ferers, in which cases the curse is to be chiefly attended to: when this is remored, the inflammation usually ceases.

The most common cause of this complaint is high feeding, without a due proportion of exercise. These cases require great care and attention, for unless proper remedies are employed on the first attack, the disease, though it appears to go off, will be frequently returning, and in all probability eventually produce blindness. The first remedy to be employed on this occasion is bleeding; and the quantity of blood that is drawn should be proportionate to the violence of the inflammation, and the condition of the animal. Should the ressels on the white part of the eye and inner part of the eye-lids appear to be distended with blood, great advantage will be derivel from scarifying the latter with a lancet. A laxative ball is to be given, and the bowels afterward kept in a lax state by means of bran mashes. I hare fom a seton, placed immediately under the eye, a very useful reniedy; but unless the operation is nicely performed, it frequently leares an 
unpleasant mark behind, which would lead a person experienced in horses to suspect that the eye hat been diseased, and might therefore diminish the value of the horse.

A shude, so ariapted as to preserve the cye from the irritation of dust and light, will be funse useful. This kind of inflummation generdily comes on rather suddenly, sometirnes attackmg only onc eyc, at others both are aifected. As tinere is no apparent cause for this sudden attack of inflammation, the groom very commonily attributes it to seeds or dust having fallen from the rack into the eye, and very little atteution is paid to it. Notwithstanding this neglect, the disease trequently goes off, and in some cases its disapparance is neatly as sudien as its attack; in a short time, however, it again appears as unexpectedly as at first, and again perhaps goes off. In this uncertain way it may continue a considerable time, the eyes sometimes appearing transparent, and free from infammation; at others, watery, inflamed, and opaque on the surface: at length the internal parts of the eye are affected, and a cataract produced.

It has been supposed, that the diseases of 
a horse's cyc are frequently herelitary, or dicpendert on some natural defect in the structure. I do not know how far this opinion may be true, but never having seen a case which seemed to corroborate it, I am not inclined to give it much credit. It is not very improbable, however, that the eyes of some horses may be naturally weak, and more liable to become inflamed when exposed to the exciting causes of inflammation, than such as are originally endued with a proper degree of strength: but it appears to me that where this weakness or aptitude to disease exists, it is more frequently the effect of some injury which this tender and delicate organ has sustained, thain a defect of natur'. When the eye becomes inflamed, it is necessary to inquire into the cause of the inflamnation: if it arise from any mechanical injury, and be not very considerable, there is a probability of its being speedily removed, by means of the remedies I have pointed out; but if the inflammation have arisen without any apparent cause, depending perhaps upon piethora, or redundancy of bloved in the system, there will be some chance of a rudical cure, proviled the proper remedises wre employed suficiently 
carly. If these be neglected at the commencement of the discase, though the inHamnation after some time appears to go ofl; and the eye, to a superficial observer, seems to lave recorered, yet the disease frequently retums, and uitimately occasions blindness. Should the disease have occured before, and particularly it the former attack were violent, there is still less chance of its being removed, and all our renedies will probabily prove ineffectual. In this case the alterative No.3 (See Index) may be iried. It frequently happens that when both eyes are infamed, and a complete cataract forms in one of them, the other becomes perfectly sound and stong. It nust be observed, that when a horse has suficred nure than once from this disease, and is in low condition, evacuations must not be made too freely: there are few cases, however, where moderate bleeding and a laxative bail are not required. With respect to topical applications, or those remedies which are applied immediately to the cye, I must confess that I have not scen much benefit derived from them, except when the infianmation has abated considerably, and there remains an opacicy or film on the surface; 
and then common salt, finely powdered, has often provel useful. But if the eye have been in this stat for some time, and the opacity is very considerable, white glass, finely powdered and mixed with honey, is a more eirectual remedy. Whenever the eyes are weak, or in a state of inflammation, the vapours which arise from foul litter should be carefully guarded against; indeed, it is by no means an improbable conjecture, that when the eyes are weak, these irritating vapours may often prove the exciting cause of inflammation.

There is a cartilaginous body comnected with the eyes of horses commonly termed the hai. Whenever the eye is drawn into the socket, (which the horse has the power of doing by means of a muscle that does not exist in the human subject) the haw is forced orer the eye, so that when clust happens to adhere to the surface of the eye, he is enabled, by means of this cartilage, to wipe it off; and as light is painful to the animal when the eye is in a state of infammation, we generally find this organ, on such occasions, drawn more thai usual into the socket, and consequently the haw becomes conspicuous on its surface. Farriers in this case consider the haw as an 
unnatural excrescence, and the cause of the disease: they frequently therefore cut it off. The once celebrated $\mathrm{Mr}$. Taplin considered the haw as a preternatural enlargement of the corners of the eye. So gross an error, for the sake of humanity and common sense, should be got rid of by all who have imbibed his mistaken notions.

\section{Locked Jaw.}

This disease, very fortunately, occurs but sclitom, as it generaily terminates fatally. It begins with a difficulty in mastication; at length the jaws becoine so completely and immoreably closed, that neither medicines nor food can be got into the stomach. The muscles of the neck are generally in a state of rigil contraction, and the animal appears to suffer great pain. It is often brought on by trilling causes, such as wounds of the foot, inflammation of the tail, from docking or nicking, \&c.; and sometimes it attacks without any apparent cause. Various remedies have been tried in this complaint, but I do not think any effectual mode of treatment has yet been discorered. Immersion in cold water, or even 
snow, is said to produce a temporary relaxation of those muscles by which the jaws are closed. Opium and camphor have been strongly recommended. I have lately been informed of a case in which a combination of these medicines completely succeeded. In Anerica and the West-India islands, where the disease is much more frequent than it is in this climate, strong stimulants have been found cffectual; it would be advisable therefore to try the same plan on horses, should opium and camphor fail. The best stimulants for this purpose are spirit of hartshorn, ether, opium, and brandy. I have been informed that a blister, applied to the spine or back, throughout its whole length, from the withers to the basis of the tail, has proved successful in several cases. I have had only one opporrunity of trying it, in which it rlid no good: but the disease had existed for some time, and had become very violent before any remedy vas enupioyer.

\section{Lampas.}

When the bars or roof of the horse's mouth, near the front teeth, become lerel with, on 
higher than the teeth, he is said to have the lampus, and this is supposed to prevent his feeding. Farriers burn down this swoln part with a red-hoi iron made for the purpose. I believe this operation is performed much more frequently than is necessary, but I have never seen any bad consequences arise from it.

\section{Roaring.}

This disease takes its name from a peculiar sound in respiration, particularly when the horse is put into a brisk trot or gallop. It seems to arise from lymph that has been effused in the windpipe or its branches, which, becoming solid, obstructs, in a greater or less degree, the passage of air. $\Lambda$ s a remedy for this complaint, blistering the whole length of the windpipe has been recommended; I believe, however, that it is always incurable, unless proper remedies are employed as soon as it is observed to be coming on. It generally begins like a severe cold, with difficulty in breathing, accompanied with a peculiar lind of wheezing : sometimes there is also considerable fever, and soreness of the throat. 
Ii some cases it attacks suddenly, and with great violence; in others, it comes on gradually, and is then more dangerous, as it is seldion attended to, and generally allowed to establish itself before proper remedies are employed. It is advisable, whenever a horse is attacked with the above symptoms, to have recourse immediately to bleeding, purging, and blistering the throat. (See Cough, Appendix.)

\section{Broken IVind.}

It seems to be universally allowed that this complaint is incurable, though it will admit of consideruble alleviation; and if its approach be perceired sufficiently early, may probably be prevented. Horses that appear to be most subject to it are those with roracious appetites, that eat eren their litter, and keep themselves in grood condition upon a moderate allowance of com; abo such as are fed highly, and at the sane tine not properly exercised. It has been ciserred by a mollern author*, "that

* "An Enciuiry into the Structure and Animal Economy of the Horse, by Richand Lavrence, Veterinary Surgeon, Birmingham, 110. " a work of much general merit. 
the most coninuix appearance of the lungs in broken winded horses is a general thickening of their substance, by which thesr clasticity is in great measure destroyed, and their weight specifically increased, at the same time that their capacity for air is diminished. During life the lungs entirely fill the cavity of the chest, so as to leave no space between tireir outward surface and the inward surface of the ribs. (Sce Structitre of the Lungs.) Thus they dilate and contract, following up by their own elasticity the action of the ribs and diaphrigin. If the chest be punctured in the chad subject, the air rusies in, and the lungs collapse: but if the horse were broken winded, the lungs do not cullapse. This state of the lungs suifichuly accouts for the dificulty of respiratsis; for as ther fuclity filutation is destivy. at the ribs cunnot exp nd without forming a votedum in the chest, which the prossure of the cxternal air prevents, which nay be reanily percerveu in alle case of bìken wind; for tiren the intereostal mitiscles are so strungly retractit, is 2 form a deep furruw between evry then, as woll as a depression in the llanks.

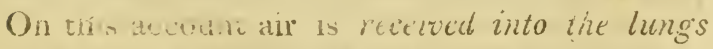

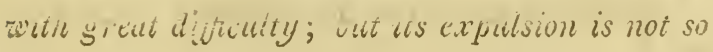


difficult, as the return of the ribs and diaphragm naturally force it out by their pressure: Thus in broken winded horses inspirution is very slnw, but expiration is sudden and rapid, as inay be seen by the flanks returning with a jerk."

It appears to me that the observations of Mr. Lawrence on this subject are not correct. 'The lungs of broken winded horses that I have examined have generally been unusualiy large, with numerous air-bladders on the surface. This must have arisen from a rupture of some of the air-cells; for in this case some part of the air which is inspired will necessarily get into the cellular membrane of the lungs, and diffuse itself until it arrives at the surface, when it will raise the pleura so as to form the air-bladders we observe*. This is the reason that the lungs of broken winded horses do not collapse when the chest is punctured; and this will serve to explain the pecular motion of the flanks in broken winded livrses, which does not consist, as Mir. Lawrence asserts, in a quick expiration and rery slow inspiration, but quite the roverse; air is received into the

* Sce Description of the Functions of the Lungs, Sic, as abeve, paşe 1. 
lungs very readily, which is manifested by a sudden falling of the flanks, but is expelied slowly, and with great difficulty, as may be perceived by the long contunued exertion of the abdominal muscles*.

When the membrane which lines the windpipe and all its branches has been affected

* A short time since, a horse completely broken winded was given to me for the purpose of making experiments relative to the glanders, a disease which has for man; years occupied my attention, and will be fully treated of in this work. On desiroying the auimal, and examining the lungs with great care, very little disease could be observed. So far from their being thickened, and in the state Mr. Lawrence describes, they were specifically lighter than natural; and thongh no air-bladours wcre perceircd on the surface, there was evidently a great deal of ail diffus $d$ in the celiular membrame of the lungs, which mist tave been occasioned by a mpture of one or more of the air-ceils, or minute branches of the windpipe; tiere berng no other source from which it could have been produced. "Now this was a case of simple broken wind, which may ve easily distinguished, not by an unustally quick motion of the fias - but b; li unequat notion. The flanks of a broken witided hurse are a long lime in drawing up or contracting, which shows the diffen ${ }^{\top} t y$ he $+t^{-1} \mathrm{~s}$ in expelling the air from his lungs, or in expiring; bet when isist is effected, the flanks diop suddenly, which shows that the air enters the lumgs, or that the animal inepires with linuch greater ease than he expires. It ofteil happons, however, that brokein wind is complicated with thickress of winc, and, as I have before observed, is sometimes occasioned by it, which probably gave rise to the opinion we lave endearouled to refute. (Ste Cough, Asthmu, and Thickness of Wind, Appendix.) 
with inflammation, it becomes thickened in consequence, and the capacity of the lungs will of course be liminished; this will calise a quicliness in respiration, but not that irregular or unequal kind of breathing by which broken wind is characterised. The complaint which is thus produced is commonly termed thick roind; and the horse so atrerted, it nade to more rapilly, wheezes lihe an asthmatic person, and is unfit for any violent exercise. It not winequently happens, I believe, that this complaint proves a cause of broken wind; for when the nembrane is much thickened, many of the finer brandies of the win lpipe are probabiy obstructed in a greater or less iegree: the violent coughing which usually accompanies this disease, will, under such circumstances, be very liable to rupture some of the air-cells. The saine cffect niay be produced by violent exercise when the stomach is distended with food or water. I believe, however, that a plethora or fulness of habit is most commoniy the remote cause of broken wind. In tint case there is generilly un mudue cictermination of blond to the lungs, whereby the secretion within the air-vessels is increased, and perhups rendered somewhat acrimomous 
and viscid, exciting a violent and troubiescine cough.

Whenever a horse appears to be imperfect in his wind, if he coughi tiolently, puthalarly when exercistil, with unusual workmg of the flanks, and if at the same time he appoar to be in good haith and spritits, ferting heartily, and agger lor wates, tet his be bled moderately, and tahe a laxative hall: by these nitans, assisted by a bran circt and regular exercist, the lungs will soon be relieves, and the combh, if not completely remored, will be consictiobly dininished, Afterward give the followng ball every noming for a week, and tali: calt isat regular extrcise is never omitred: it whil be adrisible also to prevent the horse? from filing himself too much with hay or wate: The latter should be given five or six tines a day, in snall quantities; for the common methoa of stuing a horse in waer, when his wind is supposed to be bad, is certanly prejuhiciai. Corn slzonid be giren sparingly, as nigh fecding tends very mich to aggravate the compliaint. bran is a useful dict, if mixed with com; and if carrots or any other sucmlent vey tuhte can be procured, they will be sumat oi considerable ser- 
vice. The vapours which arise from foul litter, and the air of a close stable, are extremely pernicious. I have seen very good effects from turning the horse into a paddock during the day, when the weather is farourable. When the cough and other symptoms have been removed, these means must still be persevered in, or the disease will probably return: regular and long continued exercise tends more than any thing to keep it off; but violent exercise is extrenely improper. Whenever costiveness occurs, it should be removed by means of a clyster and bran mashes; and should the horse be disposed to eat his litter, it is to be prevented by means of a muzzle.

\section{THE B.AL.}

Powdered squills,

Gum ammoniac,

Powdered aniseerls,

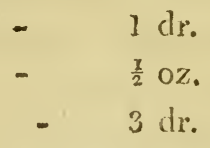

'To be made into a ball with sirup, for one dose.

Juunclice, or Yellnw's.

This discase is indicated by a yellowness of the eyes and mouth, dulness and lassitude; 
the appetite is generally diminished, the urine of a reddish or dark colour. Sometimes the complaint is attended with costiveness, but more commonly with a purging. This disease does not often arise from an obstruction in the biliary ducts, as in the human subject, but generally from increased action of the liver, whereby an unusual quantity of bile is seereted. Inflammation of the liver is sometimes mistaken for jaundice, but may be distinguished from it by the fever and debility with which it is always accompaniad.

When costiveness is one of the symptoms of jaundice, give the ball No. 1 every morning until moderate purging is produced; but if the bowels be already open, or in a state of purging, give the ball No. 2 every morning. The horse's strength should be supported by. infusion of malt or water-gruel.

THE BALL.

No. 1.

\begin{tabular}{|c|c|c|c|}
\hline Calomel, & - & - & $\frac{x}{2}$ dir. \\
\hline Barbadoes aloes & - & - & $1 \frac{1}{2} d$ \\
\hline Castile soap, & - & - & \\
\hline Rhubarb, & - & - & \\
\hline
\end{tabular}

To be made into a ball with sirup, for ons dose. 


\section{No. 2.}

Calomel anu opium, of each, 1 dir. Columbo rout, powdered, - 3 dir. Powdered yinger, - $\quad-\frac{x}{2} d r$.

Sirup enough to form a ball for onc dose.

There is a species of staggers, of which I have seen a great number of cases since I left the army, where ycllowness of the eyes and mouth is invariably one of the symptoms; which has often lod farrers to co wisiler it as the jaundics, or yelboes, as they turm it; and their remedies hare generally consisted of saffron, furm ric, or ocher inert medicines of a yellow rolour, which they sewn to consiler as an indispensable quaiity in all medicines eniployed fur the yillows. On the same principle they give drugron's blovi, a red resinuus substance, and otier red medicines, in all cases of internal hemornage or bleeding, such as bloody water, \&c. (See Staggers, and Diseases of the Stomach.)

\section{Flutulent Colic, Gripes, or Fret.}

This disease generally attacks rather suddenly, and is brought on by various causes: 
sometimes it is occasionéd by drinking a large quantity of cold water when the body has been heated, and the motion of the blood accelerated by violent exercise. In horses of delicate constitutions, that have been accustomed to hot stables and warm clothing, it may be brouglit on merely by drinking water that is very cold, though they have not been previously exercised. Bad hay appears to be another cause of the complaint; but it frequently occurs without any apparent cause, and then probably depends upon a spasmodic action of the stomach or bowels, occasioning a crinstriction of the intestine, and a confinement of air. It lias not been ascertained whether this air be procinced by a fermentation of the contents of the buwels, or formed by the arteries of thei internal coat: which erer of these is the source of the air, there is 110 doubt that the immediate cause of its formation and confinement is weakness, or a loss of vital energy. On this account medicines of a stinulating quality are the most effectual remedies; therefore the common flatulent colic is easily cured by grooms and farricis, who seldon gire any other kind of medicines. The greatest caution, howerer, is necessary 
on this occasion; and I have known many valuable horses destroyed by adopting hastily this mode of treatment. There is a species of flatulent colic, which, if treated in the common way, is sure to terminate fatally, though it is not at first of an inflammatory nature. This disease will be described in the Appendix, under the head Diseases of the Bowels; and its remote cause will be more particularly shown under the head Humours, Appendix.

The pain and uneasiness which this complaint occasivns are so considerable as to alarm those who are not accustomed to see it, and lead them to be apprehensive of dangerous consequences; but if properly treated, it may be easily and expeditiously removed. It begins with an appearance of uneasiness in the horse, he frequently pawing his litter; he voids a small quantity of excrement, and makes fruitless attempts to stale; the pain soon becomes more violent; he endeavours to kick his belly, and looks round to his flanks, expressing by groans the pain he labours under; at length he lies down, rolls about the stall, and falls into a profuse perspiration. After a short time he grenerally gets up, and appears for a minute of two to be getting better, but the pain soon 
retums, and the succeeding paroxysm is generally more violent than the former; the pulse is seldom much accelerated, nor are there any symptoms of ferer. The disease will sometimes go off spontaneously : it more commonly happens, however, when proper remedies are not employed, that the air continues to accumuiate, and so distends the intestine, as to prouluce infianmation of its coats: the distension has sometire's been so considerable as to rupture, the intestine, whereby tie horse is speedily destroyed.

As soon as this disease is observed, let one of the following draughts be given, and a clyster injectel, composed of six quarts of water-gruel or warm water, and $8 \mathrm{oz}$. of commun salt. If the disease have cxisted for scveral hours, and the pain appear to be very considerable, particularly if the pulse have become quick, it will be advisuble to bleed to three quarts, with a view to prevent inflammation and remove the spasmodic contraction of the intestine. If the disease, however, be perceived on its first attack, the draught and clyster will generally be sufficient to cure it; but should no relief be obtained by these means in an hour or two, let the drauglit be repeated, and let the belly be 
rubbed for a considerable time with the inustard embrocation. Should the disease be so - obstinate as to resist even these remedies, which will scarcely ever happen, give a pint of castor vil, with $1 \frac{\mathrm{r}}{2} \mathrm{Oz}$. of tincture of upium : as soun as the horse gets up, let him be rubibed perfectly dry by two persons, one on each side; and afterwards let him be well clothed. It is necessary in this complaint to provide a large quantity of litter, for the purpose of preventing the hurse from injuring himself during the vilence of the paroxysm.

\section{TIIE DRAUGHT.}

$$
\text { No. } 1 .
$$

Balsam of capivi, - $\quad$ - $1 \mathrm{oz}$.

Oil of juniper, - $\quad-2 \mathrm{dr}$.

Spirit of nitrous ether, - $1 \mathrm{oz}$.

Simple mint water, - 1 pint.

Mix for one dose.

No. 2.

Venice turpentine, - $1 \mathrm{oz}$.

Mix with the yolk of an egg, and add gradually

Peppermint water, - 1 pint.

Spirit of nitrous ether, - $\frac{1}{2} \mathrm{oz}$.

Mix for one dose. 
No. 3.
Camphor, - - $\quad 2 \mathrm{dr}$.
Oil of turpentine, $\quad-\quad \frac{x}{2} \mathrm{oz}$.
Mint water, - $\quad$ - 1 pint.

Mix for one dose.

As this complaint is liable to occur during a journey, in situations where the above remedies cannot be readily procured, I have annexed a formula for a ball, for the convenience of those who are in the habits of travelling. If this ball be wrapped up closely in a piece of bladder, it may be kept a considerable time without losing its virtues.

THE BALL.
Castile soap,
$-\quad-3 \mathrm{dr}$.
Camphor, - - - $2 \mathrm{dr}$.
Ginger, - - - $1 \frac{\mathrm{r}}{2} \mathrm{dr}$.
Venice turpentine, - $6 \mathrm{dr}$.

To be made into a ball for one dose.

Apoplexy, or Staggers.

This disease generally begins with an appearance of drowsiness, the eyes being VOL. I. 
inflamed and full of tears, and the appetite diminished; the disposition to sleep gradually increases; and in a short time the horse is constantly resting his head in the manger; and sleeping: The pulse is seldom much altered; in a few cases I have found it unusually slow: costireness and a defective secretion of urine commonly attend this complaint. Sometimes the disease will continue in this state for scveral days; at others it assumes a formidable appearance very early, or even at its commencement, the horse falling down and lying in a state of insensibility, or violent convulsions coming on. Sometimes a furious delirium takes place, the horse plunging and throwing himself about the stable, so as to rencier it dangerous for any one to come near him. From this variety in the symptoms, writers on farriery have divided the disease into tue sletpy and the mad staggers.

There is another kind of staggers, which arises from a distension of the stomach, and most commonly attacks horses employed in agricuiture, or in any kind of hard work, when their condition is not equal to their labour, and particularly when they are badly managed with respect to food and water. Since the 
author left the army, he has met with a great number of cases of this kind; and being informed that it uniformly proved fatal, destroy ing a very considerable number of horses annually, he was led to pay particular attention to it; and was the more strongly induced to this, from finding his own treatment unsuc. cessful.

The bodies of horses that died of the complaint were carefully examined, and at length a morle of treating it was discorered, which, if seasonably employed, almost always proves successful. As the disease is now known to originate in the stomach, it will be described under that head in the Appendix. (See Stomacil Siaggers.) It is sufficient to observe here, that it may be distinguished from apoplexy, $\mathrm{Or}^{\circ}$ genuine staggers, by a yellowness of the eves and mouth, and a twitching or convulsive motion of the muscles of the breast; the horse appears very feeble, the head harging down as if oppressed with a considerable weight; the fore legs totter, and frequently give way suddenly, so that the animal appears to be on the point of falling, but he rarely falls down, except in the last stages of the complaint; he seems to be insensible, and often forces his 
head against the wall with such violence, that the projecting parts are much bruised.

From the view we have given of the staggers, it will appear, that the terms which farriers have adopted to distinguish its different appearances are very inadequate; and that it would be better to consider the disease under the two following heads; viz. the idiopathic and the symiptomatic staggers. In the former, blecting is the grand remedy, and seldom fails of affording relief, if employed with freedom at the commencement of the discase. It will be adisable also to give the following purgative draught, and inject a stimulating clyster, composed of a gallon of water and $8 \mathrm{oz}$. of common salt. Should not the symptoms abate in eight or ten hours after the bleeding, there wili be great probability of obtaining relief by opening the temporal arteries, and suffering them to bleed freely.

I once saw a case in which the efficacy of this plan was remarkably conspicuous: the horse had been labouring under the disease for several days, and delirium had taken place, though he had been bled freely, and in erery respect, according to the accoum I receired, reated properly. When I saw him, he was 
lying down in a state of insensibility, having just before been plunging and throwing himself about very volently: the attendants supposed him to be dying; and, indeed, I should have been of the same opinion, had not the pulse retained some degree of strength. I immediately opened both temporal arteries, and after they had bled about ten minutes, the horse got upon his legs, appeared perfectly easy, and from that moment gradually recovered without the assistance of any other remedy.

When the disposition to sleep is not removed by the first bleeding, the head should be blistered, and a rowel inserted under the jaw.

\section{PURGATIVE DRAUGHT.}

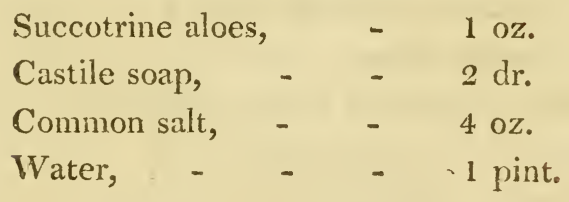

Mix for one dose.

Diarrhaa, or Purging.

This is not a very common disease in the horse, and seldom difficult of cure. It may 
be occasioned by a suppression of perspiration, or by an increased secretion of bile. From whatever cause it may proceed, give in the first place the following laxative ball; and if the disease do not cease in two or three days, let the astringent ball be giren. Warm clothing is particularly required in this complaint, and exercise should-not be neglected; his water should be moderately warm, and given frequently in small quantities. When a purging is accompanied with griping pains and fever, it is to be considered as a case of inflammation in the bowels, and treated accordingly.

\section{LAXATIVE BALL.}

Barbadoes aloes, - $-2 \mathrm{dr}$.
Powdered rhubarb,
Cascarilla bark powdered,
Castile soap,

Sirup enough to form a ball for one dose.

ASTRINGENT BALL.

\begin{tabular}{|c|c|c|}
\hline Porvdered opium, & - & - \\
\hline Prepared chalk, & r & 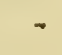 \\
\hline Powdered cimnamo & & - \\
\hline Tartarised antimon & & - \\
\hline
\end{tabular}

To be formed into a ball with sirup, or mixed into a dink with mint water for one dose. 
Diabetes, or excessive Staling.

This disease often proves extremely obstinate, and not unfrequently incurable: I am inclined to believe, howerer, that if attended to at its commencement, a cure may be effected without much difficulty. The complaint at first consists merely in an increased secretion of urine, the horse staling frequently, and in considerable quantity ; the urine is generally transparent and colourless like water; at length he becomes feverish, the mouth feels dry, and he seems to suffer much from thirst; the appetite is diminished, and the pulse becomes quick; he is generally hidebound, and gradually loses flesh and strength. Lime water has been much recommended as a remedy for this disease: I have seen it giren, howerer, in two cases, without any good effect. Others recommend diaphoretic medicines, from a supposition that it depends in great measure upon a suppression of perspiration. Bark and other tonics have also been considered as uscful remedies. I had four cases of diabetes under my care, nearly about the same time; and they were all speedily cured by means of the following: ball: 
BALL FOR DIABETES.

Opium, - $\quad-\quad 1 \mathrm{dr}$.
Powdered ginger, - $\quad 2 \mathrm{dr}$.
Yellow Peruvian bark, $\quad-\quad \frac{1}{2} \mathrm{oz}$.

Sirup enough to form a ball for one dose.

But these were all recent cases, and not attended with fever, nor had the horse lost much strength, or become hidebound in any considerable degree; yet the disease was well marked, and would, I doubt not, have produced all these symptoms, had it not been opposed as soon almost as it made its appearance. In all these cases the quantity of urine discharged was very considerable; the mouth was dry; and there appeared to be a constant thirst. It seems, therefore, highly necessary to attend to this disease at its commencement, since, if neglected, it becomes extremely obstinate, and sometimes incurable. Should the above remedy fail, try one of the following formulix :

BALLS FOR DIABETES.

$$
\text { No. } 1 .
$$
Emetic tartar,

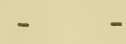
$2 \mathrm{dr}$.
() pium,
- $1 \mathrm{dr}$.
To be maile into a ball for one dose. 
No. 2.

Salt of hartshorn,

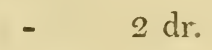

Opium, - $\quad-\quad \frac{1}{2} d r$.

Powdered ginger, - $1 \mathrm{dr}$.

Liquorice powder, - $3 \mathrm{dr}$.

To be made into a ball for one dose.

$$
\text { No. } 3 .
$$

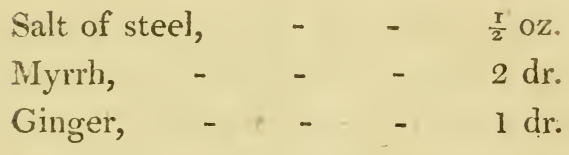

To be made into a ball for one dose.

$$
\text { No. } 4 .
$$

Powdered Columbo root, $3 \mathrm{dr}$.

Cascarilla, - - $\quad 2 \mathrm{dr}$.

Salt of steel, - $\quad-\quad 2 \frac{\mathrm{r}}{2} \mathrm{dr}$.

Prepared kali, - - $1 \frac{\mathrm{r}}{2} \mathrm{dr}$.

Tincture of opium, - $\quad \frac{x}{2} \mathrm{oz}$.

To be mixed with strong beer, or porter, and given as a drink at once.

Remark.-The horse's diet should be nutritious, and easy of digestion; and he should be allowed to drink small quantities of weak lime water; or, if he refuse this, common water, frequently. 


\section{Suppression of Urine.}

Horses are often attacked with a difficulty in staling or making water, sometimes amounting to a total suppression of that excretion. This most commonly arises from spasm in the neck of the bladder, or from hardened excrement in the rectum or latter part of the intestines.

In the first place, let the hard excrement be carefully removed by the hand, and a common clyster; and if the horse happen to be costive, wive the following laxative :

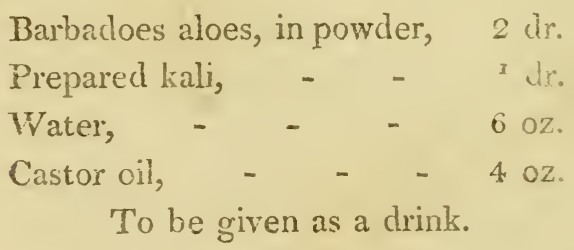

Should the disease continue, give the following bail ; or if the horse be not costive, let it be given at first:

$$
\begin{aligned}
& \text { Nitre, - } \quad-\quad-\quad 1 \mathrm{oz} \text {. } \\
& \text { Camphor, }
\end{aligned}
$$

Linsced powder and sirup enough to form a ball for one dose. 
Should there be any appearance of ferer, or should the horse appear to feel pain when the loins are pressed upon, it is probable that the kidneys are inflamed. In such cases the ball would be improper. (See Infamimation of the Kidneys, page 60.)

\section{Worms.}

There are three kinds of worms found in horses. The most common and mischievous reside in the stomach, and are named bots. They are of a reddish colour, and seldom - exceed three quarters of an inch in length. At one extremity they have two small hooks, by which they attach themselves, and the belly seems to be covered with very small feet: they are most frequently found adhering to the insensible coat of the stomach, and then they do not appear to cause any considerable uneasiness or incourenience. Sometimes, however, they attach themselves to the sensible part, and do great injury to this important organ, keeping up a constant irritation, and thereby occasioning emaciation, a rough staring coat, hidebound, and a congh. I have met with several instances of their destroying 
the horse, by ulcerating the stomach in a considerable "degree; and cases are recorded where they have penetrated quite through the stomach. It is astonishing wh what force these worms adhere, and how tenacious they are of life: they have been found to resist the strongest poisons, nor have we yet discovered any medicine capable of destroying them, or of detaching-them from their situation. It seems probable that this worm, like the caterpillar, undergoes several changes. It is said to be originally a fly, which, depositing its eggs in the horse's coat, causes an itching that inluces him to bite the part. In this way he is supposed to swallow some of the eggrs, which, by the heat of the stomach, are brought to maturity, and produce bots. When the bots are fit to assume the chrysalis state, they are spontaneously detached, and gradually pass off with the frees. This is the most rational account we have of their production.

It has been asserted, that the fly from which bots are produced crawls into the anus of horses, and deposits its eggs there; that the worms when hatched soon find their way further up the inteștines, and often penetrate into the stomach. This account is literally 
copied by a late writer on Veterinary Patho$\operatorname{logy}$ *; but it appears to me rather strange, that any one who has considered the structure of the horse's intestines should for a moment give credit to it. It seems impossible indeed for these worms to crawl from the anus to the stomach; and as far as my observation goes, they are never found residing in the intestines. Sometimes we find two or three, but they are evidently proceeding towards the anus to be expelled. I have before observed, that I am not acquainted with any medicine that is capable of detaching or destroying these worms, though I have frequently tried the strongest mercurial preparations, and many powerful medicines.

I have used the yellow emetic mercury, or the vitriolated quicksilver, as recommended by the writer just quoted, as well as every other mercurial preparation, but never saw a single bot expelied by them. (See Bots and Worms, Appendix.)

The next worm we have to describe is very slender, of a blackish colour, and seldom exceeds

* Pyding's Veterinary Pathology. 
two inches in lenogth. It is never found in the stomach, and very rarely in the small intestines, the largest part of the canal being generally the place of its residence. Here it prores a constant source of irritation, occasioning loss of condition, a rough unhealthy looking coat, and frequently a troublesome cough. A variety of alterative medicines have been proposed for the destruction of worms of this kind, and some of them are supposed to be infallible: $I$ believe, however, that none of them are possessed of much efficacy, and we ought not therefore to depend upon them.

The following are the alteratives to which I allude :- sarin, rue, box, xthiops mineral, antimony, sulphur, emetic tartar, calomel, and vitriolated quicksilver; the last two, if giren with aloes, so as to purge briskly, and particularly the calomel, are excellent remeciies; but given merely as alteratives they do no good.

I have generally found the following ball very effectual, giving the preceding night fioin half a dram to a dram of calomel. I have often mixed the calomel with the ball, and found it equally efficacious: the former method, however, is generally preferred. 
THE BALL.

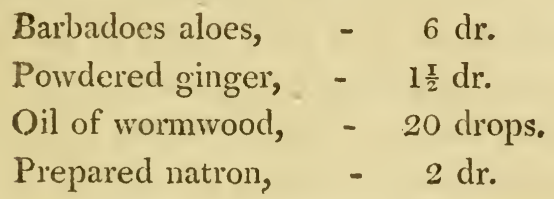

Sirup enough to form a ball for one dose:

It is often necessary to repeat this medicine, but there should always be an interval of ten days between each dose.

The third kind of worm is of a whitish colour, frequently seven or eight inches in length, and generally found in the lower part of the small intestines. Worms of this kind are not so common as the others, but appear to consume a considerable quantity of chyle, or the nutritious parts of the food. They may be got rid of by the same means that we have recommended for the small blackish worm.

We may alvays be satisfied of the existence of worms in the intestines, when a whitish or light straw coloured powder is observed immediately beneath the anus. I have sometimes succeeded in destroying worms, by giving one dram and a half of aloes every morning until purging was produced. 


\section{Hidebound.}

This term implies a tightness of the skin, which feels as if it were glued to the ribs, the coat having at the same time a rough unhealthy appearance. This complaint is generally occasioned by worms, or want of attention in the groom: it occurs sometimes, however, without any manifest cause. In such cases give the alterative ball No. 1 every morning; until moderate purging is produced; and if this do not succeed, try the alterative No. 2, which is to be given every morning for eight or ten days, taking care to assist its operation by warm clothing, good grooming, and regular exercise. The exercise should not be confined to walking, but may be carried so far as to excite a moderate perspiration. Great care must afterward be taken that the horse does not get cold. Let him be put into the stable while warm, and immediately clothed: when the legs and head have been well cleaned, remove the cloth, and continue to rub the body with large wisps of clean straw, until it is quite dry.

I cannot forbear mentioning here a remedy that is employed in some parts of Staffordshire. for this complaint, as it clearly evinces how 
necessary it is to rescue this valuable animal from the barbarous and absurd treatment of illiterate blacksmiths. An account of this operation was sent me by a gentleman who saw it practised a few months aggo. "The head and legs of the horse being secured, two men (one on each side) pull the hide from the ribs in about fifty places with pincers." The proprietor of this unfortunate animal must surely have been destitute of common sense or humanity, to allow an ignorant unfeeling farrier to perform so cruel and fruitless an operation.

ALTERATIVE BaLLS.

$$
\text { No. } 1 .
$$

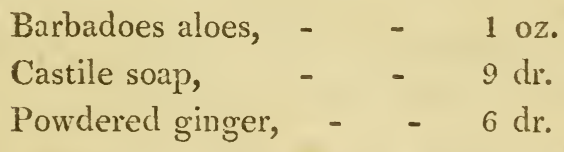

Sirup enough to form a mass, to be divided into four doses.

No. 2.

Tartarised antimony, - $2 \frac{\mathrm{r}}{2} \mathrm{oz}$.

Powdered ginger, - $\quad 1 \frac{\mathrm{r}}{2} \mathrm{oz}$.

Opium, - - - $\quad \frac{\pi}{2}$ oz.

sirup enough to form a mass, to be divided into eiglit balls.

(See Condition, Appendix.) 


\section{Surfeit.}

This absurd term is given by farriers to a disease of the skin, consisting in small tumours or knobs which appear suddenly in various parts of the body, sometimes in consequence of drinking largely of cold water, when the body is unusually warm; but it appears frequently without any manifest cause. It may be easily cured by bleeding moderately, or giving a laxative ball: sometimes, indeed, it goes off without any medical assistance. There is another disease of the skin, of the same name, which is generally more obstinate, and attacks horses that are hidebound and out of condition. In this a great number of very small scabs may be felt in various parts of the body; the horse is frequently rubbing himself; and sometimes the hair falls off from those parts which he rubs. This complaint approaches to the nature of mange, and requires the same treatment, assisted by a generous diet, good grooming, and regular exercise. (See Condition and Humours, Appendix.) 


\section{Iange.}

This disease is seldom met with except in stables where scarcely any attention is paid to the horses, and where their food is of the worst quality: it is certainly very contagious, and may in this way attack horses that are in good condition. It is known to exist by the horse constantly rubbing or biting himself, so as to remove the hair, and sometimes produce ulceration; the hair of the mane and tail frequently falls off, and small scabs are observ* able about the roots of that which remains. The mange is, I believe, a local disease, and requires only the following ointment or lotion for its removal: in obstinate cases, however, it may be advisable to try the effect of the following alterative.

MANGE OINTMENT.

\section{No. 1.}

Sulphur vivum, finely powdered, $4 . \overline{\mathrm{oz}}$. Oil of turpentine, - $\quad-3 \mathrm{oz}$. Hog's lard, - - - 6 oz.

Mix. 
No. 2.

Oil of turpentine, - $\quad$ - $4 \mathrm{oz}$.

Strong vitriolic acid, - $\quad-\quad \frac{x}{2} \mathrm{oz}$.

Mix cautiously, putting in the acid by a little at a time, and add

$\begin{array}{llll}\text { Train oil, - } & - & - & - \\ \text { Sulphur vivum, } & - & - & \text { oz. } \\ \text { Mix. } & & \end{array}$

\section{MANGE LOTION.}

White hellebore, powdered, - $4 \mathrm{oz}$.

Boil in 3 pints of water to 1 quart, then add Muriate of quicksilver, - $\quad 2 \mathrm{dr}$. That has been previously dissolved in 3 drams of muriatic acid.

ALTERATIVE FOR MANGE.

Muriate of quicksilver, $\frac{\mathrm{I}}{2} \mathrm{OZ}$.

Tartarised antimony, - - $3 \mathrm{oz}$.

Powdered aniseeds, - - $6 \mathrm{oz}$.

Powdered ginger, - - $2 \mathrm{oz}$.

Sirup enough to form a mass, to be divided into sixteen balls, one of which is to be given every morning.

Should these appear to diminish or take off the appetite, or create a purging, they must be discontinued two or three days. 


\section{Grease.}

This disease consists in an inflammation, swelling, and consequent discharge from the heels, the matter having a peculiar, offensive smell, and the heels being sometimes in a state of ulceration; the swelling frequently extends above the fetlock.joint, sometimes as high as the knee or hock. When the inflammation and swelling are considerable, apply a large poultice to the heels (See P'oultice), taking care to keep it constantly moist by adding to it occasionally a little warm water: at the same time let a dose of physic be given. After three or four days the inflammation and swelling will have abated considerably, the poultice may then be discontinued, and the astringent lotion applied fire or six times a day. Should the heels be ulcerated, apply the astringent ointment to the ulcers; and if they be deep and do not heal readily, wash them with the detergent lotion previous to each aressing. liegular exercise is of the highest importance, but it is necessary to choose a clean and dry situation for the purpose.

In slight cases of grease, the astringent lotion and a few diuretic balls will gènerally be 
found sufficient to effect a cure; but when the disease is of long standing, and particularly if the horse have suffered from it betore, there will be more diffeulty in its removal. In such cases the following alterative powder may be given in the corn every day, until it produces a considerable diuretic effect: in very obstinate cases rowels in the thigh have been found useful. Digitalis, or fox-giove, has been recommended in those swellings of the leg's which are tire consequence of grease: I have not yet tried its efiect in this way, at least not suficiently to give an opiaion on the subject. It is a violent medicine in the horse, very apt to take oif the appetite and injure the stomach, aud must therefore be given with caution : the dose is from half a dram to one dram.

Though the grease is most commonly occasioned either by high feeding and want of exercise, or by neglect in the groom, there are cases which seem to depend on general debility. I do not believe that this is ever the exciting cuuse of the disease, but am convinced that a horse is rendered more susceptible of it by being in a state of weakness, and that the complaint sonietimes owes its continuance to this cause. When a horse has suffered much 
from this disease, and particularly if he appear to be weak and out of condition, a iberal allowance of corn will tend to recove: him, if assisted by the astringent lotion and careful grooming. In cases of this kind exercise is essentially necessary. It must be obvious that when this disease depends upon debility a dose of physic would not be an eligible remedy, yet considerabie benefit has sometimes been obtained by giving the following alterative every morining untii the bowels are moderately opened.

\section{ALTERATIVE BALL.}

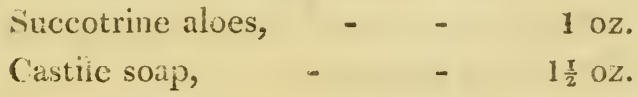

Powdered ginger and myrrh, of each, $y_{2} \mathrm{oz}$. Sirup enough to form a mass, to be divided into six balls.

This medicine', though of an opening quality, will improve the horse's strength, and at the same time promote absorption.

ALTERATIVE POWDER.

Powdered resin and nitre, of each $4 . \mathrm{oz}$. Mix and divide into eight doses. 
Nothing tends so much to prevent grease and swelling of the legs, as frequent hand-rubbing, and cleaning the heels carefully, as soon as a horse comes in from exercise. In inveterate cases of grease, where the disease appears to have become habitual in some degree, a run at grass is the only remedy. If a dry paddock can be procured, where a horse can be sheltered in bad weather, and fed with hay and corn, it will be found extremely convenient, as in such circumstances he may perform his usual labour, and at the same time be kept free from the complaint. In a few obstinate cases I have seen the mercurial alterative of service, giving one bur every morning until the bowels are opened.

ASTRINGENT LOTION.

No. 1.

Alum powdered,
Vitriolic acid, -

Mix.

No. 2.

Alum powdered, - - $4 \mathrm{oz}$

Vitriolated copper, - $\quad \frac{\mathrm{x}}{2} \mathrm{Oz}$.

Water, - - - $1 \frac{\mathrm{x}}{2}$ pint. 
No. 3.

Sugar of lead, Vinegar, Water,

$$
\text { - }
$$

- 4 oz.

- $6 \mathrm{oz}$.

- 1 argact $\sin 2 \pi \sin 4 \alpha^{\circ} x$

The strength of these lotions often requires

to be altered. Where the inflammation and irritability of the part are considerable, they must be diluted with an equal quantity of water; but if the inflammation be subdued, and a swelling and ulceration remain, the alum solution cannot be made too strong.

\section{ASTRINGENT OINTMENT.}

$$
\text { No. } 1 .
$$

$\begin{array}{ll}\text { Hog's lard, } & 4 \mathrm{oz} . \\ \text { Oil of turpentine, } & 2 \mathrm{dr} . \\ \text { Water of acetated litharge, } & \frac{\mathrm{x}}{2} \mathrm{oz} .\end{array}$

Mix.

No. 2 .

Venice turpentine, - $\quad 1 \mathrm{oz}$.

Hog's lard, - - 4 oz.

Alum, finely powdered, $=1 \mathrm{oz}$. 
MERCURIAL ALTERATIVE.

Calomel, - $\quad$ - $\quad-\quad \frac{1}{2} \mathrm{dr}$.

Aloes, - - - $1 \mathrm{dr}$.

Çastile soap, - - $\quad 2 \mathrm{dr}$.

Oil of juniper, - $\quad 30$ drops.

To be made into a ball with sirup for one dose.

ASTRIYGENT POWDER.

No. 1.

Powdered alum, - - $4 \mathrm{oz}$.

Bole, - - - $\quad 1 \mathrm{oz}$.

Mix.

No. .

itriolated zinc, powdered bole, of each, - $\} 2 \mathrm{oz}$.

No. 3.

Acetated ceruse, - - $2 \mathrm{oz}$.

Bole, - - - - $1 \mathrm{oz}$.

Mix.

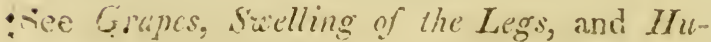
mox, Appendix.) 


\section{Mulanders and Sulanders.}

When a scurfy eruption appears on the posterior part of the knee joint, it is termed malanders; and when the same kind of disease happens on the anterior of the hock joint, it is named salanders. Should these complaints occasion lameness, it will be proper to give in the first place a dose of physic; let the hair be carefully clipped of from the diseased part; and let all the scurf be washed off with soap and warm water: a cure may then be soon effected by applying the following ointment tuice a day:

TIE ORTMENT.

Nó. 1.

Ointment of wax or spermaceti, $20 \%$. Olive oil, - - - $1.0 z$. Camphor and oil of rosemary, of each, - - $\} 1 \mathrm{dr}$. Water of acetated litharge, $2 \mathrm{dr}$. Mix.

No. 2.

Ointment of nitrated quick-? silver, olive oil, of each, $\} 1 \mathrm{oz}$ : Mix. (. 2 
No. 3.

Oil of turpentine,

Vitriolic acid, $-\quad \frac{x}{2}$ oz.

- $1 \mathrm{dr}$.

Mix cautiously, putting the acid by a little at a time, and add of
Oil of bay,
$-$
$3 \mathrm{oz}$.

Mix.

The following lotion has often succeeded:

$\begin{array}{llll}\text { Blue vitriol, } & - & - & 2 \mathrm{oz} . \\ \text { Alum, - } & - & - & 3 \mathrm{oz} . \\ \text { Water, - } & - & - & 1 \text { quart. } \\ \text { Nitrous acid, } & - & - & 1 \text { dr. }\end{array}$

Iix, and apply to the diseased part daily,

after it has been well cleansed.

Sce Humou's, Appendix; and for the mode of prevention, see ('rooming, Appendix.)

\section{Glanders.}

This disease is contagious, and has, I believe, hitherto proved incurable. The most esscntial thing to be known with respect to the glanders is the method of preventing their being conmunicated to sound horses, and the appearances by which they may be with ceratinty distinguished from other diseases. The 
symptoms are, a discharge from one or both nostrils, and a swelling of the glands under the throat. If one nostril only be affected, it generally happens that the swollen gland is on the same side of the throat. Sometimes the disease remains in this state for a considerable time, at others the discharge increases, becomes of a greenish colour, and very fetid; ulceration takes place within the nose, and the swollen gland becomes harder, and feels as if closely attached to the jaw bone.

A cold has sometimes been mistaken for the glanders, but may very easily be distinguished from them. In colds, there is generally a certain? degree of fever, the eyes appear dull or watery, the appetite is diminished, and there is almost always a cough. If the glands of the throat should swell, they are not so closely attached to the jaw bone as in the glanders, but feel loose and movable under the skin; they are also generally in a state of active. infammation, feeling hot, and softer than in the glanders. In colds, both nostrils are almost always affected; in the glanders it frequent $\}_{Y}$ happens that the discharge is from one only. In colds I have never seen the nostrils ulcerated: in glanders it always happens, though 
at different periods of the disease; sometimes ulceration takes place at its commencement, at others a month or two may eiapse before it can be jerceived.

Thestrangles have been sometimes mistaken for the glanders; but in this disease the inHumed glands very soon suppurate and burst, whereby all the other symptoms are generally removed, whilst in the grlanders the glands seldom or never suppurate. In order, howerer, to avoid all danger, it is advisable, the moment a horse is perceived to have a discharge from his nose, to put him into a stable where he can have no communication with other horser. If the glands of the throat be enlarged and inflamed, apply a large poultice to them, steam the head three or four times a day, let the horse be well clothed, particularly about the head, and give the fever powder No. 2 every day, or once in twelre hours. Should the discharge arise from a cold, it will soon be remored by these means. When considerable ul. ceration is perceived in the nose, with the other concomitant symptoms of the glanders, the horse should be destroyed instantly.

'The most effectual mode of purifying stables, in which glandered horses have been kept, 
is to remore, or carefully wash, every thing on which the horse may have deposited any matter, and afterward to cover every part of the stable with a thick coat of lime and size.

Though all the experiments hitherto made, in order to discover a remedy for this destructire malady, seem to hare proved fruitiess, I cau by no means agree with those who think that the subject is exhausted, and that any further attempts would be siperfluous: such sentiments may indeed be pardonable in those practitioners of the art who know nothing of the anatomy and physiology of the horse, or the properties of medicine, and consequently can have no principles to conduct them in their experiments; but since the art has been placed on a more respectable footing, and the practice so much improred by the attention and abilities of the present professor, we may expect that some furber and more successful experiment will be made; and that ultimately we nay see this trily useful animal resetied from a disease so eminently destructive.

It is pretty well known, that when the venereal disease first made its appearance in Europe, irs ravages were severely felt, and thousinds fell victims to it; almost every medicine 
in the Materia Medica wass tried without effect, and it was generally considered as an incurable disorder. Had the practitioners of medicine been then discouraged by the failure of so many experiments, and given it up as a hopeless molertaking, it would hare been unfortunate: indred for the rotaries of the cyprian goddess: but by persererance etery difficulty was surmounted, and the antidote at length discorered. Thus, aithough our attempts to cure the glanders have hitherto proved ineffectual, it ought by no means to be relinquished as a fruitless inquiry; rather indeed ought it to operate as a stimulus on the veterinarian, and prompt him to an exertion of all his talents and ingenuity; since the more difficulty there is in the pursuit, the more honour and profit will there be attached to the discovery. There may be many steps to ascend before we can arrive at this desirable object, and he who makes any progress toward it does a service to society: we shall not perhaps suddenly find out the method of curing the disease, though it may be accomplished by gradual and successive discoveries.

From the observations I liave been able to make on the glanders, they appear generally to 
originate in contagion, though sometimes I believe they arise spontaneously, or from the respiration of impure air. A remarkable instance of this happened a few years ago: some horses were embarked for the continent; during the voyage it hecame necessary to shut the hatchways, whereby a proper circulation of air was prevented; in consequence of this several horses were suffocated, and those that survived were immediately attacked with the glanders. That they arise from contagion, is proved by almost daily experience. How important therefore must it be, whenever this dreadful disorder occurs, to bear this circumstance in remembrance, and to employ meaus which may effec. tually prevent its spreading! and how many valuable horses might have been saved, had. the proper precautions been attended to by grooms, and those who have had the management of glandered borses!

Upon considering the origin, pirogress, and symptoms of glanders, a striking analogy will appear between them and the renereal disease. When venereal matter is applied to a part where a mucous fluid is secreted, as in the G 5 . 
urethra or urinary passage, or the internal surface of the nose, a peculiar kind of inflammation is produced, and poisonous matter formed, which has the power of producing the disease in others. If glanderous matter be applied to the nose of the horse, an inflammation and discharge of matter will take place, and this matter will possess the same poisonous quality as that which produced it. When the venereal matter is applied to the skin where the cuticle is very thin, or has been abraded, a chancre or ulcer will be produced, and the contiguous glands will become inflamed and swolten from an absorption of the poison, which will ultimately get into the circulation, and infect the whole system. When the matver of glanders is applied in a similar way to a horse, it produces a chancre, or, as it is commonly termed, a farcy ulcer: the neighbouring glands are inflamed and swollen; the poison after a time gets into the blood, and the horse becomes completely glanclered, having at the same time the discase termed farcy. When renereal matter is applied to a sound part of the same subject that produced it, it is said to be perfectly harmless : so it is with the glanderous matter. But here it must be ob- 
served, that when glanderous matter is applied to the skin of a horse already labouring under the disease, although it be taken from another horse, a chancre is not produced. Medicines which have a considerable quantity of oxygen in their composition, and which have so weak an attraction for that element, as to part with it readily, are the remedies for the venereal disease; and of these the preparations of quicksilver are the most remarkable, though nitrous acid, and oxymuriate of potash, are said aliso to be antidotes to the venereal poison. I have seen the discharge, and other symptoms of glanders, considerably diminished by the use of acids, and have known it remored for a time by means of mercurial preparations. The farcy has been frequently cured by means of mercury; but 1 believe it hias never been known to cure the glanders radically; and I have been informed that it has been very fairly tried.

From the knowledge we possess of the gylanders, we may surely be encouraged to pursue the inquiry, whenever it can be done with safety; and though our experiments may not lead us to any infallible remedy for the disease, they may teach us a more certain mode 
of prevention than any we are now acquainted with, and may possibly enable us eren to cure it in its earliest stages. It has been said that inoculation with cow-pock matter will render a horse insusceptible of glanders; but this I believe is at present merely conjecture: the idea is certainly plausible, and the experiment ought to be made.

\section{(See Glanders, Appendix.)}

\section{Furcy.}

The farcy generally appears in the form of small tumours or buds (as they are commonly termed) frequently in the course of the veins, from which they are erroneously supposed to consist in a swelling of those vessels. These tumours generally burst, discharging a thin watery matter, and degenerating into foul spreading ulcers. The contiguous glands are usually inflamed and swollen from an absorption of the poison. 'This disease sometimes makes its appearance in diffused swellings of the hind legs, or other parts of the body. The most common cause of farcy appears to be contagion, either from a glandered or farcied horse, for there can be no doubt that these 
diseases will reciprocally produce each other; whence we may conclude that they both originate from the operation of the same poison, which produces different effects according to the parts on which its noxious influence is exerted.

There being certain parts only of the body which are obnoxious to this poison, its effects are always partial in some degree; thus we find the internal parts of the nose particularly liable to be affected by it; the skin likewise is very susceptible of its action; and when the horse is suffered to live a sufficient time for the poison to acquire its highest degree of virulence, or to produce its full effect, the lungs do not escape the contagion. The farcy may ve either constitutional or local: if glanderous matter, or the matter taken from a farcy ulcer be applied to the skin where the cuticle has been torn or abraded, a chancre or foul ulcer is produced; which may easily be distinguished from all others by its peculiarly foul appearance, the edges becoming thick, and the discharge consisting of a thin and rather glutinous matter. It generally spreads rapidly, and never looks red or healthy. The absorbents or lymphatics about the ulcer be- 
come inflamed and swollen from an absorption of its poisonous matter. The swellings pioduced in this way are commonly mistaken for veins, and bence has arisen the opinion of the blood ressels being the seat of the disease: the glands, likewise, to which those lymphatics lead, becone inflamed and enlarged: at length small tumours or buds appear in the course of these absorbents, which are small absciesses arising from the inflammation of these ressels.

Thus far the disease is certainly local, and the constitution untainted, the poison being urrested by the glands, and for a time prevented from mixing with the blood; at length howerer it insinuates itself into the circulation, and poisons the whole mass. Those parts which are susceptible of its action will then be affected, though at different periods. The internal parts of the nose are generally the first to be attacked; that delicate membrane by which they are lined becomes inflamed and ulcerated, discharging large quantities of matter. The next part which is affected is generally the skin, on various parts of which farcy buds (as they are termed) nake their appearance, and degenerate into foul spreading ulcers; at length the bones of the nose be- 
come carious, or rotten; and finally the poison falls upon the lungs, and very soon puts a period to the sufferings of the unfortunate animal. Sonetimes the progress of the disease is extremely rapid, and destroys the horse in a very short time; at others it is remarkably slow, and continues in the same state for a considerable time, without affecting either the appetite or strength.

In the first stagre of the farcy, while it is perfectly local, a cure may be easily accomplished; and should the disease be discorered quite at its commencenent, topical applications alone will be sufficient to remore it. If inleed the actual cautery be freely applied at this time, so as to destroy the whole of the poisoned parts, the disease will be completely cradicated, and the chancre converted to a common sore. This will soon be evinced by the remarkable change that may be observed in its appearance : as soon as the slough comes off, instead of looking foul, it will-have a red healthy appearance, the matter will become white and thick, the healing process goes on rapidly, and the cure is soon completed merely by the application of digestive ointment. Should the disease however have been 
megुlected, or not perceived at its commencement; should the lymphatics be enlarged or corded (as it is termed by farriers), and the neighbouring glands swollen, the cure is by no means so certain. In this case some of the poison may have got into the circulation, though its effects have not been visible. Even in this stage, however, the chancre may be completely cured by the actual cautery, or other strong caustics; and if the poison should not have passed the glands, the cure will be radical - but if, on the contrary, the smallest portion of the poison should have insinuated itself into the blood, the whole mass will be poisoned, and the symptoms we have before described will successively take place.

Whenever therefore the farcy has been neglected at its first appearance, it will he advisable to give the following ball, once, twice, or even three times a day, if the horse's strength will admit of it, taking care to restrain its inordinate effect upon the bowels or kidneys by means of opium: at the same time it is necessary to keep up the horse's strength by a liberal-allowance of corn. Malt has been found useful also on these occasions. During the time the horse is taking this strong medi- 
cine, great attention must be paid to him; he must be warmly clothed, have regular exercise, and never be suffered to drink cold water. Verdigris has been much recommended in this disease, but I have never had an opportunity of seeing its effect. (Sce White's Veterinary Materia Medica, \&ic.)

The following balls have proved so efficacious, that I have seldom had occasion to try other remedies; but unless they are given for two or three weeks after every symptom has been removed, the cure will seldom be permanent. It seems probable that the farcy, as well as the glanders, arises sometimes spontaneously, though not so frequently as it is supposed. I have seen many cases where the disease could not be traced to any source of infection. Still, however, it might have arisen from contact with poisonous matter; for it is not necessary that the matter should be conreyed inmediately from one horse to another, in order to produce the disease; which is often communicated by means of matter deposited upon the manger, or litter, or about the rack; and not improbably sometimes conveyed by the hands of those who hare the ma- 
nagement of such horses, through inattention or negligence.

With respect to that kind of farcy which appears in the form of diffused swellings of the limbs or other parts, I believe it selcion ori-. ginates from infection, and does not often depend perhaps on the action of the glanderous poison, being merely common nelematous swellings, such as accompany the grease. From this we may account for the efficacy that lias sometimes been attributed to purgatives and dinretics, as renedies for the fircy. It has been said that the grease sometimes degenerates into farcy, and becomes contagious; but this I have nevr seen.

When large abscesses form in consequence of farcy, they do not require any peculiar rrcatment, but it is particularly necessary to support the horse's strength in these cuses by nieans of coin and malt. It has been supposed that the farcy depends altogether upon debility; and medicines of the tonic or strengthening kind have been recommended for its removal.

$$
\begin{array}{ll}
\text { Muriate of quicksilyer, } & -1 \text { sc. } \\
\text { Powdered anisceds, } & -\quad
\end{array}
$$

Sirup chough to form a ball. 
The quantity of muriate of quicksilver* may be gradually increased, as far as the horse's strength will allow. When riolent sickness, purging, or excessire staling is produced by it, it will be advisable either to discontinue it for two or three dars, or to diminish the dose considterably. One dram of opium will sometimes prevent such violent effects.

* Consult the authory Ifateria Medica, or sacond volune, (article Muriates) in which the propertice of this medicine are nore fully explained. 


\section{CHAPTER IV.}

\section{Wounds.}

THE first necessary operation in wounds is to remove carefully all clirt or other extraneous matter; and if the wound be made with a clean cutting instrument, and not complicated with bruising or laceration, the divided parts are to be neatly sewed together. Where it can be done, a roller kept constantly moist with the saturnine lotion, diluted with an equal quantity of water, is to be applied, in order to assist in retaining the parts in their situation. This roller is not to be removed for severa! days, that the divided parts may have time to unite, and that the wound may heal by the first intention, as surgeons term it, unless considerable swelling and inflammation come on: it then becomes necessary to remove the roller, and apply fomentations. This kind of union, however, can seldom be accomplished in 
horses, from the difficulty of keeping the wounded parts sufficiently at rest, and from their wounds being generally accompanied with contusion or laceration; yet it should be always attempted where it appears at all practicable. Fomentations and warm digestives then become necessary, in orcier to promote the formation of matter in the wound. Should considerable swelling and inflammation arise. moderate bleeding near the affected part, and a laxative medicine, or even a dose of physic, are strongly to be recommended; and a poultice, if the situation of the part be such as to admit of its application, will be found of great use. As soon as the swelling and inflammation shall have been removed, the fomentations and poultice are no longer necessary, and the digestive ointment only is to be applied: should the wound appear not disposed to heal, discharging a thin offensive matter, apply the detergent lotion previous to the digestive ointment. When the granulations become too luxuriant, that is, when what is commonly termed proud flesh makes its appearance, the caustic powder is to be sprinkled on the wound.

Slight wounds generally heal with very little trouble, and sometimes without the inter- 
ference of art; and it is from this circumstance that many nostrums have acquired ummerited reputation. In wounds of this kind, tincture of myrrh, or compound tircture of benzoin, may be used.

Whenever a considerable blood ressel is wounded, and the hemorrhage is likely to prove troublesone, our first object is to stop the bleeding; which, if the wound be in a situation that will admit of the application of a roller or bandage, may be casily effected; for pressure properly applied is generally the best remedy on these occasions, and far more effectual than the most celebrated styptics. In some cases it becomes necessary to tie up the bleeding ressels: this is rather a difficult operation, and not often necessary.

Punctured wounds, or such as are made with sharp-pointed instruments, are generally productive of more inflammation that those that have at first a more formidable appearance; and if such wounds happen to penetrate into a joint, or the cavity of the chest or belly, the worst consequences are to be apprehended, unless they be skilfully treated.

When a joint has been wounded, the synovia or joint oil may be observed to flow from the wound. The first thing to be done in 
these cases is, to close the opening that has been made into the joint; for as long as it remains open the inflammation will go on increasing, and the pain will be so violent as to produce a symptomatic fever, which often proves fatal. The most effectual method of closing the wound is by applying the actual cautery: this will appear probably a rery strange remedy to those who have not seeu its effect, yet it is cortainly the inst efficacious that can be employed, although only applicable where the wound is of the punctured kind, and small; for when a large wound is made into the cavity of a joint, and particularly if it be of the lacerated kind, it is inpussible to close it eifectually, and death is frequently the consequence. As soon as the opening has been closed, it is of importance to guard against the inflammation that may be expected to arise, or to remove it if alrearly present. For this, bleeding and purging are the most effectual remedies. A ròwel in any convenient part near the affected joint will be found useful also. Should the joint be much swollen, the blister $\mathrm{No} \cdot 2$ will prove very efficacions, and far superior to fomentations or poultices. 
Wounds about the foot, from stubs, overreaching, \&c., often prove troublesome when neglected. As soon as they are perceived, care should be taken that no dirt gets into them: the detergent lotion and digestive ointment are the most useful applications on these occasions. (See Pharmacopacia.) When the foot is wounded in shoeing, the nails being driven into the sensible parts, the compound tincture of benzoin is to be applied. When their tendons or their membranes are wounded, considerable inflammation is likely to take place, which is to be removed by fomentation and the saturnine poultice; purging is also of great use in these cases; and when the wound is large, and inflammation runs ligh, bleeding likewise may be necessary.

In extensive, lacerated, or contused wounds, the inflammation sometimes terminates in mortification. (See Inflammation.) In such cases fomentations are to be applied frequently, and the horse's strength supported by means of malt, and the cordial ball for mortification. fFor the method of treating the different kindts of wounds, see the Appendix.) 


\section{Bruises.}

In recent bruises, fomentations are the most essential remedies. When they are violent, a considerable degree of inflammation may be expected to supervene: it will then be proper to give a laxative ball, and to bleed moderately near the affected part.

If abscesses form in consequence of a bruise, discharging large quantities of matter, particularly if the matter be of a bad colour and an offensive smell, the wound also appearing darkcoloured and rotten, indicating approaching inortification; the horse's strength must be supported by allowing him a large quantity of corn: and if he can be made to eat malt, it will be found still more effectual. If the apperite go off, he must be drenched with good water-gruel, and strong infusion of malt: it will be necessary also to give the cordial ball for mortification, once or twice a day. Stimulating applications to the part, such as equal parts of camphorated spirit and oil of turpentine, are of great use.

Should a hard callous swelling remain in consequence of a bruise, the following embrocation is to be well rubbed into the part twice a

VOL. I. 
day; and if it do not succeed in removing it, recourse must be bad to a blister.

\section{EMBROCATION FOR BRUISES.}

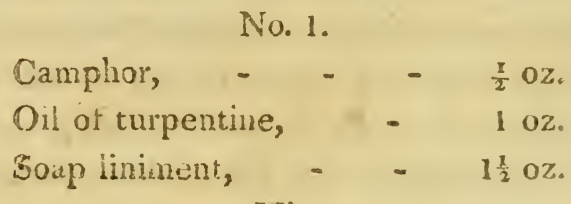

Mis.

No. 2.

Tincture of canthurides, $\quad 10 z$.

Oil of origanum, - $2 \mathrm{dr}$.

Canspinurated spirit, $\quad 6 \mathrm{dr}$.

Mix.

No. 3.

Muriate of ammonia, - $\quad 1 \mathrm{oz}$

Distilled vinegar, - - $8 \mathrm{oz}$.

Spirit of wint, - - $6 \mathrm{oz}$.

Mix.

\section{Broken Knces.}

The method of treating this accident is described gencrally under the articie Wound? being nothing more than a cuifused and lace- 
rated wound; but as it occurs frequently, and, if not skilfully treated, greatly lessens the value of a horse, it may not be amiss to be more particular on the subject. The first thing to be done is to cleanse the wound perfectly, and if it be at all deep or extensive, or mucis bruised, a goviard poultice is to be applied, by means of the leg of a worsted stocking, taking care to renew it twice a day, that it may be constantly soft and moist. This, in two or three days, will give the wound a healing appearance, and cause a white healthy matter to flow: it may then be discontinued, and the digestive ointinent applied. Should the matter assume a bad appearance, losing its white colour, becoming thin, and smeling rather offensively, something stronger will be requisite, such as the detergent lution, made hot; and if, after this, the new flesh grow too luxuriantly, rising above the skin, apply the caustic powder, and a considerable degree of pressure, by means of a linen roller or banduge. and a bolster of lint. By this treatment the wound will soon heal. But we must not stop here; for unless the sweling is como pletely removel, and the hair regenerated of its original colour and smoothuess, the horse 
would be considered of very little value. As soon, therefore, as the wound is conpletely healed, if any swelling be discernible, apply the following liniment, so as to excite a moderate degree of vesication, or blistering, and repeat it after this effect has perfectly subsided. Should the swelling feel hard and callous, and be of considerable size, the strong blister, No. 1 or No. 2, will be preferable. (See Index, Blisters.)

\section{THE LINIMENT.}

Powdered cantharides, - $2 \mathrm{dr}$.

Camphor, - - $\quad$ - $\frac{\mathrm{r}}{2} \mathrm{Oz}$.

Spirit of wine, - $\quad$ - $4 \mathrm{oz}$.

Mix them in a bottle, and let it stand in a warm pluce about a week or ten days, shaking the bottle frequently; then strain through blotting paper, at d it is fit for use.

It often happens, after the wound is perfectly healed, that a small scar or mark will be observable; and though the part may be free from any hardness or swelling, the value of the horse will be greatly lessened by this appearance. A variety of ointments have been recommended for promoting the growth of 
hair on the part, and thereby removing the blemish: the following I have found more effectual then any of them.

OINTMENT FOR BROKEN KNEES.
Ointment of wax,
$2 \mathrm{oz}$.
Camphor,
$-2 \mathrm{dr}$.
Oil of rosemary, $=-1 \mathrm{dr}$.
Mix.

The colour of this ointrient should be suited to that of the contiguous hair, which will so conceal the blemish, that it will not be observed, unless the part is strictly examined; and at the same tine the ointment will cause the hair to grow up gradually, until the mark is completely removed. If the horse be of a bay colour, the legs and knces are generally blackish. In this case mix a little ivory black with the ointment: if a chesnut colour, Armeniau bole may be mixed with it.

\section{Fistula in the Withers.}

This disease generally originates in a bruise from the saddle, and is at first simply an abscess, which by early attention and proper 
treatnent miay be easily cured; but when ne. glected, it degenerates into a fistulous sore, proves extremely difscult of cure, and cannot be removed wihout very severe treatment.

As soon as the injury is discovered, fomen. tations should be applied in order to premote supparation; and when matter is formed, let the tumour be opened, so that its contents may be completely evacuated, and a future accumulation prevented. The sore may then be healed by dressing it claily with digestive liniment or ointment; but should these prove ineffectual, apply the detergent lotion until the sore assumes a red healthy appearance, and the matter becomes whiter and of a thicker consistence. When the disease has been neglected in its first stage, and the matter suffered to penetrate among the muscles, affecting the ligaments or bones of the withers, it becomes necessury to atopt a more severe treatment.

The sinuses or pipes are to be laid open with a knife; and if it be practicable, a depending opening is to be nuade, that the matter may run off freely: the sore is then to be dressed with the following ointment, which is to be melted and poured into the cavity while very hot. 
The sore is not to be dressel until the sloughs which this olitment occasions have separated from the living parts; with generally happens two or turee days after the operation. If the surface or the sore look red and healthy, and tue matter appoar to be whiter and of a bettrensistence, a retition of this panful operation will not be required, the digestive liniment or ointment beng sufficient to complete the cure; but should the sore still retain an unhealthy appearance, and the matter continue thin and of a bad colour, the hot dressing must again be applied.

TIIE OINTMENT.

$$
\text { No. } 1 .
$$

Gintment of nitrated guicksilver, $4 \mathrm{oz}$.

Oil of turpentine, - $\quad$ - $1 \mathrm{oz}$.

Mix.

No. 2.
Verdegris,
- $\quad-\quad \frac{1}{2} \mathrm{Oz}$.
Oil of turpentine, - $\quad$ - $1 \mathrm{oz}$.
Ointment of yellow resin, - $4 \mathrm{oz}$

Mix. 
No. 3.
Oil of turpentine,
- $\quad 20 z$.
Vitriolic acid,
$\frac{1}{2}$ Oz.

Mis cautiously in an earthen vessel, placed in

a current of air, that the suffocating vapour which arises may be carried off. When they are perfectly incorporated, add

Common turpentine, and hog's $\} 2$ oz.
lard, of each,

Bees wax, - - - $1 \mathrm{oz}$.

To be melted over a gentle fire.

This ointment may be made either stronger or weaker, by increasing or diminishing the proportion of vitriol and turpentine.

\section{Poll Evil.}

This disease also generally originates in a bruise, and requires the same treatment as the fistula. It consists at first in an abscess in the poll, which by early attention might be easily cured; but if the matter be suffered to penctrate to the ligaments and bones, it frequently proves more difficult of cure than the fistula in the withers, and cannot be subdued 
without those strong remedies we have recommended in that disease *

* Since writing the above, I have discovered that the inflammation which produces poll evil does not begin, as is usually the case in other parts, on the surface, or in the cellular membrane under the skin, but between thie liganent of the neck and the bones. When we consider the weight and position of the horse's head, with the great length of the neck, it will readily appear that the muscles alone are not capable of supporting and moving so great a weight, under such mechanical disadvantages. Nature has therefore provided a strong ligament, which is firmly fixed to the back part of the head, whence it passes down over the bones of the neck. It is not attached to the first bone, but is firmly fastened to the three next: it then passes over the three other bones of the neck in nearly a straight line to the withers, where it is securely fixed, giving off a thin slip of ligament in its passage, which is united to the last three bones. It is continued from the withers to the back. This ligament, being elastic, allows of sufficient motion in the neck, and so effectually assists the muscles in supporting the head, that they never become fatigued.

When a horse receives a violent blow on that part of the poll which covers the first bone of the neck, which, as we have just observed, is not attached to the ligament, the injury will be sus tained chiefly by the sensible parts placed between the bone and the under surface of the ligament. The skin may also be liurt, and a slight degree of superficial inflammation may take place. But when inflanmation has been thus produced between the bone and the ligament, it is more likely to proceed to suppuration, or to the formation of matter; which being so deeply seated, cannot find vent at the surface, by bursting the skin like a common abscess; therefore it spreads under the ligament, and is so $i$ ong in arriving at the surface, that both the bones and ligament 
Mr. Taplin, in his Stable Directory, very pompously declains against this method of treating invetcrate cases of fistula and poli evil. It is certainly, however, the only effectual one that is kuown; and had this verbose author but seen the effect of this remedy, as well as of that which he recommends himself,

are thighly diseased before any external swelling is observed. This is the cause of the particular obstinacy of the poll evil, and. the great length of time generally required to cure it. From this ve may learn, also, how little is to be expected from such applications as are intended to disperse the swelling, and how necessary it is to adopt a bold and powerful mode of treatment. I am convinced, from what I have seen, that it is almost impossible to disperse the genuine poll evil; that by attempting it we lose time, and suffer the matter to continue its ravages upon the ligament and bones; and that the only effectual practice consists in opening the abscess freely, so that the matter may readily escape, and the diseased bones be examined. When this has been done, and bleeding las perfectly ceased, apply the ointment, No.3, described in the preceding chapter; and let the first dressing remain until the dead parts are ready to separate merely by washing. It is sometiencs necessary to repeat this application several times; and should it appear not sufficiently active, the proportion of vitriol and turpentine may be increased; but in irritable blood horses it will sometimes prove too strong. A second operation often becomes necessary, particularly if the first hâve not been boldly performed; and whenever the matter appears to be pent up, or confned in sinuses, the knife and strong dressings are the only remedies. When the wound has been brought to a herkthy state, the common digestive is the best dressing. 
before his book was written, it is probable he never would have faroured the public with the declamation above alluded to. It is surely more consistent with humanity to rescue an animal from a painful and gradually increasing disease, by means of a severe operation, than to suffer him to linger out a life of pain and misery, by adopting a mild but ineffectual mode of treatment.

\section{Saddle Galls, or Warbles.}

These consist of inflamed tumours, and are produced by the unequal pressure of the saddle. If neglected, they become troublesome sores, and are often a considerable time in healing. As soon as a sivelling of this kind is observed, let sereral folds of linen be moistened with one of the following embrocations, and kept constantly applied to the tumour until it is reduced; but if matter have been allowed to form, let it be opened with a lancet, and'afterward dressed with digestive liniment or ointment. Should it appear not to heal readily under this treatment, apply the detergent lotion made hot. When swellings of this kind are large and much infamed, it will be 
advisable to bring them to suppuration as expeditiously as possible, by means of fomentations or poultices. Should a hard swelling remain after the infammation is in great measure removed, try the embrocation for strains; and if this do not succeed, recourse must be had to a blister.

THE EMIBROCATION.

No. 1.

Water of acetated litharge, $2 \mathrm{dr}$.

Distilled vinegar, - $3 \mathrm{oz}$.

Spirit of wine, - - $4 \mathrm{oz}$.

Mix.

No. 2.

Muriate of ammonia, - $\quad \frac{\mathrm{I}}{2} \mathrm{OZ}$.

Muriatic acid, - - $2 \mathrm{dr}$.

Water, - from 8 to $12 \mathrm{oz}$.

Mix.

No. 3.

Soap liniment, and water of ? icetated ammonia, of each, $\}^{2} \mathrm{oz}$.

Mix. 


\section{Sitfasts}

Are occasioned by repeated bruises from the saddle, which, instead of inflaming the skin, as most commonly happens, cause it to become callous, and give it somewhat the appearance of leather. The following ointment is to be applied until the callous part appears disposed to separate: it is then to be removed, which generally requires somc force, and the sore which remains may be healed with digestive liniment or ointment. The sore may be washed now and then with weak detergent lotion, if it appear indisposed to heal.

OINTMENT FOR SITFASTS.
Ointment of althea,
$4 \mathrm{oz}$.
Camphor,
$-$
$2 \mathrm{dr}$.
Oil of origanum,
$1 \mathrm{dr}$.

Mix.

\section{Strains.}

This is a subject with which every sportsman ought to be well acquainter, since his horses are particularly liabie to such accidents. Strains may affect either the muscles, liga- 
ments, or tendons. Muscular strains consist in an inflammation of the muscles or flesh, occasioned by violent and sudden exertion. When ligaments are the seat of this disease, there is generally some part of them ruptured, whereby very obstinate and sometimes permanent lameness is produced: in this case also inflammation is the symptom which first requires our attention. But tendons are the parts most fiequently affected, particularly the flexors of the fore leg, or back sinews, as they are commonly termed. 'Tendinous strains are commonly supposed to consist in a relaxation or preternatural extension of the tendon; and the remedies that have been recommended are supposed to brace them up again. However plausible this opinion may be, it certainly is very crroneous; incleed it has been proved by experiment, that tencions are neither elastic nor capable of extension; and from investigating their structure and economy, we learn, that were they possessed of these qualities, they would not answer the purpose for which they were designed. From an idea that a strain in the back sinews depends on a relaxation of the tendons, many practitioners have been apprehensive of danger from the use of 
emollient or relaxing applications, than which nothing can be more useful at the beginning of the disease.

Tendinous strains consist in an inflammation of the membranes in which tendons are enveloped; and the swelling which takes place in these cases depends on an effusion of coagulable lymph by the vessels of the inflamed part. Inflammation being the essence of a strain, we are to employ such remedies as are best calculated to subdue it; and should any swelling remain, it is to be removed by stimulating the absorbent vessels to inreased action.

\section{Strain of the Shoulder.}

This disease is by no means so frequent as it is supposed to be, lameness in the feet being often mistaken for it: the difference, however, is so well marked, that a judicious observer will never be at a loss to distinguish one from the other.

A shoulder strain is an inflammation of some of the muscles of the shoulder, most commonly, I believe, those by which the limb is comnected with the body. The lameness which 
this accident occasions comes on rather suddenly, and is generally considerable. When the horse attempts to walk, the toe of the affected side is generally drawn along the ground, from the pain which an extension of the limb occasions: in violent cases he appears to be incapable of extending it.

When lameness arises from a disease of the foot, it is generally gradua! in its attack, unless occasioned by an accidental wound, and does not at all hinder the extension of the limb: an unusual heat and tenterness may also be perceived in the foot; and as the horse stands in the stable, the affected foot will be put forward, that it may bear as little as possible of the weight of the body.

The first remedy to be employed on these occasions is bleeding in the shoulder or plate vein; then give a laxative ball; and if the injury be considerable; let a rowel be put in the chest. By means of these remedies and rest, the disease will generally be removed in a short time; a cooling opening liet, with perfect rest, will also be necessary. When the inflammation and lameness begin to abate, the horse should be turned into a loose stall, and after a week or two he may be suffered to 
walk out for a short time every day: but should this appear to increase the lameness, it must be discontinued. The intention of moderate exercise, after the inflammation is in great measure subdued, is to effect an absorption of any lymph that may have been effused, and to bring the injured muscles gradually into action.

After an accident of this kind, particularly when it has been violent, the horse should not be worked in any way for a considerable time, as the lameness is very apt to recur, unless the injured parts have had sufficient rest to recover their strength. If lie can be allowed two or three months' run at grass, it will be found extremely conducive to his recovery, provided he is prevented from galloping or exerting himself too much when first turned out. It is necessary also to choose a-situation where there are no ditches in which he may get bogged. With respect to embrocations, and other external applications, they are certainly useless, unless the external parts are affected; and then fomentations may be employed with advantage. 


\section{Struin of the stifte.}

In this case the strfle joint will be fornd unusually hot, tenur, aur sometimes swollen. The rene lies are fomentations, a rowel in the thigh, and a desse of physic. When by these meuns the infammation of the joint has abated considerably, and at the sume time the swelling and lameness continue, the embrocition for strains, or a blister, should be applied.

Strains in the hock joint require the same treatinent.

Strain of the Hip Joint, (commonly termed Whirl Bone, or Round Bone.)

When lameness occurs in the hind leg, the canse of which is too obscure for the farrier's comprehension, he generally pronounces it to be a strain in the round or whirl bone; and with all that affectation of infallibility, so commonly observed in those gentlemen. I have seen several cases of lameness which were supposed to be occasioned by an injury of this part, but after attentire examination an incipient spavin was found to be the cause. I would adrise therefore in such cases, that the hock 
joint be carefully examined, and if unusual heat or tenderness be observed on the seat of sparin, it is probable that the lameness arises from this cause, and that it ma be removed by the application of a blister. I have met with several horses that had been severely burnt and blistered in the hip, when the hock was evi. dently the seat of the disease.

Strain of the Flexor Tendon, or Back Sinew.

A strain of the back sinew depends, as we have before obscrved, on an inflammation of the membranes in which it is enveloped * and is sometimes complicated with a rupture of the ligaments which are situate immediately under the sinewst. When the lameness and swelling are considerable, bleed in the shoulder vein, and give a dose of physic; then let the saturnine poultice be applied, so as to extend from the hoof to the knee, and let it be frequently moistened with the saturnine lotion. When the inflammation and lameness have abated considerably, and a swelling still remains, apply the embrocation for strains, rub.

* See Plate 9, aaa the lack sinew, $b 6$ the menbranes,

t See Plate 10. 
bing it well on the part twice or three times a day. If this do not succeed, recourse must be had to a blister. - It will be advisable also to turn the horse loose into a large stable or barn, and to give him this kind of rest for a considerable time: should he be worked too soon after the accident, the part is very liable to be injured again, particularly when it has been violent. Should the swelling continue, notwithstanding these remedies have been carefully employed, particularly if it feel callous and hard, and be perfectly free from inflammation, it will be necessary to apply the actual cautery (See Firing): this operation, however, must never be performed while any inflammation remains. These swellingrs sometimes prove so obstinate, that even repeated blistering and the actual cautery are ineffectual; as soon, however, as the inflammation which caused them is completely removed, they seliom occasion laneness, yet they will not admit of any violent exertion in the part, and are therefore always an impediment to epeed.

SATURNINE LOTION.

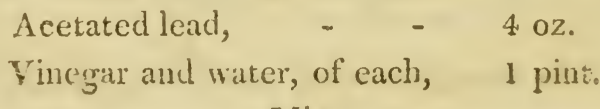


SATURNINE POULTICE.

Fine Bran, - - $\quad \frac{x}{4}$ peck.

To be made into a thin paste with hot saturnine lotion: to this add as much linseedmeal as will give it a proper consistence.

EMEROCATION FOR STRAINS.

No. 1.

Dil of rosemary and cam-
phor, of each,

Soft soap, - - - 1 oz.

Spirit of wine, - $\quad 20 z$.

Mix.

No. 2.

Soft soap, spirit of wine, oil $\left.\begin{array}{l}\text { of turpentine, and oint- } \\ \text { ment of elder, of each, }\end{array}\right\} 4$.

Mix.

\section{Ring-Bones}

Are bony excrescences about the small pastern bone, near the coronet, or an ossification of the cartilages of the foot. (See Anutomy of the Foot, and plate 5, fig. 1, and plate 7.) 
If observed in its incipient state, a blister will probubly be of service; but when of longer standing and large, the actual cautery will also be necessary. This remedy, however, is by no means unturmly successful, the cumplaint being frequently incurable; and if it have proceeded su fir as to cause a stiti joint, there is no chance of recovery.

\section{Thorough-Pin.}

By this term is meant a swelling both on the inside and outside of the hock joint. When one of the tumours is pressed with the fingers, the Aluid which it contains is forced into that on the uppusite side. From this communicatiun between the two swellings, the disease has pr bably obtained its name.

It is generaliy a consequence of hard work, and therefore difficult to cure: the only remedies are bisters and rest.

\section{Wir.dgalls}

Consist in an enlargement of the mucous sacs, which are placed behind the flexor tendons for the purpose of fucilitating their motion. The swelling appears on each side the 
back sinew; immediately above the fotlock joint. If puicture $l$, tirey dischorge a fluil re-

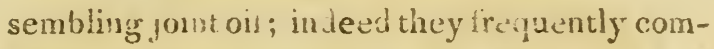
municate with the carity of the joint, and therefore cannot be opene I without danger of producing an incurable lameness. blsters are the only appircatious likely to be of service, and these schlom eifect a cure u.lless assisted by rest. This coinplaint dues not oiten vecasion lameness, and is therefore seldo n much attended to; but as it is almost always a consequence of thard work, and often renders a horse unfit for nuch iabuur, it dimmsines nis value considerably.

I have sometincs applied rollers or bandages to the legs with gool effect, keeping them constantly woist with the following embrucation:

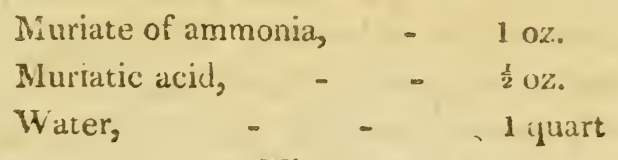

Mix.

$$
\text { Spients }
$$

Are bony excrescences about the shank-bone, $i$. . between the kuee and fetlock joint; they 


\section{CHAPTER V.}

Anatomy and Physiology of the Foot.

OF all the diseases to which horses are liable, there are none more difficult of cure, or that occur so frequently, as those which attack the foot; and huwever improbable it may appear to those who have not paid much attention to this subject, it is an incontrovertible fact, that almost ail of them are the consequence of bad shoeing, and inproper management of the foot.

No one can be aware of the importance of this branch of the veterinary art, but he who has had frequent opportmities of seeing these diseases, and has taken the trouble to inquire into their causes. Such a man will be conrinced, that nearly half of the horses that become unserviceable are rendered so by some defect in the feet; and he will find that such defects are most commonly occasioned by a bad method of shoeing: therefore it must surely 
Plote G.

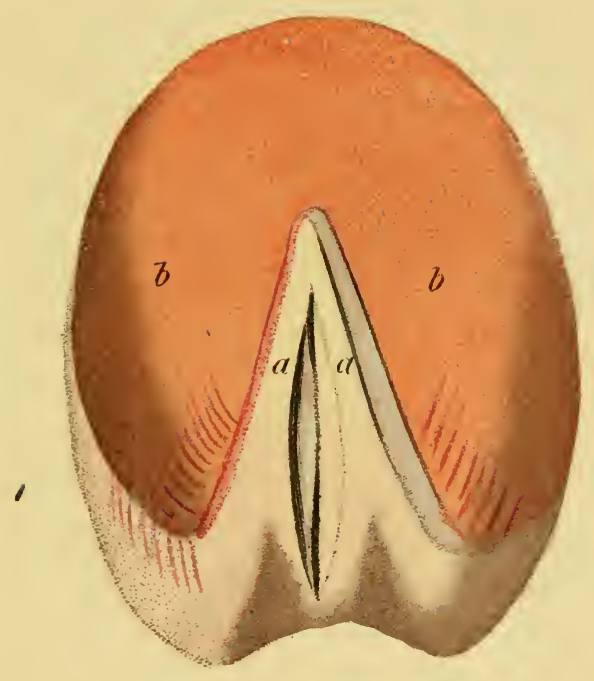

efenvilite Front 

be of importance to every man who values his horse, to acquire such a knowledge of this subject as may enable him to preserve so useful an animal from a multitude of diseases.

The bad effects which arise from the common practice of shoeing are so gradual, that we can easily account for their having been generally orerlooked: the gradations between soundness and absolute lameness are so numerous, that it has been found rather difficult to trace the disease back to its source; ; and this camnot be done readily without having some knowledge of the structure of the foot, and the particular uses of the various parts which compose it. It is necessary also to be well acquainted with the natural form of the foot, in order to determine how far it las beew altered or destroyed by any plan of shoeing. For example, take a horse that has a sound. well-formed foot, let it be improperly pared, and let bad shoes be applied; in all probability limeness will not be the immediate consequence. By a repetition, bowever, of this practice, it will be found that the original shape of the foot is gradually altered, and eventually it will be'so far deformed as to produce perhaps incurable lamencss; therefore we ought not to 
be satisfied with a plan of shoeing, merely because a horse is not immediately made lame by it, but should examine also the effect produced by it upon the shape and structure of the foot; and this rule may invariably be depended on, that any mode of shoeing and treating the foot, which has a tendency to alter the form given to it by Nature, is highly absurd and destructive; while that practice which tends to preserve its original form is founded upon sound and rational principles.

It has been very justly observed, that if we wish to examine a perfect foot, such as Nature made it, it is generaily necessary to find one that has never been shod; for the common mode of shoeing is so frequently destructive, biat we seldon meet with a horse whose feet have not lost, in some degree, their original form; and this deviation from their natural shape is generally proportioned to the length of time he has worn shoes. From this circunstince, writers on farriery have been led to form various opinions respecting the most lesirable form for a horse's foot; but had they consulted vature, this variety of opinion would not have existed: they would lave been convincerl that the feet of all 
horses in a state of rature, or not improperly shoed, are nearly of the same shape; and surely no one will dispute that this form, which the Creato: has given it, is the most perfect, and far better adapted to all the purposes for which the animal was designed, than any that can be given by the most ingenious farrier.

A person unacquainted with the anatomy of the horse's foot woild naturally suppose, that the internal parts are simply enclosed by the hoof, and that by its harduess it served to protect them from the blows and pressure to which they would otherwise be constantly exposed; but very little refection would convince him how incomplete and inadequate such a protection would be. Let him he convinced that those internal parts are replete with blood-vessels and nerres, and possessed of a high degree of sensibility; let him consider, also, what an immense weight is thrown upon them at every step, and what painful concussion must be occasioned to the animal, were this the only safeguard a gainst external injury. Nature, ever provident, has so constructed this part, as to obriate these inconveniences. If we examine any part of the animal economy, we are astonished at the infinite wisdom that is displayed in it. It is not how 
ever too much to assert, that the structure of the horse's foot is strikingly beautiful and curious: here we find a varicty of wonderful contrivances to prevent any painful concussion, from carrying heavy burdens, or from the most violent exertions; but such is the folly and obstinacy of farriers, that they ficquently destroy or pervert the whole of this beautiful mechanism, and the poor animal is doomed to painful labour, or perpetual lameness.

It would not be consistent with the objects of this chapter, to give an elaborate description of the anatomical structure of the horse's foot; but it will be essentially useful to give such an explanation of it, as will enable the reader fully to comprehend the principles of shoeing, and the method of preserving the feet from many troublesome and incurable ciseases.

The horse's foot is made up of a great varicty of parts, some of them possessing blood-ressels and nerves, like other parts of the body, and highly scnsible: others are composed of a dead horny substance, perfectly destitute of feeling. All the external parts of the foot, which, when taken together, are termed the cnffin or hocf, are composed of this horny substance; which is not only very hard, but is 
possessed also of a considerable degree of toughness and elasticity, that render it extremely durable, and well calculated to protect the sensible parts which it encloses.

The hoof consists of the wall or crust, the sole, the fros; and the bars. The upper part of the crust, where it is connected with the skin, is termed the cornnet; the lower part in front, the toe; the sides of the crust are named the quarters; the quarters terminate in the heels; and the heels are connected with the frog. The crust grows from the coronet, and instead of taking a perpendicular direction, becomes oblique in its descent, whereby it acquires a conical figure, being considerably wider at the basis than at the coronet. This description of the hoof applies only to the lealthy foot that has not been improperly treated; fur when the bars have been cut away, and the frog mutilated and prevented from receiving pressure, the heels will contract or approach each other, and the shape of the foot will be considerably altered.

When we examine a hoof that has been recently separated from the foot, an immense number of small orifices or pores nay be observed in that groove which is found on the 
inside of the coronet. Into these orifices the extrenities of those ressels are inserted which secrete the horny matter, the whole of which appears to be pervaded by a fine fuid, serving to prevent brittleness, and to preserve in the hoof a proper degree of clasticity.

All the internal suriace of the crust, except the groove we have just mentioned, is covered by a beautiful membranous or laminated sub. stance, which very much resembles the under surface of a mushroom. This is united, or rather interwoven, with similar laminæ or membranes, which cover all the anterior and lateral surfaces of the sensible foot, forming a very secure union between the crust and the internal parts. Nor are these membranes possessed merely of great strength : they possess likewise a considerable degree of elasticity, constituting one of those curious springs which Nature has provided to prevent concussion when the animal is in motion. That these laminæ form a union between the crust and sensible foot, of sufficient strength to support the atimal's weight, has been proved beyond a doubt, by removing from a living horse the buttom of the hoof, that is, the sole and frog. In this case, had the lamine been unable to 
support the horse's weight, the internal foot must have slipped through the hoof, so as to come down upon the ground: but this did not happen; and the sole, as it was reproduced, assumed its proper concave form.

As these laminx form so secure a union between the crust and the internal foot, it is evident that the weight of the horse is in great measure supported by the crust, which therefore ought to possess considerable strength ; for if it were too weak and flexible, it would not be adequate to the burden which it has to sustain, and must consequently bend to it. In this case the hoof would lose that oblique form which it had originally, and would approach the horizontal line. (See Fig. 1 and 2, Plate 3.) At the same time, the sole would lose its concave form, from receiving an unusual degree of pressure, becoming fiat, and at length convex or projecting. (See Fig. 2, Plate 2.) But when the crust is sufficiently strong, the internal foot, and consequently the whole animal, is suspended by those elastic membranes, as a carriage is by its springs; and though the bottom of the internal foot is in contact with the sole, it nevertheless does not press upon it considerably, except when 
the horse is in motion, and then the back part of the sole descends a little, being somewhat elastic, and suffers the lamina to elongate in a surall degree, so as to prevent any painful concussion.

The bottom of the hoof is formed by the SOLE, the Frog, and the BARs.

The sole is rather concave or hollow on its external surface, and consists of a different kind of horn from that which forms the crust, being of a scaly texture, and sometimes soft and pulverable on its exterior surface: its use is to defend the sensible sole, that lies immediately under it. From its concave form the horse is enabled to tread more firmly on the ground, and the sensible parts are less exposed to blows or pressure than they would be had it been made either flat or convex; and being somewhat flexible and elastic toward the heels, it assists in the action of those curious springs we liave just described.

The firg is a very important part, and requires to be particularly considered. It is intimately united with the sole, but is composed of a tougher and more elastic kind of horn. It resembles a wedge in its form; but toward: the heel, where it becomes wide and ex. 
panded, there is a separation in the middle which is continued to the heel. When the frog receives the pressure of the horse's weight, this separation is increased, and consequently the froy becomes wider; and, as it is connected with the heels of the crust, the same effect must be produced upon them.

As great part of the frog is placed behind the coffin bone, all the intervening space between it and the back sinew being filled with a fatty clastic substance, it forms another of those curious springs which Nature has provided to prevent concussion.

When the frog is in contact. with the ground, it is evident, from its connection with the heels of the crust, as we have before observed, and with two cartilages or elastic bodies, which are corered in great measure by the heels and quarters of the crust, and belong to the internal foot, that it nust tend to widen or expand the heels; and however they may be disposed to contract, by the foot being kept hot and dry, such contraction camnet possibly take place while the from bears on the ground, because it is then opposed by a rery considerible part of the animias weisut.

It has been suppoxed by sone, that the 
principal use of the frog is to serve as a cushion and point of support to the back sinew. When we consider, howerer, the structure and relative situation of these parts, this opinion does not appear to be very probable. From what lats been said of the frog, the reader may judge of its importance, and how necessary it is to attend to its preservation: but such is the mutilating practice of farriers, so determined do they seem on all occasions to act in opposition to Nature, that this essential part is generally the first that is destroyed or rendered useless.

The bars form two ridges, one on each side the frog, extending from the heel of the crust toward the toe of the frog: they appear to be a continuation of the crust, being, like it, composed of strong longitudinal fibres. At the part where it joins the crust, a very firm bearing is afforded for the heel of the shoc. (See Fig. 2, Plate 1.) The use of the bars is, to oppose any risposition there may be in the hoof to conract, by acting as props to the heels: but in the common practice of shoeing they are srenerally destroyed; for farriers have supposed that they bind the heels together, and prevent their expansion: they therefore name 
them binders, and cut them away in order to open the heels, as they term it. This practice, however, is not now so frequent as it used to be. (See Plate 1, Fig. 2, and Plate 6.)

Having finished our description of the hoof, we shall proceed to describe the internal or sensible foot, which is represented in Plate 5 *, as it appears when recently taken from the hoof, the arteries having been injected with wax red coloured.

All the parts of which the internal foot is composed are, as we have before observed, endued with great sensibility; and so nicely is it adapted to the cavity of the hoof, that it. completely fills it, without suffering the least inconvenience from pressure: but when the foot has been improperly treated; when the frog has been deprived of its hard surface for the purpose of giving it what farriers conceive a neat and fashionable appearance (as if $\mathrm{Na}$ ture had been so clumsy in this part of her work, as to require a polish from the hands of these ingenious gentlemen); when the frog has been thus mutilated, the bars destroyed, and shoes applied that are eithēr turned up or

* Erontispiece, 
made very thick at the heels; and when this shoe, for tine purpose of saving trouble, has been applied to the foot nearly red hot - in such circumstances the hoof must necessarily contract, whereby its carity will be diminished, so that the nerves and blood-vessels will be compressed, the circulation of the blood impeded, and inflammation and lameness will most probably be the consequence.

All the auterior and lateral surfaces of the sensible fout are covered with that membranous or laminated substance which we have before described; but it difirs from those lamina which are found on the internal surface of the crust, in possessing numerous blood-ressels, which can be easily demonstrated by injecting coloured wax into the trunk of the arteries; but the laminæe of the crust cannot be made to appear vascular even by the finest injection, and are therefore supposed to be insensible. At the upper part of the sensible foot, where the laminæ terminate, a roundish prujecting body nay be observed, extending ail round the coronet to the back part of the frog: this is termed the coronary ring. Its surface is covered with the extremities of vessels, which are very conspicuous 
when the arteries have been injected with coloured wax or sise: it is from this part that the hoof is formed.

The bottum of the internal foot is formed by the sensible frog and sole: the former perfectly resembles in shape the horny frog, to the concavities of which its convexities are nicely adapted. In describing the horny frog, we had occasion to mention its connection with two elastic bodies or cartilages that are in great measure covered by the heels and quarters of the hool; but this connection is through the medium of the sensible frog, which is more immeliately united to those cartilages. When the former comes in contact with the ground, and receives the pressure of the horse's weight, the latter is forced upward and rendered wider, and at the same time the cartilages are forced upward and outward, tending thereby to expand the heels and quarters, and assisting in taking off concussion. From the sensible frog and sole, the horn which composes the exterual frog and sole is secreted. For this purpose they are supplied with numerous blood-vessels, the extrenities of which may be seen upon their suiface, and become very conspicuous. 
when the arteries have been injected with coloured sise. Hence we are enabled to account for thrushes, and that rottenness of the frog whici generally accompanies this disease; for when the sensible fiog is compressed and inflamed by a contraction of the heels, it becomes incapable of performing its principal function, that is, the secretion of horn; and the blood which should have been applied to this purpose is chiefiy expended in forming that offensive matter discharged in thrushes. From this we may learn also the cause of that unnatural thinness in the soles of horses that have pumice or flat feet. When the crust gives way: to the pressure of the horse's weight, allowing the internal foot to bear so upon the sole as to render it either flat or convex, the extraordinary pressure which the sensible sole receives inflames it, and impedes in a greater or less degree the secretion of liorn.

The sensible sole lies immediately under the horny sole, by which it is defended from blows or pressure. When the horny sole loses its concave form, and becomes thin, and incapable of performing its function, if flat shoes were applied, or if the sole were suf- 
fered to bear upon the ground, lameness would be the consequence; and it is for the purpose of preserving the sole from pressure that the concave or hollow shoe is employed in those cases. When these parts which we have described are removed from the sensible foot, the tendons, ligaments, and bones, come into view.

In Plate 9 is a back view of the bones, ligaments, and tendons. In this the course and insertion of the back sinew, or flexor tendon, may be seen, as well as the lateral cartilages. The flexor tendon is enclosed in a sheath, which is laid open in one part in order to show the tendon: it has been removed also from the bottom of the tendon, that its insertion may be clearly seen.

In Plate 10 are represented the ligaments, for which purpose the tendons were removed. The lateral cartilarges may be seen in this riew also.

In Plate 11 and 12 are a front and back riew of the bones. It will be unnecessary to gire a particular description of these, as their form and relutire situations may be seen by referring to the plate. It may be useful, however, to point out the sesamoid bones, and the naricula, 
or nut bune: the former are connected posteriorly with the lower extremity of the cannon, or shank bone: they consist of two small bones, firmly united by means of very strong ligaments; they compose part of the fetlock joint, having a movable articulation with the cannon bone. Their external part affords a smooth polished surface for the back sinews to slide upon, and the same ligament which composes this surface comes round the back sinews, so as to form a sheath for them, and keep them in their situation. In this sheath a fluid similar to synovia, or joint oil, is formed, for the purpose of rendering it smooth and slippery, and enabling the tendon to move casily upon it. As these bones project a little, they serve as a pulley for the tendons to slide upon, and afford a considerable mechanical adrantage to the flexor muscles of the limb. The nut bone serves as another pulley for the tendon or back sinew to move upon: it is connected posteriorly with the coffin bone and the small pastern, and affords the same lind of polished surface and sheath for the tendon as we have before described. 



\section{"THE AGTS OF A THORS I}

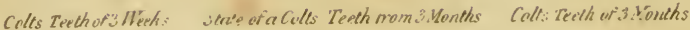
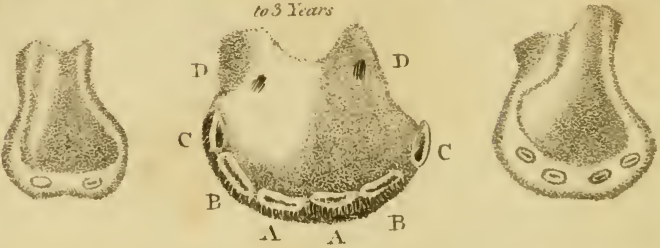

$A$ the Pincer's

c che Corners.

B. the Seturaters

D the Tiskis or Tushes
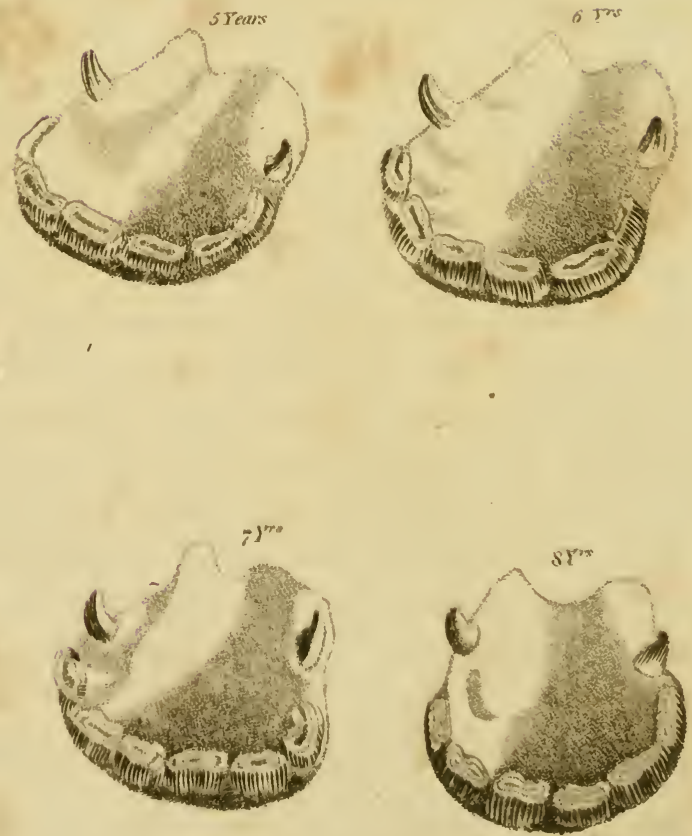


\section{CHAPTER VI.}

\section{On the Practice of Shoeing.}

HAVING given, in the preçeding chapter, a concise description of the horse's foot, and pointed out the uses of the various parts which compose it, I shall now describe the method of shoeing. It will be necessary to premise, that the mode of shoeing most commonly practised his a destructive tendency, and produces such a variety of diseases, that we seldom meet with a foot that has not lost, in a greater or less degree, its original shape: it must be obvious, therefore, that one kind of shoe cannot with propriety be recommended for general application, and that it is necessary on all occasions to adapt it carefully to the state of the foot. This constitutes the most difficult part of the art of shoeing; and from neglecting this precaution, shoes of the best form have often occasioned lameness.

In Fig. 1, Plate 1, is represented a colt's 
hoof in a state of nature, of which no part has ever been cut away, or ever been shod: this we have given as a standard of perfection, from which the goodness of feet in general may be judged of; for surely no one will hesitate for a moment in admitting that the natural form is the best it can possibly possess.

In Fig. 2 of the same plate is shown a perfect foot, properly prepared for the shoe. In this foot the superfluous horn has been cut away, and an even surface made for the shoe to bear upon.

If we examine the feet of a hundred colts, it will be found that more than ninety of them are of the same form. It is true that some may have grown more luxuriantly than others, whereby the crust will be deeper, and the bottom part may have been partially broken, so as to give the foot a ragged and uneven appearance; still the essential shape is the same; and when this superfluous horn has been remored, it will be found that the bottom of the foot will be nearly circular, the sole concave, the bars distinct, and the frog and heels open and expanded.

In preparing a horse's foot for the shoe, the lower part is to be reduced, when luxuriant, 
which is generally the case, more particularly at the toe, and this is to be done by means of a buttress or rasp: the loose scaly parts of the sole are likewise to be removed, so as to preserve its concavity; and a small cavity is to be made with a drawing knife, between the bar and crust, to prevent the shoe from pressing on that part, and occasioning corns : it is, however, necessary, in doing this, to take particular care that the connection between the bar and crust is not destroyed or weakened, which would of course render the bar useless.

The junction of the bar and crust affords a firm bearing for the heel of the shoe, and is to be rasped perfectly flat, and so low as to be exactly on a level with the frog, that they may bear equally on a plane surface before the shoe is applied; incleed, the whole of the bottom of the crust is to be made perfectly flat and even at the same time with the rasp, that the shoe may bear equally on èvery part of it. Farriers should never be allowed to do this by means of a hot shoe, which is too frequently the case. If any ragged parts are observed in the frog, they are to be carefully removed with a knife; for, if suffered to re- 
main, they might afford a lodgement for dirt and gravel. Thus do we prepare a foot for the sisoe; and to a foot of this description, I mean one that is sound and perfect, or that has nut suifered any material alteration in its form from improper shoeing, the shoe (Fig. 3, Plate 4) is to be applied.

The toe of the shoe, for a midnle-sized horse, is about an inch in width, and half an inch in depth or thickness; the heels about half an inch in width, and three eighths in depth. The wearing part of the toe is to be made of steel; and it may be observed, that the nails are brought very near to the toe, but not quite round it; for when that is done, there must also be a groove made, which considerably weakens that part, and almost all horses wear principally at the toe. Both surfaces of the shoe are perfectly flat; and the heel of the shoe rests upon the junction of the bar and crust, beyond which it should nerer extend.

It will be supposed, perhaps, that a shoe which is flat on that surface next the foot will be apt to produce lameness by pressing on the sole: but let it be recollected, that this shoe is recommended only for a sound foot, in which the sole is always a little concave; so 
that it cannot possibly receive any pressure from a flat shoe. It may be said also, that when the nails are placed so far from the heels, the shoe will not be sufficiently secure, and will be frequently loosened; but as the shoe bears equally on every part of the crust, this objection cannot have any weight. It must be granted, however, when a foot is pared in the common way, that is, when the heels have been opeied, and the shoe so applied, that nearly an inch of the heel has no bearing upon the crust; that, if the nails were placed so far from the heels as I have recommended, the shoe would be very insecure; for, as much of it as had no bearing upon the crust would operate occasionally as a lever in raising the nails; and consequently the shoe would frequently be loosened. Farriers therefore find it necessary, when the foot has been thus pared, and the shoe applied in this way, to place the nails in the quarters, by which the shoe is certainly rendered more secure than it would be had they been placed nearer the toe.

Many disadvantages, however, attend this method. In the first place, by placing the nails in the quarters, they prove a considerable 
obstacle to the expansion of the heels; and as the crust is generally much thinner at the quarters than at the toe, the sensible parts are more liable to be wounded: but this does not apply to the hind feet, in which the crust of the quarters is generally thicker than that of the toe. When a horse overreaches, if any part of the shoe has no bearing upon the crust, it is very liable to be struck by the toe of the hind foot; and shoes are often forced off in this way. To this may be added the insecurity of such a shoe when a horse is rode on a deep or heavy ground.

It will probably be observed of the shoe which I have recommended, that it is inconsistent with the principle which has been laid down respecting the necessity of the frog's receiving pressure. I believe it is an incontrovertible fact, that unless the frog receives a certain degree of pressure, it will become soft, and incapable of affording sufficient protection to the sensible frog, which it covers; and that the heels will gradually contract, and the natural form of the foot will be destroyed; for I have proved, by experiment, that the bars alone are not sufficient to prevent contraction, though they certainly oppose it with 
considerable force; but it does not follow from this that it is necessary for the pressure to be constant, nor do I believe that a shoe which allows the frog to bear upon the ground, when the horse stands upon a plane hard surface, can be always applied, even to sound feet, without inconvenience. There can be no doubt that a horse in a state of nature has his frog almost always in contact with the ground, and then of course he feels no inconvenience from it; but when burdens are placed upon his back, and he is driven about upon hard roads, he is certainly in very different circumstances: and if the frog in such cases were constantly exposed to this severe pressure, it would some. times, I believe, occasion lammeness.

In the foot, prepared for the shoe, (Fig. 2, Plate 1,) the frog and heels are on a level, and if placed on a plane hard surface, would bear equally; by applying the shoe, (Fig. 3, Plate 4, the frog would be raised three-eighths of an inch from the ground; so that when the horse is going upon a hard surface, where he would be most liable to feel inconvenience from the pressure on the frog, it receives none; but upon soft yielding ground the frog certainly receives pressure, and without giving the ani= FCL, I, 
mal any pain. To a horse that travels or works regularly, and is occasionally taken upon soft ground, I believe the pressure the fiog receives in this way is quite sufficient to preserve the foot in a state of health; but when a horse is liept almost constantly in the stable, stanling upon hot litter, particularly in hot and dry weather, his fect will certaisly be undergoing an alteration in their form, and will be in a progressire state towards disease.

In these cases, howcrer, contraction of the hoof may be effectually prerented by means of the patent artificial frog, invented by Mr. Coleman*. By this ingenious contrivance a horse's frog maly receive sufficient pressure, in whaterer circumstances he may be placed, to prevent contraction, and keep the foot sound and healthy, without the inconvenience of wearing thin heeled shoes; but it must be remembercd, that whenever the frog is much exposed to pressure, whether it be by applying the patent frog, or by the thin heeled shoe, and reducing the crust at the heels, it is necessary the quarters and heels should possess a proper degree of pliancy. If they be rigid and inflexible, it is evident that the sensible

* Irofessor of the Veteriuary College. 
frog and cartilages would be placed between two fixed points, and they would consequently be bruised and inflamed. I have indeed seen several cases of lameness produced in this way. Whenever the hoof, therefore, appears to be too dry and strong, or to have lost its natural elasticity, it is necessary to rasp the quarters, and keep the whole hoof moist, either by applying several folds of flannel round the coronet, constantly wetted, or by making the horse stand in soft clay four or five hours during the day: by these means the natural flexibility of the horn would be restored, and the heels and quarters yield in a small degree, whenever the horse's weight was thrown upow the frog.

Having said as much as appears to be reciuisite of the method of shocing a sound foot, I shall proceed to describe those diseases of the foot which render a different kind of shoe necessary. In the first place it will be proper to observe, that when a horse, even with a sound foot, has worn shoes that are very thick, or turned up at the heels, particularly if at the same time the crust at the heeis have been suffered to grow so high that the frog is kept. at a considerable distance from the ground, it 
would be rery improper to reciuce thi I suddenly, so as to allow the trog to renter pressure, since the back sinews would in this case be injured, and lameness miglit ensue. In feet of this description it is necessiry to remove from the toe all that can be done without exposing the part too much, and to lower the heels gradually: the toe of the shoe should be rather thin, and of the best steel.

The shoe for draught horses should be male flat on both surfaces, provided the sole is of a proper form and thickness, but if fat or convex, and consequently too thin, which is often the case in horses of this description, the internal surface of the shoe must be concave: still the external surface should be flat, for the convex shoe, which is commonly used for draught horses, prevents them from treading securely, and renders them incapable of exerting th: whole of their strength. 


\section{CHAPTER VII.}

\section{Diseases of the Foot.}

THE most frequent cause of lameness in the foot is a contriction of the horny matter that composes the hoof, gencrally accompanied by an incrased concavity and thickness of the sole. 'The cavity of the hoof being thus diminshet, the sensible foot suifers a greater or less degree of compression, which occasions in it infammation and lameness. When we examine the bottom of a contracted foot, insteal of being circular, it will be found of an oblong form; the heels and frog will appear as if they had been squeezed together. Sometimes the frog has become rottell, and discharges an offensive matter.

The sensibie fout may also be compressed and inflamed by an increased thickness, and a consequent loss of elasticity in the hoof and sole, and in this case there is seldom any considerable alteration observed in the external form of the foot. 
We sometimes meet with horses that go perfectly sound, though their hoofs are much contracted: on the other hand we often see severe lameness produced by a slight degree of contraction. In attempting to cure this disease, the first step to be taken is to remove carefully with a knife all the rotten parts of the frog, anct apply tar to those which are sound. A small quantity should also be poured into the cleft of the frog; this will promote the secretion of horny matter, and if assisted by pressure, will increase the solidity of that which is already formed. The quarters and heels are then to be rasped, particularly at the coronet, and the superfluous parts of the sole removed with a butteris and drawing knife. The toe is to be shortened as much as can be conveniently done; and if the heels be too high, that is, if the crust at the heels be too deep, it will be necessary to reduce it with the butteris and rasp. It frequently happens, however, in feet of this description, that the heels are too low; in such cases they must be carefully preserved; and when a shoe is applied, it should be made thicker at the heel than at the toe, and somewhat longer than that recommended for a sound foot. 
When a contracted hoof has been thus sreated, the next thing to be done is to keep the fout as moist as possible, and expose the frog constantly to pressure, either by meaus of the artificial frog, or by reducing the crust at the heels. When these remedies have been persevered in for a snort time, the frog will have acquired a certain degree of hardness and solidity; it will then be proper to turn the horse out into some soft meador ground, without shoes, taking care that the bottom of the foot is occasionally reduced, so that the fiog may constantly receive pressure. If the foot be examined after a short time, it will be found that all the new formed hoof at the quarters and heels, that is all the horn that has been prolused at those parts since the remedies were first employed, instead of growing down nearly in a perpendiculur direction, or obliquely inwaru, is forced outward in its descent, so that the cavity of the hoof will be considerably enlarged, and tire compression of the inturnal parts removed. When the horse has been at grass a sufficient time fur the new hoof to grow completely down, the shape of the fout will be found much altered; the heels, insteau of being narrow, will be open 
and expanded, the frog will be considerably widened, and not squeezed together as before, and the oblong form will be changed to one that is more circular; in short, when the frog during this time has been properly exposed to pressure, and the quarters so rasped as to be rendered sufficiently flexible, the hoof will be found very similar in its form to that of a colt.

In cases where a contraction of the hoof has already produced inflammation and lameness, particularly if the lameness be not recent, it will be advisable to blister the pasterns previous to turning the horse out; and when the inflammation is very considerable, a laxative ball, with a cooling diet, will be serviceable. The crucl operation of drawing or tearing off the sole has been recommended as a remedy for contracted feet, but very little reflexion will convince any one of its inefficacy. Whenever it has been supposed to do good, the benefit has probably arisen from the long run at grass that becomes necessary after it, and then the advantage might have been equal, perhaps greater, had the operation been omitted. It has been observed before, that in contracted hoofs there is generally an increased concavity in the sole, 
whence we may reasonably conclude that it opposes the contracting causes, though in the end it is not capable of preventing the contraction from taking place. Upon a horse that has been lame from this disease a considerable time, it is difficult, if not impossible, to perform a radical cure; in such cases I have several times succeeded in removing the lameness, but the internal parts had become so irritable, or their organisation had been so altered, that very moderate work would cause the lameness to return. When the lameness is not so considerable as to render the horse totally unfit for work, it will be advisable to apply a shoe that is thicker, wider, and longer at the heels, than that recommendel for a sound foot; and if the froy be tender and rotten, the bar shoe will be found serviceable. (Plite 4, Fig. 2.) It will be useful also to keep the hoof as moist as pussible, by making the horse stand in wet clay four or five hous during the day.

In examining after death the feet of horses that have been thus diseased, we find $g$ :.erally that the laninæe have heen destruycd, the form of the coffin bone altered and its size diminished, or the lateral cartilages cssified. 
In some cases, however, no appearance of disease can be perceived on the internal parts of the foot. When the disease has gone so far as to injure the laminx, cartilages, or coffin bone, there is not a possibility of removing it, which shows how necessary it is to attend to the feet of horses more than is commonly done: and that whenever any alteration is perceived to be going on in the shape of the foot; when the heels appear to be getting narrower, the frog squeezed together, and discharging matter, in consequence of the compression which the sensible frog suffers; it surely must be of importance to adopt such measures as will not only prevent the disease from going any further, but will also restore the foot to its natural healthy state: for when it has gone so far as to produce absolute lameness, the cure is by no means certain. How frequently do we meet with horses that are said to be tender in the feet! and haw subject are they to fall in consequence of this tenderness, which generally arises from contraction of the crust! In this case the sensible frog is extremely irri:able and inflamed; and the homy frog which Nature designed for its protection being soft or rotten, and inadequate to its function, every. 
blow that it receives must of course give the animal very considerable pain; and I have known many valuable horses thrown down in this way; since however high and wide the heel of the shoe may be, the frog will be subject to occasional blows from sharp projecting stones. Whenever therefore any of thuse symptoms make their appearance, and whenever the foot seems to be undergoing an alteration in form, immediate recourse should be had to the mode of prevention we have pointed out.

The next disease to be noticed is the flat and convex sole, or, as it is more commonly termed, the pumice foot, which is represented in Plate 3, Fig. 2. This disease most commonly occurs in heary draught horses, and seems to arise from a weakness of the crust; for when the sole becumes flat or convex, the erust also loses its proper form, and becomes flatter, appearing as if it had been incapable of supporting the animal's weight, and had therefore given way, allowing the internal foot to press so upon the sole as to give it the appearance we observe. This explanation of the disease will perhaps appear better founded, if we consiler that, when a horse is drawing a 
heavy load, not only his own weight, but great part of that which he is drawing also, is thrown vlimatcly upon his feet; and as the fore feet support by far the greatest share, it is not at all ustonishing that the crust should sometimes give way; for though it possesses sufficient strength for the purposes of the animal in a state of nature, yet that strength is limited, and not always adequate to the heary burdens which the crust has to sustain. When the sole becomes flat or convex, it is rendered also thinner than it is naturally, and sometimes so much so, as to yield easily to the pressure of the finger. The sole in this state is of course incapable of affording sufficient protection to the sensible sole, which is then closely in contact with it; and if it be exposed to pressure, lameness must be the consequence. It is almost superfuows to observe, that the flat shoe would be ill adapted to a foot of this description: it becumes necessary in this case to apply one that is concave on its internal surface, that she sole may not receive any pressure from it, and of sufficient width to protect the sole as much as can be done from the pressure of the ground. In Plate 4, Fig. 1, this shoe is represented, in waich it may be observed, that 
although the internal suriace is concave, still there is a flat surlace for the crust to bear upon. In attenıting to cure this disease, it is first necessary to take off the horse's shoes, and to make him stand on a fiat hard surface: this kind of pressure will harden the soles, and in the end render them thicker, particularly if tar be frequently applied to them. I cannot say that 1 have ever seen the disease radically cured by this treatment, but I have known considerable advantage lerived from it, especially in one cuse, where the soles, from being convex and very thin, became fiat, and suffciently firin to bear moderate pressure without inconvenience to the horse.

We sometimes meet with horses, particularly among those that are well bred for the turf, whose pasterns are remarkably long and oblique in their position, while the heels are very low, and the toe of considerable length. If thin heeled shoes were applied to feet of this description, or if the toes ware not kept short, the horse would be very liable to lameness, from the extraordinary pressure to which the ligaments and back sinews would be exposed: the heels therefore of such horses are to be carefully preserved, and the toes keps 
as short as possible. The shoes which are applied should be made sufficiently thick and long at the heel to make up for the deficiency of horn in that part, in order to relieve the ligaments and back sinews; and with the same view the toe should be made rather thin, and of the best steel.

There is another kind of deformity sometimes observable in the foot, that is, the hoof loses that oblique form represented in Plate 3, Fig. 1, and approaches towards the perpendicular (Fig. 3): at the same time the heels become very high. In this case it is necessary to reduce the crust at the heels, and apply the thin heeled shoe.

\section{Sund Cracks}

Are longitudinal fissures in the hoof, genc. rally near the heels, beginning at the coronet. Horses, whose hoofs have become dry and brittle, are most subject to them. They generally occur in the hot and dry months of summer, and seem to be occasioned by a strong disposition in the hoof to contract, at a time when it is dry and intlexible. They do not always cause lameness, and are sometimes 
very easily cured: but when the fissure is so deep as to reach the sensible parts, it often produces very severe lameness, and requires a considerable time to be completely remored. Having rasped the quarter, let the crack be opened with a drawing knife, so that the actual cautery, or red hot iron, may be applied to it. This will cause a matter somewhat resembling glue to exude, which will tend to fill up the fissure, and protect the sensible parts that would otherwise be exposed. Our next object is to remore the contractile disposition of the hoof, without doing which every other remedy would avail little. This is to be effected by keeping the hoof constantly moist, either by meaus of clay, or by turning the horse out to grass in soft moist ground: but previous to this it is necessary to rasp the bottom of that quarter which is cracked, so that no part of it may bear upon the shoe.

\section{Corns.}

Corns are generally the consequence of bad shoeing, or improper management of the foot, snd may therefore be aroided by following 
the lirections $I$ have given under that head: but when they d, occur, it is necessary to remove the red part, or corn, with a drawing knife, and to apply the shoe so that the tender part may net receive any pressure. When it has been ne ylected, we sometime; find matter formed in this part, which often breaks out at the coronet : in this case it is necessary to make an opening for the matter in the angle between the bar and crust. (See Fig. 2, Plate 1, Letter $e$.)

The sore is to be dressed with compound. tincture of benzom, and the cavity to be loosely filled with digestive ointment, which is to be kept in by means of a bar shoe.

\section{2 uittor.}

This disease generally arises from a wound or bruise in the coronet, and, if neglected, penetrates under the hoof, forming sinuses in various directions. The most effectual method of treating this complaint is to ascertain, in the first piace, the direction and extent of the sinuses, and then to force into them with a strong probe some crystallized. 
verdegris, rolled up in thin blotting or silver paper. This, though apparently a severe remedy, will be found very effectual. Sublimate and arsenic have been strongly recommended as remedies for the quittor; indeed it is probable that any caustic application would effect a cure; but I have succeeded so well with the crystallized verdegris, that I have not been induced to try those medicines. When a corn has been neglected and suffered to break out at the coronet, or when the foot has been wounded, or pricked, as it is termed by the farrier, in shoeing, and this is not discovered until matter appears at the coronet; though these may be considered as cases of quittor, a different treatment is required from that we have just described. In these cases the cure greatly depends on making an opening for the matter in the bottom of the foot, where the nail which inflicted the injury entered; or if produced by a corn, the opening must be made in the angle between the bar and crust, at e, Fig. 2, Plate 1. The best dressing on these occasions is the compound tincture of benzoin and digestive ointment: a puultice is sometimes required to soften the horny mat- 
ter, and subdue any inflammation that may exist in the fout.

\section{Thrush.}

This disease consists in a discharge of fotid matter from the cleft of the frog, which part is generally rotten, and so sott as to be incapable of affording sufficient protection to the sensible frog, which it covers: hence arises that tenderness of the foot which is so uften observed. When this complaint attacks the fore feet, it is seldom, if ever, an original disease, but merely a symptom or an effict. The cause is generally a contraction of the horny matter at the quarters and heels, by which the sensible frog is compressed and inflamed: the discharge which takes place is a consequence of this inflammation, and may be considered as an ineffectual cflort of nature to cure it. The discharge, howerer, certainly diminishes the infammation, and prevents it from becoming so considerable as it otherwise would; for it often happens when it has been stopped by the injudicious application of astringents, or when it ceases spontancously, that the 
inflammation becomes violent, extends to the other parts of the foot, and occasions severe lameness, which generally is relieved or removed by a return of the discharge. But we are not to infer from this that an attempt to cure thrushes is improper; it only shows that it is necessary in the first place to remove the cause of the disease. With this view the quarters are to be rasped, and the huofs kept constantly moist by making the horse staud in clay some part of the day, taking care to keep the frog dry by means of tar. When by these means we have succeeded in removing in some measure the compression and consequent inflammation of the sensible frog, it will be advisuble to apply some astringent to the frog, which, if assisted by pressure and tar, will render that part firnı and solid, and the discharge will of course cease when the inflammation leaves the sensible frog.

The best astringents for this purpose are a solution of white or blue vitricl, aluin, \&c. There are some cases, however, of tirushes, which, though occasioned by compression of the sensible frog, it is difficult, if not impossible to eradicate. I have examined feet with this disease after death, and have found 
the concave part or cleft of the sensible frog in a state of ulceration, which of course rendered it incapable of secreting horny, matter, and proved a constant source of thrushes.

With respect to those thrushes which attack the hind feet, and which sometimes, though rarely, happen also in the fore feet, independently of the above cause, a different treatment is required. When the discharge has existed for a considerable time, by stopping it hastily we frequently produce inflammation and swelling of the legs: still it is necessary to check the disease, since, if neglected, it sometimes degenerates into that dangerous disease termed canker. It is advisable, therefore, in such cases to keep the bowcls open by the following laxative ball, given every morning until the desired effect is produced, and repeated occasionally. The best application for the frog is tar, and one of the abore astringents : other remedies, however, have beén strongly recommended, among which are powdered lime, Egyptiacum, tincture of myrrh, and other astringents. This treatment will be greatly assisted by two or three hours' exercise every day, and frequent hand-rubbing to the legs. 


\section{LAXATIVE BALL.}
Aloes, - - - $2 \mathrm{dr}$.
Castile soap, - - $3 \mathrm{dr}$.
To be made inta a ball for one dose.

\section{Canker.}

This disease frequently originates in a thrush, and most commonly attacks the hind feet : it generally proves difficult to cure, and not unfrequently incurable. 'The frog is the part first attacked, which becomes soft and rotten, discharging matter of a peculiariy offensive smell. The horny frog is at length totally destroyed, and the sensible frog, instead of secreting horn, forms a substance somewhat resembling shreds of leather. The disease soon extends to the sole and other parts of the foot, even to the coffin bone, and is then, I believe, incurable. The first thing to be done is to cut away freely all the diseased parts ; and when the bleeding is stopped, let the following liniment be applied, and repeated every morning; the dressings may be kept on by means of a bar shoe. Pressure on the diseased part will very materiaily assist in effecting a cure. Whenever the foot is 
dressed, such diseased parts as may again make their appearance are to be carefully removed: and to such as do not appear to be sufficiently affected by the liniment, let a little sulphuric or nitrous acid be applied. When the parts which were diseased begin to look red and healthy, and the discharge loses that peculiar smell before noticed, becoming whiter and of a thicker consistence, there is great probability of a perfect cure being effected; and when these farourable appearances take place, some mild application will be proper, except to such parts as do not appear to have entirely lost their foul appearance.

STRONG LININENT.

\section{No. 1.}
Oil of turpentine,
- $1 \mathrm{oz}$.
Sulphuric acid,
$\frac{\mathrm{I}}{2} \mathrm{Oz}$.

Mix very cautiously.

Tar, - $\quad$ Mix. 4 oz.

No. 2.

Red nitrated quicksilver, $\quad 1 \mathrm{oz}$.

Nitrous acid, - $\quad 2 \mathrm{o} z$.

The former being dissolved in the latter, mir them cautiously with four ounces of tar. 


\section{MILD LINIMENT.}

Crystallized verdegris, finely powdered, $1 \mathrm{oz}$. Honey, $2 \mathrm{oz}$.

Powdered bole and alum, of each, - $\frac{x}{2} \mathrm{oz}$. Vinegar enough to give it the consistence of a liniment, to be mixed over a gentle fire.

\section{Cutting.}

$\Lambda$ horse is said to cut when he wounds the inside of the fetlock joint with his foot in travelling. This may arise from various causes, the most common of which seems to be an improper position of the foot; the toe, instcad of being in a line with the point of the shoulder, inclining either inward or outward. In the latter case we generally find that the inner quarter of the hoof is lower than the other, and that the faulty position of the foot depends upon this inequality of the quarters: it must be obvious, therefore, that the remedy in this case consists in lowering the outer quarter, and making the inner branch of the shoe thicker than the other. When the toe inclines 
inward, it renders a horse liable to cut on the inside of the knee, at the lower part of the joint: this is termed the speedy cut, from its happening upon the trot or gallop, and is considered as a clangerous failing in a horse, the violence of the pain which the blow occasions sometimes causing him to fall very sudcienly: The remedy for this is to keep the toe as short as possible, that being the part which generally inflicts the wound, and to alter the insproper position of the foot. Cutting frequently depends upon weakness or fatigue, and is therefore very liable to happen to young horses when rode hard over deep heary ground. The only remedy in this case is to avoid the cause until the legुs acquire more strength, or to protect the wounded part with leather, or a boot, as it is termed. Whenever a horse cuts, it is advisable to ascertain what part it is that inflicts the wound, and this may often be done by applying tar to the wounded part: this will of course adhere to the part of the hoof or shoe which comes into contact with the wound. Should it be the edge of the shoe, which I believe is seldom the case, the cause may be easily removed by the far- 
rier. Whatever part of the hoof it may be, it should be rasped away as much as can be done with safety, and particular attention paid to the position of the other foot, which, if improper, should be improved as much as it can be by shoeing. 


\section{CHAPTER VIII.}

\section{MISCELLANEOUS.}

\section{Of Bleeding.}

'THis operation is frequently necessary in the diseases of horses, and is performed either with a lancet or phleme, in the neck vein.

The blood should always be preserved, that the quantity drawn may be accurately known, and that its quality may be ascertained. If after it has coagulated, a white, or rather a light buff-coloured jelly, be found on the surfice, an infammatory state of the body is inclirated; but in order to render this criterion useful, the blond must not be taken from too small an oritice, nor should it be suffered to run down the sides of the ressed which receires it.

Blool drann from a healthy horse very soon cpagniates, and ippears like a uniformly res? 
jelly, with a small quantity of fluid resembling water floating on its surface. This red jelly may by washing be rendered of a light buff colour, and exactly resembles the buff or sise, as it is termed, of inflamed blood. The most healthy blood, therefore, contains this sise; and the cause of its not being conspicuous in such blood is, that cougulation takes place before the red colouring matter can have time to separate from it; but as blood that is drawn from an animal labouring under general inflammation or fever always preserves its fluidity much longer than healthy blood, and as the red colouring particles are specifically heavier thin the fluid with which they are mixed, they will of course be gradually subsiding as long as the mass continues fluid, leaving a coat of buffcoloured jelly on the surface.

It has been observed before, that healthy blood, when suffered to coacrulate, appears to consist of two parts, the red jelly termed crassamentum, and the water, or serum; and that the former may afterward be separated, by washing, into two parts, viz. the red coloured particles, or red globules, as they are *ermed by anatomists, and bull-coloured jellyo 
or coagulable lymph. The proportion, which these component parts of the blood bear to each other, seems to depend upon the state of the system at the time it is drawn. When the body is inealthy and rigorous, we find but little serum; when it is preternaturaliy excied, or in a state of inflammation, there is still less; and when the animal is weak and debilitated, there is gencrally an abundance of serum. Another circumstance to be attended to in examining blood is the firmness or tenacity of the coagulum. In health, the blood, when drawn and suffered to coagulate, is of a moderately firm consistence, and easily broken; but when the system is nighly excited, as in general infammation, so great is the tenacity of the mass, that the finger can scarcely penetrate 1t. On the other hand, when the powers of life are weak, as in the lattcr stage of symptomatic fever, the blood almost loses its power of coagulating. I recollect a glandered horse that was made tile subject of experiments, and that died in consequence of large and repeated doses of mercury; the debiiity this pioluced was excessive; and the blood appeared as thin, and nearly of the same colour, as claret 
The necessity, therefore, of examining blood that is drawn from a diseased horse must be obvious, as it assists in fuming a judgment of the nature of the disease, and points out the proper remedies. When blood exhibits buff on its surface, particularly if at the same time the coagulum be firm and solit, we may be certain that the complaint is inflammatory, and that bleeding may be repeated with a Irantuge. If on the other hand the mass of blood be wanting in tenacity, and have more scrum than usual, we may sufely conclude that the sjstens is in a state of dehility, and consequently that bleeding is highly improper.

In cases of symptomatic fever it wili gene. rally be necessary to take away four or five quarts of blool at the first bleading; I have seen even six quarts taken with manifest advantage. It is at this pericd of the disease (its commencement) that copious bleeding is particularly useful; and it is from an absurd preju. dice which obtains against this practice, that so many horses are destroyed by such fevers. It is truly laughable to hear a groom or farrier pronouncing with an affectation of unerring sagacity upon the qualities of blood, frequently observing that it is two hot, and that conse- 
quently the horse must have a ferer; that it is too dark coloured, and therefore foul; or that it is too thick, and consequently unfit for circulation; and sometimes it is said to be full of Inmours. Itith respect to the heat of the blonil, it will be sufficient to observe, that it preserves nearly the same temperature while circulating in the body, whether the animal be an inhabitant of the most sultry or of the coldest country, whether in health or in the highest fever.

As to the colour of the blood while flowing from the body, it may be either red or of a lark colour, as the operator pleases ; since by pressing on the vein, for a short time before the orifice is made, it may always be made to appear of a dark colour. If an artery be opened, the biood which flows from it will be of a bright scarlet colour. The opinion that blood sometimes becomes thick or riscid in the body was supported by many respectable philosophers, but is now universally abandoned, because it has been prowed to be erroneous.

I think it a bad practice to bleed horses frequently when there is no urgent occasion, as they thereby acquire a plethoric habit; and unless the operation be regularly performed and gradually increased in frequency, trouble- 
some diseases might ensue. Horses of a full habit, that are consequently liable to inflammatory complaints, will receive most benefit from moderate and long continued exercise, and good grooming. When bleeding is performed for the cure of important inflammatory diseases, a large orifice should be made in the rein, and the blood drawn in a large stream, as we thereby diminish the action of the heart and arteries much more readily than if it were drawn slowly from a small orifice. In cases of exterual and circumscribed inflammation, topical bleeding is eminently useful, which is done by opening some veins contiguous to the affected part, or by scarifying the inflamed surface.

Thus in diseases which depend upon an undue proportion of blood in the vessels of the brain, relief will often be obtained by opening the artery of the temple; and when the eye is much inflamed, it will be found useful to scarify the inner surface of the eye- . lid. 


\section{Of Physic.}

In purging horses, great care and attention are necessary, their bowels being particularly irritable, and liable to inflammation. The physic commonly given is certainly too strong, and I am convinced that many horses have heen destroyed by the immoderate doses that have been recommended by writers on fillriery. When this happens, the mischief is generally attributed to the coarseness or impurity of the medicine, and the druggist is undeserredly censured. A modern author has ingeniously arailed himself of this prejudice, to explain the violent effects which his cathartic prescriptions have sometimes produced. I must presume, however, to suggest, that these elfects were more probably occasioned by the excessive quantity than by the impurity of the purgative ingredients.

The only certain and safe purgative for horses is aloes; and of the different kinds of alves, the Burbadocs is undoubtedly the best. The succotrine, which is generally considered the mildest, as well as the most certain in its effect, is too weak, and so very uncertain and rariable in its operation, that 
we cannot use it without frequent disappointment. Practitioners seem now to be convinced of the superiority of the Barbadocs aloe, as it has been. sold of late nearly at double the price of the succotrine.

If the reader wish to have farther information on this subject, he is requested to consult the author's second rolume, or Veterinary Materia Medica, \&c.

It is advisable to preprare a horse for physic by giving him bran mashes for a day or two. This will gently relax the bowels, and remove any indurated freces that may be lodged in them: it will also tend to facilitate the operation of the medicine.

About a peck of bran divided into four feeds will be sufficient for twenty-four hours; and as it is desirable to give the horse but a small quantity of hay, I think it advisible to add to each bran mash about a pint or more of bruised or broken oats, which will tend to preserve his strength and condition. He should be allowed to drink a moderate quantity of water frequently.

When a horse is purged for the first time, it is prudent to give a very moderate dose. iVere the common quantity given to one of 
weak, irritable bowels, there would be danger not only of producing great debility, and thereby of counteracting the intention of the medicine, but likewise of destroying the animal, by bringing on an inflammation of the bowels; and this is by $n o$ means an unusual occurrence. should the first ball not operate sufficiently, a stronger may be given after an interval of a few days:

* Mír. John Lawrence recommends from one ounce and a Buiti to fourteen drams of succotrine aloes, as a moderate dose for a race-horse, a dose which I am sure would in many horses prove very injurious; and as a reruedy tor that kind of colic or gripes which often kappens froms 100 strong a dose of plysic, or from i.ad managoment during its operation, he recommends in slight cuses a cordial ball, and in more serious cases cimptior dissolved an a small quantity of gin, with vil of atuber, and balsam of curpivi and Per's, all of them powertul stimulants, and very likely is such cases to praduce inthinnation in the bowels. Whenerer Ghorse appears sick and griped atter taking fhysic, or, as the ahove author properly describes lim, langing down his head, refuring his fnod, appearing as if swollen in the carcase, heaving

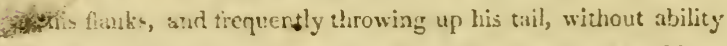
(') evacute, all medicines of as stinuleting quality should be woidul, the stritglat get should be empticd by the hand, and efterward clystets of water-griud, vith olive or linseed nil, should Tie injected. The hose should be allowed to drink frequently of warm water, or thin water-gruel; and if he refuse 10 drink, it is atsolutuly necessary to drench hin several times a dity. These matas, assisted by walking excrise, will soon bring on an cratcuation, aird the horse with be relicved. It is often supposed twet 
The morning is the best time for giving a purgative, the horse having previously fasted two or three hours. If he be clisposed to drink after taking the ball, give a moderate quantity of warm water, which will promote its solution in the stomach, and consequently expedite the operation. During this day the horse is to be kept in the stable, and fed with bran mashes and a moderate quantity of hay: he may be allowed also to drink plentifully of warm water; and if he refuse it in this state, let it be offered nearly cold. The following morning he is to be excrcised; and at this time the medicine will generally begin to operate. Should the purging appeat to be sufficient, he need

these unpleasant symptoms are caused by soine bad quality in the alocs. But I am convinced from long experience that it is not so; and I will venture to aflirm that the above symptoms are always occasioned either by too large a dose of alocs, or by treating the lorse improperly after he has taken it. Another ocircumstance may somctimes assist, and that is, the stomach containing too large a quantity of food at the time physic is given, and particularly if the food be deficient in moisture. But this can nerer happen if the directions we have given be duly observed. I have for seseral years employed the Barbadoes aloes very extensively, giving often from thirty to fifty doses in the course of a week; and have formd that, from half an ounce to one ounce may be consiciered as the proper dose. For a delicate blood-horse halt an ounce generally proves sufficient; to a common saddle-loorse, fiveg or six drans; to a waggon-horse, 1 ounce. 
not be taken out a second time; but when the desired effect does not readily take place, trotting cxercise will tend to promote it. During this day also he is to be carefully supplied with bran mashes and warm water. Warm clothing, more particularly when out of the stable, must not be omitted. The next day the purging will generally have ceased, and then -a small quantity of corn may be allowed. When physic does not operate at the usual time, the horse appearing sick and griped, relief may generally be obtained by giving a clyster of water-gruel, and making him drink freely of warm water, assisted by exercise. When the purging continues longer than usual, and the horse appears to be considerably weakened by the evacuation, let the astringent ball be given.

It will be observed, perhaps, that some ingredients, commonly thought necessary in physic, have been omited in the following formula. These medicines have been proved, however, to te perfectly useless. Jalap, though given to the amount of four ounces, will produce very little purgative effect upon a horse; nor will salts or cream of tartar. Rhubarb, however large the dose, will not operate 
as a purgative, though it may be useful in moderate doses as a stomachic.

\section{No. 1.}

Barbadoes aloes,

Prepared natron,

Aromatic poivder,

Oil of caraways,

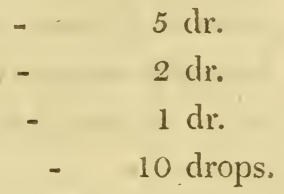

$5 \mathrm{dr}$.

$2 \mathrm{dr}$.

$1 \mathrm{dr}$.

10 drops.

Sirup enough to form a ball for one dose.

No. 2.

Barbadoes aloes,

Castile soap,

Powciered ginger,

Oil of caraways,

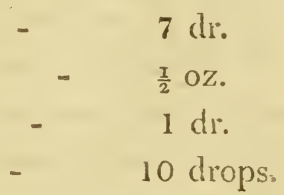

$7 \mathrm{dr}$. $\frac{\mathrm{I}}{2} \mathrm{OZ}$. 10 drops.

Sirup enough to form a ball for one dose.

No. 3.

Barbadoes aloes,

Prepared natron,

Aromatic powder,

Dil of anisis-seeds,

$\begin{array}{ll}- & 1 \mathrm{oz} . \\ - & 2 \mathrm{dr} . \\ - & 1 \mathrm{dr} . \\ - & 10 \text { drops. }\end{array}$

Sirup enough to form a ball for one dose.

The ball No. 2 I have generally found sufficient for strong horses, and have scarcely 
ever had occasion to go further than No. 3. should any one, however, be desirous of a stronger medicine, it may readily be procured. by adding one or two drams of aloes, or one diam of calomel to the ball No. 3 : but I must not oinit to observe, that there appears to me to be a considerable danger in making the aldition.

Since the former edition of this book was published, I have found great difficulty in procuring genuine succotrine aloes, and have often been disappointed by it; I have been induced therefore to use the Barbadoes, and can now recommend it with confidence, in preference to every other kind. The Barbadoes aloe is of a dark brown colour, approaching to blackness, of a strong disagreeable smell, not very brittle, and opaque.

\section{Diuretics.}

These are medicines, which, by stimulating the kidneys, increase the secretion of urine. The following formulse I have found both conrenient and efficacious. 


\section{No. 1.}

Castile soap, - - - $4 \mathrm{oz}$.

Powdered resin and nitre, of each, $2 \mathrm{oz}$.

Oil of juniper, - $\quad \frac{\mathrm{r}}{2} \mathrm{OZ}$.

Linseed powder and sirup enough to give it a proper consistence, to be divided into six balls for strong, or eight for weak delicate horses.

No.2.
Castile soap,

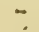
402
Venice turpentine,
$20 z$.

Powdered anise-seeds enough to give it a proper consistence, to be divided into six balls.

\section{Alteratives.}

These are medicines which prociuce their effects almost insensibly : the following formula will be found eflicacious:

ALTERATIVE POWUERS.

$$
\text { No. } 1 .
$$

Levigated antimony,

$-6 \mathrm{oz}$

Flowers of sulphur,

8 oz:

Mix for eight doses. 
No. 2.

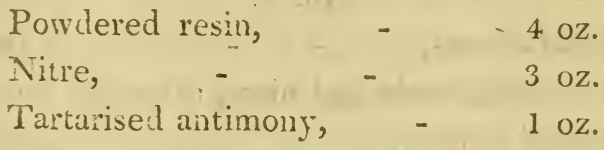

Mix for eight doses.

No. 3.

Unwashed calx of autimony, Ciilomel, - - $2 \mathrm{dr}$.

Powdered anise-seeds, - $4 \mathrm{oz}$.

Should a ball be thought more convenient than a powder, the change may be easily made by the addition of sirup and linseed powder.

A dose of the alterative powder should be given every evening with the corn until the whole quantity (that is, eight doses) are used.

But the puwder No. 3 should not be continued so long, on account of the calomel which it contains, unless the horse be taken great care of, and the effects of the medicine carefully watched. Whenever it is observed to vccasion sickness, griping pains, loss of appetite, or purging, it should be immediately discontinued, until these symptoms go off. 


\section{Laxatives.}

This term is applied to opening medicines that operate rery mildly, and produce so gentle a stimulus upon the intestines, as merely to hasten the expulsion of their present contents, without increasing their secretions. Castor oil seems to be the best medicine of this kind, though the oil of olives or of linseed will produce nearly the same effect. The dose of the former is about a piut; but the latter may be given to a pint and a half. When a laxative ball is required, the following will be fornd useful:

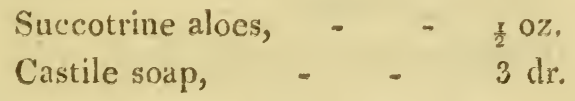

Sirup enough to form a ball for one dose.

\section{Blisters.}

Previous to the application of a blister, the hair should be cut from the part as closely as possible, the blistering ointment is to be well rubber on it, and afterwards a small quantity is to bè spread orer the part with a warm knife. When the blister begins to 
operate, horses are very apt to bite the part, which, if suffered, might produce a permanent blemish. It is necessary therefore to guard against this accident by putting what is termed a cradle about his neck, or by tying him up. to the rack. When the legs are blistered, the litter is to be entirely swept away, as the straw might irritate the blistered parts.

\section{BLISTERING OINTMENT.}

\section{No. 1.}

Spanish flies, powdered, - $\frac{2}{2} \mathrm{oz}$. Oil of turpentine, - $\quad$ - $1 \mathrm{oz}$. Ointment of wax or hog's lard, $4 \mathrm{oz}$. Mix.

No. 2 .

Oil of turpentine, - $\quad 1 \mathrm{oz}$.

To which add gradually,

Vitriolic acid, - $\quad 2$ dr. Hog's lard, - - - $40 z$.

- Spanish flies, powdered, - $1 \mathrm{oz}$. Mix. 


\section{No. 3.}

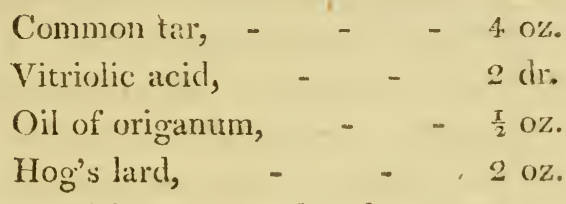

Spanish flies, powdered, $1 \frac{x}{2}$ or $2 \mathrm{oz}$.

Add the vitriolic acid gradually to the tar, and then the rest of the ingredients.

Remark.-The blister No. 3 is remarkably useful in removing enlargements of the back sinews or windgalls. It is necessary to be very careful in mixing the vitriolic acid with the tar; for unless they are intimately incorporated, the acid will act as a caustic upon the skin, and produce ulceration. I hare seen horses suffer severely from this, particularly when in blistering the legs it has been applied also to the back part of the pastern, or to the - heel, a part that should always be protected from the action of the blister, by haring some hog's lard smeared over it; being so irritable that a blister sometimes causes ulcers; which in this part are difficult of cure. Sublimate is often recommended as an ingredient in blisters, but it is very apt to ulcerate the skin, and 
leave a permanent mark or blemish. I have therefore omitted it in the abore formula; but in cases of bone sparin, in which severe blistering is nccessary, it may be employed with advantage. I have for some time employed the following blister for common purposes, and find it more conrenient than the others.

$$
\text { No. } 4 .
$$

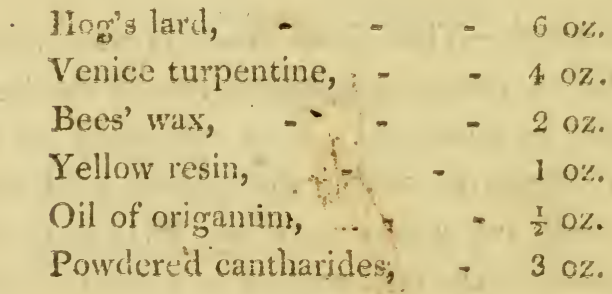

Melt the first four ingréients; and wher removed from the fire, and not too hot, stir in the oil of origanum and cantharides: continue stirring until cold. Should this blister become too hard in winter, it may be softened by rubbing it. with a little oil of origanum or turpentine, in a mortar or on a slab. 


\section{Eomentations.}

Fomentations are commonly made by boiling wormwood, soutrieturood, camomite flowers, and bay leaves in water, so as to make a strung decoction, which, being strinined off, is to be applied as hot as it can be, witnout giving pain to the animal, by means of large flannel cloths. The efticacy of fomentations depends in great measure on thcir use being continued for a considerable time together, and being frequently repeated.

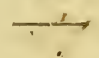

\section{Poubticé.}

The following mixture will be found useful as a common poultice: fine bran 1 quart; pour on it a sufficient quantity of boiling: water, to make a thin paste; to this add of linseed powder enough to give, it a proper consistence.

\section{Roreels.}

When these are used with a view of relieving internal inflammation or fever, it will be . found useful to apply blistering ointment 
instead of turpentine, or the digestive commonly made use of, for this will produce a considerable degree of inflammation in a short. time.

\section{Clysters.}

A variety of compositions have been recommended for clysters by those who have written on the subject, there being scarcely an article in the Materia Medica that has not been occasionally employed in this way. I have found, however, from considerable experience, that for a common clyster watergruel is as efficacious as the most elaborate composition. When this cannot be readily procured, I have been in the habit of using warm water, and without perceiving any difference in the effect. Where a purgative - lyster is required, from four to eight ounces of common salt may be added; and if an anodyne be wanted, or an astringent, let half an ounce of opium be dissolved in a quart of water-gruel. The best method of administering clysters is by means of a bladder and pewter pipe. If a clyster be employed for the purpose of emptring the large intestines, 
or of purging, the quantity of liquid should not be less than a gallon, or six quarts; but when it is used as an anodyne or astringent, froin a quart to three pints of liquid will be sufficient.

s. Pulse.

In the managrement of sick horses great advantage may be derived from attending to the state of the pulse, as we are thereby enabled to judge of the degree of violence of the discase, and the probability there may be of recovery: we are in some neasure assisted also by it, in ascertaining the nature of the complaint, and the application of remedies.

In a healthy horse the pulsations are about 36 or 40 in a minute, and may be felt very distinctly either on the left side, or in an artery which passes over the lower jaw bone; in short, pulsation may be felt in erery superficial artery. When the brain is oppressed, the pulse generally becomes unusually slow. In a case of water in the brain, which occurred lately, the pulse fell to 23 in a minute; in the progress of the discase, howerer, it became unusually quick. 
When a horse appears rather dull, and does not feed properly, it is advisable to examine the pulse, and if it be found to exceed the standard of health, immediate recourse should be kad to bleeding. By this timely interference many iangerous complaints may be prevented. When the pulse rises to 80 or 90 in a minute, there is reason to be apprehensive of danger; and when it exceeds 100, the disease frequently terminates in death. 


\section{CHAPTER IX.}

Condition.

By the term Condition is to be understood not merely a fat and sleek appearance in a horse ; it implies also a proper degree of vigour, by which he is cnabled to perform extraordinary labour, without being too much fatigued. Every defect with respect to condition must originate either in disease, or in bad grooming. Under the latter head must be comprehended feeding, exercise, and the general management of the stable: the former will include rarious disorders, which will be concisely described, and the most effectual means pointed out for their removal.

In treating of the anatomy and physiology of the internal organs, an explanation has been yiven of that curious process by which the body is nourished, and enabled to perform its various functions with regularity. Thence it will appear, that in order to produce that de-

VOL. I. 
gree of vigrour and general healthiness of appearance which constitute good condition, it is necessary that these organs should be in a state of health, and that no impediment should exist to the performance of their functions. This, however, sometimes happens; we shall therefore proceed to show the various imperfections which tend to prevent a horse from acquiring condition.

1st. Tenderness in the mouth, preventing the horse from masticating fiecly.-It sometimes happens that the molar teeth or grinders wear so irregularly, as to have sharp edges, by which the inside of the cheek is wounded: the pain which the act of chewing occasions in this catse induces the horse to swallow some wirt of his food unbroken, which, being difficult of digestion, frequently passes through the body unchanged. This defect is particularly inconvenient in horses that are separated from others by bails only*; as in barracks their more active neighbours have an opportunity of sharing their allowance. This complaint may be removed by rasping down the sharp edges of the tecth, for which pur-

* See further remarks on bails in the subseçnent section, "The Stable." 
pose there are files made by veterinary instrument makers, and by applying to the wounded cheek the following mixture:

Powdered alum, - $\quad-\quad \frac{7}{2} \mathrm{oz}$.
Honey, - $-2 \mathrm{oz}$.
Vitriolic acid, (strong)
Infusion of roses, - 12 drops.
Mix.

It will be necessary, until this defect is completely removed, to give the horse broken corn, which may be more easily digested. It has sometimes been found necessary to remove. a projecting tooth before the horse can be relieved, for which purpose a large strong tooth instrument is made.

When young horses are cutting their teeth, the mouth sometimes becomes inflamed and tender. This is another circumstance which may impede mastication, but is easily remcred by washing the inflamed parts frequently with the above mixture. Should a slight degree of fever supervene, bleed moderately, and give a dose of the fever powder. The corn which is given should be either soft- 
ened by steeping it in boiling water, or be broken in a mill.

The lampas is said to be another impediment to feeding (See Lampas), and is therefore removed with a red-hot iron. This operation is certainly performed much oftener than is necessary.

2d. Weukness of the stomach or bowels.Horses that have acquired the vicious habit termed crib-biting, suffer great inconvenience from the waste of saliva which it occasions; the stomach, being in great measure deprived of this liquid, performs its functions imperfectly; hence arise flatulent colic or gripes, general emaciation, and debility. The remedy commonly employed is a leathern strap, buckled tight round the neck, inmediately beneath the jaw. This, howerer, is seldom effectual. A better method is to cover the elge of the manger, and every other part he can lay hold of, witl sheep skins, (the wool side ontwarl) until the habit is destroyed. There are other causes by which the energy of the stomach may be impaired. Anong these are excessire fatigne, bad foid, defoct in respiration or breathing Eond air, taniug tro much food or water at once. 
or at any improper time, bots, fever ; in shore the stomach is so important an organ in the inimal system, that scarcely any part can be materially injured without affecting it in some degree; and whenever the stomach is hurt, the whole system seems to sympathise and partake of the injary.

Weakness of the stomach is sometimes rey easily cured. The powers of nature indeed are often capable of restoring its tone: at others we fund the disease extreneiy ubstinate, resist. ing the nost powertul medicines. 'This difference depends upon the rariety in the causes by which the weakness is induced. When it arises from loading the stomach with improper food, that contains scarcely any muriment, such as straw, and where the horse has been fed in this way for a consilerable time, the diet should be gradually changed to one more nutritive. During the time we are making this alteration, it is generally necessary to give one or two doses of laxative medicine, joined with aromatics (See Laxatives), to prevent infammatory affection of the eyes, lungs, or heels, or, according to the more fashionable langua ge fooms, to prevent humours from break-

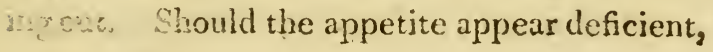


the cordial ball will be found of great service, given occasionally. When excessive fatigue is the cause of the weakness, which we often find after a hard day's run with the hounds, nothing is so effectual as the cordial ball, particularly in old horses: it soon gives them an appetite, and renders them fit for work again nugh sooner than they would otherwise be. Where a speedy effect is required, the ball may be mixed with a pint of good beer or ale.

If a horse, after sweating from exercise or any other cause, is allowed to drink fieely of cold water, the stomach is suddenly debilitated, and the whole system is affected in consequence; hence arise flatulent colic, suppression of urine, shirering, quick pulse, and other symptoms of fever. (For the remedies, consult the Index.)

The stomach sometimes becomes weak gradually, and without any apparent cause. This, is first indicated by the appetite failing, which is soon followed by general debility, emaciation, and an unhealthy looking coat. The most effectual remedies in this case are the tonic balls and a nutritious diet; corn should be given more frequently than usual, but in small quantities; and a little malt on these occasions is 
extrencly useful. The stable should be well ventilated, but not cold; regular exercise will also be very beneficial, and should never be onitted. It should be understood, howerer, that, although exerrise teids to promote strength, if carried beyoud the anmal's power, it becomes a cause of debility: it is highly neccssary, therefore, when a horse is in a state of weakness, to take care that his exercise is but moderate.

Worms in the stomach and bowels are a frequent cause of leanness and debility in horses; and while they exist, every exertion to promote condition will be ineffectual. (See Worms.) A defect in the organs of respiration will also produce weakness and emaciation.

If the blood be not duly supplied with that vivifying principle, which is derived from the air by breathing, a greater or less degree of debility must be the consequence; hence a want of tone is always observable in the stomach and bowels of broken winded horses, as well as a deficiency in the muscular power in general. The same evils will result from keeping a horse in too close a stable, where the air dues not contain the usual proportion of this principle. 
3d. Imperfection in the liver or pancreas, or olstruction in the tubes or ducts, by which their respective juices are conveyed to the boincls. (See Anatomy of Internal Organs.) The liver is rot often diseased in the horse, unless it b. from internal inflammation. When the ex. icrior surface of the bowels or stomach is attacked by inflammation, it will spread, if not speedily checked by bleeding, \&c., to the surface of the liver, and other internal parts; and when horses die from this disease, which they often do from inproper treatment, the liver is generally found inflaned or mortified throughout its whole substance: but this is an acute disease, and therefore not connerted with the present subject. (See Inflommation of the Liver.) It sometimes happens, howerer, that a horse becomes weak and lean, eitier from a deficiency or a redundancy of bile. In the former case, digestion will be imperfect, and the horse frequently costive; the appetite will be bad, the aninal languid and sluggish, and generally hidebound, the coat looking rough and unhealthy. The best renedy in this case is to give small doses of calomel, soap, and aloes, as recommended in jaundice, so as to keep the bowels in a more 
open state; or if the disease have existed some time, give in the first place a mercurial purgative, and afterward the following alterative:

Calomel, - $\quad$ - $\quad 1$ scruple. Aloes, - - - $1 \mathrm{dr}$.

Cascarilla powdered, and rinubarb, of each,

$$
\{2 \mathrm{dr} \text {. }
$$

- Ginger,

Castile soap,

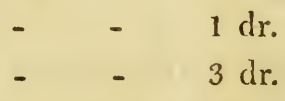

Sirup enough to form a ball, to be given every morning for five or six days, unless it: occasions purging, in which case it is to be discontinued for two or three days.

The horse's diet should be light and nutritious, consisting of ground oats, carrots, malt, zc. : regular exercise is of great use. In the spring or summer, a run at grass is the best remedy. When there is too much bile formed, it occasions a loose state of the bowels, which. causes the horse to become weak and thin. This complaint depends upon increased action. of the liver, which generally ceases in a short time without the aid of medicine. Should the: purging continue so as to reduce the animal's strength, the following medicine may be given, 
and assisted by a light nourishing diet, and very moderate exercise.

Powdered columbo root,
Cascarilla powdered,
Prepared natron, $\begin{aligned} & 1 \mathrm{~d} \text { dr. } \\ & \text { Opium, - } \quad-\quad 2 \mathrm{dr} \text {. }\end{aligned}$

To be given every morning.

There are no external appearances by which a diseased state of the pancreas can be ascertained, though it is probably sometimes a cause of ill condition. There is reason to believe that want of condition depends in some cases upon an imperfect action of the lacteals, or those delicate vessels which convey the chyle, or nutritious parts of the food, into the blool. All the interual surface of the bowels is covered with very minute orifices, which are the mouths of the lacteals, and are supposed to be always open, to teceive such parts of the digested food as are destined for the nourishment of the system. It is not improbable that these minute orifices may sometimes be obstructed, or that the lacteals may be deficient in energy. Therefore when a horse continues thin and ill-conditioned, withont 
any apparent cause, this may be suspected; and the success we have often met with in such cases, by giving a mercurial purgative, joined with a moderate stimulant or stomachic medicine, seems to justify the opinion. The following formula may be employed on this occasion :

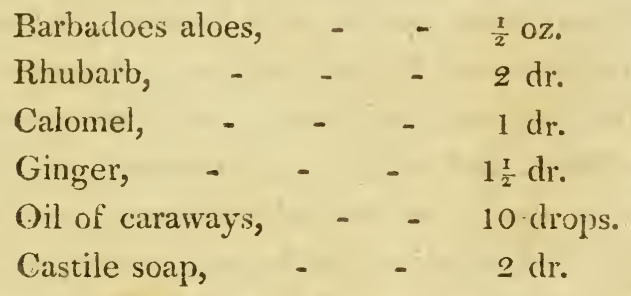

Sirup enough to form a ball.

I should have observed before, that we sometimes meet with horses, particularly those of the blood kind, that have an almost habitual looseness or diarrhera and some that cannot bear even moderate work, or even drinking freely of water, without becoming loose in the bowels, and consequently weak and faint. Such horses are generally observed to sweat much with the most moderate exercise, and sometimes when standing in the stable. This complaint is sometimes merely temporary, and 
is most likely to happen in the early part of spring, or about September and October; at which periods some changes are generally raking place in the coat, by which the bowels, and often the whole system, are rendered irritable and weak. In this case, the symptoms generally disappear with the cause; but as a horse may remain in this situation a considerable time, and be unfit for work, it is advisable to call in the assistance of medicine. The first medicine to be given is a stomachic laxative, and after that the tonic ball. The horse should be clothed moderately, and exposed as little as possible to a current of air: but the stable should be well ventilated, and his water at the summer temperature, that is, about 50 degrees by Falırenheit's thermometer. His exercise ought not to exceed a walk: but he may be taken out twice a day, if the weather be favourable. With respect to those horses that are habitualiy weak, or rashy as it is termed, becoming loose and weak from moderate work, or other trifling causes, there is no great chance of radical cure: but the animal will derive great benefit from medicine and care, and often be enabled to do his work wisth spixit, and without much inconveniences 
The proprietor of such horses should always, be provided with the following cordial, which should be given, not only when the looseness and weakness actually are present, but at any time when considerable exertion is required of him. If he be wanted for a journey, or a day's hunt, let him have a ball a little before he sets off, and another when he returns. If the horse be very young, it nay be worth while to attempt a radical cure, by a long run at grass. Horses of this description require great attention from the groom: they should never be exposed to the air without clothes, unless in the hot days of summer. Their water should be always at summer temperature, and given in small quantities often. Their food should be easy of digestion, their oats and beans given in a broken or bruised state, and their daily allowance should be dirided into four or five feeds. Their hay should be of the best quality : mow-burnt hay is particularly injurious. A brisk circulation should be kept up in the skin and extremities, by frequent wisping the body, and handwubbing the legs. Moderate exercise is necessary; and the horse should always be attended. 


\section{COMPENDIUM OF THE VETERINARY ART.,}

to the moment he comes into the stable, either from work or exercise. (See next chapter.)

STOMACHIC PURGATIVE.

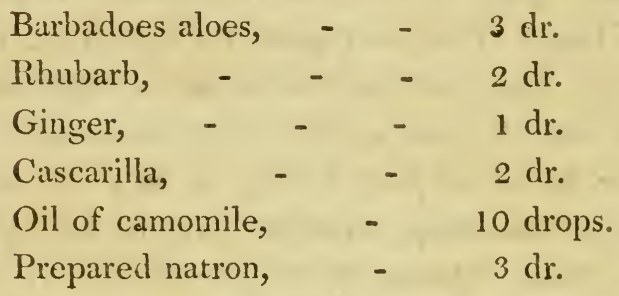

Sirup enough to form a ball for one dose.

\section{TONF BALL.}

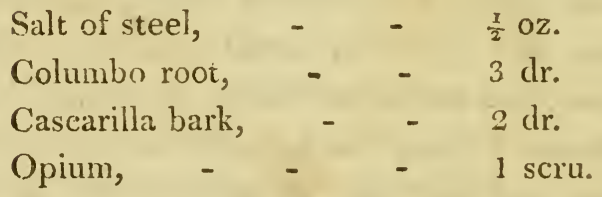

Sirup enough to form a ball for one dose.

Remark. - Arsenic is an excellent tonic,. but must be given with caution, and in small doses. (See the author's second volume, or Materia Medica, where a great variety of forsnulæ for tonics are given.) 
CORDIAL BALL.

Caraway seeds, recently powdered, $2 \mathrm{dr}$. Winter's bark, powdered, - $3 \mathrm{dr}$. Prepared chalk, - - - $2 \mathrm{dr}$. Opium, - - - - $\frac{1}{2} \mathrm{dr}$. Oil of anise-seeds, - 20 drops.

Sirup enough to form a ball for one dose.

Having given a short account of the diseases or imperfections which prevent a horse from acquiring Condition, it remains for us to point ont what kind of Stable Management or grooming is most conducive to his attaining it; and as a good stable is the first thing to be attended to, and is generally allowed to have considerable influence on the health and condition of horses, it will not perhaps be thought superfluous if we say a few words on this subject.

\section{The Stable.}

In the construction of a stable, there is perhaps no circumstance more deserving 
attention than that of ventilation, or of having contrivances for the ready admission of fresh air, and for the escape of that which has been rendered impure by breathing; and it is really extraordinary that so little attention should have been paid to so important a circumstance. Grooms in general make a point of closing every aperture they can find; and if at any time they are prevailed upon to open a window, it is commonly so small, and so inconreniently situate, as to be but of little service. Let any one for a moment consider how foul an atmosphere must be produced, in a close stable in which several horses are kept, by the constant exhalation of unwholesome vapours from the litter, by the steams of perspiration from the skin, and by noxious airs from the lungs; and he will not be surprised at the long catalogue of diseases, to which this improper treatnrent must subject these useful :tnimals.

If a doubt remain in the mind of any one as to the impropriety of such close stables, let him enter one early in the morning, on its being first opened, and he will experience such a painful sensation in the eyes, and so. violent a cough, as will afford him the most 
convincing proof of the noxious and stimulatiug nature of such an atmosphere; yet such is the obstinacy and ignorance of grooms in general, that they cannot be prevailed upon to abandon this injurious practice. Even at this time stables are generally built too low, and miprovided with effectual means of ventilation.

A stable should be as lofty as it can be mads conveniently, at least twelve feet; the foul air will then circulate in the higher parts, and the animal will not be constantly breathing an unwholesome atmosphere, which he must do when the ceiling is scarcely higher than his head. Proper apertures must be also made in the ceiling, communicating with the atmosphere by square wooden tubes, so contrived as not to admit the rain into the stable: the foul air and other univholesome rapours will then readily pass off, while a proper quantity of fresh air may be admitted by means of windows. The next circumstance to be attended to is nearly connected with, and not less important than, ventilation; namely, the so constructing a stable as to be able to regulate its temperature, or keep the air at any degree of heat that may be thought proper. 
It is generally allowed that a uniform tempervture in a stable is very desirable; and it is certain that many of the diseases of horses are caused by sudden changes in this respect. Even slight variations of temperature, if frequent, are injurious; yet few stables are to be tound where this inconvenience is effectually guarded against. To accomplish this desirable purpose, the windows should be in different sides, so that when a cold wind blows from any point, it may be shut out, while fresh air is admitted by the opposite window. There should be several of the apertures we have described in the ceiling, that they may be occasionally shut either wholly or partially, so that, by means of these and the windows, the temperature can at any season be easily regulated, according to the weather, or state of the horse's health, more accurately if a thermometer be kept - an instrument which appears to me a necessary appendage to a well conducted stable. If during the cold day's of winter the contrivance we have proposed should be found insufficient to raise the temperature of the stable to the desired point, the air may be easily warmed to any degrce 
by means of stores placed on the outside, with iron chimneys passing through the stable.

Light is also a thing of much importance in the construction of a stable; and for the purpose of admitting it readily to every part, the windows should be large and properly placed.

There is no doubt that the eyes of horses are often injured by dark stables; and when a horse is just taken from a dark situation, it is easy to perceive that light at first irritates the eye, and gives pain; and this is more remarkable when he is brought suddenly into the sunshine; nor is it to be wondered at that so delicate an organ as the eye should suffer materially from the frequent repetition of this sudden change.

Though a light stable is desirable, the sunshine should not be allowed to fall on the eyes of a horse as he stands in his stall; nor should the walls or ceiling be of a white colour, as under such circumstances the eyes would be over stimulated, and rendered weak; and when it is considered how liable horses are to diseases of these organs, and how frequently they terminate in blindness, no one will think any circumstance tending to their preservation too 
trifling to be noticed. With regard to the best colour for the walls and ceiling, a stone or clore colour is perhaps to be preferred, and may be made by mixing a little lamp-black, ivoryblack, or blue-black, with the common whitewash.

The door should be larger and higher than we usually see it, for horses are very liable in passing through a narrow or low one, to strike their hips or heads; I have seen some troublesome accidents happen in this way; besides, cven if the hair be struck off about the hips, it is thought a blemish, because it may not grow again; or if it do grow, the hair may be white.

In fitting up the interior of a stable, particular attention nust be paid to the size of the stalls, which should not be less than six feet wide, and the silles sufficiently high to prevent any sort of contact or communication between the horses. I know it will be urged as an argument against this, that they are sociable animals, and thrive better with $a$, companion than when alone; this is certainly true: but, on the other hand, I am convince I from long observation that horses do not feel themselves in solitude, when they are thus 
prevented from touching or playing with their neighbours; besides, if we consider the numerous accidents that happen from low stalls, how frequently they kick or bite, and otherwise injure each other, there can be no doubt I think of the superior advantage of high stalls. At this moment I have under my care a fine mare, who from kicking very high got her hindleg over the stall, and has received a deep and extensive wound, which will probably prove fatal. The stalls should also be of considerable depth, that a horse may not, by drawing back, have the power of kicking those in the adjoining stalls. The method of separating horses by means of bails, or poles, suspended by chains, I think very injudicious; the only recommendation it can possibly have is the little expense that attends it, and its allowing a greater number of horses to stand in a stable. I am convinced, howerer, from what I observed during the time I had the hinour of serving in the royal dragoons, that, notwithstanding these recommendations, they are really in the end more expensive to government than stalls would be; scarcely a day passing without some accicient happening from the bails: many dangerous, and some fatal 
wounds were occasioned by them. I once saw a horse break his spine, or back bone, by endeavouring to rise while under the bail; and several horses lost their sight from being bitten in the eye: but the most serious inconvenience perhaps attending bails is the impossibility almost of feeding every horse equally; some horses feeding very sluwly, and others so expeditiously, as to devour as well as their own great part of their neighbour's allowance in a short time. To this may be added the facility with which contagious diseases are communicated, the disturbance a horse is liable to when fatigued, and the difficulty of lying down quietly.

The floor of the stall should be made of hard brick, as a more equal surface is then formed than can be obtained by paving with pebbles. Very little declivity is necessary to drain off the urine; and as great inconvenience sometimes arises from suffering a horse to stand in a stall where the fall is considerable, creating unnecessary exertion in the muscles of the hind leg, and keeping the ligaments constantly in a tense state, it has been recommended to make the drain in the middle of the stall, whereby the hind and 
fure feet of the horse might stand on a level. In whatever way, however, the stall is made, it should be carefully cleaned once a day, that none of that putrescent matter may accumulate which generates ammonia, or that pungent vipour which is so abundantly found in close filthy stables. An iron rack is preferable to one of wood, being more easily kept clean, and furnishing no splinters; which, where wooden racks are used, sometimes injure the mouth. The manger may be so contrived, as to slide into the wall like a drawer; and then, while the groom is wisping him, he would have nothing to lay hold of with his mouth, by which practice horses often become crib-biters. The heighth both of the rack and manger should be such as to enable the horse to feed with the greatest ease: the former is sometimes made so high, that the horse is obliged to exert the muscles of his neck considerably, in order to reach "it; and this has been so placed, under an illea of its having a tendency to make him carry his head more gracefully : it is more probable, however, that the only effect of it is to make the horse uncomfortable while feeding. It has indeed been lately recommended, as the best plan, 
to place the racks on a level with the manger; so that the horse may feed as he does in a state of nature; but I have had sufficient trial of this plan to be convinced of its being in every respect less convenient and economical than the common rack.

Feeding, Exercise, and Grooming.

These are subjects of considerable impor tance, and require more attention than is commonly paid to them, as the health and condition of horses depend greatly on their being properly managed.

When a horse is in a state of nature, and using only voluntary exercise, there cannot be a doubt that the green food, which the bountiful Creator provides for him, is better calculated than any other to keep him in perfect health, and satisfy his wants: but when he is domesticated, and employed in the various labours for which he is found so essentially useful, it is necessary to adiapt the quantity and quality of his food to the nature of the work he has to perform. When therefor: we mdertake to get a horse into condition, it is 


\section{FEEDING, EXERCISE, AND GROOMING. 263}

necessary first to inquire for what kind of labour he is designed; whether it be for the turf, the chace, or the road. $\Lambda$ horse, without doubt, provided he is in health, may have his condition and wind brought to the highest state of perfection it is capable of, merely by judicious management in respect to feeding, exercise, and grooming; and notwithstanding the great mystery and sccrecy affected by those who make a business of training lace horses, I will ventore to affirm, that it is a very simple process, and easily to be accomplished by any one, who will attentively consider the principles we shall lay down, and not suffer himself to be influenced by an ignorant groom. It is a fact, not sufficiently known perhaps, that the strength of an animal, or any part of the body, may be increased to a considerable degree, by means of exercise properly conducted; and as breathing is effected by muscular exertion, it follows that the strength or perfection of this function, or as it is commonly termed good raind, must depend on the strength of those muscles by which breathing is performed; and by keeping in riew this single principle, we shall do moro for the improvement of a horse's wind, than 
we could by learning all the mysteries of training. In order to have a clear idea of the method of getting a horse into high condition and good wind, let us suppose him just taken from, grass; it being understood, that every horke, who works hard during the other parts of the year, will in summer be allowed this necessary relaxation; without which the feet, as well as the siners, joints, ligaments, \&c., of the limbs, will be liable to suffer materially; and not unfrequently the general health of the animal is injured by such priration. But should any one be so situate as to be unable to procure this renovating indulgence for his horse, he must endearour to substitute for it a large airy stable, where the animal may be turned loose. If he cannot get fresh vegetable food, such as lucerne, vetches (tares), clover, de., he will find carrots a useful succedaneum during this time of rest. The horse should be allowed to drink frequently; and if he be not immoderate, he may be suffered to drink as often and as much as he pleases. He should be fed sparingly with oats; and on no account be allowed beans or any thing of the kind. The hest general diet of the dry kind is, 3) erhaps, a mixture of outs, chopped hay, and 
bran; to be given alternately with green food; or if a sufficient quantity of green food can be procured, very little dry meat will be necessary. This treatment will serve in some measure as a substitute for a run at grass, provided the stable be large and airy. The light also should be freely admitted; and if a convenient court be aljoining to the stables, the horse may be suffered to run in and ont at pleasure: but if there be nothing but the stable for him to run in, it will be proper to walk him out quietly erery morning and evening, allowing him to drink freely in a running stream or river; the feet, diring this time, should be kept cool and moist, for whichi purpose they may be stopped daily with a mixture of soft clay and cow-dung. When a horse is taken from grass, or from the situation and treatment we have just described, in order to be got into condition for racing, hunting, or the road, the first object of attention is to bring about the necessary change in his food, and other circumstances, as gradually and with as little inconvenience to the animal as possible. If he be taken from grass, let lim be put at first into a large airy stable, and suffered to exercise himself in it 
Let him drink fiequently; and, instead of depriving him suddenly of his green food, allow him at first some carrots, with bran, and a moderate quantity of oats. He should be walked out once a day at least. His allowance of oats should be gradually increased, and that of bran and carrots in like manner diminished, until the latter is wholly discontinued. If he be a large drinker, he should be allowed bue a moderate quantity at once; but at all times, and in aimost all circumstances, it is proper to allow a horse water four times a day; which, instead of oppressing his stomach, or injuring his wind, will facilitate digestion, and matcrialiy conduce to the preservation of health, and the improvement of condition. I am aware of the prejudice that exists against this practice-that it is supposed to give a horse a large belly, and render lim unfit for galloping any length of time, without endangering his wind. I am convinced, however, not only by my own experience, but by that of some experienced sportsnien also, that, so far from injuring a horse ib any one respect, it is extremely beneficial; and that, when a horse is allowed to drink four or hre times a day, he is not in- 
clined to drink much, and often does not drink so much in the twenty-four hours, as one that is allowed to drink only twice a day as much the pleases. As the horse's allowance of outs is increased, so should his exercise be ; and if this be properly managed, there will be no absolute necessity for bleeding or medicine. It is necessary, however, to observe the horse carefully during the time we are increasing his allowance of oats, and diminishing that of carrots and bran; and if he appear dull, or have a cough, however trifling, it indicates an inflammatory disposition of the body, and points out the propriety of moderate bleeding, or a laxative. But under proper management I do not think such symptoms would ever take place, though they almost always do when a horse is changed from grass to a close stable and dry food too suddenly; and in such cases both bleeding and purging are indispensably requisite to prevent the occurrence of very serious discases. It is from this circumstance, perhaps, that the absurd custom of giving exactly three strong doses of physic, as a necessary preparative, took its origin. When a horse has been taken from grass about a week, I think it advisable to 
grive him a very mild purgative, such as No.1 (See Physic); not that I am conrinced of its being absolutely necessary, but because it cinnot do any hurm; and it the horse bave been fed too liverally, or not exercised suificiently-or should the stomach and bowels be out of order, or have any worms in thema mild purgative will be of great service. It is on this ground that $I$ always recommend two or three doses of mild plysic during the time a horse is getting into condition; but 1 have seen so many instances of the injurious effects of the strong physic recommended in many books of farriery, and commonly given by grooms, that I think it necessary to advise the reader never to suffer his groom or smith to prepare or prescribe a dose of purging medicine. That such strong doses are often giren without any immediate bad effect, is no proof of their innocence, still less of their utility. I can truly assert, that I have secn many liorses quickly destroyed by strong physic, and a great number that have never perfectly recovered from the debility it occasions *.

* A valuable blood-colt was attacked with colic, which appeared to be of the flatulent kind, and, though violent, not 
During the first week of the horse's being taken into a stable, walking exercise is most proper; but after this it may be gradually incredsed to a trot or canter; and if the exercise occasion any degree of perspiration, he should be carefully cleaned, and otherwise attended to, as soon as he grets into the stable.

By thus gradually bringing a horse from a statc of nature, that is, from the open air and green food, to a comfortable stable and dry grain, he will be in little danger of those troublesome diseases, which are often the con-

dangernus. The usuel remedies were inefiectually employer; and it was found, in attempting to give a clyster, that the internal cont of the git was so loose and so cularged, that there was no possibility of injecting it: the colt died athont sixteen hours after the attack. On evanining the body after death, all the bowels ware fotiid neatly heuthy, except the rectum, or last gut, natar us termination, in which the inner crat was so loose and large, that the cavity was nearly obliterated, and scarcely any passage leat for the excresent. The internal sensible coat of the stoniach appeared elso in a distessed state, being very tender, and easily separated; but it was not inflamed. About at week atter, I was accidentaliy intormed, that the man who had the care of this coit, and was about to train him for the turi, had given him three doses of physic; and that the "last had oper. ated so well, that he thought the colt would never have ceased purging." This was nearly the man's expression, which he had communicated, in the way of consersation, to a groom, betore the colt was taken ill. 
sequence of sudden changes, and of a different kind of management; and by duly proportioning his exercise to the nutriment lie receives, and by gradually bringing the mus. cular system to that degree of cxertion for which the animal is wanted, there is no doubt that his wind, strength, activity, and grencral condition, will be brought to the highest state of perfection it is capable of attaining. In describing the general management of horses in the stable, we thiuk it necessary to be very particular, as there are many apparently trifling circumstances which have considerable influence on the horse's health, though genewally little attended to.

Horses employed in lunting, mail or stagecoach horses, in short, ail that are obliged to undergo great and rupid exertion at certain periods, require a different treatment from such as work more moderately. The former have occasion for lying down as much as possible, that the muscles may the more readily. recruit their strength. But the latter do not require so much rest in a recumbent state, and suffer no inconvenience from standing during the day; therefore their litter should be removed every morning, and shook up in 
FEEDING, EXERCISF, AND GROOMING. 273

the open air. The advantages of this plan are considerable, though it may be thought by knowing grooms an unnecessary trouble. The feet will be thus kept cool; and the hoof will not be so disposed, as it commonly is, to. contract or shrink; for straw, being a bad conductor of heat, causes the feet to become too hot; in which state the horny matter has always a tendency to. contract: hence arise sand-cracks, thrushes, \&c. Unless a horse has thin flat soles, it is always proper to siop the feet, as it is termed, with a mixture of cow-dung, beaten into a smooth mass with a Jittle fine clay, and a small proportion of potash. The feet should be examined daily; and if the soles should appear to be softened too much, that is, if the horn bends or gives way in the least under the thumb by the strongest pressure we can inake, the stopping must be discontinued.

Horses that have been acclistomed to stand on litter during the day sometimes feel a difficulty in, or reluctance to staling, when they are deprived of it. In such cases, a little straw. should be thrown under the belly, so as to prevent the urine from splashing about their. legs. 
The best food for horses that work hard is oats and hay, with a moderate quantity of beans. The latter, however, should not be allowed, unless the horse's work be considerable, as under moderate exertion they dispose the system to inflammatory complaints, such as conghs, inflamed eyes, \&c. I am convinced that horses whose labour is severe are often injured by being stinted in water, particularly when they are allowed a large quantity of food. It is a common practice with wagyoners, when their horses come in from a long and fatigning joumey, their strength almost exhausted by long-continued exertion and sweating, to offer them inmediately in mlimited quantity of fuod, and very little (most commonly not a drop) of water. Under such circumstances, the stomach is not able to digest the food that is taken in; and I firmly believe that the stagrers are often the consequence of such mankigentent. When a horse comes in from a long journey, he should always be allowed a small quantity of water before he is fed; and if he be alluwed a little immediately after. feeding, it is more likely to promote digestion, and prove bereficial, than to injure, the animal. It is certanly a good plan, to give 
horses a moderate quantity of water just before the end of their journey; and I am satisfied that, by allowing them to sip a little water several times during a long journey, particularly in warm weather, they are refreshed and invigorated, but never injured. When beans are given to a horse, they should always be broken; and it is probable that oats would be more nutritious in that state. A horse that works modcrately does not require more than a peck of good oats, and about twelve or fourteen pounds of hay in the twenty-four hours: but large draught horses require a greater quantity both of oats and hay.

Horses employed in hunting, for expeditious travelling, require great attention as to grooming, fceding, \&c. Their allowance of hay should not cxceed twelre pounds in the twenty-four hours; and it should be divided into three feeds - four pounds in the morning, two at noon, and the remainder at night. If a peck of oats be allowed for tise same period, it should also be divided into at least three feeds, giving water before epch. When a larger allowance of grain is required, which must be the case with hunters, posthorses, - \&c., either the quantity of oits may. 
be increased, or a certain proportion of beans may be added; but on no occasion should the quantity of hay be increased for horses of this description. I think there would be no danger, and perhaps great advantage, in allowing horses that work hard, either in hunting, posting, or in mail or stage-coaches, an unlimited quantity of good oats, with a moderate proportion of beans, provided it be given at several times, so that they may not load their stomachs, and injure the digestive power. If any other food be given with the oats and beans, which however appears needless, it should consist of clover-hay, cut like chaff, and a small quantity of fresh bran: the former, if not cut too short, will make him rnasticate his food more perfectly, and cause it to be digested more easily: but when a horse has any kind of cough, or is imperfect in his wind, neither cut hay, chatf, nor bran, should be given, as they are apt to irritate the throat, and excite coughing; and it is necessary also in this case to sift the oats, and shake the hay, so as to free them from dist, as this. will often occasion a violent cough for a time, and aggravate the original complaint. This. will be more effectual, if the oats and hay be 
slightly moistened with water. Horses of this description being generally greedy of water, and so voracious as to devour their litter if kept from hay, it is advisable to muzzle them immediately after feeding. Some advantage also will be derived from giving them a moderate quantity of carrots now and then, particularly when their work happens to be but moderate, this regetable being nutritious and easy of digestion.-Much has been said by writers on farriery respecting the kind of water that is most wholesome for horses. The greater part seem to prefer pond-water, where the bottom is composed of clay and chalk. It appears to me, that the most desirable kind of water is that which horses like best, provided it be not too cold; and I think it probable, that the ill effects, that have sometimes been produced by drinking certain kinds of water, have not been occasioned by foreign or impure matters contained in it, but merely by its coldness; and I have found it the best plan to give clear river water in summer, and well water in winter; the latter being warmer in cold weather than water exposed to the air, and colder in summer. Some old author (I think Dr. Bracken) has expressed a suspicion 
that the hardness, as it is termed, in well water, might occasion the stone or gravel. This is a disease, however, that scarcely ever happens -to horses, though we sometimes meet with stones of a large size in the bowels, formed gradually by the earthy matter taken in with the food; and if they were subject to calculous diseases like men, it is almost impossible that the very small quantity of stony matter contained in hard water could have any share in their formation, being quite of a different nature from that foum in the human bladder. It seems to be generally known, that brackish water 'that is, water impregnated with saline matter, which is commonly met with near the sea) is rather injurious to horses, causing a rough dry coat, and loss of condition. This, perhaps, is not occasioned by any direct operation of the saline matter which such water contains, but by the horse not dimking a sufficient quantity, on account of its umpleasant taste, for the purpose of ligestion.

It is by 110 means advisable to accustom horses to warm water in winter, or to let the water stand many hours in a warm stable, so as to become nearly as warm as the air of the stabie; is it makes the horse liable to the. Hit- 
tulent colic or gripes, whenever he happens to drink cold water.

In sickness, and during the operation of physic, when it is absolutely necessary to allow warm water, it should never be discontinued suddenly: the change should be brought about as gradually as possible. It is not a good practice to give hurses nitre and other medicines in their water or food, because the dose cannot be accurately ascertained in this way; and the water, instead of promoting digestion, often has a contrary effect, exciting nausea, and weakening the stomach. It appears to me a better plan to water horses, during their exercise, at a pond or running stream, than in the stable, except it is in winter; and even then it would be advisable, were it not for the inconvenience they are liable to suffer from standing in the water while drinking: but the common practice of gailoping them immediately after is highly improper.

It has been asserted by some, that horses work better, and wore effc ctually preserve their wind and condition, when allowed only a small quantityof water; or, as they express it, "It matters not how little he drinks, provided he feeds 
heartily." This opinion, like many others, has arisen from the foolish and mischievous practice of forming general rules upon a few facts, or a very limited experience; and too often, I fear, from examining those facts through the medium of prejudice. It must be granted, that we sometimes meet with horses that become loose in their bowels, and fall off in courlition, sweating violently, and appearing fatigued from moderate exercise, if allowed to drink even two pails (five or six gallons) in the twenty-four hours; particularly when they are employed now and then in hunting, or any kind of violent exercise : but this is to he attributed to a weakness of constitution not often met with in horses, and points out to us the necessity of observing a horse attentively when we first undertake the management of him, in order to ascertain what quantity of water is most conducive to the preservation of his health and condition; and if we find a horse shivering, and his coat staring immediately after drinking freely, it is not to be liastily concluded, that he is to be allowed only a small quantity of water claily. In such a case, a very moderate quantity. should be given at once, and the horse shoult. 
FEEDING, EXERCISE, AND GROONING. 281

be exercised immediately after, in which way he will generally be soon brought to drink a proper quantity in the course of the day without inconvenience. The best time for exercising horses is early in the morning, as soon as the stable is opened; eluring which time the stable-doors should be kept open, and the foul litter thrown out. As horses that work moderately do not require a bed in the day time, it will be advisable in such cases to remove all the litter from the stall, and expose it to the air; spreading only a small quantity at the back part, to prevent the horse from splashing his legrs in staling. It will perhaps be thought unnecessary to excrcise horses that work, particularly such as are employed in bunting or expeditious travelling: I think, however, they are always the better for it, provided it be done with prudence. It certainly is not proper to take out a horse for exercise, that is designed for hunting the same day; but in the intermediate days it should never be omitted; and if a horse's work be moderate, such as ten or twelve miles a day, a lixtle exercise in the morning will enable him to perform it better. Horses of a full habit, or such as are subject 
to humours (See Humours), are greatly benefitted by exercise, which on such occasions may be carried so far as to produce sweating. But great care is then necessary: they should be walked about for some time, that they may cool gradually; and as soon as they return to the stable, they should be well wisped, and their legs hand-rubbed. Swelling of the legs, grease, inflamed eyes, and other troublesome complaints, will be thus more effectually prevented than by bleeding every now and then; which, though it afforits temporary relief, will gradualiy increase the dispusition to disease. The exercise which a horse enjoys, when kept loose in a large stall, is particularly beneficial, and should always be alluwed when the stable is sufficiently large to admit of it, instead of being kept constantly in one position, his bead tied to the manger, and his fore leg generally higher than his hind legs: he can then turn limself about, and enjoy comparatively a state of liberty.

In summer, or whenever the weather is temperate, horses should be cleaned in the open air when they return sweating from work or exercise; for, if put immediately into a warm stabie, they often continue to perspire 
FEEDING, FXERCISE, AND GROOMING, 283

so long, as to suffer some injury from it. The common practice, however, of washing the legs with cold water should never he allowed, unless the horse be exercised, or have his legs well rubbed immediately after It is superfluous, perhaps, to point out the impropriety and danger of plunging a horse into a river while sweating from severe exercise, a practice commonly adopted by proprictors of post and stage-coach horses: that it is often done with impunity must be grunted; but it is probable, that many of them suffer from the treatment, though the ill effect is not often immediately observed*.

* It appears, from the experiments of Dr. Currie, that when the heat of the slin is above the natural degree, the application of cold water is highly refreshing aud invigorating; but when the heit of the system has been in some measure exhausted by continued exercise and perspiration, it will generally produce considerable debility; and in the hmmm body the most dangerous conscquences have ensued from it. The same observation applies to cold water taken into the stomach, which on such an occasion has been known to cause sudden death. It is probable, therefore, that many of the diseases of these poor animals arise from the debility which this treatment nccasions; and perhaps the mischief would be greater, were it not that the river or pond is generally at a little distance from the stable, so that they get some exercise immediatcly after their immersion, and that the stable is generally very warm. 
When a horse returns from exercise or work, his feet should be carefully picked out and washed; and if the hoof be dry and brittle, feeling hot, and appearing contracted, a mixture of cow-dung and soft clay should be applied to the soles. The horse's heels also require attention; and if any small ulcer or crack, as it is termed, be observed, or if they be tender, swollen, or smell offensively, the proper remedies should be immediately applied. These things, however, very rarely happen when the groom does his duty. It should be remembered, that when a horse is changing his coat, that is, about the latter end of September, and beginning of October, he is more susceptible of cold than at any other time; and as the coat then falls off so readily, the curry-comb should be laid aside, and the horse exposed as little as possible to cold or rain. Moderately warm clothing, and frequent hand-rubbing to the legs, will be found highly useful at this time. When these preciutions are ncglected, horses often become weak and unfit for much work, sweating profusely from moderate exercise, and sometimes purging: troublesome cough and staring coat generally accompany these 
symptoms. The common remedies on this occasion are bleeding, or strong purgatives, which are sure to increase the debility; noi are antimonials, or medicines that act upon the skin, proper to be given. The most effectual medicines are those of the tonickind, with moderate stimulants (See White's Feterinary Materia Medica); and when the bowels are loose, a small proportion of opium. These, however, will avail little, unless assisted by due attention to grooming. Though we have so strongly recommended rentilation in stables, it must not be inferred that a cold stable is desirable: horses seem to thrive most in one that is moderately warm. I have known old horses, that could not be kept in condition in a cold stable, even upon the highest feed, do well when removed to a warmer one: this, however, is the effect of habit; and it is probable, that if a horse were accustomed, from the time he is first taken up, to a cold stable, he would never require any other: but when from his youth he has been kept in hot stables, his body constantly clothed, and his stomach frequently stimulated by cordials, it cannot be supposed that he is able to endure cold. It is necessary therefore, 
on purcluasing a horse, to discover in what manner he has been kept, and whether he have been accustomed to any particular management; for instance, the custom of giving cordials to horses, after a hard day's hunt, is often rendered necessary by the practice of keeping them without food or water on the morning they are so employed. In describing the peculiarities in the structure and economy of the horse's stomach, we have observed, that this organ is remarkably small, requiring to be supplied frequently with food. When a hunter then goes out with an empty stomach, and is perhaps kept out eight or ten hours without feeding, generally galloping great part of the time, the stomach is so exhausted on his return, that he has scarcely any appetite, and refuses his food, until the stomach is roused by a strong cordial: a habit is thus induced, and cordials, after a time, become as necessary to a horse accustomed to it, as spirit to a dram-drinker.

Yet there surely can be no danger in giving a moderate quantity of oats and water very early in the morning, previous to hunting. If he have to walk four or five miles to cover, there can be no danger of his stomach being 
oppressed by the time lie arrives, nor a donbt of his performing better than he would otherwise have done.

\section{Of the Age of a Horse.}

The age of a horse may be discovered by certain inarks in the front teeth of the lower jaw and the tushes, until the eighth year, about which time they are gencrally worn out. In experienced person can, however, after this period, judge of the age, with some degree of accuracy, by the countenance and general appearance of the animal, as well as by the length of the teeth, and forn of the tushes.

Between the second and third year, a colt begins to change his sucking tecth, as they are termed, for others of a larger size, and of a difierent form and colour. The sucking teeth are small, of a delicate white colour, some of them perfectly smooth on the upper surface; others have a small narrow carity on that surface, but very unlike those marks of the permanent teeth, by which we judge of the age. The number of teeth in the front of the mouth are twelve, six in the lower and six in the 
upper jaw. (We take no notice of the molares, or grinders, as they are not concerned with this subject.) When a colt is three years old, we may observe that the four front sucking tecth are lost, and that, instead of them, four others have sprung up, of a very different appearance, being larger, of a darker colour, and having a considerable cavity on the upper surface, and a small dark coloured groore in front: these are termed horse's or permanent teeth. Between the third and fourth year, the four teeth next these are lost, and replaced, in the way we have just described, by horse's tecth; so that when a colt has completed his fourth yeur, there are eight horse's teeth observable, and only four colt's teeth, one at rach extremity, or corner, as it is termed. About the middle of the fifth year these also fall out, and are succeeded by horse's teeth. "The comer teeth of the horse, particularly of the under jaw, are different from the rest, being smaller, and of a shell-like appearance: their cavities are chiefly within, the-upper surface being a mere edge; but about the end of the fiftn year they are larger and more like the other teeth. It is generally between the fourth and fifth year that the tushes make. 
their appearance, though sometimes earlier.The tushes are four in number, and situate about an inch from the corner teeth; at first they are small, terminate in a sharp point, are lather convex on their external surface, but within have two concavities or grooves separated by a ridge. These, as well as the teeth, are gradually undergoing an alteration in their form, becoming longer, and losing the concavities on the internal surface. $\Lambda$ bout the seventh year the concavity is considerably diminished, and in old horses the surface becomes convex, the tush acquires a round form, and the extremity, instead of being sharp, is quite blunt, as if the point had been broken off, and the new surface afterward polished. We must now return to the teeth, the appearances of which we have described, as far as the completion of the fifth year of a horse's age. After this period wo judge of the age by the size of those cavities which we have described on the upper surface of the tooth; for the friction to which that surface is alnust constantly exposed gradually wears it down, and at length the cavity or mark is totally obliterated. The marks in the upper teeth most commonly remain until the twelfth s.or. 1. 
Year, sometimes longer, but those in the under tecth are worn out about the end of the eighth year; we shall therefore contine cur description now to the under jaw.

As the two front teeth are the first that make their appearance, it is obvious that their marks will be lost sooner than those of the other teeth; and if we examine the mouth of a horse that has just completed his fifth ycar, we shall find, that they are nearly, and sometimes quite worn out: those in the adjoining teeth are about half their original size, while the marks of the corner or end teeth are perfect. At the end of the sixth year, the only carities observable are in the corner teetl, and these are about half their or:ginal size: the tooth has at this perior lost the shell-like appearance we have before described, and is not different firom tw: other teeth, except in having a mark or carity ou its upper surface. At the end of the serenth ycar the marks of the comer tecth also are obliterated, and then the horse is said to be aged. We often find, howerer, that the marks of the corner teeth are $1 \mathrm{nt}$ rotaliy efiaced at this period: a smalt dirk coloured spot may be observed in most lantes 
until about the end of the eighth year. From this period we have no criterion by which the age may be ascertained, but it is said that the marks of the upper teeth will enable us to judge of the age until the thirteenth year; the marks of the front teeth heing worn out when he becomes eight years old, those of the adjoining teeth at ten, and the corner teeth at twelve: but I cannot say how far these marks can be depended upon.

On the Management of a Morse during a Journey.

Previous to setting out on a journey, erery precaution should be employed to bring a horse into as perfect a state of health as possible; as we thereby aroid much trouble and inconvenience. Should he be at all subject to grease or swelling of the legs, a dose of physic is to be recommended, taking are to preserve the heels clean, and to keep up a brisk circulation in the legs by frequent hand rubbing. Should the feet of the horse be tender, it is necessary to enquire into the cause of that tenderness: if it arise from corns, let the directions be followed that are given under that head; if it proceed fiom flat and thin soles, apply tar to 
them, and let the horse stand upon a flat surface, without shoes, by which means they will be rendered thicker and more firm; and when he is rode let the concave shoe be made use of. When thrushes or rottenness of the frog are the cause of the tenderness, cut away the diseased parts, apply tar with a plediget of tow, and upon this place the artifical frog - the natural frog will in consequence soon become firm and solid, and the tenderness will be in great measure removed: if the thrushes be occasioned by a contraction of the heels, which is frequentiy the case, it will then be necessary (c) rasp the quarters moderately; and should they appear to be too strong, wanting a proper degree of elasticity, keep the hoof constantiy woist. Horses that travel during the winter are very liable to have their heels inflamed and cracked, as it is termed, unless great attention is paid to them in the stable. In cases where the heels are already thus affected, they should be washed with moderately warm water as soon as the horse gets in, and afterward carefully wiped dry with a soft cloth; if much inflamed, the astringent lotion is to be applied; and if there be any ulcers or cracks, use the astringent ointment, and let the alterative powder, 
No. 2, "be given occasionally. When a horse's wind appears to be imperfect, he should not be allowed to fill himself with hay or water, and must be prevented from eating his litter, which horses of this description are generally inclined to do, particularly when stinted in hay: in this case costiveness sometimes uccurs, which always increases the complaint. To remedy this, let a clyster and if few bran mashes be given. Too high feeding is also very prejudicial in these complaints, as any thing which tends to create a plethora, and determine too much blood to the lungs, is sure to aggravate the disease. To a horse that purges or scuurs in travelling, and appears faint, sweating much with moderate exercise, give the cordial ball, the efficacy of which is sometimes inereased by being mixed with a pint of ale or strong beer: if the complaint do not give way to this treatment, let the astringent ball be given.

As soon as a horse comes into the stable, let his feet be well cleancd, and all dirt ò gravel carefully removed. It is a very common practice with usticrs, even in winter, to tie the horse up in the yard, that he may undergo the ceremony of having his heels washed with cold water. This should never be permitted 
during the winter, as many bad consequences may arise from it. During hot weather, when the roads are dry and dusty, allow a horse to crink a small quantity of water now and then, while on the road; this not only refreshes lim considerably, but has the useful effect of coolingr and moistening his hoof's, as he will grencrally be made to stand in the water while drinking, nor is there the least danger to be apprehended from it, unless he is rode very hard immediately before or after. In winter he shoukl never be taken into the water if it can be avoided conveniently.

Should the horse appear dull and lose lis appetite, let him be bled moderately, and take a dose of nitre with a bran mash; this, with a little rest, will soon recorer him. It is a common practice, when this happens, to give cordials, which are very improper, and often do much injury to the animal, by bringing on a ferer. Sone horses are particularly subject to the Hatulent colic or gripes; this is often the case with crib-biters; on such occasions it is adrisable to be always provided with a remedy, and, as a ball is the most convenient form, I have given a recipe for the purpose. (See Itatulent Colic or Gripes.) A suppression of 
urine, or great diffeculty and pain in staling, is an accislent that sometime's occurs in tarvelling; and in such cases. a diuretic bull is commonly given, which, though sometines successful, has often done mischief. 'The most effectual way of relieving the horse is by throwing up a clyster, and bleeding molerately: should there be no appearance of infammation in the kidneys, a dose of nitre may also be given. The common practice of loading a horse with clothes, and keeping him in a close warm stable, if he happen to take cold during a journey, is certainly improper, since he is liable to be frequently exposed to wet and cold in trap̧elling. It is a well-known fact, that animals are not lmrt by being kept in any uniform temperatur, whether it be hot or cold; and that their diseases moie commonly arise fiom sudden changes, or frequent variation of temperature.

When a horse becones suddenly lame in trarelling, let the feet be carefully examined. Should the lameness be occasioned by a wound from a nail or flint, apply tincture of myrh or friars' balsam, having previously removed all dirt or gravel from it; and if the wound have been inflicted by a nail, let it be carefully 
opened to the bottom with a small drawing knife, and proper means used to prevent dirt from getting to it.

CORDIAL BALLS.

No. 1.

Cummin seeds,

Anise seeds, and

Caraway seeds, of each, $4 \mathrm{oz}$.

Ginger, - - - $2 \mathrm{oz}$.

Treacle enough to make it of a proper consistence for balls. The dose about $2 \mathrm{oz}$.

No. 2.

Anise seeds,

Caraway seeds,

Sweet fennel seeds, and

Liquorice powder, of each, $4 \mathrm{oz}$.

Ginger and cassia, of each, $1_{2}^{\mathrm{x}} \mathrm{O} z$.

Honey enough to form them into a mass.

The dose about $2 \mathrm{oz}$. 
No. 3.

Cummin seeds,

Coriander seeds, and

Caraway seeds, of each, - $4 \mathrm{oz}$.

Grains of paradise, - $1 \mathrm{oz}$.

Cassia, - - - $\frac{\mathbf{r}}{2} \mathbf{O} Z$.

Cardamom seeds and saffion, of

$$
\text { each, - - - } 2 \mathrm{dr} \text {. }
$$

Liquorice, dissolved in white

$$
\text { wine, - - } \quad-4 \mathrm{oz} \text {. }
$$

Sirup of saffion enough to form a..mass. The dose about $2 \mathrm{oz}$.

$$
\text { No. } 4 .
$$

Powdered ginger, - - $4 \mathrm{oz}$.

Powdered caraway seeds, $8 \mathrm{oz}$.

Oil of caraways, and

Oil of aniseeds, of each, $\quad 2 \mathrm{dr}$.

Liquorice powder, - - $8 \mathrm{oz}$

Treacle enough to form a mass. . 



\section{$A P E N D I X$.}

\section{Obserzations on Ifrounds.}

IN the former editions of this work this subject was treated of rather concisely : further experience has, however, convinced me, that the common method of treating wounds is so drectly in opposition to reason and nature, as . to render a detailed account of the proper mode: of tratment indispensable.

Wounds of the human body, when inflicted with a keen instrument, are often cured, merely by bringing the dirided parts into contact, and keeping thein in that situation by means of suture (stitches), or sticking-plaster and bandage. In a few days nature completely reunites the parts, without any infammation or suppuration having appeared. This surgeons call union by the first intention, and is so desirable a method of healing wounds, that it . 
is generally attempted, even under circumstances which render its accomplishment doubtful. In the wounds of horses this kind of union can scarcely ever be effected, from the difficulty of keeping the wounded part in a state of rest, and from the laceration and contusion with which their wounds are generally accompanied.

To render the subject more clear, we shall divide wounds into the following classes:

1. Simple incised wounds.

2. Lacerated and contused wounds.

3. Punctured wounds.

4. Wounds of carities.

\section{Simple incised Wounds}

Are those inflicted with a keen instrument, by which the skin or other parts are neatly dirided, without being torn or bruised.

This kind of wound, however, seldom happens to horses: when they do occur, though there is little probability of effecting a union by the first intention, it should always be attempted; and if the divided parts cannot be kept together by sticking-plaster and bandage 
alone, the lips of the wound should be neatly sewed, so as to be held firmly in contact with each other, with waxed thread several times doubled; and if the situation of the wound will admit of it, a bandage or roller should be afterward applied to assist in the accomplishment of this end, and render the stitches less painful. But how different from this is the practice of farriers, ignorant of the animal economy, and the wonderful power with which the Almighty has endued the animal system, of recovering itself when injured, and of reproducing flesh that has been destroyed! They officiously prevent this desirable union by putting tents (that is, lint or tow moistened with some stimulating liquid) between the lips of the wound, by which they are effectually hindered fion cohering, howerer naturally disposed to unite: but this is not the only evil of the practice. In extensive wounds the injured parts are so irritated by exposure and their applications, that mortification is sometimes the conseqence. Far better than this would it be, to leave the wound to nature, merely keeping it clean, and, when the first inflammation has subsided and white matter appears, bringing the separated parts as near 
to each other as possible, and retaining them in that situation by means of bandage. By this method the wound would heal much more speedily, and the consequent blemish, or scar, would be considerably lessened. It is unnecessary to say more of the simple incised wound, for should the attempt to heal it by the first intention fail, it becomes necessary to assist nature as in lacerated wounds: still, during the whole cure of a simple wound, it is proper to keep the divided parts together as well as we can, which will be found more useful than any balsamic vulnerary or healing application, that the most expert farrier's rereipt-book can furnish.

\section{Lacerated and Contused Truinds.}

The wounds of horses are nost commonly. inflicted with some blunt instrument, and consequently the parts are rather torn asunder than simply and neatly divided: at the same time, the iustrument is generally applied with . such force that the skin, flesh, \&c. are considerably bruised; for example, when a horse falls upon his knees, is kicked or bit by another horse, in attempting to leap gets his:. 
Lind or fore-leg entangled in a gate, and in other such accidents. In these cases the laceration and contusion are so considerable, that the kind of union before mentioned is totally impracticable: it is, notwithstanding, adrisable to keep the divided parts together as well as we can, taking care to allow the matter which forms, to escape freely, and avoiding the violent stimulating applications commonly used by farriers on sach occasions, which, to say the best of them, always increase the infammation and danger, and obstruct the cure. I have seen a horse die in the greatest agonies, fiom a wound received in entangling the hind-leg in a gate, by which not only the shin and Hesh were excessirely torn and bruisst, but the stifle-joint was also much injured. In this case, the fatal event and the excessive pain were undoubtedly accelerated and heightened, if not altogether uccasioned, by the caustic applications of the farrier employed *..

* A shurt time ago I was induced by respectable recommendation to employ a practising farrier in our Veterinury Infirmary as superintending groom, under an idea that he might be the more useful from being capable of applying poultices, fomentations, giving balls, \&ic.-Though like his Vulcanian brethren extremely ignorant, lie appeared tractable and desirous of instruction: unfurtunately my plan of trusting in some. 


\section{In the treatment of extensive lacerated} wounds the first object is to remove any dirt,

measure to nature in the treatment of wounds and ulcers appeared to him to arise from negligence; and in the excess of his zeal, during the time I visited my out patients, he endeavoured to compensate for my apparent omissions by his own industry. Finding several cases unusually obstinate, I was led to make some inquiry into the business, which was soon explained, when informed that this indefatigable practitioner had used nearly an ounce of lunar caustic (argentum nitratum) in a fortnight. This man has since had the presumption to set himself up as a veterinary practitioner, and now deals out his caustics and opposes nature without control.

It has since appcared, that this man was induced to offer lis services, by supposing that such an employment would after a short time be considered by the public as a sufficient sanction for his practising the veterinary art.

The celebrated St. Bel, first professor of our veterinary college, in lis obscrvations on veterinary medicine, justly remarks, " that at this time the art appears otscured and bewildered by the illflaced confidence of the owners of horses upon the blacksmith of the parish, upon illiterate and conceited grooms, or upon a set of ignorant and presuming inen, infinitely more dangerous than all the rest, who, arrogating to themselves the title of doctors, distribute thcir nostrums to the destruction of thousands, whose varied disorders they treat alike, without consulting nature or art, either about the cause or the effect.-Miserable aninal! thou canst not complain, when, to the disease with which thou art affected, excruciating torments are superadded by the unmeaning efiorts of ignorant men, who, atter pronouncing a . hackneyed common-place opinion of thy case, proceed with all expedition to open thy veins, lacerate thy flosh, cauterise thy sinews, and drench thy stomacb with drugs, adverse in general 


\section{splinters, or uther extraneous matter that may}

be in the wound; if a flap of skin hang down,

to the cure they engage to perform!"---So extensive is the mischief occasioned by this "ill-placed contidence" of which St. Bel speaks, and so serious an obstacle has it hitherto proved to the progress of veterinary science, that I must beg leave to make a short quotation from Mr. Richard Lawrence's ingenious publieation.

"The necessity of long study in anatomy, pathology, and the composition of druge, to qualify a practitioner in medicine, is universally acknowledged; and as the horse cxists by sinilar laws, and is subject to many of the diseases incident to mankind, ir cannot require much penetration to discover, that studies of the same uature must be absolutely requisite to constitute a good farrier: but if conclusions were to be drawn from the basis on which the veterinary system has hitherto rested, it would seem that the science of farriery has been considered as a nutural gift, and not in the least dependent on the tedious process of medical inquiry and investigation; for every blacksmith, groom, and stable-boy, not only conceives himself, but is often believed by his employer, to be fully competent to the important task of curing diseases, of the nature of which le is totally ignorant. Surely nothing can be more ausurd than to imagine, that a groom, by haring fed and cleaned a horse a few years, must consequently become acquainted with his diseases and their causes. It would be equally plausible to assert, that hecause he knows by ocular experience that the sun rises in the morning and sets at night, he must be an astronomer.

"The majority of the affluent, to avoid the trouble of reflection, suffer themselves to be influenced, in matters of this nature, by men whose opinions on any other subject they would treat svith the utmost contenpt. Few things can be more affecting to a liumane and contemplative mind, than the sufferings of a ante 
of flesh be nearly torn off, they should be carefully replaced, and never cut off, however unseemly they may appear to the farrier, mless so much bruised as to be irrecoverable. When the parts are so divided as to require considerable pressure to bring them together again, it is improper to sew the wound up, as the tendency of the parts to recede from each other would constantly keep the stiches upon the stretch, and so irritate the wound as to bring on excessive inflammation, and perhaps ultimately gangrene or mortification. The

and patient animal, the estimable contributor to our pleasures and comforts, when affected with some violent disease, in which nature excrts her utmost efforts to relieve herself: but how must this scene of distress be heightened conla the proprietor be convinced, that the very men lie applies to for assistance only ascoravate the evil by their ignorance!"

The carl of P'embroke, whose jurlicious treatise on horses lias bech miversally approvd, seems to have been aware of the mischicvous tendency of encouraging these illiterate pretenders, when he observes, "Whocver het his farrier, groom, or coachman, in consideration of his having swept dung out of his stables ior a greater or jess muniver of yeat: ever eren mention any thing more tlan water-gruel, a clyster, or a litile bleeding; and that ton very seldom; or jrutend to talk of the nature of fect, the seat of lamimess, sickness, or their cures, may be very certain to find limsclf wry shostly quite on foot." 
only thing to be kept in view in these extensive wounds is, to employ the most effectual means for keeping the inflammation within bounds, until suppuration takes place, which is indicated by the appearance of white matter, and the subsidence of the inflammatory swelling, and abatement of pain and fever. On many occasions, the parts may be brought carefully together as near as can be without employing considerable force, and may be supported in that situation by a proper bandage. Whenever stitches are mployed in such wounds, and drawn tight, they give excessire pain to the animal, and bring on a dangerous degree of inflammation: the violent pain often causes symptomatic fever, and aftor all, the intention of employing them is not answered, as they always separate in two or three days, and leave the wound as open as at first, presenting a much more formidable appearance from the mischief caused by the increased inflammation, and the retention of putris matter. After cleaning a lacerated wound with wam water, which, when its situation and depth render it necessary, should be injected with a syringe; the dirided slin, flesh, \&c. should 


\section{be carefully brought togrether and secured as we have directed above*.}

* The common practice of farriers in these cases is, to apply freely some stimulating spirituous preparation, such as spirit of wine and camphor, friar's balsam (which is a solution of certain resin and balsams in spirit of wine), brandly, and many other things equally injurious: some of then use even a mixture of oil of turpentine and acid of vitriol; and then, as if they were determined to do all the injury in thei power, the wound is plugged up with a quantity of tow, moistenci with the same stimulating preparation with which the wound was washed or syringed. A few days ago, I was desired to attend a horse that had met with a deep and extcnsive wound by entangling, it was supposed, his fore-leg in a gate while at grass: the farrier had been there beforc me; and observing a syringe in his hard, I inquired what liruid he had employed, and was tolıl "Branuly." Upoin expressing my fear that so stimulating an apilication would do mischicf, the farricr inmediately replied, "There is no danger of that, for I put a litte vil with it; and you know the one is hot, and the other coli." I conld not but smile at the ingenuity of the explanation, but reruested that nothing of the sort might be again emplnyed.

The proplar prejindice in fayour of those spiritunus or balsamic preparat ow, at they are termed, in all kinds of wounds, has becin the cause of wich mischiel in veterinary, periaps wot much less in bumati, sti:-"y. The eredit they have acquired is owing to the woncicrini property, with which the animal body is endued, of uniting parts that twa been divir!ed, nerely by keeping them in contact with each other. Many astonishirg in ances of this have been reinted by writers on surgery; and it las been proved, that if even a tooth recently drawn be replaced in it's sucliet, it will soon become as firm as the rest. The spur of a 


\section{If the horse be in good condition, and} have not lost much blood from the wound,

cock just cut off being stuck into the comb, will soon adhere, and grow as it did upon the leg. A respectable author relates the case of a man who accidentally stepped on-a keen instrument, and nearly divided his foot: all the bones, tendons, \&c. were divided, except the bone going to the little toe; he bled profusely, and fainted, by which the hemorrhage was stopped. A surgeon then brought the divided parts together, and secured them with splints and bandage. The man was thorough!y cured in a short time, and the foot became as perfect as the other. Surgeons are now so convinced of the power of nature to heal simple incised wounds, when the divided parts are kept in contact with each other, without the assistance of any spirit, balsain, or salve; which they know rather impedes than expedites the cure, that a practitioner would be laughed at, were he to sdopt so absurd a practice: it appears, indeed, that balsams were first used on account of their glutinous quality, in order to keep the parts more completely in contact: with the same view, white of egg, gum-water, and other things of the sarne nature were employed. It is to be lamented, that the public are still so prejudiced in favour of stimulating preparations, such as, friar's balsam, tincture of myrrh and aloes, and above all the famous Riga balsan, which is preferable from being less stimulating, that a veterinary surgeon can hardly venture to trust nature a littie in the tratnent of wounds, without being accused of negligence. It ruay be depended upon, however, that in every case of simple incised wounds, where these preparations have beeis thought to efrect a cure, they have not in the least contributed to it: nature has beell the restorer, in spite of the obstacles opposed to leer efforts. Wounds that have degenerated into ulcers, either from bad management, or from the parts having been lacerated er bruised, often require the application of utimulants; but even 
he should be bled rather freely: in other circumstances it will be proper to omit that operation, or take only a small qumtity. A. purging draught or ball should be given as early as possible, and the horse's diet confined to hay and mashes, or bran: he nay be allowed to drink freely and frequently, and must be kept perfectly at rest.

The wound should be cleansed once or twice a day, as may be found necessary, wich water at blood heat; which, when the wound is deep, may be done more effectually by means of a syringe. The only external application necessary at this period is a fomentation (See Fomentation). When this plan is adopted, the inflammation, swelling, and ferer, which always follow an extensive lacerated wound, will be much more moderate than it would otherwise have been, and in a few days will have subsided considerably; a winte inatter will then flow from the wound, and the horse will not appear to suffer much pain. When this has been accomplished, it is necessary to endearour as much as pos-

in such wounds they are not to be empleyed, until the influmussien which neerearily tollows the injury has subsided. 
sible to bring the divided parts together, and there will be less danger and pain from drawing the bandage with more force for this purpose. Warm water may still be used for cleansing the wound; but when the inilammation is quite gone off, some stimulating liquids may be employed, but these are unnecessary when the divided parts can be brought into contact. When this cannot be effected, or when there is a loss of substance, the wound cannot heal without the formation of new parts, and stimulants are often required to accelerate this process. At first, the weaker preparations are to be used, such as dilute spirit, or a weak solution of blue vitriol: but when the healing process goes on slowly, the matter becoming thin, and loosing its white colour, the stronger stinulants, as tincture of Renzoin, or even oil of turpentine, may be applied, and the constitution invigorated by a mitritious diet, such as malt and oats, or carrots; and when the discharge is very considerable and appears to weaken the animal, this is more particularly necessary, and must be assisted by medicines of the tonic kind, such as Perurian bark, Cascarilla, vitriolated iron, and sometimes 
porter or beer, and even opium; it is only in very deep and extensive wounds, however, where there is a profuse discharge, and constitutional weakness, that this treatment is required.

When wounds of this kind terminate fatally, it is generally from the violence of the inflammation and symptomatic fever causing gangrene, delirium, and total exhaustion. Our first and principal object, therefore, should be to restrain this inordinate inflammation by every means in our powcr; but farriers, ever in opposition to nature, generally destroy their patients in thcse cases; torturing the unfortunate animal by the application of violent stimulants, and even caustics; cramming into the wound hard tents, and persuading his employer that this cruel and absurd treatment will infallibly heal the wound. When we have succeeded in these extensive lacerated wounds so far as to bring on a healthy suppuration, a discharge of white matter, and an appearance of new fiesh sprouting up in various parts, in small granulations of a red colour, we may be satisfied that the danger is orer.

At this period we may safely use more force in bringing the divided parts together: 
and if the wound appear languid, wanting that red appearance we have just described, and discharging thin matter, some of the stimulants we have mentioned may be, employed: still it is improper to cram tents into the wound, or daub them orer with stinking ointments. If the red granulations form so luxuriantly as to rise above the level of the skin, they wust be kept down by red precipitate, burnt alum, or other applications of this kind; pressure will also be effectual on this occasion, laying a piece of soft lint on the part, and confining it with a roller. Should the sides or edges of the wound become callous, caustics must be applied to remore the oll surface, and then fresh attempts should be made to bring them into contact. When the matter has penetrated from having been confined, so as to form sinuses, fistulix, or pipes, as they are commonly termed (that is, narrow, deep ulcers ruming in various directions), their sides if possible should be brought into contact by means of pressure. If such sinuses have existed for some time, the sides will have become callous, and incapable of uniting: it is then necessary to apply caustic, either by injecting some liquid caustic, such as strong VOL. I. 
solution of blue vitriol, dilute nitrous acid, \&c. with a syringe, or by dipping lint in the same, and passing with a probe to the bottom. of erery sinus. (See Iristula, Poll-cril, and Quittor.) 'This is the only occasion on which tents are proper. If it be impossible to bring the sides of the sinus into contact, it can only be cured by the formation of new fiesh, to promote which it is necessary to inject daily some stimulating liquicl, such as spirit of wine, tincture of benz'sin, \&c.; keeping the orifice open, lest it heal before the deeper part. Iren these, however, will be found ineffectual, if the sides of the sinuses be callous; and then should be preceled by the caustic as above described (Sce Clcors, Fistulu, Pollril, and Quittor), which sometimes requires tra be repeated. I thomght it necessary to be thins minute in describing the treatment of lacerated wounds, as it is a subject of great Importance, and generally little understood. Under this head it is proper to treat also of guis-shot wotmels, in which the ball enters with sisch force, and the parts are so much bruised, thet then vitality is ciestroyed; therefore nothmg can provent their sejaration, or sloughing as it is termed. This generaliy taikes place a 
few days after the accident, and until that period it would be highly inproper to use any kind of pressure, or attempt to bring the sides of the wound into contact. The first thing to be done in these wounds is to extract the ball, should it have lodged; but we must not employ any violent means to effect this, as it is more easily done after the dead parts have separated and a healthy suppuration has taken place. Sometines the ball penetrates so far as to be felt near the opposite side of the part: where an incision should then be made in order to extract it. Whenever matter ponis up or is confined in any lind of wound, it is

- proper to make such an opening as will allow it to escipe freely: setons are sometimcs employed for this purpose. (See Frounds of Cuities and Punctured IVounds.) In gunshot wounds it is improper to bleed, as hemorrhage often happens when the dead parts separate: in othe: respects they are to be treated as we have above described. Indeed their treatment must depend greatly on the importance and situation of the wounded part, as the ball may penetrate a joint or the cavity of the chest or belly. (See Wounds of $\mathrm{Ca}$ vities.) 


\section{Punctured Trounds.}

This kind of wound also often occurs in reterinary prectice. The feet are particularly liable to it, and not unfrequently they are inflicted through the carclessness or impatience of the groom. During the time of ny service in the army, I may truly assert, that more than fifty cases occurred, in which the wound was inflicted by the fork used ibout the litter, either by accident or by the savage violence of the groom. It is but just bowerer to acknowledge, that a good soldier will sacrifice eren his own repose to that of his horse, and thinks nothing a labour that can contribute to the health and comfort of his faithful companion; but anong so great a number of men, there are too often some of a different description. Punctured wounds of the feet are most frequent, and are caused, either by the horse stepping on a nail, or picking up a nail us it is termed, or by carelcssness of the furrier in shoeing. In the former case the nail generally enters the frog, and often penetrates the joint of the cofin bone. (See Anutomy of the Foot.) The sole is generally sufficiently hard to resist the 
nail; but the froug is commonly of at softer and more spungy nature. When the coffin joint is wounded, there is danger of an incurable lameness from the joint becoming stiff; but by proper managrement the wound is often closed in a short time, and the free motion of the bones preserved. (See Wounds of Joints, under the head Wound of Curities.) Whenever the foot is wounded by a nail, it is necessáry immediately to open the orifice in the horny matter by means of a drawing knife: if the joint be wounded, synovia or joint oil will issue from the wound, but in very small quantity. An experienced person can easily ascertain this point still more certainly by tracing the wound with a probe. The treatment of this kind of wound will be described in the chapter on Wouncis of Cavities; but when the joint has escaped the injury, after enlarging the opening made by the nail in the horny matter, and cutting away the hom from the contiguous parts, until it becomes very thin, i little tincture of benzoin is to be poured into the womd; the stinulus of which, so far from being injurious as in lacerated wounds, will soon bring on a secretion of healthy matter; a little tow, or lint, 
dipped in tar o: Venice turpentine, is then to be applied, and the whole foot kept cool by means of a bran poultice. The most essential part of the treatment is opening well the orifice in the borny matter: for in wounds of this kind we always find, that soon after the nitil has been withdrain, the puncture in the hora nearly closes; but the liring parts that have been wounded underneath the hom soon inflame and swell; consequently they suffer considerable pressure, as the horn is too thick and inflexible to give room to them as they swell. At length matter forms, which, being. confined by the homy covering, diffuses itself between the sensible and insensible parts, sumetimes so extensively as to render it necessary to remove great part, or even the whole of the latter. This operation, so often cmelly and annecessarily performed by farriers, is termed druwing the sole. In the case describsed, where the parts are separated by the matter, the operation is periomed with but little pain to the animal. But those offcious practitioners too often tear it of when perfectly healthy, and with a view to remove a lameness, of the cause and seat of which they are totally ignorant. Often hare I been 
desired by the owner of a lame horse to draw the sole, under an idea that it was an infallible remedy for an obstinate lameness, or for 2 desperate wound of the coffin joint $*$

When it has been found necessary to remove some part of the horny sole, in consequence of matter having formed under it, a pledget of tow dipped in diggestive ointment, or a mixture of Venice turpentine and hog's-lard should be applied. Sometimes we find the coffin bone diseased, in which case the injured part generally separates, and then a new horny sole is gradually formed. When

* This mischievons and cruel operation is held in such ligh estination by farriers, that they exultingly display the soles of their unfurt nate patients, nailed to their doors, or windorwshutters, as a sort of diploma, or undeniable sanction to practise the ait of firriery. We have reason to lope, that this abominable and cruel practice will not long exist, as the condition of this most useful aninal has of late experienced a considerable melioration, and will, we trust, by the laudable encouragement now given by many distinguished, I may say, illistrious personages to the veterinary science, be soun rescued from the hands of those tarbarous and presaning practitioners. The ingenious genttcman I have before mentioned, so liberal in the use of canstics, was equally proud of lito skill in tearing off the soles from horse's feet, and I am informed often boasts in ale-houses, atmong grooms and other companions, of his skill in this operation, and more particularly of his profound knowledge of the "Ottomy (meaning nutomy) of the horse." 
a horse's foot is wounded by the farrier in shoeing, he is said to be pricked; the nail, instead of being driven into the horny insensible part only, is either forced into the living parts, or so near to them as by it's pressure to give such pain to the animal as to cause him to go lane; inflammation gradually takes place in consequence, and at length matter forms, which, if not allowed to escape by removing the shoe and cutting arvay the horn with a small drawing knife, spreads under the hoof, and after some days breaks out at the coronet. (See Anatomy of the Foot.) In this case the mischief is not always discovered immediately after shoeing. The pressure upon the sensible parts is sometimes too inconsiderable at first to occasion lameness; so that when the horse is observed to go lame, the farrier pronounces it to be in the shoulder, and the poor animal is tormented by the strong oils or even blisters applied to that part, while he is suffering from another cause. It is in this way that the disease is sometimes allowed to run such lengths as we have described. When the nail is so driten as to wound the sensible parts at once, the horse goes lame inmediately after; and the cause 
being generally suspected, the shoe is taken off, the opening in the horny part enlarged with a drawing knife, and a little tincture of benzoin applied. The lameness is thus soon removed, the shoe reapplied, taking care not to place a nail or suffer the shoe to press on the injured part, and the horse becomes capable of returning to his work*.

When wounds of this kind have been so neglected, that matter breaks out from the coronet, it is still necessary to enlarge the opening in the horn beneath; and if it have closed (which it generally does), the horn must be removed with a drawing-knife, that the matter may escape freely: the upper wound (in the coronet) will then soon heal, by applying the tincture of benzoin. Purictiered wounds in other parts are often inflicted. with the stable fork, either acciclentally or intentionally: I have often known joints wounded in this way. (For the treatment of joint wounds, see IVounds of C'vities.) When.

* The remedy commonly employed by farriers in these wounds is oil of turpentine poured into the wound, and then set on fire with a candle: the more knowing oncs, however, prefer oil of zitriol, perhaps as being more simple, rendering the application of the candle unnecessary. 
the flesh only is punctured, the orifice must be kept open that the wound may heal from the bottom; and if the sides become callous and indisposed to heal, a mild caustic may be injected, such as solution of blue vitriol. In punctured wounds of the fleshy parts, it is of consequence to procure a free exit for the matter: with this view we often make counter openings with a knife, or pass a seton through the wound. In recent wounds, however, of the punctured kind, those irritating applications are improper: wounds of this kind are frequently followed by considerable pain and inflammation. It is therefore necessary to keep the orifice open; and if it be small, to enlarge it with a lancet, when the pain and inflammation have subsided. Should the wound appear indisposed to heal, and be found upon examining with the probe to be as deep as at first, there is reason to suppose that it's sides have become callous: a caustic is then to be applied throughout it's whole course; and after a day or two, or when white matter is ohserved to flow from the wound, such pressure should be applied, where it is practicable, as will bring the sides of the wound into contact, and continued until they 
are united. When punctured wounds are so situate, that the matter can freely escape, there is much less difficulty in curing them, than when they are in a situation of a different kind; or where the orifice, instead of being the lowest, is the highest part of the wound. This inconvenience, however, is sometines obviated by making a new opening, with a knife or lancet, or by passing a seton through the wound: but in some situations this cannot be done: nor can we in many cases apply sufficient pressure to bring the sides together. The wound can then be healed only by the formation of new parts, by which. the cavity is filled up; to effect which we inject stimulating liquids, such as proof spirit, tincture of benzoin, or solution of blue vitriol, taking care to keep the orifice open, that the bottom of the wound may be first healed.

The most formidable punctured wounds generally happen while a horse is cmployed in hunting, in leaping over gates or hedges: he is then said to be stakerl. The deeper and more lacerated these wounds are, the more earefully should we aroid the irritating applications and tents of the farriers, adopting 
in their stead the same treatment we have directed for extensive lacerated wounds.

There is another kind of punctured wounds which is likely to occur in military service; and in a charge of cavalry upon a line of infantry, it is astonishing that so many should escape the bayonet as we generally find do on such occasions. Those are generally of considerable depth, and often followed by profuse bleeding. When the bayonet penetrates the belly or chest, the wound is commondy fatal, particularly if any of the large blood-vessels within these cavities be wounded. When merely the fleshy parts are wounded, there will be little danger, particularly if there be no considerable blood-vessel opened. The treatinent of these wounds is nearly the same as we have already described, except that it is more frequently necessary to enlarge the orifice or mouth of ho wound; and that there is often occasion to perform a rather difficult operation; namely, that of tying the artery in order to stop the bleeding; for when a large artery is wounded, the blood flows so copiously as to require the most expeditious mpeans of suppression, It is difficult for a 
person unacquainted with anatomy to perform this operation of tying the artery. Therefore if no professional person be present at such an accident, it is advisable to endeavour to stop the bleeding by pressure, giving up all attempts to tye the artery; and not placing any dependance upon those preparations called styptics. (See Materiu Medica.)

Pieces of spunge or lint, secined with bandagge, will be found most convenient for this purpose. If the wounded artcry be of considerable size, which may be known by the quantity of blood and the force with which it is thrown out, the bandage should not be removed till the second or third day*.

In these wounds, also, it is necessary to avoid the stimulating applications and tents commonly employed by farriers: but when the inflammation has subsided, and the wound does not appear disposed to heal, they may be used with advantage. It is of importance

* It is easy to distinguish between a wounded artery and a rein. In the latter the blood is of a darker red colour, flows in a uniform stream, and with little force: in the former, the blood is of a bright scarlet colour, and is thrown out by jerks, with considerable force. 
to procure a free exit for the matter, for which purpose a counter-opening may be made, when the situation of the wound will admit of it.

All punctured wounds are liable to become fistulous; that is, when the sides cannot be brought into contact by any means, they often become callous. It may be necessary to repeat, that in such cases caustics must be applied to destroy the callosity, and then gentle stimulants are to be injected to promote the formation of new flesh. There is more difficulty in healing wounds of tendons or ligaments, than Hesh-wounds; and in such cases, after the frrst inflammation has subsided, the stronger stimulants, and even caustics, are often required. (See the author's Veterinary. Muteria Medica, or 2 nd Tol.)

\section{Trounds of circumscribed Carities.}

(Under this head we shall describe wounds of the Chest, Belly, Joints, Sheaths of Tendons, and Blood-eiessels.)

When the chest or belly is punctured, there is generally danger of a fatal termination: the 
danger, however, is proportionate to the extent of the injury, and is always greater when any of the parts contained in the cliest $O r^{\circ}$ belly are injured. This kind of wound is most liable to happen in military service, and is most commonly inficted with the bayonet and ball. Even in small wounds of these important cavities there is danger of inflammation taking place in the bowels: it is necessary therefore to close the wound as neatly and expeditiously as possible, by sewing it up; taking care however that the needle do not pass through the fleshy parts, but merely through the skin. It is proper also to bleed according to the strength and condition of the animal, and to give a purgative draught. If swelling and inflammation come on, foment firequently with a decoction of the bitter lierbs. (See Fomentations.) If the wound do not unite by the first intention, white matter will soon make it's appearance. A little tincture of benzoin may then be appried. In extensive wounds of the abdomen or belly, the bowels often come out through the opening, in which case there is considerable danger, though the bowels may have 
escaped the injury. Should they have been woun led, let the vound be very neatly stitched up with a sinall needle and waxed silk, and then gentiy replaced within the belly, taking care firt $t$ renore any lirt or other matter

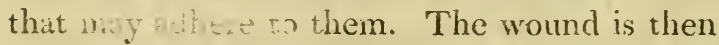
to be calchily. useal as we have before directed, and suppricoi if possible with bandage: the end of cir jilk however with which the bowel is sewed should be kept out of the external wound. Bicciing and a clyster are particularly necessary: bran mashes, with strong gruel, or a littie sweet oatmeal stirred into each nush, is the most proper aict. If the bowels have been wounded, it is absolutely requisite to keep the horse from eating hay or straw, or any hard food; for as the digestive process is far from being periected in the horse's stumach, the hay cr straw might arrive at the wounded part in a state capable of doing great injury. In wounds of the chest nearly the same treatment is required: a purgative however may be given in such cases, before inflanmatiom has taken place; but whenever this happens, whether it be in consequence of these wounds or of wounds of the 
belly, it must be treated according to the directions given under the heads, Inflammation of the Lungs and Bowels.

The cavities next in importance to the chest and belly are those nimed joints; which in horses are more frequently wounded than the other cavities. These wounds, although from mismanagement they sometimes prove fatal, yet are of more iniportance from the circumstance, that without the greatest care and the most judicious treatment they almust invariably render the horse permanently lame; and sometimes in so considerable a degree, that he becomes nearly if not entirely useless. Previous however to entering on the consideration of their treatment, it is desirable to give such an account of the structure of a joint, as may render the directions more intelligible. A joint is formed, generally speaking, by the ends or heads of two or more bones: these ends are covered by a layer of gristle or cartilage, which is of a yielding and elastic nature: this cartilage has on it's surface a firm but thin menbrane, which is constantly forming a slippery fiuic termed synovic or joint oil : it possesses also absorbent vessels to 
prevent an undue accumulation of this fluid * The ends of the bones, thus covered with a smooth yielding surface so slippery as to move upon each other freely without suffering from friction, are then firmly tied together by a strong inelastic substance termed ligament, which completely surrounds the heads of the bones, as far at least as they are covered with the smooth cartilage. This ligament, termed by anatomists capsula. ligament, is not so tight as to prevent extensive motion of the bones, but sufficiently so to hold them firmly in their proper situation. The joint is thus completely shut up, forming a lind of sac, or what is termed a circumscribed cavity, and the joint oil which is formed is confined to it's proper situation. When a joint is wounded, or, in other words, when the capsulur ligument is wounded, the joint oil, which is a transparent fiud of a

* When a joint becomes dropsical, as in bng sparin, it is either from a loss of power in the ubsorbent ressets, or an incieased action of the vessels which form the joint oil: porhings botin these causis may concur in producing the disease, the more remote caute of which is generaily hard work, that is, too great or wo io is continued notion of the joint. The disease rerined windgul's may be explained in the same way. (Sce Hingulls, Apendix.) 
light yello:v or brownish colour, is seen almost constantly oozing from the wound, particularly when the animal moves the joint. If proper means be not employed to close the wound, inflanmation takes place within the joint, occasioning the most excruciuting pain, and at first all increased formation of synovia. If the wound continue open, the inflammation and pain become more considerable, and a symptomatic ferer takes place, which sometimes proves fatal. It often happens, however, in this stage of the complaint, that the ressels of the capsular ligament, instead of forming joint oil, pour out a large quantity of glutinous coagnlating fluid, which, filling the cavity of the joint and becoming solid, totally and permanently obliterates it. The inflammation, pain, and fever, then gradually subside, and the wound heals; but the joint can no loncrer be mored, and an incurable lameness is the consequence. From this description will appear the importance of attending to these wounds as early as possible, and of closing the wound as expeditiously as we cail. This however cunnot be crected by the means we lave recommented for other wounds. Ligaments are 
of a different nature from flesh or skin, and, when wotinded, cannot be healed without the assistance of strong stimulants and even callstics*; but these must be used with great cantion, for when they are so clumsily employed as to enter the cavity of the joint the. most violent inilammation will ensue. Some of the old farriers appear to have known the utility of caustics in these wounds; but mistaking the principle on which they acted, often injected liquid caustics into the joint, and thereby brought on the most excruciating torments. Sometimes their patients were destroyed by the fever which followed: more frequently, however, the joint became stiff or immovable, as we have before described, and

* It has been supposed, that the violent pain and inflammation, which follow the wound of a joint, are caused chiefly by the admission of air into the cavity, and a deficiency of synovia or joint oil, by which the two surfaces are exposed to friction. It is certain, however, that in these woinds there is much more synovia formed than usual; which may be known by the quantity that flows from the wound. This increased formation of synovia, however, continues only a certain time; after a time the cosgulating lynph is poured out, which, becoming solid, obliterates the cavity; but in large :vounds of the principal joints, the animad is often destroyed before this happens, by the symptomatic fever which comes un. 
the wouns haled. Other farriers, preferrin?" to employ the solid caustics, and triling int their attempts to tinust them into he carity of the joint. have applied them no farther than the orifice in the capsular ligament, and have by this fortunate failue effected a cure witbout the loss of the joint. This plan, however, cun only be adoptel in wounds "of a sma!l size, or of the punctured kind, such as those inflicted with the stable fork; and fortunately wounds of joints are most commonly of this kind. But we sometimes meet with cases where the wound is of considerable size, and much lacerated: there is scarcely a possibility then of preserving the joint; and if it hippen to the larger joints, such as the hock and stifle, there is great danger of it's destroying the animal. . In such cases causties are improper: they must be treated as deep lacerated wounds. But in the small punctired ivound of a joint, the actual cautery (hot iron) cantiously applied has been found the most expeditious and effectual remedy. I have succeeded also with the lunar caustic (nitrate of silver). Farriers sometimes employ the butter of antimony (muriate of antimony), 
and white vitriol (vitriolated zinc) ${ }^{*}$ : they often inject some liquid caustic into the wound with a syringe, such as solution of blue vitriol. The carlier the actual cautery is applied, the more speedily will it heal the wound; and it is particularly desirable to have it applied before inflammation takes place in the joint. The iron should have a round point, and be applied when at a dull red heat; the wound should be so seared as to stop the discharge of joint oil. It often happens, that after a short time an oozing of synuria is again observed: in such cases the iron must be again applied, and repeated if necessary several times. I have sometimes succeeded ultimately, though the iron had been applied

* I have heard a farrier boast of possessing a receipt for a joint hnmour ; or, as he termed it, for "Killing " joint humour." In small wounds of the inferior joints, this man sometimes sucacled. I'pon examining the remedy, I found it 10 consist chichly of white vitriol, which indeed was the only active ingredient. This, coarsely powdered, was put into the wound; but as the mini supposed it's eflicaey depended upon it's entering the carity of the joint, and subduing this formidable humour, he of course took great pains to thrust it in with his probe. In large wounds, he generally succeded in his attempt, and destroyed cither the joint or the aninal: but in small wounds of the lower juints, he merely brought it into contact with the nonnded bigament, and thereby uften efiecicd a cure. 
ineffeciually twice or three times. Wher. inflammation takes place in the joint, the most powerful remedies snould be expeditiously employed for ii's remoral, such as bleeding and purging. Fomentations and poultices in such cases are not so useful as blisters, which should be applied rather extensively about the joint; but as long as the wound in the foint remains open, the inflammation will continue; therefore our principal object should be to close the wound. There is no external complaint which occasions such excruciating pain to the animal as inflammation of a joint, particularly when it has proceeded so far as to ulcerate the bones; several cases of which have come under my observation.

THounts of the Sheaths, or Membranes surrounding Tendons.

These require nearly a similar treatment to that we hare just described, and, when of the small punctured kind, are more expeditiously healed by a judicions use of the actual cautery, than by any other remedy. These wounds also generally discharge something like synovia or joint oil, and, if suffered 
to remain open, are productive of very violent pain and inflammatiou. When they are so large as to renler the caustic an inproper application, they should be closed as neatly as possible, and liept so by adhesive plaster and bandage. This plan is equally applicable to similar wounds in joints; and, if adopted in time, will often be found very effectual: eren when the actual cautery has been applied, and the wound seared so as to be closed, the adhesive plaster will be found a useful assistant, and will often prevent the necessity of repeating the cautery. I have known a wound in the knee joint soon healed by means of the sticking plaster alone. The tendons most liable to be wounded are the back sinews: they are enclosed in a strong tendinous sheath, which, like a joint, contains a small quantity of slippery fuid, to render their motions easy, and prevent the cohesions of the parts. About the fetlock joint, or rather above that joint, there are small sacs or little bladders, connected with the tendon and ligaments, which also contain this slippery fluid, and serve to fucilitate motion in these parts. When a horse is worked too hard, these bladders contain an unusual quantity of 
the fluid or synovia, and appear swelled or puffed, constituting the disease termed windgalls. If these littie bladders receive a wound, it is generally followed by violent pain and inflammation; and, when improperly treated, a very obstinate lameness may be the consequence. In this case, nothing is more useful than the sticking plaster, prorided the lips of the wound he neatly brought together before it is applied; but if the wound be of the small punctured kind, the actual cantery should be first applied. Great care howerer is required in this case; for if the iron be not applied very lightly, and it's pointed end properly adapted to the size of the wound, it may do much mischief. Blisters are the: best remedies for any swelling, that may remain after a wound in the sheaths of tendors. or in joints; and if one blister be fornd insufficient, a repetition of the remedy rill generally succeed. The last kind of wound we have to describe is one that happens more frequently than any other, and is moir easily cured; that is, a wound of a rcin. When a vein is properly opened, and afterward carefully closed in the usual way with a yin and a little tar, it almost always hesk roI. 1. 
by the first intention: but when it is opened by a rusty blunt fleam or lancet, and particularly when the instrument is driven with such violence as to cut not only, into but through the rein, making thus an orifice both before and behind, it seldom heals so radily; on the contrary, inflammation takes place within the carity of the rein, which gradially extends or spreads until either the wound is closed, or the rein obliterated, by the coagulating matter which forms within it. If the inflammation extend to the heart, the animal is instantly destroyed; mere commonly, howerer, the rein is soon plugged up, and ceases to convey bloud. But eren in this case the disease proves very troublesome; in consequence of the jugular or neck veins being the principal channels, by winich the blood of the head returns to the heart. This obstruction to the retum of the blood canses a swelling of the large gland under the ear, in which the formation of matter is often a consequence. Someines the eye becomes infianed; and I have seen symptons of apopicxy or staggers produced by this cause. If a horse be tumed to grass in this situation, the inconvenience is considerably increased; 
the position of the head in grazing being unfavourable to the return of blood from the head. The inconvenience arising from a loss of the jugular vein is not however permanent; the smaller veins gradually enlarge, and, after a time, return the blood as readily as the jugular or neck vein did originally. When this accident happens, the mischief nay be perceived about the second day after bleeding; sometimes the day following that of the operation. When the orifice in the vein is large, and particularly if the round in the skin be but slightly closed, or if the horse happen to rub the pin out, the wound bleeds freely; and though it be again pimed up, the blood often bursts out after a short time. I have seen a case where the horse had been blecding, at intervals, three or four days, though the round had been several times firmly pinned up: this was very soon stopped by the actual cautery; but the vein wis obliterated at that part, and a little way downward and upward; and the swelling of the gland under the ear took place. When the orifice in the vein is but small, or when the vein is not transpierced, but inflames ouly from the orifice in the skin having been in- 
perfectly closed, or from hair or blood lodging between the lips of the wound, the first symptoms are swelling and an oozing of moisture from the wound. In this case the rein is often preserved, and the disease soon cured, by applying lightly the actual cautery, and by keeping the horse at rest. It must not be supposed, however, that in every case of sweling after bleeding the rein is intlamed: a slight swelling often takes place immediately after the operation, merely from the blood getting into the cellular membrane under the skin; and this swelling is sometimes succeeded by an oozing of moisture from the wound: but all this is soon removed by rubbing on it a little soap liniment. When the vein is really inllamed, there is generally a discharge of blood sometime after the operation; and if this do not happen,-the swelling extends to the grand under the ear, the whole being extremely tender and painful, often rendering the horse almost incapable of masticating or swallowing. When the disease is improperly treated, or suffered to take it's own course, sinuses form by the side of the vein; so that the probe may be passed in various directions, generally upward towards the glant, 
sometimes inward among the muscles of the neck.

The actual cautery is undoubtedly the most effectual application at first; but when the disease has been suffered to proceed so far as we have now described, it is necessary to keep the orifice open, that the matter may escape freely; and, by injecting a solution of blue or white vitriol, cause it gradually to heal from the bottom.

When the gland under the ear is much swollen, and very painful, a poultice should be applied; but when the swelling feels hard, and without tenderness, a blister is more effectual.

In taking leave of this subject, which may appear to some of my readcrs to be spun out to an unnecessary length, I must beg leave to observe, that wounds in general, more particular those of circumscribed cavities, require so much care and consideration in order to be treated with success, as to convince me of the propriety of giving a detailed description of them. 


\section{Diseases of the Eyge.}

Anong the various diseases to which domestication and improper management have subjected the horse, those of the eye are more frequent and often more obstinate than any other; and what makes this subject peculiarly interesting and important is, that unless a horse's eye be absolutely perfect, he is liable to start and stumble; and it is allowed that +1 horse, whose visual organs are imperfect, is often more unsafe to ride than one totally blind. Another consideration induces us to make some additions to this subject, which is, that these diseases, when allowed to exist any time, or when improperly treated, are scarcely ever cured; and, though apparently removed for a time, ultimately terminate in blindness ; whereas, by seasonably applying proper remedies, the eyes have been perfectly and permanentlyrestured. When the disease inst appears, our treatment must in some measure be guided by thestate of the horse's condition, strength, and age. Such as areyoung and in high order require at first both blceding and purging: but old horses, particularly when low in condition, cannot bear the loss of much blood, or the 
operation of a strong purgative; stiil local bleeding is proper, and a dose of laxative medicine. The local bleeding consists in opening the rein which appears to proceed from the inner corner of the eye, orin scarifying the inner surface of the eychil. This operation' is proper in all circumstances.

Horses of the former description often require a repetition both of the bleeding and purging, with a cooling diet, and frequent exercise. The most essential locul remedy is blistering the cheek and temple, so as to create a considerable discliarge; and if the first application be not sufficiently powerful, let the part be washed with suap and water, and a fresh blister laid on. Ihave found this far more effectual than setons or rowels, and have now greater dependance on it than on any other topical remedy. When the inner surface of the eyelid appears unusually red, it is nore particularly proper to scarify it with a lancet, during the first stage of the complaint, while the eye is extremely irritable, and the inflammation considerable.

The following lotion may be frequent!y applied with a soft spunge; but no force sheuld be employed to get it under the eyelids: 
EYE WATER.

No. 1.

Tincture of opium, - $\quad \approx \mathrm{dr}$.

Water of acetated litharge, - $1 \mathrm{dr}$.

Pure water, - 8 oz.

Mix.

No. 2.

Ext. of hyosciamus or henbane, 1 dr.

Pure water, - $8 \mathrm{oz}$.

Rub them together in a mortar, pouring on the water gradually; and when perfectly mixed, aitd of the

Water of acetated litharge, - $1 \mathrm{dr}$.

When the inflammation abates, and the horse begins to open the eye more perfectly, we often observe a cloudiness on the surface sometimes so considerable as to intercept the light, and prevent vision. This, howerer, may soon be removed by putting into the eye some stimulating powder, or by washing the eye with a solution of white vitriol, two or three drans to cight $\mathrm{o} z$. of water. When by these means the disease has been removed, we should carefully guard agrinst it's recurrence, by exer- 
cising the horse regularly, and avoiding such things as may suddenly -suppress or check perspiration. Moderate feeding too and good grooming are necessary. By continuing this kind of management, the eye will gradually recover it's strength; but if these precautions be neglected, the disease generally returns; for though the eye appears to be quite recovered, it cannot be supposed, that so delicate an organ can be suddenly restored to it's original strength after such an attack. As horses are too frequently treated improperly, it is not to be wondered at, that this disease should so often return after having been apparently cured; nor ought we to attribute it to any peculiarity in the constitution of the horse, or in the structure of kis eyc. The disease we have now been describing is that which arises from some internal cause, either a greneral fullness of the system, or partial determination of blood to the eye, in conseguence of suppressed or diminished per-. spiration. When the eye becomes inflamed from a blow, a bite, or any external injury, it is generally soon cured merely by washing the eye with the above lotion; but when the injury is considerable, bleeding and purging, and particularly local bleeding, are also necessary:

a 5 
When the eye itsclf is wounded, so that the liumours, as they are termed, run out from the wound, blindness must be the consequence. But if the surface of the transparent part or glass of the eye be slightly scratched only, and the whole surface or part of it become opaque, or have a film as it is commonly termed in consequence, such opacity is often removed by throwing under the eyelid some stimulating powder, such as salt. If this fail, a little finely levigated glass, mixed with honey, may be put under the eyelid, by which it will soon be diffused over the surface of the eye. In these cases, however, such applications are not to be used, until the violent intammation, which the accident occasions has abated. Among the various diseases of the eye described by writers on farriery there is one, which they term moonblindness, from it's supposed periodical recurrence. This complaint is considered incurable, perhaps justly; but I have little doubt that it might be prevented. Whon the eye becomes inflamed from an interual cause, and the inflammation is allowed to exist for any time, a weakness of the part is the consequence; and though the inflammation be remored, the yeakness will continue. But if the causes which 
first produced the complaint be avoided, or, in other words, if the horse be properly exercised, fed, and groomed, the part will gradually recorer it's original strength: if, on the contrary, as soon as the inflummation is gone off, the exsiting cause be again applied, the eye will more readily become diseased than it did at first; being in a weak state, and consequently more irritable, or susceptible of inflammation. The second attack will of course increase the weakness or disposition to disease; and after this the case may be justly deemed incurable. After repeated attacks the interior parts of the eye b.ecome diseased, and at length a caturact or incurable blindness takes place. It often happens, however, that the eye continues in this fluctuating state some time. In some cases a cuturact forms rather suddenly.

I have often met with cases, where a small speck or opacity formed in the crystalline humour, and continued without alteration for twelve months. In one case no alțeration happened in two years: but this speck or opacity in the inner humour, or crystulline, always hinders vision in some degree, and is frequently. the cause of a horse's starting. 


\section{Locked Jaw'.}

I have lately met with a case of locked jaw, that appeared to have been caused by a wound in the foot, which was completely cured by the following treatment. - Upon examining the horse, I found the wound in the foot nearly healed; the jaws so closed, that he could not even take food into his mouth, though he was constantly endeavouring to do it, and appeared very hungry, having been incapable of eating any thing about twenty-four hours before I saw him; the muscles of the neck were in a natural state, though the jaws were so closed as to prevent his taking food into his mouth; the teeth were not absolutely in contact; and we were able, but with great difficulty; to introduce gradually a large dose of opium and camphor. When we first attempted to give this draught, the animal appeared so agitated and resisted so much, that it required the assistance of screral men to give it. As soon as the medicine was given, a strong blister was applied to the spine, or middle of the back, beginning at the withers, and continuing it the whole length of the spine, even to the basis of the tail: the blister was carefully 
rubbed in, and afterward a fresh quantity was spread upon it in order to expedite it's action. A caustic was then applied to the wound in the foot. In about six hours we endeavoured to give some strong gruel, and found much less difficulty in doing it than in giving the medicine at first. The jaws, however, were still nearly close, and some dexterity was required to pour the gruel into the throat. Soon after this another ciose of opium and camphor was given, and water-gruel several times. During this time the jaws appeared to be rather more open, and there was less difficulty in giving the gruel. About twenty-four hours after the application of the blister, during which time he had taken two strong doses of opium and camphor, and some gruel, the horse was able to feed, and even to eat hay. Another dose, but weaker, of opium and camphor was given: the complaint did not return. The fatality of this disease in horses, and the consideration that a clearly stated case can be more closely followed than a general description 'of the treatment, have induced me to give a detailed account of this successful case. 


\section{Fever.}

In the former editions of this work, fever was considered either as a simple or original complaint, arising from suduenly suppressed or checkei perspiration, or as a symptomatic or complicated disease, depending up sn an affection of one or more of the internal organs, or their membranes. In both cases bleeding was recommended as an essential remedy. My practice since that time has not given me reason to change this opinion materially; but as some modem writers on farriery have described another kind of fever, termed putrid, or typhus, in which bleeding is extremely injurious, I think it necessary to state the observations, which an extensive practice has suggested to me on this subject. The grand characteristic of fever I conceive to be, an unusually quick pulse, $i$. $e$. from seventy to a hundred in a minute; a peculiar kind of sensation which it gives to the finger, as if it were struck sharply by the vibration of a cord; and at the same time a feebleness, or smallness, quite different from that gradual swell of the healthy pulse. When a horse labours under considerable debility, either 
from hard work, want of sufficient food, or other causes except fever, the pulse is more or less languid or weak; sometimes slower, at others a little quiclier than usual; still, howerer, it swells gradually, and does not gire that sensation we have described, and which physicians term hardness.

In fever there is either a total loss or a diminution of appetite, and the animal appears to be in pain; the natural evacuations (dung and urine) are generally deficient; and upon lifting the eyelid, we generally find it unusually red. The mouth feels hotter, and the tongue is comnonly dryer than usual.

In simple debility or weakness, whether it be occasioned by hard work or any ocher cause except fever, the mouth and tongue are in their natural state; the pulse, though weak and sometimes not easily felt if we press much upon the artery with the finger, does not give that sharp hard stroke which characterises fever; the horse readily sweats; and when the weakness is considerable the ears and hind legs will feel rather cold, and his fianks generally move quicker than usual. If blood be drawn, it will be found very different fiom that of a horse labouring unde: 
ferer or inflammation. (see Bleeding.) The appetite, though dininished, is not quite gone; the inner surface of the eyelid is seldom unusually red, often less so than in health; and the horse does not appear to be in pain. Though bleedirg in such cases is extremely injurious, a nild laxative is useful, unless the dung be softer and in greater quanity than natural; and if there be a deficiency of urine, or any difficulty in roiding it, a diuretic, composed of camphor and nitre, should be given. 'This symptom, however, scldom occurs in these cases. After the laxative, tonics, with a nutritious diet and good grooming or nursing, generally restore the animal in a short time to health. This disease is sometimes mistaken for fever, and treated improperly. 'They are cases of this kind, howerer, that farriers so frequently cure under the name of fever by medicines of the cordial or tonic kind.

I never saw any kind of fever, in which bleeding and generally laxatives were not manifestly useful, if employed judiciously at an early period; that is, if the quantity of blood drawn, and the strength of the laxative, wcre properly adapted to the strength. 
of the animal and the violence of the disease, and employed at it's first appearance. Severul cases have occurred where debility quickly succesded the inflammatory commencement, and rendered bleeding, sometimes purging also, highly improper; and it is perhaps such cases, that some writers have mistaken for the typhus, or low putrid fever: others appear to me to have copied their description of it from thut given by writers on human diseases.

In cases of simple debility I have found the following medicines of great use, giving the laxative in the first place if the horse be costive, or even if the bowels be in a natural state: during it's operation, however, it is advisable to give strong gruel instead of bran mashes.

\section{LAXATIVE.}

Barbadoes aloes, -

Powdered canella,

Prepared kali,

$-\quad-3 \mathrm{dr}$.

Mint water,

Mix for one draught. 
TONIC.

Ycllow Peruvian bark,

$6 \mathrm{dr}$.

Cascarilla

Powdered opium, - $\quad-\frac{\mathrm{r}}{2} \mathrm{dr}$.

Prepared kali, - $\quad$ - $1 \mathrm{sc}$.

Sirup enough to form a ball for a dose.

It is often necessary to increase the proportion of bark, and sometimes of the other ingredients; but when the horse becomes costire, the opium must be omitted.

The most proper food on these occasions is good sweet oats, and the best hay given frequently in small quantities. The horse should be allowed to drink also frequently; his exercise should be very moderate; and when the weakness is considerable, he should be allowed to exercise himself in a large stall or box, and not taken out until he gets stronger. If he become costive, a clyster, or eren a mild laxatire may be given. I have met with a disease in colts of about two or three years old, in which the debility was extremely obstinate. The disease began with swelling about the chest and belly, great 
weakness, diminshed appetite, and a rather quick pulse, without that hardness churacteristic of fever. In the most remarkable case of this kind, the colt (three years old) was at tacked in the month of May while running in a fine piece of grass: the first appearance of illness was his separating hinself from his companions, standing with a dejected appearance, and not grazing as usual. When examined, considerable swelling was observed about the chest, between the fore legs; and when I saiv him, the pulse was about sixty in a minute, yet soft: he did not refuse his food entirely, but appeared indifferent about it; nor was there any symptom which indicated an affection of the internal organs. He voided his urine without difficulty, and in the usual quantity; but as the dung appeared harder, and in less quanticy than is usual with horses at grass, a weak laxative was first administered. He was taken up and put loose into a cuol stuble, which opened inio a large court, the door being left open: he was offered frequently young lucerne, clover, \&c., and allowed to drink when he chose it. 'The swelling and weakness increased consiclerably; a medicine, composed of bark, vitriolated iron (salt of steel), 
and a little canella, was therefore given, and a more urutritious diet allowed; viz. gruel, arrow-root powder boiled in the usual way with water, and a handful of oats now and then. The tonic medicine so improred his appetite, that he readily took a moderate quantity of this food; yet the weakness continued, the swelling increased, and the pulse remained in a low feeble state, but rather slower. The swelling was scarified, and a large quantity of water eracuated, by which it was greatly diminished; the dose of tonic medicine was increased, and joined with diuretics occasionally. His appetite improving, he was allowed to take an unlimited quantity of the most nutritious food, which was varied so as to keep up his appetite; and by persevering in this plan about a fortuight he appeared to be quite recovered. About a fortnight after this the discase returned with greater violence, the swelling extended all over the under part of the chest and belly, the pulse became very weak but not much quicker thin before, and the animal was extremely feeble. By persevering in the use of the tonic medicines, and assisting them by the most nutritious diet, such as strong gruel, new milk, 
oats, \&c., the colt perfectly recovered. I have seen several cases of this kind, one of which proved fatal from the negligence of the owner, who did not supply the colt with a sufficient quantity of nutriment, which seems to be as necessary as medicine; and when a colt in this complaint refuses his food, I have found it necessary to arench him frequently with strong grui, boiled arrow-root, sago, or milk. It is proper also to vary the food so that the animal may be tempted to eat oftener than he would otherwise: for this purpose carrots, lucerine, \&c., are useful. The oats should be perfectly sweet; and should the colt be found to prefer them in a moist state, they may be sprinkled with water.

Epidemic Fever-or Distemper.

The epidemic diseases of horses generally appear in the form of a violent catarrh, or cold. The first symptoms are cough, heaviness of the head, the eyes often watery, or a little influmed: sometimes there is a quickness of breathing; and the inflammation of the membrine which lines the throat, nose, and wind- 
pipe, is often so considerable as to cause a difficulty in swallowing; the pulse is generally quicker than usual. If the proper remedies be not employed at this period, the horse becomes very weak, and considerable fever takes place; the appetite goes off; the cough and quickness of breathing increase; and debility is so great, that the aninal staggers in his walk. There is an offensive discharge from his nose; and after lingering some time, the horse dies from a consumption. Nore commonly, however, a discharge of white matter takes place from the nose after the discase has continued a few days, by which the cough and other symptoms appear to be lessened; but though the horse slowly recovers lis health and strength, a troublesome and sometimes incurable cough remains. When the discase is properly treated at it's commencement, the horse perfectly recovers in a short tine, unless the attack is very riolent; aud even then by judicious management the cough, as well as the other symptoms, may be cured.

When an epidemic happens, horses should be carefully watched; and on the first appearance of any symptoms of the disease, the horse 
should be bled moderately, unless he is in low condition, or previously exhausted by hard work, old age, or unwholesome food. After blecding, give the following laxative, and let the horse's diet consist of bran mashes, sweet hay, and a very small quantity of oats. When the attack is moderate, these remedies are generaliy sufficient to efiect a cure, taking care to prevent a relapse by nursing, and giving every day a close of some antimonial preparation, of which that which resembles Dr. James's fever powder is the best.

But when the inflammatory symptoms are at first violent, when there is a quickness of breathing, soreness of the throat, and distressing cough, a blister to the throat is necessary; and unless reakness forbids, bleeding even to three quarts is proper. A laxative is always beneficial at first, if the bowels be not already too open; after which the antimonial with nitre is to be given daily. Warm clothing, and frequent hand-rúbbing to the lègs, are useful; but a close stable is injurious. The horse should be turned loose into a large stall; and if a discharge from the nose appear, let it be encouraged by causing the vapour of warm water to pass through the nostrils, 
and clothing the head and ears. When the disease from being neglected or improperly treated at first becomes alarming, and the weakness considerable, nothing but tonic medicines and a nutritious diet can do any good.

\section{LAKATIVE.}

Barbadoes aloes, - - $2 \mathrm{dr}$.

Tartarized antimony, - $1 \mathrm{dr}$.

Mis first with about $4 \mathrm{oz}$. of warm-water; and then add $4 \mathrm{oz}$. of castor vil.

To be given at one dose.

\section{Diseases of the Stomach.}

The principal diseases of this important crgan have been before described. There is one, however, which I have but briefly noriced, and which has been denominated stomach staggers, from it's resemblance to upop'exy, or brain staggers.

A description of the symptoms has been given already. (See Stuggers, p. 97-99.) It has been proved, that this disease arises fiom a distension of the stomach by food. 
The stomach, with its contents, of one horse that died of this complaint, weighed nearly sixty lbs. Its coats were so stretched that they were easily torn, and had, no doubt, lost all power of contracting. Some time before death, the food which it contained was rather hard, consisting of imperfectly masticated hay and oats. The yellowness observable in the horse's eyes and mouth apprared to have been occasioned by the pressure of the stomach upon the gall duct, causing the bile to return into the circulation. A considerable number of horses that died of this disease was examined, and the same appearance cbserved in all of them: we therefore concluded the immediate cause of this kind of staggers was an accumulation of indigestible food in the stomach : but as the disease also happened to horses at grass, and in two or three case. even to such as had been at grass some time without being changed into other grass, it became necessary to inquire into the couse of this accumulation. In nany cases, where it attacked horses kept in stables, it was ascertained without difficulty. The horses most liable to it were such as had been much exhausted by hard work, unwholesome food,

IOL. J. P. 
or old age; and not unfrequently all three of these causes had concurred in exhausting the animal's strength. Most commonly the immediate cause was found to be that which we have before alluded to in page 274 ; that is, allowing a horse that has been kept a considerable time without food, and just come into the stable from a long and fatiguing journey, to eat an unlimited quantity of food, without giving a sufficient quantity of water to enable the stomach to digest it. This, however, could not have been the cause in the horses attacked at grass; yet upon inquiry it was found, that such horses had been used ill or worked hurd, previous to their going to grass, and were generally old horses. It is probable therefore, that the disease was brought on by the horse's eating voraciously of some unwholesome grass, which might act as poison on the stomach, depriving it of the digestive power, the effect being more readily produced in weak stomachs or debilitated constitutions. Whenever the stomach staggers happen, the proprictor is greatly alarmed from an opinion which generally prevails of its being contagious. There are some circumstances which seem to countenance this opinion; 1st. that 
it often attacks more than one horse when several are kept in the same.stable, not at the same time, but in succession; many farmers having lost several horses in a short time from this disease. I am satisfied however that it is not infectious; and when a farmer happens to have sereral horses attacked with staggers, either at the same time or in succession, it can only be attributed to his negligence or hard treatment of the animal: considerable experience and careful investigation have convinced me of the truth of this remark. The only method of removing this disease is to exhibit strong purgatives, joined with aromatics and other stimulants, at an early period; for if the stomach be distended to a certain degree, no medicine can restore it*.

* When the stomach has its vital power considerally dimiaished, its contunts become subject in some degree to chenics? laws, by which all dead matter is governed, or in other word; fermentation will take place, and a quantity of air be extricated in consequence so as to increase the distension. This often occurs to horned caltle when brought suddenly into a iuxuriant pasture, particularty clover. I once met with a case where a horse, getting loose during the night, found the corm-chest open: nent morning he was lying dead in the stable: and on openin; th: body, a large quantity of oats was found in the stomacis. Then= 
I do not think it advisable in this discase to give a large quantity of purgative medicine at once, but some powerful stimulus must be exhibited in order to give the stomach sufficiant energy to expel its contents. The purgative, with weaker stimulants, may be repeated once in ten or twelve hours; and about a pint of salt water erery second hour; with a teaspoonful of compound spirit of ammonia. This will serve to moisten the contents of the stomach, and stimulate moderately at the same time. Clysters are also to be giren now and then, so as to remore any hard "xcrement, that mag' get into the last gut. The distension of the stomach causes an accumulation of blood in the ressels of the brain; the horse hangs down his heal, or forces it against the wall, appearing insensible. It is necessary then to take a moderate quantity of blowl from the temporal artery; but in rebilitated constitutions, copions bleeding is rery injurious. It is advisable, when this sunptom is cbserved, to eontrire some means for supporting the horse?s head. If by these

part it was ruptured; and some of the corm had fallen through the opening into the cavity of the belly. I have sines bearch of suo eiruilar car's, 
means we succeed in procuring an eracuation of hard dung, there is reason to expect a recovery, particularly when, after emptying the gut by a clyster, or by the hand, a fresh quantity is soon after found in it. When the excrement becomes thinner, or the horse purges, we maty be satisfied that the disease is removed, and then we have only to support the animal's strength with strong gruel given frequently, a simall quantity of oats now and then, and tonic medicines. Should the horse be inclined to eat hay, a very small quantity only should be allowed at once. By adopting this plan I have often succeeded in curing this dangerous disease; but it is absolutely necessary to watch the horse constantly, and apply the proper remedies frequently. Without this attention success must not be expected. Besides, horses thus affected will often injure themselves during their delirium, unless constantly watched and prevented. I do not think it difficult to distinguish between this and that kind of staggers which depends simply on an affection of the brain: 'in the latter there is a more furious delirim; the eyes and mouth are not tinged yeliow; there is not that conrulsive twitching in the breast; 
the fore-legs do not give way now and then, as if the horse were on the point of falling; it generully attacks horses in high condition, particularly such as have been well fed and not sufficiently exercised.

The stomach staggers, on the contrary, generally attacks horses of debilitated colistitutions, that are worked hard and ill fed. When it attacks horses apparently in good condition, we coinmonly find that they are rather old, and have been exposed to hard work: cases of this kind sometimes occur among waggon horses, particularly when from the sickness or inability of one or two of the team the remainder are obliged to perform the whole of the labour: sometimes it happens, as we have before obserred, from feeding voraciously as soon as a lorse returns from a long journey, and not taking in any water, or not ellough, to moisten the food and render it digestible, or frum swal. lowing the foot hastily without proper mastication. In whatever way this complaint is brought on, the symptoms are always nearly the same, varying only in degree. The delirium is generally proportioned to the distension of the stomach. When this is con- 
siderable, the animal appears to suffer the most excruciating pain; and though generally delirious or stupid, it is very different from that furious madness, which inflammation of the brain occasions. When the stomach staggers has happened to horses at grass, they are generally found in the hedge; and if taken out, are always attempting to gro forward until they meet with some obstacle, and are so insensible, that if a deep ditch or pit lie in their way, they do not endeavour to avoid it, but generaliy fall into it. I never saw a case in which there was not that convulsive twitching of the chest, and tottering of the fore-legs, before describet: yellowness of the eyes and mouth is also a constant symptom. I thought it necesiary to be thus particular on this subject, as it is really a very serious and destructive lisease, and, unless treated in the way I have pointed out, amost ahrays proves fatal. I shall subjoin a few formulic for the medicines to be given in this dicease. 


\section{STOM.ACHC PURGATIVE.}

$$
\text { No. } 1 .
$$
Barturitoes alces, 6. dr. to 107.
Calonel, - $\frac{x}{2} \mathrm{dr}$. to $1 \mathrm{dr}$.
Cascarilla, - - - $2 \mathrm{dr}$.
Oil of penpermint, - 20 drops.
Tincture of cardamoins, $2 \mathrm{oz}$.

Viatel (as warm as it can be conveniently

$$
\begin{aligned}
& \text { given) } 12 \mathrm{oz} \text {. } \\
& \text { Mix for one dose. }
\end{aligned}
$$

The quantity of aloes must be regulated by the horse's size, strength, \&c. I have sometimes added' a dram of prepared ammonia to this draught, which, though it renders the calomel less active, seems to be a useful addition. If no evacuation be obtained in about twenty hours, give another dose, with half the quantity of aloes, aud about $6.0 z$ of castor oil; and, during the interval, let some moderate stinulant be given; as,

$$
\text { No. } 2 .
$$

Common salt, - _ $10 \%$ Water, - - - $80 \%$

Compound spirit of ammonia, $1 \mathrm{dr}$. Mix. 


\section{No. 3.}

Tincture of cardamoms,

2 oz.

Mint water,

$12 \mathrm{o} z$.

\section{Mix.}

Clysters also are to be given often, composed of

Common salt, - $\quad 4 \mathrm{Oz}$.

Water, - 3 or 4 quarts.

Linseed oil, - $\quad$ - $4 \mathrm{oz}$.

Mix.

\section{Diseuses of the Bowels.}

It is a fortunate circumstance for horses, as well as for their owners, that immoderately strong physic is not so fiequently giren as it used to be. An ong the numerous inconveniences arising from the strong purgatives recommented by writers on furricry, such as twelve or fourteen drams of aloes, either alone or with calomel * there is one we have not hitherto noticed, which we shall now describe.

* A fow weeks ago. I was requested to attend a sick horse: it appeared, that the groom had given lim $10 \%$ of Cape aloes, which operated with great violence, and lad continued to act wo or three days after. On my arrival, it was too late to saxe R. 5 . 


\section{COMPENDIUM OF THE VETERINARY ART.}

Though they do not destroy a horse, they often weaken him so much, that it requires sometimes several weeks to restore the strength; but several cases have occurred where the bovels had been rendered so irritable from the violent effect of physic, that they became subject to troublesome and even dangerous diseases. A case of this kind has been already mentioned. (See page 270, note.) Sometimes obstinate costiveness is occasioned by it; at others a constant tendency to diarrhœa and colic. When a horse, whose bowels have been thus injured, is attacked with colic or gripes, the strongremedies commonly employed, such as gin, pepper, \&c., often prove fatal by exciting inflammation. The following draught will be found most useful, giving frequently small quantities of gruel, linseed tea, or any other mucilaginous fluid, and injecting a clyster of the same kind. The only method of curing. the irritability or tenderness of the bowels

the animal: he soor: after died from inflammation of the bowels. The Cape alocs are certainly the weakest kind. I have seen several horses destroyed by larger doses than this, such as ten, twelye or fourteen drams; and as often, and perhaps more, from. *ascrtrine sina Bartadces aloes. (See note to page 226.) 
radically is, to avoid every thing of an irritating quality, and very cold water, until they have recovered their original strength.

\section{THE DRALGHT.}

Oil of peppermint,

Tincture of opium,
20 drops.

$$
\text { - } \quad \frac{x}{2} 0 z \text {. }
$$

Gum Arabic (dissolred in a ? pint of warm water),

$$
\text { \} oz. }
$$

The costiveness produced by the above practice occasions symptoms, which often deceive the inexperienced practitioner. The horse appears to be in pain; often makes fruitless efforts to dung, sometines there is a suppression of urine, particularly when the proper remedies have not been seasonably: applied; some degree of fever takes place; and at length colic pains. All these symptoms may be speedily removed, by drawing out the excrement with the hand; afterward throwing up a clyster and giving the oily laxative. But I have seen hot drenches given in this complaint; and when these were found to increase the pain instead of affording relief, 
the animal was profusely bled. When the suppression of urine was observed, diuretics were giren. In some cases the disease is cured by an effort of nature; sometimes it continues so long as to cause inflammation of the bowels.

\section{OILY LAXATIVE.}

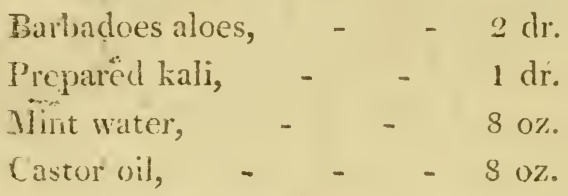

Mix for one dose.

Hoten Grease.

This also is a discase of the intestines, and generally dependant on some constitutional affection. Horses that have been well fed and had but little exercise are more liable to this complaint. 'Though such horses appear sleck and fat, they are not fit for violent or long continued exertion, unless bronght to it gradually; therefore, when suddenly put to work in thic siate, and particularly if cmployed in hunt- 
ing or other violent exercise, a fever is often the consequence, which commonlydepends upon gyeneral inflammation or increased action of the whole arterial system. In this disease, nature sometimes makes an effort to remore it; that is, a violent purging takes place; the mucus, which is constantly formed upon the inner surface of the bowels in order to lubricate and protect them from the action of any acrimonious matter that may happen to be passing through, is now formed in greater quantity, and is often so abundant, as to appear something like fat mixed with the dung. When blood is drawn from a horse in this state, a large quantity of the infammatory crust (the coagulable lymph, or buff-coloured jelly, before describeil) appears on its surface *.. (vice Bleeding:)

* According to Mr. John Lawrence, molten grease consists in a colliquation or general melting of the fat of the body, great part of which is ubsorbed, and thrown upon the blood and upon the intestines, whence it is voided with the excrement. Mr 13lainc, in his Treatise on Veterinary Medicine, has called this explamation of the discase an absurdity! and though I feel all due respect for the efforts of Gibson, Brackess, and Bartlet, as well as for their commentator and pausegyrist, Mr. Jolın Lawrence, I am compelled by experience, and the knowledge I have obtained of the animal econony from the valuable instructions of those emi- 


\section{CONIPENDIUM OF THE VETERINARY ART.}

Molten grease, therefore, is not to be considered as a distinct disease; but only as a symptom, which sometimes appears in general inflammation, or fever: it happens more frequently however in the latter. When a horse labours under fever or general inflammation, we most commonly find some of the internal organs more affected than others. When there is a difficulty of breathing, the flanks moving with unusual quickness and the nostrils expanded, it indicates an affection of the lungs; when molten grease appears, it shows, that the mucous membrane of the bowels is more particularly affected: sometimes both.

nent teachers, Dr. Baillie, Messrs. Cline, Abernethy, and Cooper, to acknowledge that Mr. L.'s description is really an absurdity, and affords a convincing proof of his incompetency either to teach or practice the Veterinary $\Lambda$ it.

l am sorry to find myself under the necessity of making this remark; but, as an opinion so erroneous must lead to practical errours, I feel it a dnty so to do. And I must beg leave to add, that what Mr. Lawrence has since written on the disease, his explanation of what he terms an inadvertent inaccuracy in his description, his sattirical rewarks on Mr. Blaine, and his attenupt to show, that Mir. Biain in his explanation of the disease meant to offer it to the who wrote abuut 176.5 had anticipated him, appears to me a strang coufirmation of Mr. Blaine's accurate knowledge of the animal economy, and of Mr. L.'s total ignorance of the subject. 
these parts are affected at the same time. The principal remedy in this disease is copious bleeding according to age, strength, and other circumstances of the case. (See Bleeding and Fever.) It is often necessary to repeat the operation; oily laxatives are to be given, and rowels inserted in the chest and belly, if the lungs be the principal seat of the disease; and the sides may be blistered, or the mustard embrocation rubbed on the sides and belly. In molten grease, or when the bowels are affected, if there be a copious purging, let no attempt be made to suppress it ; rather let it be encouraged by giving frequently decoction of linseed, gum Arabic dissolved in water; starch, or the powder of arrow root, boiled in water. When the dung is voided only in small quantity, but frequently, particularly if there be any knobs mixed with it, give a pint of castor oil, which may be repeated if necessary about two days after. In this case also it will be proper to rub the mustard embrocation on the belly. Should the disease continue after this, and particularly if there be considerable irritation about the anus, the horse frequently ejecting a small quantity of excrement, and appearing to suffer much pain, the opiate. 


\section{COMPENDIUM OF THE VETERINARY ART.}

clyster may be given. If this appear rather to increase than remove the pain and irritation, the dose of castor oil must be repeated, and a clyster thrown up, composed only of watergruel and a little oil *

Mr. Blaine, in his Treatise on Veterinary Merlicine, describes this disease somewhat differently, and considers it to be the same as the human dysentery. I must confess, however, that during an extensive practice of ten years I have nerer met with a single case that resembled the dysentery described by medical authors. I have often observed, during the progress of symptomatic ferer, internal inflammation, mucus mixed with the dung, which had sometimes the appearance of part of one of those long white worms so often found in the horse's bowels; at others it resembled a membrane. I hare observed the same

* It is necessary on this occasion, particularly, to be careful. in exhibiting the clyster, as the gut is so extremely irritable and tender, that if the pipe be rough, and introduced without caution, it may rather do ham than afiord relief: therefore let the pipe be perfectly smooth, covered with oil or lard, and not forced in with violence : it is probable, that a small short tube of kone, about three times the bnik and length of the pipe used. in tuman medicine, would be preferable on this occasion to that sommonly employed. 
thing in horses apparently healthy, or after the operation of very strong physic. I have also seen many cuses, where there was tenesmus, or considerable irritation in the rectum, the horse frecuently voiding a snall quantity of dung, and appearing in pain. But this was always either a symptom of some more important complaint, and easily removed, or the effect of physic, and very unlike dysentery. (See Inflammation of the Lungs and Bowels, and Symptomatic Fe'er.)

\section{OPIATE CLYSTER.}

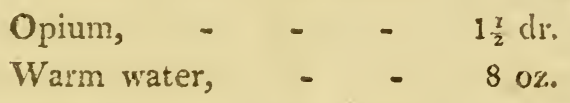

\section{Miz.}

'To this add about a quart of smen water; that is, starch boiled in water in the usual way, and of a proper consistence for a clyster.

\section{Diseases of the Urinary Organs.}

Suppression or stoppage of urinè may arice from several causes. It generally takes place when horses are attacked with Hatulent colic, and is then improperly considered as the 


\section{COMPENDIUM OF THE VETERINARY ART.}

cause of that complaint; but when the colic is removed, the horse stales freely. In obstinate cases of suppression, where the horse has not been observed to stale for two or three days, it is necessary to examine the bladder, which may be easily done by introducing the hand into the rectum or straight gut, through which the biadder is readily. felt when distended with urine: when the bladder is found in this state, an evacuation must be speedily obtained, or the animal may be destroyed. In mares there is no difficulty in introducing a catheter, or hollow tube, into the bladder, through which the urine will flow out. In a horse this operation is not practicable, on account of the great length and curvature of the passage: it has been reconmended, however, in such cases, to introduce a bougie, or long smooth probe, into the passage, and to pass it forward, until it arrives at that part where the principal curvature is; that is, about two or three inches below the anus. The probe being held steadily in this situation by an assistant, the operator is to make an incision carefuily, so as to cut upon the top of the probe, and lay open the passage. This being done, a hollow tube, 
even the finger, may be readily passed into the bladder, and let out it's contents.

In making this incision, the skin is to be drawn on one side, so that when the operation is finished, and the urine evacuated, the opening in the urethra, or passage, and in the parts which cover it, will not correspond; and the opening in the former will be completely covered. IVithout this contrivance a fistulous opening would probably remain during the horse's life; indeed such a consequerice is to be apprehended, in whatever way the operation is performed; but fortunately such obstinate cases of suppression very rarely occur.

When the bladder, upon being examined through the rectum, is found empty, or when it cannot be felt at all, the suppression must depend on a disease of the kidneys. When these organs are much inflamed, they cease to form urine, or form it only in very sinall quantity; but the most common cause is a gradual decay of the kidney. (See Inflmmation of the Kidney, page 60,) This is known by the horse having become thin and weak gradually; having been attacked before with similar complaints but in a less degree; having been observed to move his hind legs 
awkwardly in trotting; and giving way when pressed upon the loins. When it is clearly ascertained, that the suppression of urine arises from this cause, and particularly if the horse be old, and extrensely feeble, there is no chance of recovery; and death soon terminates his misery. It may happen, however, that the kidneys cease to perforn their office, or do it imperfectly from other causes, without having suffered an alteration or decay in their organization or structure. In such cases, provided no symptoms of inflammation exist, the following drink may be given and repeated when necessary.

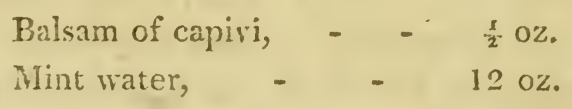

Mix for one dose.

It may be necessary on some occasions to give a larger quantity of the balsam: it is advisable, however, to begin with a small dose, and carefully watch it's effect: if it appear to incrcase the animal's pain, without causing an evacuation, there is reason to suspect, that some mistake has bee mate as to the cause of the suppression; and the symptoms 
should be again carefully investigated. It has been observed before, that suppression of urine is most commonly occasioned by spasm in the neck of the bladder, and sometimes by an accumulation of hard excrement in the rectum. In the former case, the cainphorated ball (see page 106) soon affords relief: in the latter, it may be obtained by draving out the hard excrement with the hand, clysters, and a laxative.

We sometimes observe horses frequently endearouring to stale, voiding only very small quantities, and that with some degree of pain, or straining. Such symptoms depend on a diseased irritability or tenderness of the bladder; so that when only a small quantity of urine gets into it, it immediately contracts, in order to squeeze it out. It may sometimes depend on the urine being anusually strong or acrid: in either case the following drink may be given, and the horse should be allowed to lrink freely. If he refuse to drink, he should be drenched frequently with water-gruel, deroction of linseed, marshmallows, \&c. If he be costive give castor oil and clysters. 'This disease is commonly occasioned by blis- 
ters, the cantharides of which they are composed being absorbed into the circulation.

THE DRAUGHT, OR DRINK.

Camphor, - $\quad-\quad 1_{2}$ to $2 \mathrm{dr}$.
Powdered opium, $\quad-\quad \frac{\mathrm{r}}{2} \mathrm{dr}$.

$\left.\begin{array}{l}\text { Gum Arabic dissolved in } \\ \text { warm water, }\end{array}\right\} \mathrm{oz}$.

Mix for one dose.

And let it be repeated, if the symptoms continue, about twelve hours after, giving, during the interval, gum Arabic dissolved in water, decoction of linseed, \&c. From too great exertion in leaping, or from other causes, a horse sometimes voids bloody urine. In such cases the mucilaginous drinks, composed of gum, linseed, \&c., are proper. It is necessary also to give the following draught, night and morning, until the urine assumes it's natural colour.

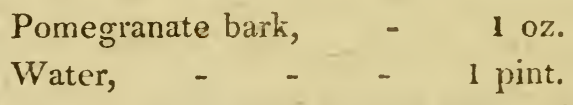

Boil them about half an hour: strain off the liquor, and add,

Powdered alum, - $\quad 10 z$.

For one dosc. 
If this prove ineffectual, add to it about a dram or two of vitriolic acid, or even more, provided it be so diluted with water, or the above decoction of pomegranate, as to do no injury to the throat: this point may be determined by dipping the finger into the mixture, and applying it to the tongue. If it be so sour as to occasion some degree of pain, or a very unpleasant sensation, more water may be added.

When the disease continues some time, there is danger of it's proving fatal; the horse's strength must then be supported by the most nutritious diet; and tonics, such as bark, with opium. (See Fol. II., or Materia Medica.) Vitriclated iron may also be tried, warn embrocations may be rubbed upon the. back or loins, or a warm plaster laid on it, composed of common turpentine, Burgundy pitch, and bees' wax; four parts of the first, two of the second, and one of the third article. When the urine assumes a brown or coffee colour, the pulse becoming very quick and weak, intermittent or irregular, and the animal getting gradually more feeble, there is no chance of recovery. 


\section{Grease.}

This disease has been described before in page 117; but in one of the formulæe for an astringent lotion (No. 3) there is an important error of the press; instead of water 1 ounce read 1 quart.

In inveterate cases of grease the heels often become ulcerated, sometimes in a considerable degree. These ulcers are generally very painful, particularly when situate on the back part of the pastern ; they are also more diflicult to cure in this situation from the frequent motion of the part. In the treatment of these ulcers, or cracks as they are often termed, cleanliness is of great inportance; and when they appcar inflamed and painful, apply a soft poultice, in which a little Goulard has been mixed, for two or three days. The following ointment (No.1) may then be applied, spread on tow, and secured with a light thin bandage. It often happens, that cracks or ulcers appear in the heels, withont that general swelling of the leg and discharge of matter, which constitute the disease named grease. It may then be soon cured by applying the 
astringent ointment, and giving a few doses of the diuretic alterative (see Vol. II, or Materia Medica): but when it is accompanied by the grease, laxatives or purgatives are proper, according to the condition of the animal. If the ulcers in the heel be deep, exercise appears to prevent their healing; and shave found it the best plan, when such ulcers are not accompanied with much swelling; to keep the horse in the stable until they are nearly healed, dressing the sore with the ointment (No. 1), and applying a bandage so as to keep the part as steady as possible. When this plan is adopted, it is necessary to keep the horse on a cooling opening diet, and to rub the legs frequently and briskly with the hands: a few of the diuretic alterative powders should also be given. When proud flesh, as it is commonly termed, appears in the ulcers - that is, when the néw flesh rises above the level of the skin - it must be destroyed by caustics; such as blue vitriol powdered, or dissolved in warm water, or lunar caustic. When this is neglected, they sometimes increase to 2 large size, and become almost of a horny consistence, in which state they are commonly named grapes. Should the ulcer continue VOL. I. 
foul after applying the poultice, and without that red appearance which indicates healing, the hot solution of blue vitriol is to be poured "pon it, and the poultice repeated: this will cause a separation of the foul parts, or a sloughing, as it is termed; after which the sore will look red and healthy, discharging white matter and gradually filling up with new flesh, which, if it rise above the surface, is to be repressed with caustic.

In receut cases of grease in which the heels are inflamed and swollen, and discharge a whitish coloured matter, I have seen much good done by fumenting them for a considerable time with warm water, in which a small quantity of Goulard has been mixed, and applying immediately after the Goulard poultice. In obstinate cases of grease, where the matter discharged is very solid, the fermenting poultice is useful; that is, a poultice of linseed meal, warm water, and yeast: this soon removes the offensive smell, and causes a more healthy or less acrid matter to be formed. Powdered charcoal has been recommended for the same purpose.

In these inveterate cases, rowels in the thigh are necessary, and should always be em- 
ployed before any astringent applications are used. This unpleasant remedy however is only necessary, when the disease has continued some time. In recent cases, the Goulard poultice and mild purgatives will soon reduce the inflammation considerably; and then the cure is easily accomplished by astringent lotions. To prevent a return of the complaint, exercise and good grooniug are indispensably necessary: frequent hand-rubing of the less. and a diuretic powder now an then, are also useful. Horses with white lind legs, or such as are much disposed to swelling of the legs: should be bandaged for some time, particularly after hard work, keeping the bandage constantly moist with a solution of alum in water. In those hard habitual swellings, which are sometimes a consequence of grease, I lare several times seen blistering and firing tried, but never saw them do any good: the best palliative in such cases is the bandage applied as before directed.

In some cases of grease, the infanmation seems to extend to the cellular membrane under the skin, causing more severe pain and lameness, than when it is superficial. T'his inflammation generally terminates in an abscess 
of the heel, which bursts, and leaves a deep ill-looking ulcer. After this the general swelling of the legs subsides, and the animal appears to be considerably relieved: the ulcer however is extremely irritable, and difficult to heal, particularly if the horse be exercised. By applying poultices and warm digestive ointment, and by keeping the horse at rest, the ulcer gradually heals.

OINTMENT.

No. 1.

Fresh hog's lard, - $\quad$ - $4 \mathrm{oz}$.

White lead, finely powdered, $1 \mathrm{oz}$.

Mix.

ASTRINGENT OINTMENT.

No. 2.

Hog's lard, - - - $4 \mathrm{oz}$.

Palm oil, - - - $2 \mathrm{oz}$.

Fine olive oil, - $\quad$ - $1 \mathrm{oz}$.

To be melted, by placing the pot which contains it in boiling water: when melted, stir in $1 \frac{\pi}{2} \mathrm{oz}$. of the water of acetated litharge, and continue stirring until nearly cold.

When ulcers of the heels do not appear disposed to heal, the above ointment should 
be changed for one more stimulating, or the sore should be washed with a solution of blue vitriol previous to it's application.

STIMULATING OINTMENT.

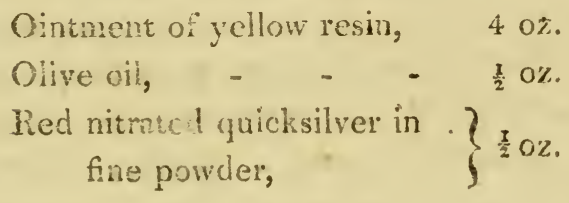

Mix.

\section{Coush.}

This disease so frequently occurs, and is so often rendered incurable by improper treatment, that it appears necessary to give it a more particular consicleration than we have done in the former editions of this work. Catarrh or cold is generally the origin of those troublesome and often incurable coughs, which have been named chronic coughs. Sometimes, however, they depend on irritation in the stomach and bowels. When a liorse catches culd as it is termed, if the attack be not violent, it is seldom thought necessary to take him from his usual work: he is bled moderately, takes a little nitre, and the complaint receives 
no farther attention, except a bran mash now and then, with nitre. By continuing his work, and being occasionally exposed to wet and cold, there is constantly an undue determination of blood to the membranes of the throat, windpipe, \&c.; oi, in otlier words, the catarrhal infiammation is krpt up by these means, till at length the membranes become thickened and irritable to sitch a degree, that the cold air, or the vapours and dust of the stable, irritate the membrane of the windpipe, so as to excite coughing almost continuaily. When the infammation has been but moderate, the irratibility of these membranes will not be so consiclerable, and the horse will only cough now and then; or when the membrane is irritated by the food or water, or by the dust of his hay or corn, or perhaps by too great a secretion of mucus *.

* All these niembranes are lubricated by a mucous fluid, which is constantly forming on their surface. When perspiration is checked by exposure to cold, an unusual quantity of blood is thrown upon these membranes; which causes a larger quantity of the mucous fluid to be formed. Hence the discharge from the nose in catarrh : for as the horee breathes only through the nostrils, the mucus discharged from the lungs by conghing does not pass into the mouth as in man, but into the nostrils. It is probable, that the mucus formed upon the membranes, when af- 
In violent colds the inflammation of the membranes is often very considerable, so as to render swallowing painful and difficult, and. cause a rattling in the head as it is termed; that is, from the increased secretion of mucus within the nostrils, or from swelling of the membranes which lines them, the air is interrupted in its passage, causing a peculiar sound in breathing. In some cases the inflammation extends to the branches of the windpipe, in consequence of which many of the finer branches are either partially or wholly plugged up by the coagulable lymph which is poured out. Sometimes there is so much coagulable lymph poured out in the windpipe as to render respiration difficult, and cause that sonorous breathing, which is technically named roaring. When some of the branches of the windpipe are plugged up with coagulated lymph, it causes also quickness of breathing; for the lungs being now unable to contain so much air as they did before, the animal is obliged to inspire more frequently to

fected with catarr , is rather of an acrid or stimulating nature, from being loaded with saline matter: this indeed is sometimes so considerable, as to inflame the shin of the lip over which it passes. This happens also sometimes in diseases of the eye, where the tears or water from the eye are so acrid, as to infwine the skin of the nose which it flows over. 
make "I) the deficiency. The cough in this case is rery distressing and almost continual, and sometimes recurs with such violence, that we feel apprehensive of its bursting some bloodressel. Broken wind is generally the consequence of this stage of catarth. (See Broken Wind.) When the complaint has proceeded thus far, there is no probability of curing it; but if it be properly treated at first, it scarcely ever runs such lengths: it is therefore highly necessary to pay attention. to colds, though they may appear trifing, and keep the horse from work until perfectly cured. Were this done, we should seldom hear of incurable coughs, roaring, broken wind, \&c.-complaints now so common, and so frequently the cause of disputes and lawsuits in the purchase and sale of horses. On the first attack of cold let the horse be bled in proportion to his strength and the violence of the attack: then give a laxative, and let his diet consist of hay and bran mashes. As checked perpiration is commonly the cause of the disease, the head, ears, and whole body should be kept much warmer than usual: a close stahle however is improper. Warm water and warm mashes should be given fre. 
quently; and when the horse is wisped or brushed, which showlit be done twice or three times a diy, there should be an active man on each side for the purpose: when they have finished, and replaced the clothes, let them rub the legs briskly for some time with their bare hands; the horse should also be well littered, and as the straw becomes damp from his staling upon it, let it be immediately removed, and some fresh dry straw thrown in. After the operation of the laxative, give' one of the fever powders, or the following ball every night and morning. If it occasion profuse staling or purging, it should be given in smaller quantity, or less frequently, or discontinued a day or two, When the symptoms do not abate after the bleeding and laxative, and particularly if the cough increase, and the horse appear to feel pain and difficuity in swallowing water, a strong blister should be immediately applied about the throat and under the ears, and the bleeding should be repeated. By these means the most violent colds are generally cured in a short time. But when the complaint has been, neglected at first, or improperly treated, a discharge of white matter often takes- place 
from the nostrils, and the horse becomes very. fecble. Under these circumstances bleeding would be improper: but a very mild laxative may be given, unless the bowels are already open; and a blister to the throat is eminently useful. The discharge should be encouraged by steuming the head; that is, by tying the horse's head to the rack, and throwing a hot mash into the manger immediately under his nose. Strong gruel should be given freely to support his strength; and the ball (No. 2) every night. In the third stage of catarrh, that is, when coagulated lymph has been thrown out upon the membranes of the windpipe or its branches, there is little chance of a cure*.

The following expectorants may afford some relief, however, and should therefore be tried.

* I have heard of three cases, where a horse, having had that rio!ent and distressing cough for soune time, which has been described in the text as a consequence of the third stage of catarrh, was spontaneously reliered, by coughing up a large piece of coagulated lymph. In one case the horse was galloped violently up a till for the purpose: the cough which this exertion occasioned was so violent, that the animal could scarcely stand; at length a considerable quantity of coagulated l $y$ mph was discharged, and the hurse, thongh supposed to be broken-winded before, perfiectly recorered. 
Blistering the throat has also been recomin ended; but I have several times giren it a fair trial withont success.

The next kind of cough to be described is that which seems to depend merely upon an unuatural degree of irritability of the nembrane which lines the larynx, or top of the windpipe; and may be distinguished by being less violent, and not being accompanied by an unusual quickness of breathing*: the cough generally comes on after drinking or feeding, particularly when the hay or oats are diy and dusty. This kind of cough is always more troublesome in a close stable.

A blister to the throat is useful in this case; and if that be thought inconvenient, some warm embrocation should be rubbed about the throat and under the ears twice a clay, and the head and neck kept warm: the hay and oats should be free from dust, and sprinkled with water. If the horse be inclined to eat his litter, let him be muzzled; if costive,

* It is probable, that in some cases this kind of cough depends upon the stimulating quality of the nucous fluid, which is formed upon the part. It is advisable therefore, to add to anodyne me. dicines such as are of an oily or mucilaginous quality, which, if not efficacious, are certainly innocent. 
give a mild laxative, and afterward the anodyne ball or draught every morning: moderate exercise is useful. It is sometimes difficult to cure this kind of cough; and, when apparencly rcmoved, it often returns from trifling causes. By persevering in the above mode of treatment, however, I have generally succeeded.

With respect to the cough which is caused by worms in the stomach or bowels, it may be distinguished by the general appearance of the animal: he is commonly hidebound, has a rough dry coat, and becomes thin, though well fed; he appears dull, and is fatigued by moderate exercise. The most certain criterion however of the existence of worms in the bowels is the appearance of a white stain just beneath the anus, or their being voided with his dung.

This kind of cough is less violent but more frequent than the former kinds. (For the treatment of it, see IFoms.)

\section{BALL FOR CATAFRH.}

$$
\text { No. } 1 .
$$

Emetic tartar, - $\quad$ - $1 \mathrm{dr}$.
Powdered aniseed, $\quad-\quad 3 \mathrm{dr}$.

Sirup enough to form a ball for one dose. 


\section{BALL.}

No. 2.

Canella bark, powdered, $\quad 1 \frac{\delta}{2} \mathrm{dr}$. Emetic tartar, - $\quad$ - $1 \frac{\mathrm{r}}{2} \mathrm{dr}$. Powdered opium from $1 \mathrm{sc}$. to $1 \mathrm{dr}$. Camphor, from $\frac{\mathrm{I}}{2} \mathrm{dr}$. to $1 \frac{\mathrm{I}}{2} \mathrm{dr}$. Sirup and flour to form a ball for one dose.

\section{EXPECTORANT BALL. (See page 72.) \\ No. 3.}

Gum ammoniacum, from 3 to $5 \mathrm{dr}$.

Powdered squills, - $1 \mathrm{dr}$.

Opium, - - $\quad$ - $\frac{\mathrm{r}}{2} \mathrm{dr}$.

Powdered ginger, - $1 \mathrm{dr}$.

Sirup enough for a ball for one dose.

Remark. - Other formula may be seen in the second volume, or Materia Medica.

\section{EMBROCATION FOR THE THROAT.}

No. 4.

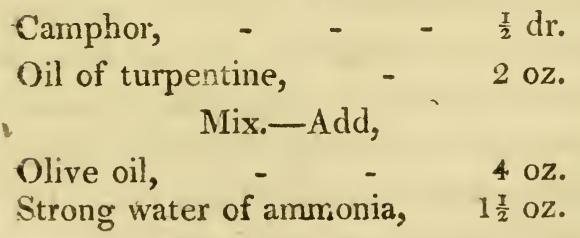

Mix. 
ANODYNE DRAUGHT.

Oxymel of squills, - $\quad 2 \mathrm{oz}$.

Opium, (mixed with $8 \mathrm{oz}$. of water) - from $\frac{1}{2} \mathrm{dr}$. to $1 \mathrm{dr}$.

Linseed oil, - $\quad 2 \mathrm{oz}$.

Mix for one dose.

ANODYNE BALL.

Opiun, from $\frac{\mathrm{T}}{2} \mathrm{dr}$. to $1 \mathrm{dr}$.

Camphor, $1 \mathrm{dr}$.

Powdered aniseed, $\quad \frac{\mathrm{I}}{2} \mathrm{OZ}$.

Soft extract of liquorice enough to form a ball for one dose.

\section{On Shoeing.}

In describing the method of shoeing fat and convex feet, a wide concave or hollow shoe has been recommended in all the former editions of this book: I have to acknowledge however my obligation to the Honourable Newton Fellowes, for suggesting to me a much better method of shoeing such feet. In flat convex or pumice feet (see Page 175, 176; and plate 4, fig. 1), the sole is so thin, as to be 
incapable of sufrering pressure without giving pain to the animal, and causing him to go lame; and so flat or even convex as to be much exposed to pressure. The shoe commonly employed for such feet is roide and hollor', so that it bears only on the crust, a space being left between the sole and the other part of the under surface of the shoe. When the horse has travelled a short time on the road, this space becomes filled with dirt, gravel, \&c., so that the sole is exposed to the same pressure as if the shoe were flat, or the horse without shoes; it is obvious then, that a shoe so narrow as to cover only the crust, and so thick as to raise it about $\frac{3}{4}$ of an inch from the ground, will more effectually protect the tender sole, than the wide hollow shoe; unless the horse be going upon a hard even surface, or the rider frequently dismounting to pick out the dirt which accumulates under the shoe.. I am convinced from the trial made of this narrow shoe, both by Mr. Fellowes and myself, that it will be found the best method of shoeing fat or convex feet; and it appears to me very probable, that upon a fair trial it would be found the best shoe for general use. Perhaps even heavy draught horses would do better 
with it, than with the wide heavy shoe, which is now universally employed for them. It may be necessary to remark, that though the narrow shoe for covering the crust only was recommended by the late Lord Pembroke, and employed by his order in his own regiment, the First or Royal Dragoons; yet for its particular application to flat or convex feet I believe we are indebted to the Honourable Newton Fellowes. 


\section{N D E X.}

A.

ABdomen, or Belly, . • . , . . 3

- viscera of, . . . $\%$. 11

Abscess described, . . . . . . 32

- - . . . . . . $i b$.

AGE Of A HORSE, • . . . . . . 287

Alteratives, . . . . . . 230

for the mange, . . . . 116

mercurial, . . . . 122

balls, - . . . . 119

Anaтомy of the internal organs, . , . 2

___ of the foot, . . . . 170

ANODYNE draught, . . . . . . . 54 .

clyster, . . . . . . . 54

Apoplexy, or STAGGERS, . . . . . 98

APPENDIX, . . . . . . . . 298

Astringent ointment, . . . . . . . 121

- lotion, . . . . 120

powder, . . . . 122

B.

Balls, cordial, • . • . . . 296

-_ diuretic, . . . . . . 230

purging or cathartic, . . . 224

- tonic, . . . . . 354 
Balıs, alterative, . . . . . 116,113

= for suppression of urine, . . . 378

_- for flatulent colic or gripes, - . 95

BILE, description of, . . . . . . 21

BLADDER, description of, . . . . . 26

Bleeding, . . . . . . . . 218

Blisters, . . . . . . 233, 236

BLOOD, • . . . . . . . 221

BoDy, divisions of the, . . . . . 3

Borrs, see Worms.

- sometimes injurious to the stomach, . 59

Bowcls, diseases of, . . . . . 369

BROKEN WIND, . . . . . . 84

- KNEE, . . . . 147

Brutses, . . . . . . . . . 14.5

C.

Canker, . . . . . . . . 213

Catarkh, . . . . . . . 69, 389

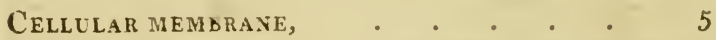

Chronic colgh, . . . . . 73,389

Circulation of the blood, . . . . 9

Clysters, • • • • • • • • 238

Colıc, flatulent, or gripes, . . . 92, 369

- how distinguished from inflammation of the bowels, . . . . . 55

Condition, • • • . • • • . 241

Cordial ball, . . . . . . . 296

Corns, . . . - . . . . . 207

Curb, . . . . . . . . 163

Cuttinc, . . . . . . . 215 
D.

Diabetes, or excessive staling, . . . 103

Diaphragm, or midriff, . . . . . 3

Diarrhea, or purging, . . . . . 101

Digestion, . . . . . . . . 17

Distemper, . . . . . . . 357

Diuretic, . . . . . . . . 230

Dropsy, of the chest, . . . . . 4

E.

Embrochtion, mustard, . . . . 54

Epiglottis, . . . . . . . . 4

Exercise, see Feeding.

Eyes, diseases of, . . . . . 75, 342

F.

FARCY, * * . . . . * . . 182

FEeding and exercise, • • • . . 26 t

FEVER, . . . . . . . 36,350

Fistula, . • . . • • • . 149

Fomentations, . . . . . . . 237

Fоoт, anatomy of, . . . . . 170

— diseases of, . . . . . 187

FrET, see Colic.

FRDG, see Foot.

G.

Gangrene, - • • • • * 33

Gastric juice, see Digestion.

Glanders, 
Glyster, see Clysters.

Grease,

Gripes, see Colic.

H.

Haw, see Eye.

HEART, . • . • . • . . . 8

Hidebound, . . . . . . . 112

Hoof, see Foot.

I.

Inflammation, . • • • . . . 1,27

internal, . . . . . . . 35

of the lungs, . . . . . . 42

_- - kidneys, . . . . . 60

—_ bladder, . . . . . 61

- - liver, . . . . . . 62

_

Intestines, description of, . . . . 15 length of, . . . . . . 15

J.

Jalndice, • • • • • • • • 91

Joints, structure of, . . . . . . 329

wounds of, . . . . . 143,329

K.

Kidneys, description of, * * . . . 26 inflammation of, . . . 60

KКLEg, RКОКеN, . . . . . 147 


\section{L.}

LACTEALS, . . . . . . . . 25

LAMPAS, . . . . . . . . 82

LARYNX, • • . . . . . • 3

Laxatives, - . 102, 106, 233, 353,360, 372

LOCKED JAW, . • • • • • 81,348

Lungs, • . • • • • . . . 3

Lyмгн, coagulable, see Bleeding.

M.

Mallenders, . • • • . . . . 123

Management, luring a journey, . . . 290

- MANGE, $1 / 5$. 2.21511

Mediastinum, . . . . . . . 4

Mesentery, . . • • . . . . 17

Molten grease, . • . • . . . 372

Mortification, sce Gangrene.

Mustard embrocation, . . . $\quad$. 54

O.

Esophagus, . . . . . . 12

P.

Pancreas, . . . . . . . . 23

Peritoneum, . . . . . . . 25

Pharynx, . . . . . . . . 12

Physic, . . . • . • . . . 229

Pleura, . . . . . . . . . 4

Pleurisy, see Inflammation of the Lungs. 
I N D E X.

Poultice, 237: also Materia Medica, or Vol. II. Pulse,

239

Purgatives, see Physic.

Purging, see Diarrhœa.

Pylorus, .

Q.

Quittor, . . . . . . . 208

R.

Respiration, . . . . . . . . 6

Restringent draught, • . . . . 54

Ring-bones, · • • • - . . . 165

RoARING, . . .. . . . , 83

Rowels, . . . . . . . . 237

S.

Saddle galls, . . . . . • . 155

Sallenders, • • . • • • . . 123

SAND CRACKs, . . . . . . . 206

Shoeing, . . . . . . 187, 398

Sinews described, . . . . . . 159

Sitfasts, . . . • . . . . 157

Spavin, . . . . . . . 168

Splents, . . . . . . . . . 167

Stable management, • . . . . 255

Stomach, . . . . . . . . 11

purgative, . . . . . 368 staggers, . . . . 98,360

Strains, . . . . . . . . 157 
Strangles, - • • • • • • . 65 Suppression of URINE, . . . . . 106 SURFEIT, • . . • . . . . . 11\%

Teети, see Age.

ThoraCiC DUCT, . . . . . . . 26

Thorax, . . . . . . . . . 3

Thorougli-pin, . . . . . . . 166

Thrush, • . . . . . . . 210

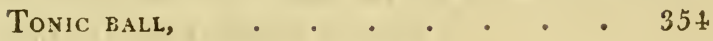

Trichea, see Lungs.

la.

Ureters, - • • • • • • • 26

URINARY diseases, . . . . . . 377

V.

VAlve of THE THROAT, . . . . . 14

Ventricles of the heart, - • . •

Viscera of the abdomen, . . . . 11

OF THE CHEST, . . . . 3

\section{IV.}

iVarbles, see Saddle Galls.

Wind, broken, . . . . . . . 84

Wind-Galls, . . . . . . 166, 337

Worms, . . . . . . . . . 107

Wounds, . . . . . . 140,298 


\section{ER RATA.}

Page 73. note, dele "Anatomy and"

- 87. - 3. of the note, after attention, dele " and will be fully treated of in this work."

- 94. line 8. after bowels, dele the rest of the sentence.

- 114. - at the bottom, dele "and Humours"

- 121. - 3. for $1 \mathrm{oz}$. read 1 quart.

- 132. - dele "(See Glanders, Appendix.)"

- 282. - 1. instead of humours, read swellings of the legs, and dele "(SeeHumours)" 


\title{
EXPLA NATIONS
}

\author{
OF TH \\ P L A T E S
}

Tí:.. T. 
Plate 1, Fig. 1, A perfect Hoof in a state of Nature. - $a$ the Sole, $b b$ the Bars, $c$ the part on which the Heel of the Shoe is to bear, and where the Shoe is to terminate -. $d$ the Heels and Quarters of the Hoof$e$ the seat of Corns $-f$ the Frog.

Fig. 3, A sound Hoof properly shoed.

Plute 2, Fig. 1, A Hoof prepared in the common way, in which the Frog has been deprived of it's hard surface, the Bars remored, a great part of the Sole cut away. - $a$ the Frog, $b$ the Sole.

Fig.2, A hoof contracted in the highest degree.

Plate 3, Fig. 1, The Concave Shoe for Feet, where the Soles are flat or convex.

Fig. 2, The Bar-Shoe, for tender Frongs.

Fig. 3. 'The Shoe for a sound Foot.

Plate 4, Fig. 1, A side riew of the sound Hoof, with a scale, shewing the proper degree of obliquity, to be 45 degrees of elevation. - $a$ the Quarter, $b$ the Heel, $d$ the Toe.

Kig. 2, Sicle view of the Convex or Punice Foot, in which the Hoof has lost it's natural form, and approaches 5 degrees toward the horizontal ine.

Fig. 3, A Hoof approaching too nearly the perpendicular.

Plate 5, A front view of the Interna! or Sensible foot. - a $a$ the sesamoid Bones, $b$ the laminated sisbstance, cthe Coronary Ring. 


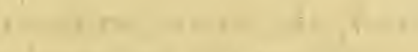

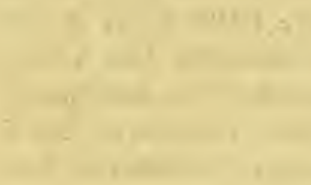

$$
+\quad-1
$$

U 2 
Plate $6, \Lambda$ bottom view of the sensible Foot.$a$ the Sensible Frog, $b$ the Sensible Sole.

Plate 7, the internal surface of the Hoof and Sole.- $a$ the laminated substance, $b$ the groove for the Coronary Ring, $c$ the internal surface of the horny Sole, $d$ the internal surface of the horny Frog.

Plate 8, 1 Section of the Fuot.-a part of the large Pastern Bone, $b$ the small Pastern, $c$ the Coffin-bone, $d$ the Navicula or Nut-bone, $e$ the Frog, $f$ the Sole, $g$ the Crust, the red live between the Crust and Coffin-bonc represents the laminated substance; hi the Flexor Tendon or Back Sinew, ik the fatty, elastic substance between the Frog and back Sinew.

Plate 9, A back view of the Bones, Ligaments, and Tendons-aca the back Sinew, $b$ it's sheath, $c c$ the lateral Cartilages, $d$ the bottom of the Coffin-bone.

Plate 10, the same subject, the Tendons having been removed in order to shew the Ligaments that lie immediately under them.$a$ the smooth surface over which the back sinew passes, $b$ the ligament which encloses the back Sinew, forming a sheath for it, and keeping it in it's situation; in this preparation some part of the ligament was removed, in order to shew the smooth surface $a$ : dad a ligament going from the susamoid Bones to the small Pastern; its 

use scems to be that of giving strength to the Fastern Joint, which, from the oblique position of the Pastern Botnes, would otherwise have been very insecure. I believe this ligument is sometimes broken in violent striins, or when a Horse is said to be bioken clotent.

Plate 11, A front view of the Bones. -au the sesamoid Bones, $b$ the large Pastern, $c$ the small Pastern, d the Cofrin-bone.

Plate 12, $\Lambda$ back riew of the Bones.-at the sesamoid Bones, $b$ the large Pastern, $c$ the small Pastern, $d$ the Naricula or Nutbone, $e$ the bottom of the Coffin-bone.

Plate 13, A Frost Shoe. This Shoe is designed for slippery roads, and on such occasions renders a Horse perfectly secure; the sharp wedge-like substance at the Heel being merely screwed into the Shoe, may be removed and applied again at pleasure.- $a$ the Shoe complete, $b$ the female screw in the Heel, $c$ the wedge that screws into it, $d$ it's screw, $e$ the key for fixing and removing the wedge.

Plate 14, The Teeth, shewing the Age of a Horse. 
Plate1

Fig 1

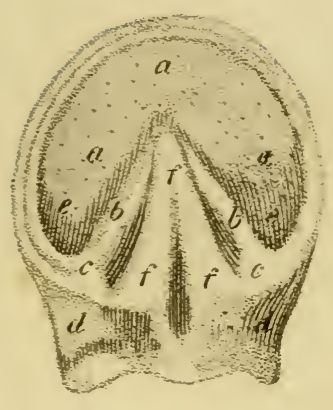

Fig 3

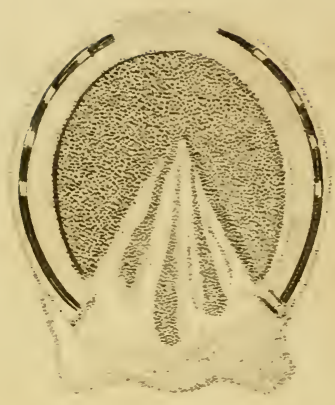

Fig 2

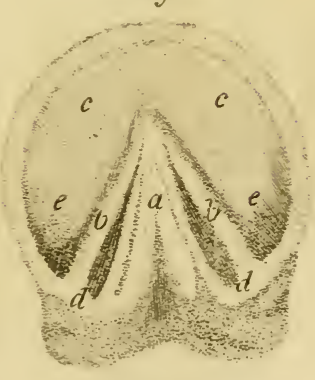



Plate 2
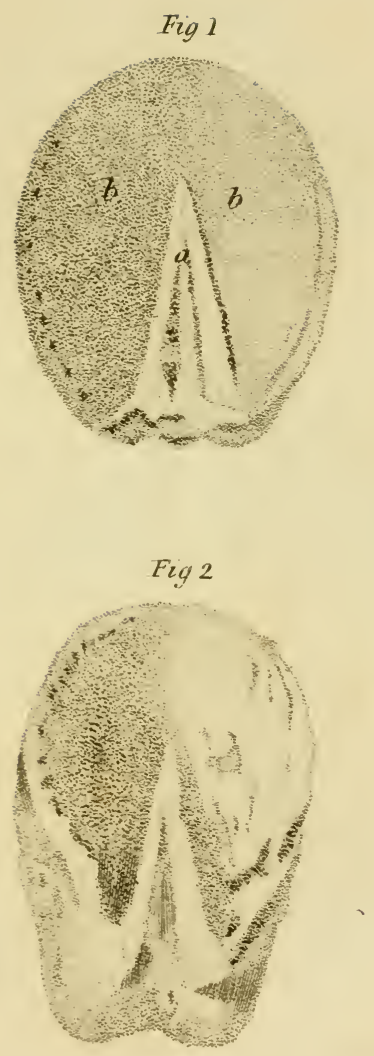



\section{3 \\ Plute 4}
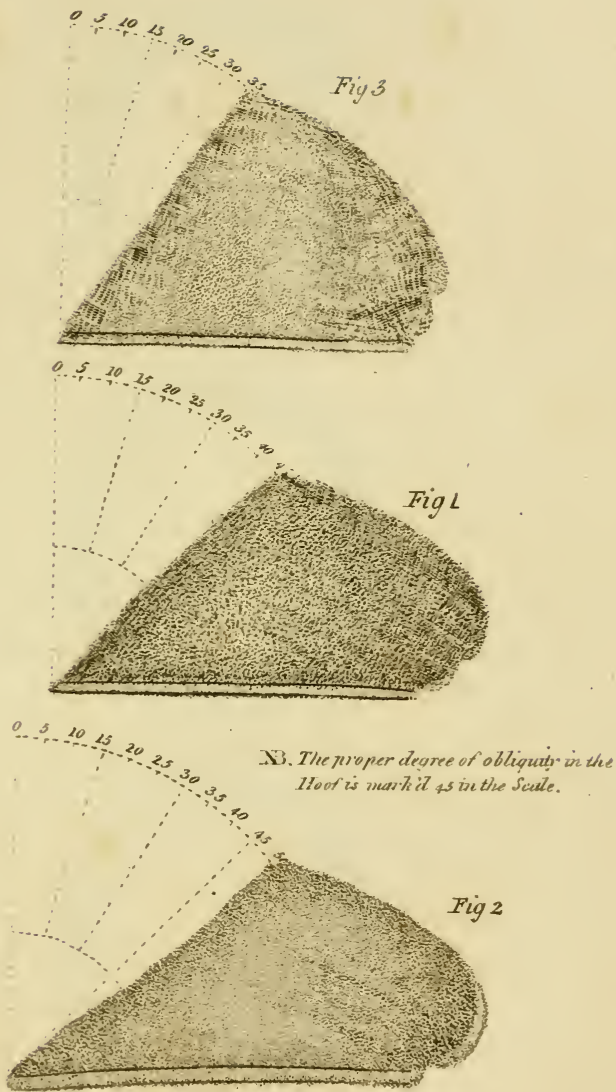



\section{$\infty$ \\ Plate 3}

Fig1

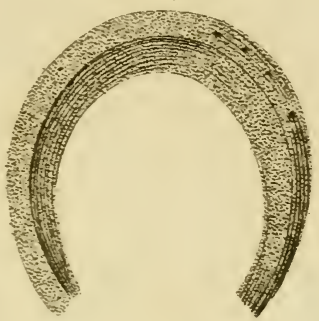

Fig 2

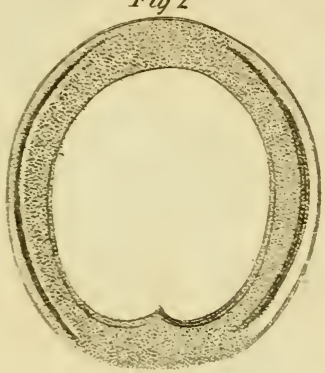

$F_{i g} 3$

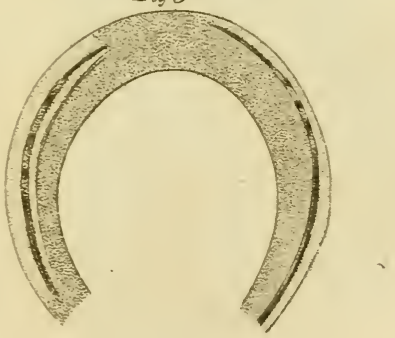



Flire $7^{\text {th }}$

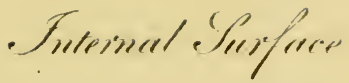

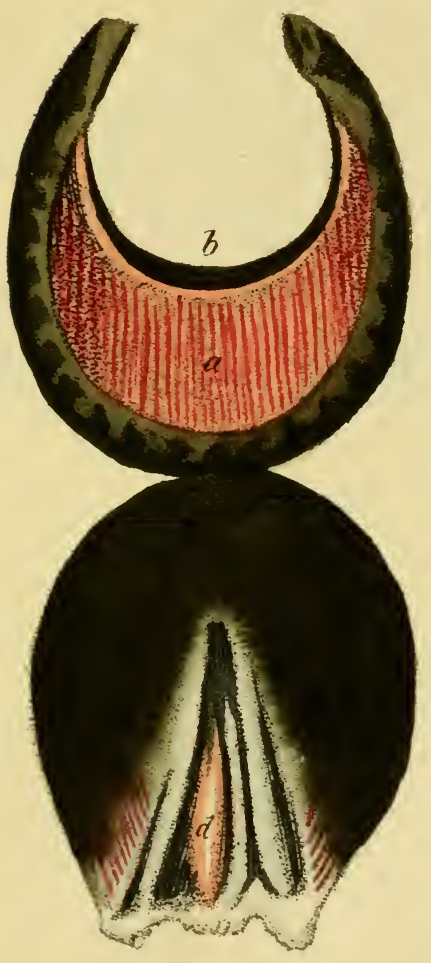



Plele \&

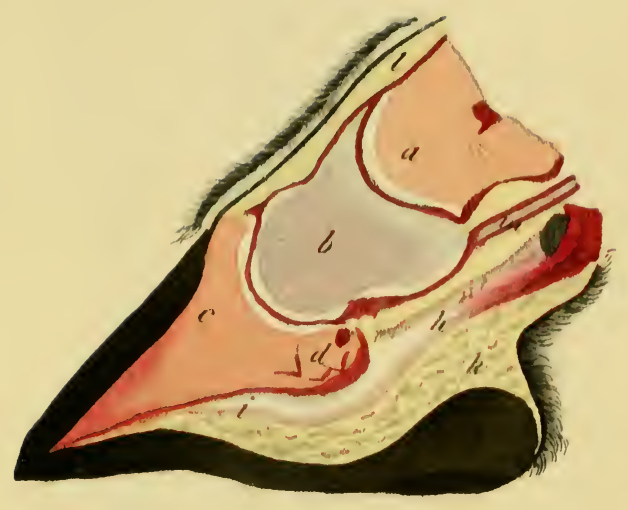

(1) feriens 

Plateg

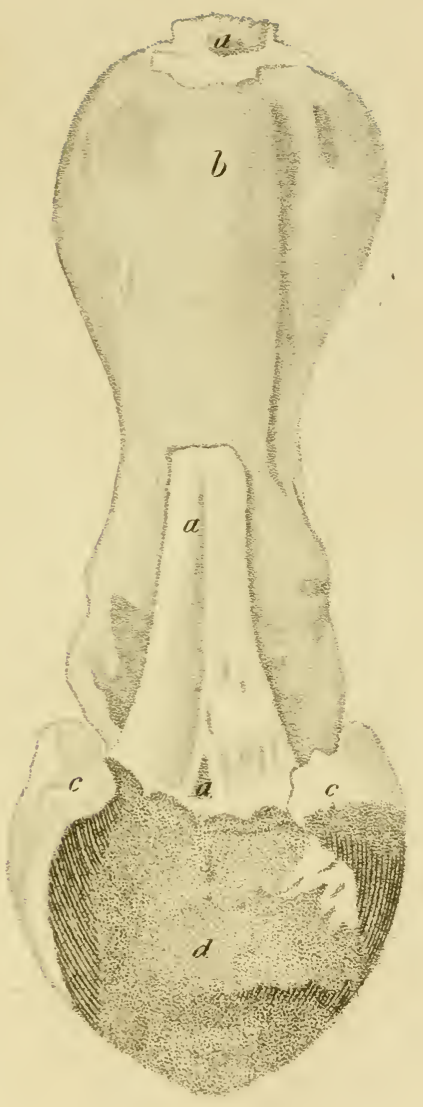



Plute 10

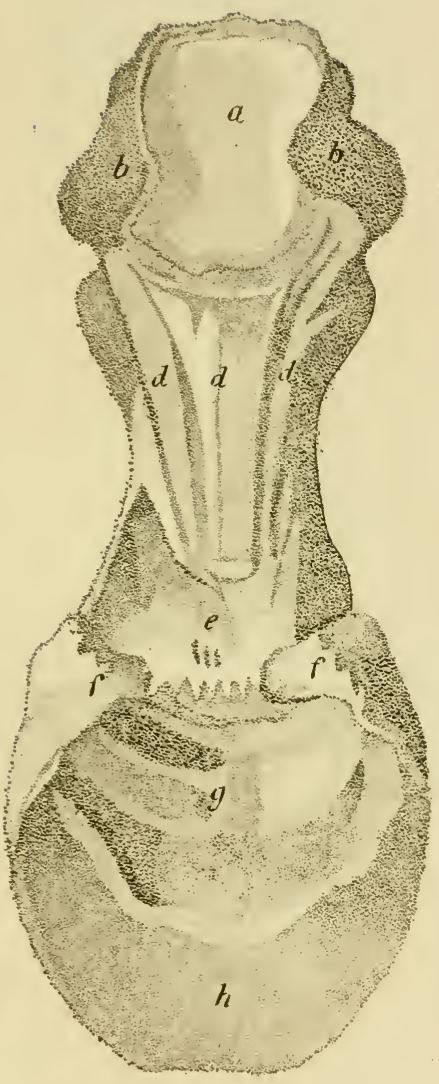





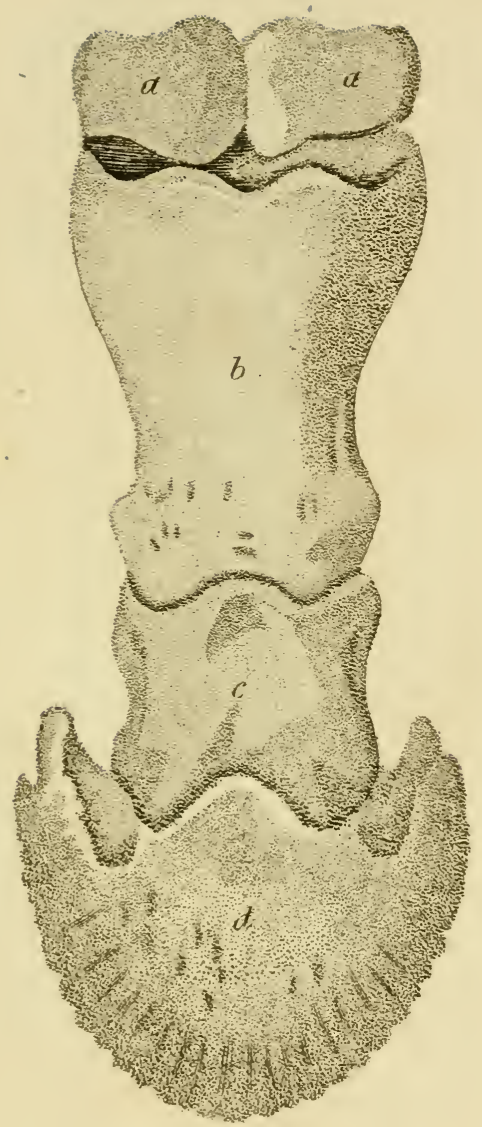


r 

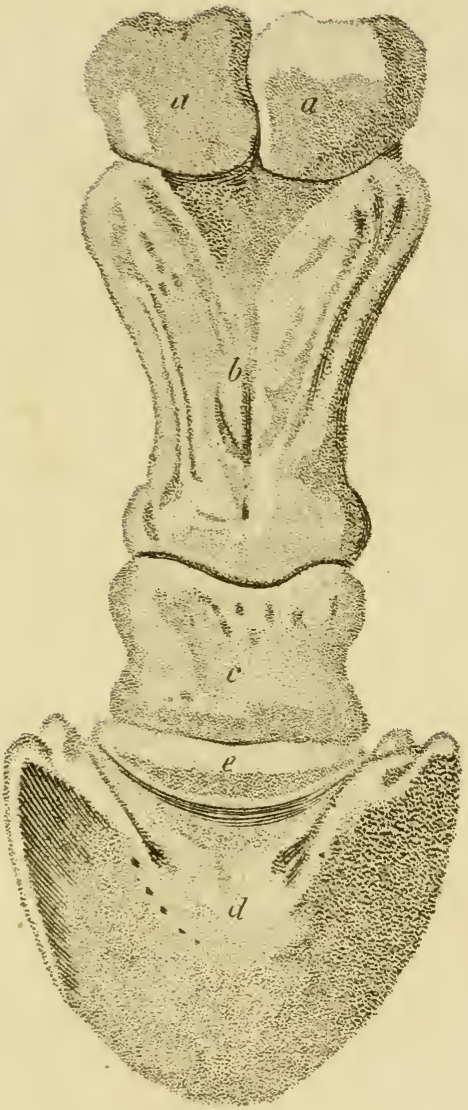


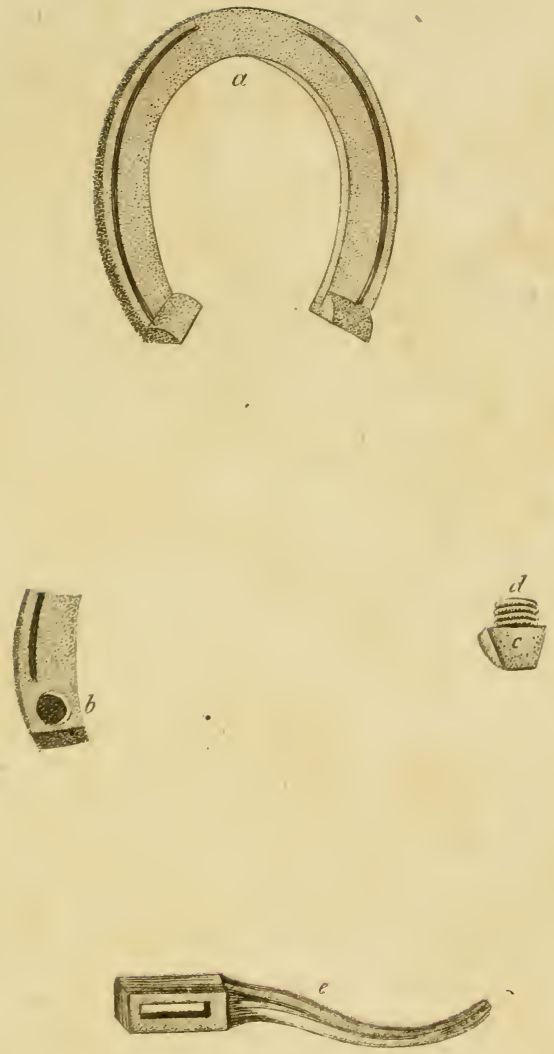

DIRECTIONS FOR PLACING THE PLATHS.

$$
\begin{gathered}
\text { Plate } 5 \text { to face the Title page, } \\
0 \text { - page 170, } \\
14 \text { page 187, }
\end{gathered}
$$

The remainder, in numerical order after the Explanations of the Plates, and before this Page. 
The Third Edition of the Second Volume of A TREATISE ON VETERINARY MEDICINE, CONTAINING

The Materia Medica and Pharmacopæia:

\section{BY JAMES WHITE, OF EXETER;}

Late Veterinary Surgeon of the First, or Royal Regiment of Dragoons.

Printed for J. Johnson, in St. Paul's Churchyard. and Lovgman, Hurst, liees, and Orye, in Paternoster-row.

Where may be had, by the same Author, price $2 s .6 d$.

An ADDRESS to a REGINENT of $\mathrm{YEO}$ MANRI CAVAIRY, respecting the Management of their Horses, when employed on actual service; pointing out the accidents and diseases that are most likely to happen on that occasion; and the most effectual and expeditious means to be employed for their remoral. With direcrions for shoeing, and practical observations on the cure and prerention of Lameness.

Dedicated to Colonel Lord Rolle. 


\title{
C.GWymne. $18 \% 6$.
}

\author{
A TREATISE
}

OF

IETERINARY MEDICINE,

IN TWO VOLS.

BY JAMES WHITE,

OF F.XETER,

LATE VETERINARY SURGEON OF THE FIRST, OR ROYAL REGIMENT OF DRAGOONS.

$$
\text { VOL. II. }
$$

CONTAINING THE

MATERIA MEDICA,

AND

PHARMACOPGEIA.

A NFIF EDITION.

\section{I.ONDON :}

RRINTEU FOR J. JOHNSON ST. PAUL'S CHURCHYARR.

1808.

C. G. Myrme. 1826. 
H. Bryer, Printer, Bridge-Street, Blackfriers

$\therefore \quad \cdots$ 


\section{P R E A C E}

TO THE

\section{FIRST EDITION.}

Within these few years only, has the Veterinary Art acquired a distinct appellation, and a solid foundation in this country. Receipts, handed down by traditionary skill, in which ingredients were accumulated without judgment, or discrimination, constituted the principles and practice of what was termed farriery; a name which it derived from the occupation of the persons who practised it, who were, in general, smiths, or workers in iron (Ferrarius; Ferrum)*.

To attempt to distinguish the causes of the horse's diseases, was far beyond th ir little skill; and, in general, random trials of the few burning medicines

* Farriers were formerly termed.Ferrers, which is certainly $\mathrm{a}$. better appeliation.
A 2 
in their list, formed their boasted practice.

The science at one time began to rise above the order of smiths, and attracted the notice of medical practitioners*; but it was not hereby greatly improved: they were not aware of the difference that has since been found to exist between the structure and economy of the horse, and that of the human subject: nor had they any idea that this dissimilarity required much consideration with respect to disease, and the effect of medicine. Hence they were led to bring the therapeutics and pathology of the human body to veterinary science; and prescribed in somewhat larger doses to the brute animal, what they had found useful to mant. Their practice was of

* See Dr. Bracken's Treatise on Farriery ; also Gibson's and Bartlett's.

+ Arsenic affords a striking example of this fact. In the human system, it is a deadly poison, but it has been given to the horse, even to the extent of two drams, without any sensible effect. (See Arsenic.) 
course unsuccessful, and the art sunk into its original disrepute. It is only since the institution of the Veterinary College, that the anatomy and physiology of the horse have been properly investigated, and the effects of medicines on his body correctly ascertained, by numerous and appropriate experiments, both in health and disease, so that a secure foundation is now laid; and, as long as scientific men continue to study and practise the veterinary art, it must necessarily be in a progressive state of improvement.

Notwithstanding many books have already been published concerning the diseases of the horse, the therapeutical part, or what relates to the medicines proper for his diseases, has not been

It has in a few instances however produced violent effects even in smaller doses.

White Vitriol, a strong emetic in the human body, in a small dose; has been given in the dose of eight ounces, without any violent effect. This, indecd, is the case with many other medicines, which in man, are considered poisonous. 
hitherto explained. Such a work appeared to the author a desideratum in the veterinary art, and has induced him to add the present volume to his Compendium, of the Diseases, \&c. of which the indulgent public has already demanded an eighth edition. Having thus ventured on untrodden ground, he had no guide to lessen the labour of the attempt ; but, by numerous and attentive trials, from the author's experience, and particular attention to this subject, he trusts he has been able to furnish a volume not wholly unacceptable even to the experienced practi. tioner. It has been the author's aim to explain the general properties of the various substances employed in medicine, accurately describing their particular effects on the body of the horse, both in health and disease; the doses in which they may be given, their composition, and in short every thing that has any relation to them. This will be comprehended in the Materia Medica, or first 
part of the book; in the Pharmacopocia are comprised, directions for forming the various compositions in the most convenient and efficacious manner, the whole forming a system of therapeutics, instructing the inexperienced how to distinguish the purest and most genuine drugs, and to compound them in such a way, as will enable him to combat with success the various diseases towhich horses are liable.

\section{PREFACE TO THE THIRD EDITION.}

- When the second Edition of the Veterinary Materia Medica went to the press, the Author was prevented by severe illness, from adding the result of his experience since the publication of the first. The present edition however, has been carefully revised; and he hopes that some usefui additions will be found in it. 


\section{A DVERTISEMENT.}

MR. WHITE may be consulted on the diseasec of horses, either personally or by letter, at his house, on Southernhay, Exeter. If by letter, the fee is half a guinea; personally, five shillings. 


\title{
VETERINARY
}

MATERIA MEDICA.

\author{
CONTAINING
}

AN ACCURATE DESCRIPTION

OF THE

VARIOUS SUBSTANCES

EMPLOYED IN VETERINARY MEDICINE,

WITH THEIR PARTICULAR EFFECTS

ON THE

BODY OF THE HORSE.

WITH OCCASIONAL OBSERVATIONS

ON THE DISEASES ON THAT ANIMAL。 



\section{MATERIA MEDICA.}

\section{AbSORbENTS. Medicines are so termed}

that correct any acidity that may exist in the stomach or bowels, by combining with the acid, and forming an inoffensive substance; in this view they are said to absorb it. Chalk, prepared oyster shells, magnesia, and the alkalies are of this kind.

Horses are sometimes disposed to eat their litter in preference to good hay, and not unfiequently they have a propensity to swallow earth, or any kind of rubbish. This is supposed to arise from the irritation of an acid in the stornach; and medicines of the absorbent lind, are recommended for its remoral ; particularly chalk, mixed with chaff, or cut hay. It is very probable, however, that the formation of acid in the stomach depends upon debility, or some diseased condition of that 
organ. Absorbents, therefore, scldom prove effectual, unless preceded by a dose of warm purging medicine; and then they should be given in conjunction with tonics, such as gentian, quassia, decoction of chamomile, seormwood, \&c. with an aromatic also, such as cassia,ginger, cascarilla, \&c. When horses are in camp or at grass, they sometimes swallow so much earth, that it forms large balls in the intestines resembling stones, which have in time occasioned death. Hence we may learn how necessary it is to purge horses when taken from camp or grass; which will probably remove any of this earthy matter that may have collected in the bowels. Horses that work in stone mills are more liable to this complaint than others: in the greater part of the cases I have met with, the horses had worked for some time in a mill, or were the property of a miller; horses in. such situations should therefore have a mild purgative given them now and then, which would probably prevent the formation of those stones; I have lately seen a case of this hind which happened to a miller's horse; the poor animal suffered the most violent pain; though, when examined after 
death, only a small stone, of about three ounces, was found. I have one in my museum which weighs 10 lb.

ACIDS. This term is applied to medicines that have a sour taste. Acils are also distinguished by their changing an infusion of blue violets or litmus to a red colour, and combining readily with alkalies and earths. Many of them also combine with or dissolve metallic substances, forming with them very useful compositions, such as blue vitriol, lunar caustic, red precipitate, \&c.

Chemists divide acids into three classes, viz. mineral, vegetable, and animal; and describe many different kinds under each class : but we shall confine our attention to such as may be employed, with adrantage, in Veterinary Medicine and Surgery.

Sulphuric Acid, Vitriolic Acid, or Oil of Vitriol. This acid was formerly prepased from grcen vitriol or copperas (vitriolated iron), or from the pyrites or fire stone. It is now, however, obtained from sulphur, by burning it with nitre, in a close vessel containing a small quantity of water, which is afterwards separated from it by evaporaon. Fitriolic acid is a powerful caustic, 
and generally requires to be diluted with water before it is used; but when it is wanted todestroy excrescences, particularly those which arise in canker of the foot, it may be used alone with advantage. One ounce of the acid to a pint of water, forms an useful lotion for obstinate cases of grease; if made a little stronger it is a good appiication for foul ulcers. Pitriolic acid is sometimes mixed with oil of turpentine and hog's lard, as a detergent ointment for ulcerated heels, or for dispersing indurated tunours; and when mixed with a proper proportion of $\operatorname{spa}$ nish flies, it forms an active blister. (See Blisters and Detergents.)

It is probable that vitriolic acid might be given internally as a tonic, with good effect; but for this purpose it requires so much dilation, that it could not be given to a horse, in sufficient quantity, without great inconvenience.

This acid, by combining with other substances, forms many useful compositions. With the mineral alkali, or soda, it forms glauber's salt; with iron, green vitriol; with copper, blue vitriol.

Nitrous Acu, or Strong Spirit of Nitre. 
This, like the preceding, is used only as an external application in Vetcrinary pracice, though it might probahly be employed internally with good elfect, were it not for the same inconvenience that attends the exhibition of the vitriolic acid.

In human medicine it has been employed as a rencely for the venereal disease, but its efficacy in this way is doubtful. I believe, however, it is universally allowed, by practitioners, to possess a considerable tonic power.

Nitrous acid, in its concentrated or strongest state, is a poiverful caustic; and when mixed with water, or unctuous substances, it forms many efficacious lotions and ointments for various external complaints. Almost every metal may be dissolved in this acid, with many of which it fo:ms very useful cautics and escharotics; with silver it makes lunar caustic (nitrated silver), and with quicksilver, red precipitate (red nitrated quicksilver.)

That usf ful medicine termed nitre, is composed of this acid, and the vegetable alkali or potash (kali.) 'The metallic combib 3 
nations of nitrous acid may be employed, either in a liquid or solid state; they may also be diluted with water, or mixed with unctuous substances, to form detergent ointments of any degree of strength that may be required.

Strong or concentrated nitrous acid is of a deep yellow colour, approaching to orange, and emits suffocating fumes of the same colour. When water is added, the yellow colour is destroyed, and it ceases to emit fumes: the same effect may be prov duced merely by the application of heat, in this state it is termed nitric acid.

AQU1-ForTis is made by mixing nitrous acid with about an equal quantity of water.

Muriatic ACID, or Spirit of Salt. This acid is obtained by distilling common salt with vitrolic acid.

Spirit of salt is generally of a light yellow colour, and when exposed to the air emits white suffocating fumes. This acid is sometimes used as a caustic, to destroy exrescences or fungous flesh, or to cleanse foul ulcers; and being considerably weaker than the two former, may be applied 
in its concentrated state, without inconvenience.

Muriatic Acid is a component part of several useful preparations, among which are calomel, sublimate (muriate of quicksilver) and crude sal ammoniac (muriate of am. monia.) When muriatic acid is distilled with a mineral termed manganese, it acquires new properties: it becomes capable of destroying the colour of vegetable substances, and is therefore employed chiefly in the process of bleaching; in this state it is termed oxygenated muriatic acid. If glanderous matter be exposed to the fumes of this acid, its contagious quality is destroyed.

Acetous Acid, or Distilled Vinegar. This well-known'acid is commonly employed as an embrocation for strains and bruises; but it proves much more efficacious in those complaints if mixed with sal ammoniac (muriate of ammonia), and a small proportion of spivit of wine. An useful lotion is also made, by mixing with vinegar a small quantity of Goulard or sugar of lead,and then diluting it with water according to the nature of the case for which it is employed. 
Goulard's extract, or extract of saturk (acetated water of litharge), is made by mix. ing litharge with vinegar, and simmering the mixture for a considerable time orer a slow fire. From the same materials, and rarying the process a little, sugar of lead is prepared (acetated lead.)

There is a medicine much used in human medicine, in febrile complaints termed min. derus's spirit, which is made by adding very gradually to rinegar, salt of hartshorn, or prepared ammonia, until it ceases to produce effervescence or boiling, and has destroyed the acidity of the vinegar: this medicme has been giren to horses in cases of fever and apparently with gond effect-The dose 8 or 10 ounces.

For all veterinary purposes, common vinegar is equal, if not superior, to that which is distilled.

Tartareous Acid, or Acid of Tartar; Cream of Tartar, consists principally of this acid having a small proportion of vegetable alkali, "or" potash (kali), combined with it.

Though cream of Tartar has been found useful in human medicine, it has no perceptible effect upon the horse, and I believe is 
very seldom used by experienced veterinarians. Writers on farriery have recommended cream of Tartar as a necessary ingredient in purgative medicine, to correct a dangerous acrimony supposed to reside in a'oes : this opinion, however, is unfounded. Aloes, if not given too largely, is an innocent purgative, and were it otherwise, cream of Tartar has not, the power of correcting acrimony. It has been recommended in febrile complaints; mixed with infusion of semna, lnitive electuary, \&c. so as to form a cooling drink. The dose from one to four ounces.

Cream of Tarta.r is found in an impure state, adhering to the sides and bottoms of ressels in which wine has been kept.

AIR. The health of horses very much depends upon the salubrity of the a $r$ in which they are kept; and it is probable, that many of their diseases arise from the little attention that is paid to the ventilation of stables. It is said that even the glanders, a fatal and contagious disease, has been generated by confining horses in an impure air. It is a common practice with grooms, particularly those who fancy themselies

B. 5 
profoundly skilled in the art of farriery, to stop every crevice they can find in the stable, so that pure air is with difficulty admitted; and the noxious vapours arising from the litter, from perspiration and respiration, are in great measure confined. Horses thus situated must necessarily suffer in a greater or less degree; and though the air may not be so contaminated as so occasion fatal diseases, it is sufficiently so to de. bilitate the constitution, and thereby lay a foundation for numerous complaints, as well as to create local diseases, such as inflamed eyes, obstinate coughs, and perhaps, moonblindness as it is termed. Horses that have weak eyes and lungs are sure to be injured by this treatment: another inconvenience arising from it is, that of rendering a horse very susceptible of cold. Tenti. lation is, therefore, an object of great importance in the construction of stables; and is. most conveniently done by making proper: apertures in the ceiling, communicating with the exterial air; anil, by means of window, adajted to the form and size of the stable. It is a bad method of Ventilation to leave the upper part of the racks open, so 
as to communicate with the roof of the build. ing, as a current of air is thereby produced in the stall, from the ready ascent of the light air, over the horse's head. The litter should not be suffered to remain in the stall during the day, but be removed to some open place and well shaken, that the ammoniacal vapours it affords may be thoroughly dissipated. Should it be necessary for a horse to lie down in the day time, he should be allowed fresh straw.

ALKALIES. Alkalies form one of the classes of saline bodies, and are of three kinds: 1st, The vegetable alkuli, kali or potash. 2d, The mineral alkali, soda or natron; and the volatile allicali or ammonia. Fach of these will be described under the following heads : kali, natron, and ammonia; which names are employed by the London college of physicians. Alkalies are distinguished by their changing blue vegetable colours to a green, and yellow to orange; by combining ripidly with acids, and forming with them neutral salts, (see acids;) and by rendering oils miscible with water, (see emulsions and soap.) The vegetable and mineral alkalies, from not beins B 6 
evaporable except in a high degrce of heat, were termed fixed : and ammonia, being evaporable in a low temperature, obtained. the name of volatile alkali.

ALKANET ROOT. The only use of this root, is to give an elegant red colour to: oils and ointments.

ALOES. This is the inspissated juice of certain plants of the same name, and the most effectual purgative for horses we are acquainted with: Jt is of an intensely bitter: taste, and of a strong, unpleasant odour.

The different sorts of aloes are distinguish. ed by the names of the places whence they are brought.

Succotrine Aloes is brought from the island Socotra, in the Indian ocean, and is supposed to be more safe in its operation than the other kinds. It is of a dark, reddish, or brown colour, quite opaque, and has a less disagreeable smell than the others; it sells at a high price, and is therefore not unfrequently adulterated. I have been so often disappointed in the effect of succotine uloes, or rather what is cominonly sold under that name; that I now always use the 
Barbadoes, which cannot be so easily adul. terated without detection *.

Barbadoes Aloes is brought from Barbadoes, and has been generally considered as a rough medicine, very liable to produce griping, and other unpleasant effects; but $I$ have always found it a safe and efficacious purgative. Barbadoes aloes is of a darker colour than the former lind, less brittle; and of a stronger and more disagreeable smell. It is certainly more active than the succotrine, and, as far as my experience goes, more certain in its operation, nor have I ever found it produce those dangerous effects that have been attributed to it, when given in a proper dose, and when the horse is not neglected during its operation: indeed, every kind of aloes is liable to produce even fatal consequences if given too largely, or if the horse be treated improperly while under their effect $t$. There is a

* At this time (Dec. 14, 1805.) Succotrine Aloes are at about the same price or cheaperthan Barbardoes.

†. A late writer on Cattle Medicine, asserts that the Barbadoes Aloes is very rough, and often dangerous in its operation; and hinks his opinion contrmed by an expcriment racde on his own stomatb. 
peculiarity in the horse's intestines which renders them more liable to be injured by purgatives of every kind, than those of any other domestic animal; cathartic medicines should thereforc be always prepared by persons of judgment and experience.

CaPe Aloes is rather transparent, and very brittle; it is easily powdered, in which state it is of a bright yellow colour; the odour arising from it is 110 : so strong as the Barhadoes, but rather stronger, and less agreeable than the succotrine. This kind

I can confidently asseri, that I have given many hundreds of doses since the first publication of this book, and that not one single case has occurred in which it operated in a rough or unpleasant manner; I have also given an extensive trial to the Succotrine and Cape Aloes, and again found them very weak and uncertain in their effect. The former are therefore preferred, on account of their superior strength; the common dese for a hunter being 4 . or 5 drams, joined with soap or kali, \&c. this dose is equal to 7 or $8 \mathrm{drams}$ of Succotrine Aloes; their purgative quality being of the same kind, though a given weight of the former contains more of it than the same weight of the latter; it may be proper to add that my experiments have been made on the horse, and not on man. 
is sold at a much lower price than the others, but is so weak and uncertain in its effect, that it is seldom employed in veterinary medicine. The dose of succotrine aloes is from five drams to nine; of Barbadoes, from four drams to an cunce; and of the Cape, from six to ten drams.

Aloes generally operates more speedily when joined with soap, or either of the fixed alkalies. (See Alkalies.)

Alocs is sometimes given as an alterative in the dose of one or two drams. It is also an ingredient in Fryar's Balsam, and compound tincture of myrr: ; preparations often used by farriers. (See Cathartics, Vuineraries, Alteratives.)

ALTERATIVES are medicines that act very gradually upon the constitution, and therefore require to be continued for some time. The medicines most commonly used as alteratives in farriery are antimony, nitre, sulphur, and resin: these are generally given together, particularly the three former.

Though a mixture of these may some. times produce good effects, it is by no aneans an eligible medicine; indeed, I have 
seen it given frequently, but have very seldom observed it do any good, and in the few cases where it appared beneficial, nature, perhaps; had no inconsiderable share in the operation.

$\therefore$ It is commonly supposed that the good effects of alteratives arise from certain changes they produce in the blood: it is more pro. bable, however, that they act only on the solids; and thongh their action is scarcely perceptible, they will be found upon a careful examination to produce some sensible effect, either upon the bowels, the kidneys, or the skin, increasing the action of those parts, and causing them to secrete their respective juices or fuids more copiously. Another effect of alteratices, is to augment the vigour or tone of the system. From this view of the subject it appears necessary to divide alteratives into four classes, viz. Laxatizes, diuretics, dicpheretics, and tonics.

Laxative Alteratives are useful in many case, and may often be substituted. for purgaties with great advantage.

When a horse is troubled with worms, and is ton weak to take strong medicines, or when he camnot be spared from his work, 
they are extremely convenient, and generally beneficial. In obstinate cares of grease, and in chronic inflammation of the eyes, they often do good; they are generally serviceable also in coughs of long standing, or even when they are recent, if not caused by strangles, in which disease the throat is often so inuch inflamed, and so very sore, as to render the exhibition of medicine by the mouth improper. Glysters bowever are often beneficial in those cases. In short, there is no medicine of more general utility in the diseases of horses, than the laxative alteratives, the most effectual of which is aloes, in the dose of one or two drams, with an equal quantity, or rather more, of castile soap.

When it is employed to destroy worms, from ten to twenty grains of calomel may be added. Common sult, in the dose of three or four ounces, is sometimes employed as an alterative, and general!y opers the bowels in three or four chays.

DiURETIC Alieiatives are composed of nitre, resin, soap, and turpentine; I have observed that corrosive sublimate acts generally as a diuretic in the horse, wheis given 
as an alterative, and sometimes very violently, if continued for two or three weeks. Diuretic alteratives are employed in swellings of the legs and other parts, or as a preventative, in horses that are subject to such swellings. They are given also to improve the coat and general condition of the animal.

Though not so effectual in many cases as the preceding, they are certainly very convenient and innocent, and produce so little disturbance in the body, that a horse may continue his work while taking them, without the least danger, even in the winter season. Nor is there any trouble in giving them, as a horse readily eats them, when in the form of a powder, with his corn. The laxative alterative has not this advantage, the aloes, of which it is composed, being extremely bitter, and therefore require to be given in the form of a ball.

Draphoretic Alteratives are composed of medicines that act on the skin, gradually increasing the insensible perspiration, and giving a smoothness and gloss to the coat. The most effectual medicines of this class, are the preparations of antimony 


\section{ALTERATIVES.}

(see $\Lambda$ ntimony); but these may be rendered more efficacious by being joined with other medicines. (See Pharmacopœia.)

The complaints in which this kind of alterative is most useful, are those termed surfeit and hidebound; they are also employed to remove an undue determination of blood to any internal organ, or to diminish general plethora.

Dixphoretic alteratives seldom prove effectual, unless assisted by exercise and good grooming.

Tunic Alteratives are composed of the preparations of iron, copper, zinc, and arsenic: there are also vegetable tonics, such as peruvian bark, quassia, gentian, and other bitter roots. It is remarkable that arsenic**, though so poisonous in the human body, is the best tonic for horses we are acquainted with, and may be given even in considerable doses with perfect safety. (See Arsenic.)

The medicines we have just named will

* Arsenic is said to be a powerful tonic in the human body, but is considered as a danigerous remedy, and must be employed with the utmoss caution, 
be fully described in their respective places.-(See Iron, Copper, Zinc, Bark peruvian, Gentian, and ( 2 uassia; also Alteratives, Phamacopoia.)

The alteratives recommended by writer's on farricry are not composed according to the distinction we have here made; but laxatires, diuretics, \&c. are mised with little discrimination: thus, as we have before observed, antimony, nitre, sulphur, and resin, form their general alterative; and when it was required to remove diseases, supposed to arise from obstruction in the blood-vessels, some ponderous medicines were prescribed; among these were Cimmar, and Ethiop's mineral. This mechanical mode of removing obstructions, however, is now totally disregarded, being incompatible with our present knowledge of physiology.

ALTHEA. See Marsli-mallow's.

ALUM. A saline body, composed of the vitriolic acid, and alumine, or pure clay. It is used internally as an asiringent in diarwhoe. diabetes, \&c. in doses from half an ounce to an ounce, and is generaliy joined with bitters and aromutic stimulants, such as gentian, cassia, aniseed, carratay seed, se. 
For external purposes alum is rery useful : it is a good remedy for the greuse, when finely powdered and sprinkled on the diseased parts; when burnt, as it is termed, it becomes an excellent remedy for cleansing foul ulcers, and more ellectual in obstinate cases of grease.

BURNT ALum is made by putting any quantity of alum in an iron ladle, or common fire-pan, and keeping it over a gentle fire, until its watery parts are evaporated, and it is converted into a light and easily pulverable substance. If exposed to a strong heat for some time, the alum is decomposed, and of course useless.

ALKOHOL. See SpIRIT rectified.

ALLSPICE. JAMAICA PEPPER.

This is seldom employed in reterinary medicine, being very inferior to many chea $_{1}$ er medicines of the same class; its essential oil, howerer, possesses a considerable stimulant power, and may be employed in the composition of cordial medicines.

The dose is from twenty drops to half a dram.

AMBER. This is what naturalists te:m a bitumen. It affords only one preparation 
that is used in veterinary practice, -an essential oil, of a dark colour, and very disagreeable odour,-which is employed as an embrocation in strains, bruises, \&c. generally mixed with other oil, such as oil of elder, turpentine, \&c. It is given internally as an antispasmodic, in doses from two drams to half an ounce. For medical purposes this essential oil is rectified, whereby it becomes of alighter colour, and loses in some degree its unpleasant smell; but it does not appear to be rendered more efficacious. There is a sult of amber kept in the shops, procured from amber by sublimation, but it is never used in veterinary practice.

AMMONIA. This is the modern term for what was named volatile alkuli, and is procured either from bones or sal ammoniac. It is kept in the shops, both in a solid and a liquid form. Strictly speaking, pure ammonia exists only in the form of gas, or air; but water will absorb a considerable quantity of this air, and when saturated with it becomes a violent stimulant, capable of inflaming and even blistering the skin. This is termed water of pure ammonia, or strong spirit of sal ammoniac, and is extremely 
useful in dispersing indolent tumours, if mixed with an equal quantity of sweet oil, in which camphor has been dissolved. It is a good application also in swellings of the back sinews, or other parts, in consequence of straius or bruises. Water of pure ammonia is too strong for internal use; but when ammonia is by a chemical process combined with carbonic acid, or fixed air, it assumes a solid form, and is rendered sufficiently mild for internal use. In this state it is named prepared ammonia, rolatile sal ammoniac, or smelling salt, being much used for smellingbottles, as its quick pungent odour is well calculated to remove faintness.

Prepared Ammonia is an excellent stimulant and cordial, and may be given in doses from half a dram to two drams. I have seen it very serviceable in the latter stages of fever, when debility is the leading symptom.

When prepared ammonia is dissolved in water to saturation, it forms reater of mild ammonia, or common spirit of sal ammoniac; when distilled with spirit and some aromatic oils, spirit of sal volatile, or compound spirit of ammonia; and if assafotida be added, 
the falid spirit of ammonia is produceu which is an excellent antispasmodic. (Sce Assafoetida.)

The SAlt and Spirit of Har'tshory are nearly the same as the prepared, and the rater of ammonia; but being distilled from bones or stag horns, which are of the same nature, they are slighty impiegnated with animal oil, which gives them a peculiar smell, and is supposed to increase their antispasmodic power. (See Antispasmodics.)

AMMONIACUM is divided into two sorts: the first is of a yellowish colour, interspersed with small pieces of wood, and other extraneous matter; the other, in small pieces or drops, of a whiter colour than the former, and much more pure; this is commonly called diop ammoniacum. The forner, however, may be employed for vetcrinary purposes, making a little allowance in the dose for the extraneous matter it contains; but this may be in a great measure separated, by pounding and sifting.

Gum Ammoniacum is an excellent expectorant, in doses from three to five drams. It is advantageously joined with powdered 
squills, and in some cases with camphor, balsam of tolu, and opium.

Horses that are of a full habit, should be bled and take "a laxative ball previous to the exhibition of those expectorants, which generally renders them more efficacious. It may be proper to observe, that ammoniacum is never to be employed in recent coughs, arising from catarrh, or cold, but only in the chronic kind, that are not dependent on inflammation.

ANGELICA. An aromatic plant, too weak for veterinary purposes.

ANGUSTURA BARK. This is said to be a good tonic and stomachic medicine; and is often employed by medical practitioners, in cases where the Peruvian bark does not agree with the patient. It does not appear to be necessary in veterinary practice, and is very rarely used.

The dose is from half an ounce to an ounce or more.

ANISE-SEED or Anisced. This seed is much used in horse medicine, as a stimulant and cordial, but its powcr is by nò means considerable. It is thonght to possess also inexpectorant quality, and is therefore 
given in coughs and other complaints of the lungs, but is generally joined with other expectorants. It is certainly, though weak, a very grateful stimulant, and does much good where the stomach is weak, and disposed to flatulency ; it is, therefore, an useful ingredient in cordial medicines. The dose is about one ounce or rather more.

All the virtues of aniseed reside in its essential oil, which is easily obtained by distillation. This is by far the neatest and most convenient form for using the medicine, and should generally be preferred.

The dose is from half a dram to one dram.

ANTHELMINTICS. Medicines that destroy worms, or expel them from the intestines. The most effectual are the mercurial purgatives. (See Pharmacopœia, article Anthelmintics.)

A variety of vegetables have been thought to possess this quality, but without fourida. tion; among these are box, rue, savin, and wormwood. Æthiop's mineral, antimony, sulphur, and tin, have also been considered as anthelmintics: but I have never known any of them effectual in this way. I believe, 
lowever, that tin has not been fairly tried; and as it is an efficacious anthelmintic in dogs, it may probably be found useful in horses*. Of all the mercurial preparations, calomel is by far the best for this purpose, and may be given with aloes, soap, and some aromatic oil, with a little gingerMany prefer giving the calomel at night, and the purgative the following morning. Aloes are a good anthelmintic, particularly when mixed with a small proportion of gamboge. Arsenic bas been very fairly tried, and does not seem to possess any anthelmintic power. A saline substance has been lately introduced from India, as a remedy for that species of worm, termed botts. It seems to be composed of common salt and liver of sulphur, and is named sal indus. It does not appear to deserve the character that has been given of it; though like salt or brine, it will sometimes cause the common or intestinal worm to be evacuated.

* I have lat ely had an opportunity of trying the efficacy of $T$ in, as a worm medicine; it sometimes destroys them, but not uniformly; and appears to be more effectual when joined with Calomel.

C 2 
$\Lambda t$ present we know of no certain remedy that will destroy botts, though they often pass off spontaneously. (See Compendium, Veterinary Art, Worms. - See also Anthelmintics in Pharmacopœia.)

It has been supposed, that worms are sometimes generated in consequence of debility in the digestive organs. Tonics have therefore been recommended, particularly the vegetable bitters, such as bark, wormwood, camomile, \&c. When worms are discovered in the horse's dung, after a fair trial has been given to mercurial purgatives (especially if he appears to be weak, and incapable of much work), it would be adviseable to give tonic and cordial preparations, with a generous diet: but, whenever this is done, there must be proportionate exercise.

ANTIMONY. This is a heary, shining, brittle mineral, somewhat like black lead when powdered, but of a darker colour. It is common in Germany and France. A small quantity is found in Cornwall, but not sufficiently pure for medicinal purposes.

Antimony is composed of a metallic substance termed regulus of antimony and sul- 
thur. It is given as an alteralive, in doses of an ounce or more, to improve the coat 'and condition of horses; some give it to destroy worms, but it does not appear to possess any power of that kind. A variety of useful preparations is made from antimony, many of which are more. efficacious than the mineral itself: among these are liver of antimony (sulphurated oxyd of antimony), antimonial powder, which is said to be the same as James's powder, emetic tartar (tartarized antimony), golden sulphur of antimony and kermes mineral; each of these will be described in its proper place.

ANTISEPTICS are medicines which prevent putridity, or remove it, if already begun. The most efficacious are bark and other bitters ; opium, wine, ether, ammonia, and camphor.

Horses do not appear to be subject to those fevers which, in the human system, are termed putrid; so that these medicines are not often required. In gangrene, or mortification of the external parts, however, they are very useful. The efficacy of these medicines seems to depend on their tonic or strengthening quality; as putridity 
in the living body, is generally the effect of a high degree of debility.

ANTISPASMODICS are medicines which possess the power of allaying inordinate or painful motions in the system, particularly those involuntary contractions in parts which are naturally subject to the command of the will.

Medical writers divide antispasmodics into two kinds, viz. stimulants and sedatives. To the former belong arsenic, preparations of copper, zinc, and iron; also ammonia, ether, essential oils, \&c. The latter comprehends opium, musk, camphor, and all the vegetable narcotics.

Medicines of the fœtid kind, such as galbanum, assa fœtida, \&c. have also an antispasmodic quality.

When spasm arises from irritation, sedatives are to be given, but when it depends merely on debility, tonics are evidently proper.

APERIENTS. Opening medicines. (Sec Laxatives and Cathartics.)

AQUAFORTIS. Weak nitrous acid. (See Acid nitrous.)

\section{ARABIC GUM. (See Gum Arabic.)}

ARSENIC. There are two kinds of $\alpha r-$ 
senic kept, the white and the yellow. The latter is a combination of white arsenic and sulphur, either natural or artificial, varying in colour according to the proportion of suiphur, which, when considerable, gives it an orange or red colour; it is then called realgar, and used as a pigment only.

White arsenic is obtained in the process of roasting certain ores. The arsenic sublimes, and is found in chimneys adapted to the purpose. It is beautifully white and very heavy, but easily reduced to a powder. The powdered arsenic of the shops is generally adulterated, and ought never to be depended upon. The practitioner should always buy it in the lump, and either powder it himself or see it done.

White arsenic is one of the best tonics in horses that we are acquainted with; and, though a violent poison in the human system, may be given to this animal with perfect safety. From its tonic quality it has often suspended, or apparently cured, the glan-. ders; but its effect in this way, I believe, is never permanent.' It is prudent to begin with a small dose, but not less than eight grains. This may be gradually increased to 
twenty or thirty, and continued as long as there is occasion. In experiments on ylandered horses, I have seen a dose of two drams given twice a day, and continued for a week: at which period it produced inflammation of the bowels. I have often known two drams given for two or three days successively, without any perceptible effect; it will sometimes, however, in that dose, occasion great disturbance in the stomach and bowels. In smaller doses it seems perfectly innocent. When arsenic is employed as a tonic or strengthening medicine, it should be finely powdered, and mixed into a ball with aniseed, ginger, or other cordials. At the same time, attention should be paid to the horse's dict, \&c. It is necessary to give some mucilaginous liquid, such as water gruel, or infusion of linseed, just before the arsenic, that it may not act upon the to mach too violently. (See Balls.)

The cases in which arsenic is said to be most beneficial, as e those where horses become weak and emaciated without any apparent cause; sweating with the most moderate exercise, and almost incapable of doing a day's work. 
I have tried its powers as a vermifuge, and though in some cases it appeared to destroy the worms; it was by no means uniform in its effect. In one case where it was given by way of experiment to a glandered horse, it appeared to have destroyed some botts, which were found dead in the stomach.

ASSA FCETIDA, a gummy and resinous substance, possessing a powerful and most unpleasant smell. It is much used in human medicine, as an antispasmodic in nervous and hysterical complaints. In veterinary practice it is not so frequently employed, though I think I have observed good effects from it in spasmodic complaints, and some practitioners speak highly of its virtues. It is said to be serviceable in obstinate coughs, or thickness of wind, and flatulent cholic. It appears to be more efficacious when joined with ammonia, in the form of fatid spirit of ammonia, a preparation kept in the shops. The dose of assa foetida is from two drams to half an ounce or more; it is generally joined with galbanum, ammoniacum, \&c. When employed as an expectorant, squill is an useful adidition.

C. 5 
The dose of the fœid spirit of ammoria, is from one ounce to one and an half ounce.

ATTENUANTS. Medicines were thus termed, which were supposed to render the blood more fluid.

BALLS, or Boluses. This is the most common form in which medicine is given to horses, and generally the most convenient. Every groom ought to make himself expert in giving balls, without using the instrument termed a balling iron; but there are some horses that will not take a ball by any other means. In giving a ball the horse's tongue is drawn out on the off or right side, and held firmly with the left hand while with the right the ball is quickly passed over the tongue into the Pharynx, or top of the gul- . let : the moment the right hand is withdrawn from the mouth the tongue is let loose, and the ball generally swallowed. The balling iron is so contrived as to keep the mouth open, while the ball is forced into the throat; it is then immediately withdrawn.

Balls should be made at the time they are wanted, as by keeping they often become so liard as to be almost insoluble in the stomach, sometimes passing through the intes. 
tines unchanged; by keeping they also lose much of their strength, particularly when the ingredients are evaporable in the common temperature of the atmosphere, which is the case with camphor, ammonia, essential oils, \&c. But the most serious inconvenience which arises from giving balls that have been kept until they become very hard, is, that they are liable to stick in the throat or gullet, and thereby endanger the horse's life: indeed, I have known horses destroyed in this way.

When balls are composed of very stimulating ingredients, the horse should drink a little water before they are given, to prevent too strong an action upon the stomach : it is better to give the water before the medicine, as a horse can seldom be induced to drink immediately after.

When arsenic, sublimate, or any of those corrosive medicines are given, a considerable quantity of water gruel or decoction of linseed should be given before the ball. Balls cannot be conveniently given, unless wrapped up in paper; but for this purpose the softest and thinnest should be chosen.

BALSAMS. Balsams are generally fluid.

C 6 
of variousdegrees of thickness, odorous, and combustible; they resemble resins, being soluble in spirit of wine; and, when thus dissolved, impart to water a sweetish taste, and a milky appearance.

Balsam of Canada is a very pure kind of turpentine, and though preferred on this account to Venice and common turpentine, is unnecessary in veterinary medicine, being very expensive; whereas Venice turpentine is much cheaper, and I believe equally efficacious.

Canady balsum is a strong diuretic in the dose of one aunce or more; in smaller closes it has been recommended in chronic cough, and diseases of the lungs.

Balsam of Copaiva, or Capioy, possesses nearly the same properties as the preceding. It has been often employed, with success, in the flatulent cholic or gripes; it has been given, also, in chronic cough with good effect.

The dose is about one ounce or more.

Balsam of Gilead is nearly similar to the capivy, but more pleasant. Many virtues have been attributed to these balsams by medical writers : they were supposed to heal 
ulceration of the lungs, kidneys, or other internal parts, and to be powerful corroborants. They do not appear however to possess these qualities, nor do they seem to differ much from turpentine in their medical virtues. (See Turpentine)

Balsam of Peru. This is of a different kind from the former balsams, being more stimulating, and better calculated as a remedy for obstinate coughs : it should be assisted, however, by other expectorants, such as squills.

The dose is from one to two drams. (See Expectorants and Pectorals, in Pharmaco.. pœia.)

Balsay of TOLU. This is generally in a solid form, of a light yellowish colour, and fragrant odour: it is used for the same purposes as the balsam of Peru, in doses from two to four drams.

BALSAM OF SulprHur. This is made by boiling sulphur and olive oil, until they are united: they form a dark-coloured mass

- rather like treacle in appearance, but more tenacious, and of a very disagreeable odour.

Balsam of sulphur is used as an expecto. rant; but farriers frequently employ is is 
recent inflammatory coughs, which is highly improper. It may be useful, however, in chronic coughs.

The dose is from half an ounce to one ounce.

BARBADOES TAR is a bituminous substance, brought from the island of Barbadoes. It is nearly of the colour and consistence of common tar, but smells differently, and its colour approaches more to brown. It has a considerable diuretic power, and is said to be useful in chronic coughs. Farriers frequently use it for this purpose; but by giving it indiscriminately they often do mischief. They also employ it as an external remedy in strains and bruises, generally dis. solved in oil of turpentine, and oil of elder.

BARBADOES ALOES. See Aloes Barbadoes.

BARILLA. The name of a sea plant from the ashes of which mineral alkali, or soda, is obtained in an impure state. (See Alkalies.)

BARK, PERUVIAN, or Jesuit's Bark. Thoughin the human subject bark is an useful tonic, and febrifuge medicine, it has no 
very remarkable effect on the horse. I have seen it do good, however, in gangrene, or mortification of the external parts, when mixed with opium, ammonia, and ginger. It is serviceable also in cases of debility, arising from large suppurations, and where there is a copious discharge of matter. It may be employed likewise in diabetes, a disease consisting in an excessive discharge of urine.

The dose is from six drams to one ounce and a half, or two ounces.

There are three sorts of bark : the pale or jesuits, the red, and the yellow. The first is considered the best, and is most commonly used, but the others do not greatly differ in their effects. Oak bark would probably be found an useful substitute for peruvian bark. By boiling bark in water a considerable time, its virtues are said to be considerably diminished.

BARLEY is sometimes used as food for horses; but is less fit for that purpose than oats, or beans: I have known it tried as a substitute for the former, when it was found difficult of digestion, and productive of my complaints: if horses, however, be 
accustomed to it gradually, it proves very nutritious and useful.

BATHING. A remedy seldom employed in the diseases of horses. I once saw an obstinate case of costiveness removed by driving the animal into a-river. It is said, that lameness, arising from strains, may be cured by making the horse swim; but I am inclined to doubt the efficacy of this practice. The warm bath :vould probably be found serviceable in spasmodic complaints, if it could be easily managed.

BAY-LEAVES are used only as an ingre. dient in fomentations.

REANS are often used as an article of diet. If given moderately to horses that work hard, they prove extremely useful and invigorating, but to such as are not much worked they often do harm, by disposing the system to inflammatory complaints.

BENZOIN, or gum Benjamin. A concrete resinous substance of a yellowish colour, inclining to pink, and variegated with small white masses. By exposure to a strong heat, it gives out an extremely light flowery substance, which is termed flowers of Ben. aamin. This is beautifully white and fram 
grant, and used in medicine in coughs, and other complaints of the lungs. In veterinary medicine neither the resiu or flower are employed, nor do 1 know any disease in which they are likely to be of use.

The former is an ingredient in the tranmatic or fryar's balsam, now called compound tincture of Benjamin; and the latter is employed in making paregoric elixir, or camphorated tincture of Opium.

BISTORT. The roots of this plant are considered the most powerful of the vegetable astringents; they have been recommended as a styptic, to restrain hæmorrbages, but ought never to be depended upon for this purpose. Many imaginary virtues have been attributed to this plant; perhaps as a powerful astringent it may be useful in certain cases of diarrhœa, particularly that to which horned cattle are subject. The dose is from half an ounce, to one ounce, and may be given either in powder, or boiled in water and made into a drench.

BITHWORT. This root, though formerly celebrated, is now very rarely ema ployed. Farriers sometimes use it as a stimulant, but its powers are slight, and it is 
now superseded by more valuable medicines.

BLEEDING. This operation is frequently required in the diseases of horses: and if employed seasonably, and to a sufficient extent, is the most efficacious remedy we are acquainted with. When a horse appears dull and heavy, and indifferent about his food, by bleeding we often prevent a fever. If a horse is bled at the cornmencement of a cold, the complaint generally proves moderate, and of short continuance. In all cases of internal inflammation, or symptomatic fever, bleeding is the most essential remedy, provided the operation be performed at an early period, and the blood drawn in sufficient quantity. In such cases, I have often taken away five quarts, and repeated the operation the following day when it appeared necessary. By bleeding copiously at first those formidable diseases are crushed at once, while by suffering them to proceed or become at all violent, which they will do, unless this practice is adopted (or if only a small quantity of blood is drawn), they generally prove fatal: nor will bleeding then be of any service. 
BLEEDING is either general or local; that is, it is done either so as to affect the system in general, or a particular part only. For general bleeding, the jugular or neck vein is most convenient.

When the vein is firmly pressed with the fingers of the left hand, the blood is prevented from descending, and that part of the vein which is above the fingers, is considerably distended and becomes very conspicuous; in this state it may be easily opened with a lancet held in the right hand. The vein will continue to bleed as long as the pressure below is continued.

Farriers bleed with a fleme, which though a clumsy method of operation, is certainly safer in unskilful hands. In topical bleeding a vein is chosen as near as possible to the affected part, or the vessels covering the part are opened: in the inflammation of the eye, for example, relief is often obtained by scarifying the inner surface of the eye lid, or by opening a small vein, which is easily seen going from the inner corner of the eye towards the nose.

A graduated tin vessel, capable of containing five quarts, is very convenient for 
the purpose of receiving the blood; every pint being marked on the inside of the ressel, so that the quantity of blood that is taken off may be exactly known. The blood should always be preserved, that we may judge from its appearance of the nature of the disease, and whether it is proper or not to repeat the operation. When it continues fluid a considerable time, it denotes an in. flammatory state of the system. Should a whitish or light buff coloured jelly appear on its surface after it has coagulated or settled, and should this jelly be of considerable thickness, rather firm, not easily penetrated by the finger, we may be satisfied that the horse's complaint is inflammatory ; that bleeding was a proper remedy; and that, if the symptoms continue, the operation may be repeated with advantage: but if the blood coagulates quickly, is uniformly of a dark liver colour, loose and easily broken, ivith a considersble quantity of water upon its surface, it denotes debility, and shews that the disease arises from a weakness of the system; that instead of bleeding, tonic and cordial medicines are to be employed, with every thing that may tend to restore the ani. mal's strength. 
In order to judge correctly by the appearance of the blood, it should be drawn from a large orifice, and not suffered to run down the sides of the ressel which receives it. The first quart that is drawn should be put aside for examination, and not shaken or disturbed in any way until it has perfectly coagulaced.

When blreding is employed as a preventative, or in any slight complaiate, from two to three quarts muy be taken off, according to the horse's strength and condition; but in cases of internal inflammation or fever, a more copious evacuation is necessary.

When horses are taken from camp, or grass, and put into warm stables, they are very subject to inflammatory complaints, and dangerous fevers: under those circumstances, moderate bleeding now and then will prevent such diseases. Horses that are getting into condition, as it is termed, are liable to similar disorders, unless moderate bleeding is occasionally employed. I am inclined to believe, however, that it is a bad practice to bleed often upon trifling occasions; it is liable to $i$. duce a plethora $o x$ fulness of habit, whereby a horse is ren- 
dered more susceptible of disease than he would otherwise be. Moderate purging and regular exercise, with a proper regulation of diet and temperature, are fully adequate to the prevention of disease on those occasions; but these are too often neglected.

We are told by a pretender to veterinary science, that it is seldom necessary to pin up the orifice, which is made in the skin by bleeding. I grant there is not often any danger to be apprehended from its bleeding again, but unless it is pinned up, that is, unless the lips of the wound are brought into contact, and kept in that situation, by passing a pin through the edges of the skin, and twisting a little tow round it, as is generaily done by farriers, considerable inflammation and swelling will sometimes take place in the wound, and matter will often form in consequence. I can also assure that gentleman, from considerable experience, that the fleme has been found upon many occasions, particularly for opening the neck vein, a better instrument than the lancet; the latter makes an orifice in the skin, not larger than the vein, and as the 
horse is generally a little restless, the blood soon gets between the skin and the vein, plugging up the orifice in the latter, and sometimes diffusing itself in the cellular membrane, so as to cause a swelling. I do not know whether this opinion is sanctioned by Solleysell, la Fosse, Gibson, and other old writers, or not: I can only say, that I have learnt it from experience, which I consider a surer guide than any book of farriery, not excepting the Philosophical Treatise of the gentleman to whom I allude. I have before endeavoured to shew the advantage of early and copious bleeding in the fevers of horses, whether simple or symptomatic. (See the Compendium, Bleeding and Fevers.)

I think it necessary, however, to repeat, that it is the most important remedy we can employ on these occasions, and may be carried to the extent of five quarts, or even six in large strong horses with the best effect. The practice of bleeding moderately in fevers is highly to be reprobated: it raises for a short time delusive hopes of a recovery, but scarcely ever proves effectual. I do not mean to recommend such plentiful 
bleeding on every occasion, or when a horse is merely affected with a catarrh or cold; it is only proper in cases of real fever's, depending cither upon internal inflammation, upon an undue determination of blood to the interior parts of the body, or upon general inflammation. The disease termed staggers, must be iucluded.

BLISTERS. This term is applied to medicines that inflame the skin, and cause watery bladders to rise upon its surface; the most useful of this kind is the cantharis or spanish $\mathrm{fly}$, which forms the principal ingredicnt in all our blisters. There are many others, however, which are generally mixed with it, as auxiliaries, among these are hele. bore, euphorlium, turpentine, \&c. (See Pharm. article Blisters.)

BLISTERS are of great use in veterinary medicine, they are extremely efficacious in dispersing callous swellings, the consequence of strains, bruises, \&c.

In inflammation of parts remote from the surface, they are of great service. When the internal parts of the foot are inflamed, relief is generally obtained by blistering the pastern, provicled the subordinate or auxi- 
liary remedies are not omitted, such as rasping the hoof, paring the sole, soaking the horny part of the foot in warm water, or applying a poultice to it, and giving a dose of physic.

Blistering is the best remedy for curbs, windgalls, spavins, \&c. It is serviceable also in inflammation of the internal organs. When the lungs are inflamed, for example, by blistering the sides extensively, we lessen the determination of blood to the diseased part, and thereby afford great relief. (See Compendium.)

Broken knees, unless skilfully treated, frequently leave a callous swelling on the part, for the removal of which, blistering should always be employed. When blisters are properly made, and free from any caustic ingredients, such as sublimate, vitriolic acid, \&c. there is no Aanger of destroying the hair; and if the first blistering does not prove effectual, it may be repeated until the desired effect is produced.

BLUESTONE. BLUE YITRIOL or Vitriolated Copper. This is composed of oxyd of copper and ritriolic acid. It is extremely useful, as a mild canstic and detergent, aurd 
is an excellent application to almost every kind of ulcer, disposing them to heal sooner than any other application. The best method of using blue vitriol is in a state of solution, that is, put as much of it (in pow. der) into a pint of water as the latter is capable of dissolving, and to facilitate the solution, let the water be boiling hot: this solution may be used alone, or diluted with water, as the circumstances of the case may require; it may also be made stronger by the addition of strong nitrous acill, or vitriolic acid. When blue vitriol is used in substance, it should be finely powdered and sprinkled on the ulcer.

In bad broken knees, the ligaments are often wounded, and there is generally some difficulty in healing the wound; I know nothing that does so much good in those cases as the solution of blue vitriol, particularly if applied hot.

As an internal remedy, blue vitriol is said to possess a tonic power, but it shou!d be given cautiously, and much diluted. I once saw six ounces given to a glandered horse, by way of experiment; it soon destroyed the animal, by occasioning the most 
violent inflammation of the stomach and bowels: it appeared to have acted as a caustic on the former organ.

In giving blue vitriol, I would recommend a very small dose at first, not more than half a dram, which might be given in the form of a ball, provided it is properly diluted in the stomach, by making the horse drink immediately before, or after.

BOLE. A red clay, containing a small proportion of oxide of iron, often used by farriers as an astringent in diarrhcea, or in bloody urine, but it certainly does no good in those complaints. It is sometimes, however, serviceable as an application to ulcers, where the diccharge is thin, and acrimonious.

BORAX, when dissolved in water, is sometimes applied to the mouths of young horses that are infarned by cutting teeth; I have found, however, that alum, which is much cheaper, would be equally effectual.

BOX. The leaves of box have been said to destroy worms, but if really anthelmintic, it is certainly too weak to deserve our attention.

BRIMSTONE. (See Sulphur.)

D 2 
BUCKBEAN. An useless plant, and though valued formerly, is now scarcely ever employed.

BUCKTHORN. The juice of the berries of this plant is supposed to possess a purgative quality, and is generally made into a syrup with sugar, though farriers sometimes employ it with other purgatives ; it is certainly useless as a medicine for horses.

BURDOCK, a common plant, known by its burs. The leaves are said to be diuretic; and are employed in making the green elder ointment, or Pompilion. (Ung. Papuleon) so much used by farriers.

BURGUNDY PITCH. The inspissated juice of a species of fir tree; it somewhat resembles yellow resin, but it is less brittle and transparent. What we commonly meet with in the shops, appears to be an artificial composition. Burgundy Pitch is often used by farriers in making charges, and strenghthening plasters, also in some of their ointments.

BURNT ALUM. (See Alum.)

BUTTER OF AN'TIMONY, or muriated Antimony, a dark coloured liquid, possessing strong caustic powers and composed of antimony and muriatic acid. 
It has been highly spoken of as a remedy for quittors and other ulcers of a similar kind; it is certainly a strong caustic, and may be employed in cases where such applications are required.

There is something peculiar, however, in this caustic, which is, that by coming into contact with a moist part, it is immediately decomposed, so that when applied to ulcers, its action is of very short duration.

CALAMINE, or Lapis Calaminaris. $\Lambda$ metallic calx, which, when powdered, resembles a white earth inclining to a red colour. It is employed for the purpose of drying or healing ulcers which discharge a thin acrimonious matter; it is also mixed with hog's lard, oil, and wax, so as to form an ointment, which is used for the same purposes. This ointment, or cerate, is the celeirated Turner's Cerate.

CALOMEL. Is the most useful of the mercurial preparations, and composed of oxide of quicksilver, and muriatic acid. When prepared, it is a fine white powder, rather inclining to yellow, and very ponderous. It is the most efficacious anthelmintic we are acquainted with (See $A n$ - 
thelmintics), and an excellent alterative. It has often cured that destructive disease termed farcy, and has considerable effect in the glanders; though it has not hitherto been so employed as to cure that disorder radically. When a brisk purgative is wanted, calomel may be added to the common physic, which is composed chiefly of aloes. It has been given with good effect in obstinate cases of grease, chronic inflammation of the eyes, and diffused swellings of the hind legs.

Though calomel possesses all these useful qualities, it must be given with caution, and its effects carefully watched, as it sometimes acts very violently and unexpectedly on the stomach and bowels, and induces a dangerous degree of weakness. A profuse saliva. tion is sometimes the effect of calomel: the mouth becoming so sore, and the tongue so swollen, as to prevent the horse's feeding : When these accidents occur, the medicine should be discontinued a short time, and the horse allowed to drink plentifully of water-gruel, linseed infusion, or any other mucilaginous drink. When the bowels are affected, opium is the best remedy; in sone 
eases, where it has produced great irritation about the anus or bladder, opium should be given in the form of glyster. (See Glysters.) If the mouth becomes very sore, let it be washed with a solution of alum, by means of a syringe.

Whenever culomel is giren, the horse must be kept walm, drink warm water, and bave regular exercise. When calomel is given as an anthelmintic, or as a purgative, the dose is from one dram to two; as an alterative, from fifteen grains to half a dram. Calomel generally acts upon the kidneys, increasing the discharge of urine. (See Alteratives and Anthelmintics.)

CAMPHOR, is procured from a Japanese tree, and brought to Holland, where it is purified from much extraneous matter; from thence it is imported into this country.

Camphar is a medicine of considerable efficacy in the diseases of horses, though scarcely known to farriers as an internal remedy. It is a powerful sedative and antispasmodic; and I think an exceilent remedy that can be employed in fevers. When joined with nitre, it gives speedy relief in suppression of urine, or difficulty 
in staling; except when it arises from inflammation of the kidneys, - but in the horse this complaint is generally spasmodic.

Camphor is a good remedy in flatulent cholic, or gripes, particularly if joined with oil of juniper or other carminatives. (See Carminatives) It has been recommended also in locked jaw, mixed with opium. The dose is from one to two drams; though it may be given, I believe, to a greater extent without danger. The dose I employ. is one dram and a half, or two drams.

As an external remedy, comphor is much used; it is generally dissolved in spirit of wine, oil of turpentine, or common oil, so as to form embrocations for strains, bruises, hard swellings, \&c. Soap is often added to those solutions, and sometimes oil of rosemary. (See Embrocations.)

CAMOMIL.E. A bitter herb, the flows's of which are employed in fomentations. No other use is made of camomile in veterinary pructice.

CANTHARIDES, or Spanishflies. These insects are found alhering to trees of different kinds in France, Germany, and 
Spain; those from the latter country are considered the best.

Cantharides are so very acrimonious, that they inflane, and excoriate the skin; and hence raise a more perfect blister than any other substance : this property renders them extremely useful in veterinary practice, in which a good blister is the most important of all external remedies, Cantharides should be finely powdered; but previously to this operation they should be sifted, that they may be free fiom a great deal of dust and useless matter, which we generaliy observe with them. When powdered, they may be either formed into an ointment, a liniment, or a spirituous tincture; but the former is the best form, and most commonly used. (See Blisters, Pharm.)

CAPSiCUM. The pod, when powdered, forms Cayenne pepper, which is a most powerful stimulant. I have been informed it is used with the best effect as a horse medicine in the East Indies, but could not learn precisely what the complaints were in which it was employed, though I believe it was the fatulent cholic, or gripes. I bare seen it
D 5 
given in cases of flatulency, weakness of the stomach, and indigestion, with success, in doses of one dram, joinea with a little powdered aniseed, liquorice, and syrup, so as to form a ball. (See Cordials, Pharm.)

CARMINATIVES. Medicines that correct flatulency in the stomach and bowels. (See Carminatives, Pharm.)

CARAWAY. The seeds are much used in veterinary practice, as a cordial, and carminative. The essential oil, which contains all the virtues of the seed in a concentrated state, is the most convenient for vetcrinary purposes, the dose of which is from half a dram to a dram, it may be mixed either with ale, milk, or water, into a drench; or formed into a ball with liquorice powder, ginger, and honey. When the seeds are made use of, they should be powdered, but never boiled in any liquid, according to the practice of farriers, as their virtues are thereby, in a great measure, evaporated; nor should they be purchased in powder, for by being kept in that form, their essential oil is gradually dissipated.

In whatever form it may be used, caraway 


\section{CARMINATIVES-CARDAMOM SEEDS. 50}

is cerlainly an useful cordial and carminative. The dose of the seed is about an ounce; to which may be added a dram or two of powdered ginger. It may be useful to observe that from 20 to 30 drops of oil of caraway, are an useful addition to aloes, in making a purgative ball, or, as it is commonly termed, a dose of physic. (See Cordial Carminatives, and Cathartics.)

CARDAMOM SEEDS. There are two sorts of cardamoms, the greater and lesser; the latter are commonly sold in their shells or pods, from which they are easily freed; they are preferred in medical practice, probably on account of their more grateful smell and taste, but the larger sort, which are generally termed grains of paradise (See Grains of Paradise), are better for veterinary purposes, being stronger stimulant, and much cheaper. The lesser cardamoms make an elegant cordial, and are possessed of considerable strength; their pods also have the same properties, but in a weaker degree. The dose, when the pods and seeds are powdered together, is from 1 to 3 drams.

D. 6 
Grains of $P$ aradise will be noticed in its proper place.

CARDIACS. (See Cordials, I'harm. and Mat. Med.)

CARBONIC ACID AIR, or Fixed Air. In medical practice this air has been employed on account of its antiseptic quality, in foul and fotid ulcers, or in gangrenous wounds. It is generally applied by means of a fermenting poultice, composed of oatmeal and yeast. This poultice has been found serviceable in that disease of the horse's heels termed grease, generally correcting the offensive smell which attends it.

CARROTS, are sometimes used as an article of diet, and may be giren in moderate quantity, with great advantage, to horses that are thick winded, have coughs, or are disposed to inflimmatory complaints, such as grease, inflamel eyes, \&c. They appear to be easy of digestion, and very nutritious.

CASSIA. A bark, somewhat like cinnamon botis in appearance and taste, but thicker and larger. There are some fine picces of cassia which so nearly resemble 
cinnamon, as to be not easily distinguishable from it, and are frequently sold for it in the shops. For every veterinary purpose, cassia is equal to cinnamon, provided it is well chosen; such parts should be selected as have a pleasant, sweetish taste, succeeded by one extremely hot and pungent : this is generally found in the thinner pieces, which are curled up like cinnamon.

Cassia is a strong aromatic stimulant, and an efficacious ingredient in cordial preparations. The dose is from 1 to 3 drams. An essential oil is obtained from cassia, which bears a very high price, but is so excessively powerful, that two drops will impart a strong taste to half a pint of water.

CASSIA BUDS. These nearly resemble Cassia in their taste and medical qualities, and may be used for the same purposes.

CASTOR. A peculiar animal substance, taken from the beaver: it has been extolled by some practitioners as an antispasmodic and sedative; while others have doubted its efficacy. It is very seldom used as a horse medicine; nor does it seem likely ever to be much employed, there being. 
cheaper and more certain medicines of the same class.

CASTOR OIL. An useful laxative in cases where it is necessary to open the bowels, and at the same time avoid irritation; it is, therefore, extremely proper in ferers, accompanied with costiveness, particularly when there appears to be pain and irritation in the bowels.

The dose is from a pint to a pint and a half.

It has been asserted that castor oil is a good remedy for worms; tut I have seen it given in this case without effect.

CATAPLASM. (See Poultice.)

CATECHU. (See Japan Earth.)

CAUSTICS. Are substances that burn or destroy parts to which they are applied. The most powerful is the red-hot iron, or actual cautery, which is often employed in veterinary practice, to remove sparins, \&c. (See Firing.) Many of the otber caustics are possessed of great strength, and speedily destroy those parts to which they are applied: Such are the pure alkalies, potash and. soda; the vitriolic and nitrous acids, or a solution of silver, quilksilver, or copper, in 
nitrous acid. If a solid caustic is wanted, nothing is more convenient than the lunar caustic (nitratedsilver.) The milder caustics'are more frequently useful than those we have mentioned, such as blue vitriol (vitriolated copper,) red precipitate (red nitrated quicksilver,) burnt alum, verdigris, \&ic.

The strong caustics are employed to destroy unhealthy or diseased parts; but those of the milder kind are very useful for the purpose of bringing obstinate ulcers into a lrealing state, without any apparent destruction of parts. (See Cantstics, Pharm.)

CAYENNE PEPPER. (See Capsicum.)

CENTAURY. This herb is a weak bitter, and of no use in veterinary practice.

CERATE. A term given to certain ointments or salves, in which wax is an ingredient.

CFRUS', or White Lead: This is sometimes used in ulceration of the heels, when the discharge is thin and acrimonious.

It is generally made into an ointment with hog's lard and oil; but perhaps would be found more useful if merely sprinkled on the part in fine powder. 
CHALK should be fincly lerigated or prepared, as it is termed, before it is given. It is sold by druggists in this state; and is a good remedy in diarrhœa, if joined with opium and ginger, or other cordials. It has been found serviceable also in correcting acidity of the stomach, and in that obstinate diarhoa which fiequently destroys horned cattle.

The dose is from one ounce to two ounces. (See Astringents, Pharm.)

CHARCOAL. $\Lambda$ charcoal poultice has been recommended as an application to the heels, when affected with grease, with a view, perhaps, to destroy the offensive smell with which that disease is accompanied.

CHIO TURPENTINE. (See Turper. tine.)

CICUTA. (See Hemlock.)

CINCHONA. (See Bark.)

CINNABAR. A heary mineral of a dark red colour, sometimes prepared artificially. It is composed of quicksilver and sulphur, and has been employed as an alterative in obstinate coughs and thickness of wind, in doses of half an ounce daily. Cinnabar is 
the most useless of the rhercurials, and may, without impropriety, be dismissed from our Materia Medica.

CINNAMON. This well-known spice is a powerful stimulant, and an excellent cordial ; its high price, however, prevents its being used much in cordial preparations; so that when good cassia can be procured, it may be on all occasions substituted for it in veterinary practice.

CLOVES. A stimulant of considerable strength, but seldom employed in veterinary medicine, on account of its high price. The essential oil of cloves is sometimes used in the dose of 20 or 30 drops, in cordial preparations, or in purgative medicine, to prevent sickness or griping.

COLTSFOOT. Though this plant was once considered as an useful remedy in coughs, it is now totally disregarded.

COLOQUINTIDA, or Bitter Apple. $\Lambda$ violent purgative in the human system; but quite inert in the horse, having produced no perceptible effect in the immense dose of four ounces.

COLLYRIUM, or Eye Water. (See Pharm.) 
COLOMBO, the root. A good stoma. chic bitter, much used in human medicine, and though rarely employed in veterinary practice, seems to be worth a trial in cases. of indigestion and flatulency.

The dose is about one ounce; it would perhaps be more effectual if joined witls ginger or cassia.

CONTRAYERVA, the root is consider ed by medical practitioners as a mild diaphoretic and cordial, but it is never used in veterinary practice.

COPPER. This metal is a component part of blue vitriol (vitriolated copper) and verdigris, two valuable preparations. (See Blue ('itriol and Verdigris.)

CORAL, white and red. These act only as absurbents, though formerly accounted unthelmintic.

CORIANDER, the seed. A weak aro. matic stimulant, not used in veterinary medicine.

COWHAGE, or Cowitch. A pod produced by a plant growing in the West India Islands, and other warn climates, where it proves very troublesome to cattle and other domestic animals, on account of the 
spiculæ which grow upon the surface of the pods; these, when applied to the skin, excite a painful kind of itching. The down is a powerful anthelmintic in the human subject, and would probably be found very serviceable in the horse; but I believe it has never been tried. It is generally mixed with treacle or honey.*

\section{CRETA. (See Chalk.)}

CREAM OF TARTAR. (See Acid Tartareons.)

CROCUS. (See Saffron.)

CUCUMBER, wild. The fecula or mucilaginous part of the fruit, is a violent purgative and emetic, in the human subject, but has not been tried in the horse. $t$

CUMMIN, the seed. A weak stimulant, but its essential oil is an useful cordial and carminative, in doses from half a dram to one dram.

DANDELION, though formerly consi-

- I have since given a considerable dose to a borse without any perceptible effect.

+ I have lately tryed this medicine in doses from $\frac{1}{2}$ dram to $I$ dram and $\frac{1}{2}$. It produced na visible effect. 
dered as a deobstruent, is now quite neglected, being too inert for any medical use.

DEADLY NIGHTSHADE. This plant has been considered as the most powerful of the narcotic poisons; it has been found, howerer, an useful medicine, when cautiously employed. Physicians usually prescribe it as a sedative, in doses of five grains, gradually increasing the dose until some perceptible effect is produced. In the horse it has scarcely been tried, nor does it seem likely to supersede opium as a sedative. The powdered leaves are most commonly employed, but it is also used in the form of extract. The first dose for a horse should be about two drams of the powder, or one dram of the extract, which might be gradually increased.

In human medicine, a decoction of the leaves is sometimes employed as a fomentation in cancerous complaints. This might probably be found serviceable in painful tumours, or ulcers of the horse.

DECOCTIONS are made by boiling any medicine in water until its virtues are extracted.

(Sce Pharm.) 
DEMULCENTS. Medicines which have the power of diminishing the effect of acrimonious, or stimulating substances, upon the sensible parts of the body. There are two sorts of demulcents; the one, possessing an oily or mucilaginous quality, sheathes the sensible part, and thereby defends it from the action of the stimulus; the other being a watery fluid, dilutes the stimulus, and diminishes in a certain degree its power. Among the former may be reckoned, gum arabic, gum tragant, and marshmallow, with various oils : the latter consists principally of water.

DEOBSTRUENTS. Medicines that remove obstructions.

DETERGENTS. A term employed in surgery, for those applications which have the power of cleansing foul ulcers, and inducing a disposition to heal.

DIAPENTE. A compound powder much used by farriers, as a tonic, or stomachic, it is composed of gentian root, bay berries, bithwort, myrrh, and shavings of ivory, of each equal parts; the last article, as well as the myrrh are now generally omitted. This powder is very inferior to those formulæ, or 
receipts, which may be found in our Pharmacopœia. (Articles, Tonics and Stomachic.)

DIAPHORETICS. Medicines that increase the natural discharge by the skin, which, when they act in so considerable a degree as to occasion sweating, are termed sudorifics.

It is extremely difficult to produce any visible effect upon the horse's skin, by means of medicine alone, but when it is assisted by proper exercise, and warm clothing, we can generally give a fine glossy appearance to the coat, though it is very diffcult to produce sensible perspiration, unless it be by violent exercise and immoderately warm clothing. The most effectual diaphoreties in the hors? medicines are of the hot stimulating kind, combined with antimonial preparations and opium; these, however, can seldom be employed with propriety in the fevers of horses, which are generally an effect of internal inflammation : they are useful only when horses are hidebound, have a rough dry coat, and appear in a state of debility. The effects of this class of medicines are so very uncer- 
tain in the horse, and so rarely succeed unless assisted by exercise, that it seems probable that exercise, a proper diet, and good gromming form the only effectual Diaphoretic. (See Compendium, article Fevers. Pharm. aricle Diaphoreics.)

Enetic tartar, and other preparations of antimony, minderus's spirit, and camphor are the diaphoretics which are employed in febrile complaints.

DIET. Nothing tends more to the preservation of tive horse's health than proper management, with respect to his diet, in the regulation of which, it is necessary to consider the exertion or labour that is required from him.

It is a mistaker notion that horses possess the highest degree of strength, of which they are capable while running at grass, in a state of nature, for there can be no doubt that the natural strength might be considerably augmented by high feeding and proportionate exercise, provided it is done gradually.

When a horse, however, is kept upon a full diet, and not allowed sufficient exercise, many dangerous diseases are engender- 
ed; to this cause may be attributed the frequency of his inflammatory complaints, and his most dangerous fevers may often be traced to this source; hence also originate swellings of the legs, grease, cough, inflamed eyes, and many other evils.

If a horse's work is moderate, his diet should be so likewise ; but when his work is irregular, that is, when he is employed only once or twice a week, and then in hunting, or some violent and long continued exercise, his diet must be such as to render him at all times adequate to his work; above all things, regular exercise in the intermediate days is indispensably requisite.

Horses that work hard, and constantly, should always be allowed a moderate quantity of beans with their oats, but on no occasion is barley a proper article of diet.*

This subject will be found more fully treated of in the compendiums.

* It is probable that barley may, by proper management, be given to horses without inconvenience. The stomach should be gradually brought to it, and to render it more easy of digestion, it should be coarsely ground, or merely broken and mixed with an, equal quantily of bran. 
DIGESTIVES. Medicines which promote suppuration in ulcers, and cause them to discharge a white healthy matter. (See Pharm.)

DIGITALIS. (See Fox-Glove.)

DITTANY OF CRETE. The essential oil of this plant, resembles that of origanum, and may be employed for the same purposes. (See Origamum.)

DIURETICS. Medicines that increase the secretion of urine; an effect more readily produced in the horse than in the human body. There is a great variety of medicines that act as diuretics, the principal are, the various kinds of turpentine, balsam, soap, the fixed alkalies, nitre, \&c.

Diuretics are much used in veterinary practice, particularly in diffused swellings of the legs, or other parts, and grease; when given in moderate doses, they may be continued for several days, and a horse may work without danger during their operation. The diuretic alterative in our Pharmacopœia is an excellent medicine for horses that are subject to swelling of the legs, and in slight cases of grease ; but in more violent complaints, we raust employ more active reme. 
dies, these being adapted only to mild cases which do not prevent a horse from working. DRAGON's BLOOD. A resinous substance of a dark red colour, which, when pure, is entirely soluble in spirits of wine. Dragon's blood, was formerly employed as an astringent, and styptic, in fluxes and internal bleedings, but modern practitioners scarcely ever use it. It is still employed by farriers, in the complaint of horned cattle, which they term red water, or bloody urine, but without effect; nor is there any disease of the horse in which it is likely to be useful.

DRASTIC. A term applied to purgative medicines that are violent in their action.

DRAUGHTS, or Drafts. (See Drenches.)

DRENCH. A medicine in liquid form. This is a very inconvenient method of giving medicine to horses, some part of the dose being generally wasted. It is preferable, however, on many occasions, to every other form, on account of the medicine acting in much less time than in a solid form: in flatulent cholic, or gripes, for example, where the symptoms are extremely urgent, and alarming, a proper drench will soon re- 
lieve the animal, while a ball would require several hours to produce any effect. Farriers commonly compose their drenches, with ale whatever the qualities of the other medicine may be, which is extremely absurd, since the properties of the liquid should always correspond with the virtues of the other ingredients. Cordial drenches, therefore, may with propriety be made with ale, but those of a contrary tendency should be mixed with water gruel, or water.

The best instrument for giving drenches is the horn of an ox; the opening being cut obliquely in the form of a spout. Bottles are sometimes used on an emergency to give drenches, but they are attended with danger, and should be handed cautiously. In giving a drench, the horse's tongue should be held with the left hand, and when the head is sufficiently elevated, the medicine is to be carefully poured into the throat, immediately letting go the tongue, while the head it kept up until the drench be swallowed. Drenches are very seldom given with dexterity, and great part of the medicine is sometimes wasted. Every groom should 
Icarn to give them with facility and always keep a proper instrument in the stable.

EARTH. Horses at camp or grass are sometimes disposed to eat considerable quantities of earth : this should always be prerented, if possible, as it sometimes accumulates, and forms larye balls in the iutestines, which generally destroy the aninial. Horses employed in mills for grinding have been often destroyed in this way. (See Absorbents.)

EGGS. These have been recommended for the improvement of a horse's wind, but they certainly do not possess any quality of that kind. They are also used for the purpose of mixing oils, and balsams, with water.

ELATERIUM. This preparation of the wild cucumber, acts on the human body as a most violent cathartic, and is seldom given in larger doses than one grain. I gave a healthy horse that I purchased for the purpose of maling experiments, half a dram, or 30 grains, at one dose, which did not produce the slightest effect; it did not even diminish the appeite, or move the bowels or kidneys. After an interval of 24 hours, 
1 gave the same horse one dram and a half or 90 grains, which proved equally incrt. About a week after, I gave the same animal two drams of the best SCAMnovy I could procure; it produced no effect: 24 hours after, half an ounce was given without ef. fect. About a week after this, 6 drams were given at a dose, which produced a moderate purginer. A few days after, I gave the horse half an ounce of the down taken from the pouls of Doticlos pruriens, or Couhagt, mixed with weacle, having ouserved symproms of worms; not the least effect was pioduced.

ELECA MPANE. The :ont of this plant is a weak aromatic stimidant, and formerly reconmended in coughs, to promoce expec. toration : farriers use it for the sane purpose; but, as we have many medicines of this lind of greater efficacy, it hardly deserves notice.

ELDER. The leaves and blossom are employed, the former in the preparation of an ointment and oil of a green colour, and of little or no use; the latter is used in makiug a white ointment, formerly recommended in inflammatory affections of the skin, 
\&c. but not more efficacious than simple fat, or lard. There is, also, a distilled water made from it, which is often employed in the composition of eye-waters, but does not appear to possess any medical qualities that do not exist in simple or distilied water.

ELECTUARY OF SENNA, or Lenitive Electuary. This is an useful laxative in the human body, but though recommended for the same purpose in the horse by writers on farriery, is certainly too weak to produce any effect, though given in the dose of a pound. (See Senna.)

ELEMI GUM. A resinous substance, sometimes employed in the composition of digestive ointments.

ELIXIR, PAREGORIC. A preparation of camphor and opium, but in too dilute a state to be adapted to veterinary practice.

EMETICS. Medicines that excite vomiting. It is very generally believed that horses are incapable of vomiting; I have met with one instance, however, where it occurred spontaneously, and was soon after succeeded by purging.

Medicines that are considered as the most violent emetics in the human system, are 
ELECTUARY OF SENNA-ENETIC TARTAR. 79 generally inert in the horse. A remarkable example of this may be noticed in white vitriol (vitriolated zinc,) of which a horse has taken twelve ounces at a dose, without much effect.

Emetic Tartar, or Tartarized Antimony. A preparation of antimony (See Antimony) and cream of tartar. (See Acid, Turtareous.) This is a violent emetic in the human subject, even in the quantity of one or two grains; but in more minute doses it is used as a febrifuge.

In the horse, it is a very safe medicine, and useful in fevers: it is generally given in doses of two drams, which may be repeated every day, or even twice a day should the case require it: when the bowels are affected by it, a small quantity of opium may be added; many practitioners join with it camphor and opium, or camphor and nitre, both of which are often highly useful. Emetic tartar seems to be the best of the antimonial preparations, though others are occasionally preferred: but there is some difficulty in deciding this point; for all the preparations of antimony have so little activity in the system of the horse, that their F. 4 
effects are not often perceptible; we know them to be useful, however, from their fre quently subduing or mitigating the disease for which they are employed. Whenever emetic tartar is given, or any other antimonial, its effects will in great measure depend upon the attention and management of the groom. In fevers, the horse should be well littered, and clothed with a rug or blanket, of sufficient width to cover the belly as well as the back. The neck, head, and chest should likewise be clothed; the clothing, however, nust be regulated by the season of the year, and the temperature of the air. The legs should be well hand-rubbed several times a-day, and warm water giren. When the antimonial is given to remove surfeit, or relax the skin, it may be materially as sisted by exercise, and moderately warm clothing

A late witer on farriery, recommends one ounce of antimnnial wine, with a decoction of rue and camomile, as a remedy in inflammatory fever. This quantity of antimonial wine contains about four grains of emetic tartar; a dose too mintite to produce any: cffect upon the lorse. 
FMBROCATIONS. (See Pham.)

EMUISION. A term given to preparations in which oil is blended with water, by means either of mucilage, the yolk of an egg, or a small quantity of alkali. (See $A$ lkali.) Emulsions have a milky appearance, and are a convenient vehicle for pectoral medicines, being supposed to possess that quality in some degree.

ENEMA. (See Glysters.)

EPISPASTICS. See Blisters.

ElRYNGO, the root. A weak aromatic stimulant, of no use in veterinary medicine.

EPSOM SALT, or Vitriolated Magnesia. $A$ neutral salt, formed by the combination of magnesia and vitriolic acid. It is commonly obtained from the water of certain springs, in which it is formed by nature. The virtues of this sait are similar to those of Glauber's salt. (See Glauber's Sait.)

ESSENCE. This term is applied to essential oils, and very properly, since they generally contain all the medical virtues of the substance from which they are extracted.

Essence of Peppernint. The prepa- 
ration sold in the shops by this name, is made by dissolving a small proportion of oil of peppermint in rectified spirit, or alkohol, that has been previously tinged with some green colour.

Essence of Mustard, appears to be composed of camphor, oil of rosemary, and oil of turpentine, which form a good stimulating embrocation.

ESSENTIAL OILS. The smell, taste, and other qualities of vegetables, frequently reside in a volatile oil, particularly in those vegetables, or certain parts of vegetables, that have a strong odour and taste ; as mint, pennyroyal, peppermint, lavender, caraway seeds, anise seeds, juniper berries, lemon peel, santal wood, \&c. This oil being volatile, may be extracted, and procured in a separate state, by distillation; and as it contains all the useful qualities of the substance it was obtained from, is termed an essential oil, which is found very convenient in medicine, particularly for veterinary purposes.

ETHER. This is the most volatile liquid sve are acquainted with, and evaporates readily in the common temperature of the at- 
mosphere ; it must be given, therefore, with great expedition, or a considerable part of the dose will be lost by evaporation. It is a powerfulantispasmodic, and may be given with advantage in obstinate cases of flatu. lent cholic, and other spasmodic complaints. On some occasions it is joined with tincture of opium, or camphor, with good effect.

The dose is about one ounce, which should be mixed with a pint of water.

The high price of Ether prevents its being much used in veterinary medicine. It is a powerful remedy, however, when properly applied; and may be considered as an important medicine.

E'THIOPS MINERAL, or Sulphurated Quicksilier. A preparation made by rubbing equal parts of quicksilver and flower of sulphur together, until the mixture becomes black, and the quicksilver invisible.

Ethiops Mineral was formerly considered a very useful medicine; capable of destroying worms, and curing chronic eruptions, and other diseases of the skin. At present it does not appear to be valued much by physicians for any purpose; but whatever its virtues may be in the human body, it is s. 6 . 
certainly very inert in the horse; and though still employed by farriers as an antlelmintic and alterative, is unworthy of notice, while we can procure so many valuable preparations of quicksilver:

EUPHORBIUM, A gum resin, that exudes spontaneously from a large oriental tree. It is brought to us in small drops, of a pale yellow colour, which are generally mixed with woody and other extraneous matter.

Euphorbix $\mathrm{x}$ is found useful in veterinary practice, as an external application. It is generally employed in the form of tincture: sometimes it is mixed into an ointment with hog's lard, mercurial ointment, oil of origanum, oil of bay, \&c. being previously reduced to a fine powder. It is also frequently an ingredient in strong blisters, to which it proves a powerful auxiliary. In whaterer form euphorbium is employed, it proves extremely acrimonious and stimulating, and is therefore well calculated to reduce callous swellings of the back sinews, or other parts, curbs, windgalls, \&c.

The tincture is made by digesting, or steeping, one ounce of the powder in four 
or six ounces of rectified spirit; frequentiy shaking the bottle which contains the mixture, and heepnng it in a warm place; after eight or ten days it is to be strained off, and kept well corked. Some add to this a little oil of origanum, or camphor. 'There is another kind of tincture made by digesting the powder in astrong solution of potash, which also acts very violently. In powdering euphorbium, the mortar should be placed where there is a current of air, that the dust which arises might be blown off, otherwise it would get in to the nostrils, or throat, and prove excessively troublesome.

EXERCISE. We have observed under the article diet, that the horse's exercise should be always proportionate to the quantity and quality of his food; or ratier, that the latter should be adapted to the former, in order to preserve him in health. We have further to reniark, that in other points of view, exercise is of great importance. In training horses for the turf or the chase, it is by exercise, properly conlucted, and a well regulated diet, that we enable hisis to perform those wonderful exertions that are re quired from him, and bring his wind to the 
highest degree of perfection which it is capable of attaining. In training a horse, whether he be designed for the turf, the chase, or the army, this precaution must always be observed,-that his exercise never exceeds his strength. Many horses have been destroyed by neglecting this precaution, particularly in the army, where we often see horses recruited of three years old, When first brought to the regiment (perhaps from a considerable distance) they are weak and out of condition, often suffering from strangles, which from their weak state, do not come forward properly, but affect chiefly the internal part, causing pain and difficulty in swallowing. At this time they are unfit for any kind of work; and require a month to be brought into proper condition for the riding school. On the contrary, they are not, in general, allowed half that time, but are brought too hastily into the school, without taking time to reflect, that as they are quite unaccustomed to that, or, indeed, any kind of work, it becomes excessively fatiguing; and to young horses in a state of debility, particularly if they are not immediately attended to, and taken 
great care of when brought sweating from the school, I am convinced it is often attended with destructive consequences. Exercise, therefore, should always be moderate at first, and adapted to the animal's strength; by increasing it gradually, and in proportion to his condition, he may soon be brought to bear, without inconvenience, that degree of exertion, and velocity of motion, for which he is wanted. Exercise not only prevents disease, but materially assists in the cure of many : thus, in swellings of the heels and legs, grease, inflamed eyes, \&c. medicine, without proper exercise, seldom effects a cure. (See Compendium, where this subject is more fully considered.)

EXPECTORANTS. Medicines that increase the discharge of mucus from the lungs, and thereby relieve cough and difficulty of breathing. There are many medicines which produce this effect in the human body; but in the horse the action of expectorants is not easily perceptible. It has been said, that as a horse breathes only through his nostrils, the effect of such medicines, (if they had any) would be shewn by a discharge from the nostrils; and as they 
are not observed to cause such discharge, they must be inefectual; but in conghing, air is expired by the mouth, and it is not improbable that mucus may be discharged by the lungs at the same time, though this poin is difficult to be ascertained with precision. I am convinced, however, that some of the medicines termed expectorants, frequently prove serviceable in the horse, by relieving or curing cough, and diffeulty in breathing, or what is termed thickncss of wind; among these are squil!, and gum ammoniacum; both which I have often found very beneficial in those complaints, atthough, as we have seen, I cannot say in what manner they operated.

- EXTRACT SATURN. (See Goulard.) EYE WATERS. (See Pham.)

FEBRIFUGE. $\Lambda$ term given to medicines, that moderate or lesser the riolence of fever.

FENNEL. The seeds of sweet fennel are, in some degree stomachic and carminative, in doses frum one to tiio ounces. The essential oil they affori possesses the same quality in a stronger deg:cc. 
The dlose is from half a dram to one dram. FENUGREEK. The seeds only of this plant are employed for inedicinal purposes; by reason of their mucilaginous quality, they are used in making poultices, and sometimes in emollient glysters. Farriers often give them internally, with what view I cannot pretend to say, since they do not appear to be adapted to the cure of any complaint.

FERN. The root of male fern was for merly considered as a remedy for worins, particularly the tape-worm; it seerus now, however, to have got into disrepute. I have never heard of its being tried in horses, nor does it seem to desirve our attention.

FERRUM. (See Iron.)

FIGS. Mr. Taplin, who some time ago wrote so much anou "Earriry," recommenls figs and liquomice in his pectoral drinks for infarimation of the lungs! a disease that reçuires the inost powerful remedies. Figs certainly ro not possess any medical qualities worth notice.

FIRING. A severe operation often performad on the horse, and on some occasions 
highly useful. It consists in the application of a red hot iron to the skin, so as to burn without penetrating through it. The violent inflammation this occasions, rouses the absorbent vessels into action, by which callous or even boney swellings are sometimes dispersed; the diseases in which it is most efficacious are spavins, ringbones, old callous swellings about the back sinews, in consequence of strains, and windgalls. Firing is supposed to brace the skin, and cause it to act as a bandage on the subjacent parts. A blister is often applied to the part immediately after firing, or on the following day, to render it more effectual. It is necessary to observe, that the milder remedies should always be tried before this severe operation is had recourse to. Firing has been recommended for the purposes of strengthening the back sinews and hocks of colts, to prevent strains, and what is termed breaking down; but it is difficult, if not impossible, to conceive how the workmanship of the Deity can be improved by such means.

It has been asserted, that when firing is employed for old callous swellings of the back sinews, the swelling should be pre- 
viously reduced by blistering; that firing would then prevent any return of the complaint, whereas if the firing were performed in the first place, it would tend to fix the swelling, and render it incurable. I do not believe there is any ground for this opinion.

The hot iron is the most effectual remedy for those ulcers of the skin, which depend upon farcy or glanders.

FIXED AIRS. (See Carbonic Acid Air.)

FIXED ALKALI. (See Alkali.)

FLAG, or Yellow Water Flag. The juice of this plant, which grows plentifully near rivers, is a strong purgative in the human system, but has not been tried in the horse.

FLIES, SPANISH. (See Cantharides.)

FLOWERS OF SULPHUR, or Brimstone. This is much used by farriers as an ingredient in alterative medicine. It is procured from the impure brimstone or sulphur, which is found in the neighbourhood of volcanoes, by sublimation.

Flower of Sulphur is not perfectly pure, however; it still retains a small quantity of vitriolic acid, and other impurities, which may be carried off by washing; it then 
forms the milk of sulphur, or washed sul phur of the shops.

Flower of sulphur is sufficiently pure for veterinary purposes, and is generally given in the dose of one ounce: It is commonly joined with nitre and antimony, or nitre and resin; and is then thought to improve the coat, and general condicion of the horse, or removesweilings of the heels, and surfeit. I have given sulphur. in a variety of doses from ont ounce to eight unuces daily; but the oniy effect I could perceive was that of a mild laxative, and thint did not take place until fou cunces were given at a dose. It made no alteration in the coat or skin, though the patients were hide-bound, and had rough, dry, coats. From the observations I uade on this occasion, I do not conceive that sulphur is of much use as an internal remedy in the borse, or lhat it postesses any diaphoretic power. As topical application in mange, it is certanly very eficacious, particularly if mixcd with others remecitiss. (see Pharm. article Vintment for Mange. See also Index.)

Su! phur is very serriceable to young dogs, when they have any aprearance of Plcthora 
or cutaneous disease, generally acting as a mild laxative; it may be given to them in milk, from one tea-spoonful to two or three.

FLOWERS OF BENJAMIN. These are procured from gum Benjamin or Benzoine, by sublimation. They are of a beau. tiful white colour, very fragrant, and extremely light. In human medicine they are employed as a remedy for coughs and other pectoral complains, but they are scarcely ever used in veterinary practice; a sufficient dose for a horse would be very expensive, and it is probable that gum Benjamin would answer every purpose that can be obtained from the flowers. (See Benjamin, Gim.)

FLOWERS OF ZINC. These also are obtained by sublimation from the metal named zinc. This medicine is said to possess a considerable tonic power. It has not however, been given to horses, nor is it probable that it.would be found an useful melicine, since white vitriol (vitriolated sinc,) a more active preparation of the same metal, has been given to the amount of eight 
ounces and more, without producing any sensible effect, but it is said that in small doses, from half an ounce to one ounce, white vitriol discovers a tonic quality.

Should any one be inclined to try the flower of zinc, they may safely begin, I think, with the dose of half an ounce, and gradually increase it, until some effect is observed. The diseases to which it is adapted are those arising from debility.

FOXGLOVE. A poisonous plant which grows plentifully in this country, chiefly in elevated, dry situations. The leaves were formerly employed as an application to ulcers and scrophulous tumours; but from its deleterious quality, was seldom used as an internal remedy. Foxglove is now found to possess a remarkable power of diminishing the frequency of the pulse, therefore it will probably be found a valuable medicine in those internal inflammations which so frequently occur in horses; their most dangerous ferers depend on this cause, and when the inflammation attacks an important part, such as the lungs or bowels. It generally terminates fatally, unless the most powerful 
remedies are employed at an early period. Foxglove, on these occasions, would perhaps greatly assist the other remedies, particularly in inflammation of the lungs. It has been lately introduced into veterinary practice, but was not attended with the expected success. The complaint in which it has been chiefly employed, is swelling of the legs, but it does not appear to do much good. I have several times given it by way of experiment, and though I cannot say in what particular cases it will be found curative, yet I am of opinion, from the observations I then made, that it will be found, under proper management, a valuable remedy in those fevers which depend on internal inflammation, as also in catarrh, when the inflammatory symptoms are considerable. I believe no one will dispute, that if we can find a method of diminishing inflammatory action in the internal organs, without depriving the system of so great a quantity of the vital fluid, as is found absolutely necessary, on such occasions, it will be an invaluable discovery. No medicine appears better adapted to this purpose than forglove; 
and it is to be hoped that its virtues rill soon be thoroughly investigated.

Foxglore is an active medicine in the horse, and cannot be given with perfect safety in larger doses than half a dram, but this must be gradually increased until some effect is perceived; the horse, however, must be carefully watched, that the effect may be seen; for if too much be given, the stomach is sometimes materially injured. FRANKINCENSE. A resinous substance, similar to yellow resin, as to its medical qualities.

GALANGAL, the root. This is a warm stomachic bitter, calculated to remore indigestion and flatulency, and to promote the appetite.

The dose is about an ounce.

GALBANUM. A gum resin ; similar 'n its medical qualities to gnm ammoniacum, but inferior in efficacy.

The dose is about six drams.

GAMBOGE. A yellow resinous substance, which in the human system acts as a violent purgative; sometimes as an emetic also, even in small doses. In the horse it is not much employed, I believe scarcely 
crer; but I have found it to be an useful medicine in worm cases, facilitating the eperation of aloes, and considerably increasing their purgative quality. (See Anthelminics, Pharm.)

The dose of gamboge, when given withour aloes or any other purgative, is from three to four drams; which should be mixed with three drams of Castile soap.

GALLS. An excrescence from the oak tree, produced by the puncture of an insect. Galls are powerfully astringent, but nc.t often employed internally; they may, however, prove useful in conjunction with othe: remedies, in suppressing obstinate diarhœea.

The dose from two drams to four.

GARLIC. This is often employed by furriers as a remedy for coughs and thickness of wind; and I belicre llat in coughs af the chronic kind it has sometimes been found efficacious.

The dose is from one to two ounces.

The cloves are separated and pounded in a mortar until they form a sort of paste, which is formed into balls, with liquorice powtier : sometimes they are boiled in milk, and given in the form of a drench. 
GENTIAN, the root. A strong and very pure bitter, well calculated to remove weakness of the stomach and indigestion. It generally requires to be joined with stimulants, such as ginger, cassia, myrrh, cascarilla, \&c. and, when any acidity is sus-. pected to exist in the stomach, a small quantity of sod $a$ is an useful addition. Gentian is the basis of that famous horse powder termed diapente. Gentian root sometimes becomes rotten and useless : the purchaser should therefore, examine before he buys, and choose such parts as are sound, rather tough, and extremely bitter. It is to be feared, that the powdered gentian of the shops is not so good as it should be, and it is to be lamented that druggists, in general, think any thing good enough for horses.

The dose of pure gentian is from three drams to six. (See Pharm. article Tonics and Stomachics.)

GERMAMDER. A low shrubby plant, bitter, and somewhat astringent; but not sufficiently strong for veterinary purposes.

GINGER. A root brought from China, and the East and West Indies.

There are two sorts kept in the shops, the 
black and the white ginger; the latter is preferred for culinary purposes, on account of its more pleasant flavour, but the former seems to be equal, if not superior in strength, and being considerably cheaper, and more easily powered, I think it deserves a pruference as a horse medicine.

I consider ginger as the most useful stimulant in the veterinary materia medica; when joined with aromatics, caraway seed, anise seed, cummin seed, \&c. or their essential oils, it forms an efficacious cordial, and with emetic tartar and opium, an excellent diaphoretic for giving gloss to the coat, and relaxing the skin. Joined with bitters, it makes a good stomachic; with squills an expectorant, often relieving obstinate coughs.

Ginger is extremely beneficial in weakness, and flatulency of the stomach, and assisted by other remedies, such as oil of juniper, or camphor, it seldom fails of curing the flatulent cholic, or gripes.

The dose is from one dram and a half to three or four drams.

It should be recently powdered when used; but in a well-stopped bottle the pow- 
der may be kept a considerable time, without losing its strength.

GINSENG. A moderately warm aromatic root, highly csteemed by the Chinese, but in this country scarcely ever employed.

GL.AUBER's SALT, or Vitriolated $N a$ tron. This neutral salt, is composed of the vitriolic acid and soda, or the mineral alkali, which is now termed natron; in the London Pharmacopœia. In the human subject it is an effacacions purgative; but in the horse extremely incouvenient, on account of the large quantity required to produce a laxative effect.

The dose is about a pound.

GLYSTERS. This form of medicine is extremely useful, thot gh much neglected. It is unnecessary to describe the mode of administering them, and with respect to the various medicines employed in this way, I must refer the readur to the Pharmacopoia. (Wee Glysters.)

The best instrument for the purpose, is a polished pewter tube, about one foot in length, the bore about haif an inch in diameter : one end of this tube is to be s made that a bladcier may be securely fastened to 
it, the other finely polished, so that there may be no danger of wounding the intestine. The bladder which is fixed to it, should be large enough to contain a gallon, at least, or six quarts.

GOLDEN SULPHUROF ANTIMONY. This preparation of antinsony is scarcely known to farriers; and I believe seldom used by veterinarians. It may be found useful, however, in obstinate diseases of the skin, either alone or joined with mercurials, such as calomel, or sublimate, muriated quicksilver.

The dose is from onedram to two, perhaps even more may be given with advantage; but it is adviseable to begin with a small dose.

GOULARD'S EXTRACT. Extract of saturn, or lead. 'This is made from litharge and vinegar, by simmering them together, orer a gentle fire, until the vinegar has dissolved as much at it is capable of. Goulard, therefore is nothing more than a solution of litharge in vinegar. It is a very useful application in cases of external inflammation, and may be used either as a lotion, or in the form of poultice. Goulard lotion is 
made by mixing half an ounce of the extract to a pint of water; some add to this a little camphorated spirit, or some distilled vinegar; but when the lotion is intended for the eyes, there must be a much larger proportion of water, not less than a quart.

Goulard poultice is made by mixing as much of the lotion, with bran, linseed, meal, or any proper materials for poultice, as will give them a proper consistence. (See Poultices and Lotions, Pharm.)

Goulard is never used undiluted, nor is it given internally.

\section{GRAINS OF PARADISE. A warm} stimulating seed, often used by farriers in the diseases of horned cattle, as a cordial; and where medicines of that kind are required, it is certainly very proper; but it is very necessary to consider the case well before this medicine is employed, for if the complaint be of an inflammatory nature, grains of Paradise being a powerful stimulant, may do much injury.

The dose is from three to six drams.

GROUND IVY was formerly considered as an excellent remedy in pulmonary complaints; but it is now disregarded by 
medical practitioners, and is certainly useless in veterinary practice.

GUAIACUM. The wood and resin. The former is sometimes employed in human medicine, as an ingredient in alterative decoctions, but never in veterinary practice. The resin, commonly called gum guaiacum, is sometimes used as an alterative. Farriers employ it also in what they suppose to be rheumatic lameness, but without any advantage, I believe. Rheumatism seldom attacks horses: when it does occur, purgatives, with moderate exercise, are the best remedies.

The dose of gum guaiacum is from half an ounce to six drams.

There is a volatile tincture of guaiacum sold in the shops, which seems better adapted to rheumatic complaints than the gum alone; but its use should be preceded by a purgative.

The dose is one ounce and a half. GUINEAPEPPER.(See CayennePepper.)

GUM. There are various kinds of gum, which may be distinguished by their solubility in water, and by forming therewith a mucilage. The principal are, gum arabic; 
gum dragent; and India gum. The tro first are the best. Gum dissolved in water makes useful drinks in inflammatory complaints of the bowels, kidneys, bladder and lungs.

GUM RESFN. A natural mixture of gum and resin.

HARTSHORN. The horns of stags were formerly supposed to possess peculiar quaJities, but upon a chemical analysis they are found to be rery similar to bone, which is now substituted for it, upon all occasions.

HAR'tshonn. Spirit and salt. (See $A m$ monia.)

HAY. Clover, and the coarser kinds of hay, are said to be best adapted to draft horses, and such as are employed in slow, but laborious exercise; while saddle horses are thought to do better with the fircer kinds of hay. I believe, however, the former is most untritions, and if the quantity allowed is suited to the horse's employnent, it may be given to every kind of horse with advantage.

HELLEBORE, white and black. The root of tis p'ast, a ticularly the white het 
lebore, is extremely acrimonious, for if wounded, while fresh, it mits a juice capa. ble of blistering the skin.

Powdered white hellebore is often employed as an ingredient in blisters. It is used, also, in ointments for the mange, and other cutaneous diseases. A decoction of white hellcbore is often employed for the same purpose; but other medicines are generally added to it, as sulphur virum, turpentine, white vitriol, or aluin. Hellebore has been tried as an internul remedy in the horse; but its effect was so violent, even in the smail dose of half a dram, that it is now considered a very dangerous medicine.*

* I have lately had an opportunity of trying the effect of white hellebore. And did not find it so violent or so dangerous as it was said to be after an experiment made at the Veterinary College. To a glandered horse we gave half an ounce of the powder of white hellebore expecting it would destroy him, but it produced no effect ; an ounce was then given which caused an appearance of sickness, and a copions discharge of saliva from the mouth It was given afterwarks to several horses, and we uniformly found that in the dose of half an ounce given daily, it produced the effect we have just described. In some the first 
Black Hellebore is never used in horse medicine.

HEMLOCK. A strong narcotic; but on many occasions an useful medicine, possessing, like opium, an anodyne quality, but not so certain in its effect. It is said, however, not to produce costiveness likeopium; and, as far as I have been able to judge, this observation holds good with respect to the horse. The complaint in which it has been chiefly employed in veterinary practice, is obstinate cough, depending upon irritability, in which it often proves serviceable. The leaves are to be carefully dried and powdered. The powder must be kept in a well-stopped bottle, from which the light should be excluded.

The dose is about a dram ; butit may be gradually increased to a much larger quan" tity.

dose caused an appearance of sickness and saliva. tion; others took several doses before any effect was observed, it was given daily in a case of farcy in the dose of half an ounce, and the horse got well, no other remedy was employed except blisters, in none of the experiments did it cause any dangerous symptoms. 
There is an extract made from hemlock, which, when prepared, is a very convenient form, and not less efficacious than the powder.

The dose is about a diam, but this also may be gradually augmented to a considerable quantity.

A decoction of green hemlock, is said to be an useful fomentation in painful wounds and tumours.

HENBANE. This plant also is a powerful narcotic, and free from the constipating effect of opium. It has not hitherto been used in veterinary medicine, though likely to be found beneficial. I have tried a solution of the extract in water, in chronic inflammation of the eye, where the interior parts were very irritable, and I think with good effect. It certainly deserves a farther trial in this way.

The seeds are said to be the most powerful part of the plant; but the powdered leaves and the extract are more commonly employed.

HOG'S LARD. An article of some im. portance in veterinary surgery, being the basis of almost every ointment. 
HONEY. A small quantity of honey, dissolved in linseed infusion, is often used in those troublesome coughs, which arise from irritation, and serves in this way as a good. auxiliary to more im portant remedies. Honey is sometimes added to a solution of alum, as a lotion for the mouth, when it is inflamed and sore.

HOREHOUND. A bitter herb, with some degree of roughness, or astringency.

IIorehound is rather a popular remedy for obstinate coughs, asthmas, and other complaints of the lungs, but has been very seldom employed in veterinary practice; it may, however, be used in chronic cough, when the usual remedies fail, either in the form of powder, or decoction.

No great precision is necessary in adjusting the dose; one or two ounces of the powder, or a quart of the decoction may be given at once.

HORSE-RADISH. The root of horseyadish, when fresh, is a powerful stimulant. All its virtues may be extracted by distilling the root with water, or spirit; in which state it may be kept a long time without losing its: strength. Horse-radish water, with a small 
proportion of spirit, is a good medicine in cases of flatulency and indigestion, and is the moit convenient form in which it can be given.

HYSSOP. This plant has been esteemed as a pectoral, but it is seldom employed in modern practice; nor as a veterinary medicine is it worth notice.

INFUSIONS. A medicated liquid, made by pouring boiling or cold water on any medicine whose virtues it is capable of extracting.

INDIAN PINK. Though the root of this plant is often employed for the purpose of destruying worms in the human body, yet it does not seem at all adapted to the same purpose in the horse.

IPECACUANA. There are few medicines of greater importance in medical practice than the root of ipecacuana; but it has so little effect on the horse, though given in very expensive doses, that it is not likely ever to be considered as an article of our Materia Medica. Its principal use, in human medicine, is to excite vomiting, an ef. fect it cannot produce in the horse in the lurgest dose. Combined with opium, it 
acts as a sudorific in the human body; but for the horse we do not know any medicine, I believe, that is capable of exciting sensible perspiration, or sweating, with any degree of certainty; though it is easily brought on by violent exercise or immoderately warm clothing, and sometimes happens spontaneously. Still, however, ipecacuana may promote the insersible perspiration, like emetic tartar; and opium may be an useful addition to it.

A mixture of opium, ipecacuana, and vitriolated tartar, one dram of the two first, to one ounce of the last, forms the celebrated Dover's Powder. (Compound Powder of Ipecacuana) which has been recommended by a late veterinary writer.

ISINGLASS. This is said to consist of the dried membranes of the sturgeon, or some fish resembling it the mode of preparation, however, is kept a profound secret. When dissolved in water it forms a strong mucilage; which is an useful emollient, and serves to sheathe the bowels, bladder, \&c. when inflamed or irritated.

IRISH SLATE. An earthy substance, not used in veterinary practice. 
IRON. A metal found abundantly in almost every country, but scarcely ever in a pure metallic state, to which it is brought by various artificial processes.

Iron is the basis of several medicines, all of which, in the human system, act as powerful tonics; but in the horse this quality does not appear in so high a degree, and frequently is not perceptible. The preparations of iron, are green vitriol (ferrum vitriolatum), muriate of iron, rust of iron, tartarized iron, and others, each of which will be described in its proper place.

JALAP. In the human body, the root of jalap is a certain and efficacious purgative, and there is scarcely a book on farriery, in which it is not recommended as an ingre. dient in purgative balls, or physic; which practice is still followed by farriers, who generally put two or three drams of jalap into every dose of physic. It has been ascertained, however, first at the veterinary college: that jalap has no purgative effect on the horse, though given in considerably larger doses than farriers ever employ; but I have observed, that in a very large quan1ity, it occasions sickness, and some degree 
of purging, though its effects in this way are by no means sufficient to induce any one to eupploy it as a purgative.

I once gave eight ounces of jalap at one dose to a glandered horse, that was in other respects healthy, and had not been taking any other medicine; in atout six hours the horse appeared sick, and in pain ; he refused both food and water ; during the night he appeared to have had some small. watery stools; screral of which were perceived also the next day, but they were in rery small quantity, and accompanied with pain. The sickness continued all this day, and on the following he recorered,

Hence we find that jalap may with justice be dismissed from our Materia Medica.

JA MAICA PEPPER, or allspice. This is a good caminalive, though not very powerful. It may be given $i_{i i}$ doses from half an ounce to an ounce, in flatulency of the stomech and bowels, and may be used also as an ingredient in cordial medicines.

JAMES's POWDER. Though the preparation: of this medicine has been hitherto $\left.k_{i}\right)$ secict, there is no reason to doubt its being composed chiefiy of antimony, and 
neariy the same thing as that which is sold in the shops, by the name of antimonial poreder. (See Antimony.) I can venture to assert, that as a horse medicine, this is as us'ful and efficacious as James's pozeder. It is an excelient nedicine in fevers of every kind; and tiough usually given in the small dose of a scruple, or half a dram, may be exhibited with perfect safety and better effect, in a much larger quantity. I never give less than two drams, and sometimes three, and I have seen even one ounce given at a dose without the least inconvenience. It seeins to act on the skin like emetic tartar, and promote the insensible perspiration, bu: I do not think it so certain in its effect as emetic tartar: it is sometimes joined with opium, camphor, nitre, or ginger, according to the nature of the clisease: with gin. ger it forms a good medicine for horses that are hide-bound; but this compound is not proper in fevers, or any complaint arising from inflammation.

JAPAN EARTH, improperly so called, being an extract of an Indian plant. It possesses a coasiderable astringent power, and is sometimes found bencficial in those diarrhaus or loosenesses, which are caused by 
weakness and relaxation of the intestines. It may be employed also in cliabetes, or piofuse staling, with alum, opium, ginger, or other remedies suited to the particular circumstances of the case.

The dose is from two drams to three or four.

JESUITS BARK. (See Bark.)

JOHNSWORT, There is an oil of johnswort kept by druggists, which appears to be nothing more than common oil, coloured with verdigris. The herb was formerly employed in fomentations, but is now thought unworthy of notice.

JUNIPER. Many virtues have been attributed to the berries of this shrub, but without any foundation, except as to its diuretic and carminative qualities, which it certainly possesses in a considerable degree. Juniper berries generally form a part of diuretic balls and drenches; they are recommended also in flatulency of the stomach and bowels.

The dose is from one ounce to two ounces.

Juniper berries are often injured by keeping; becoming dry, shrivelled, or nearly rotten. The purchaser should choose such 
as are plump, rather heary, and moist internally.

An oil is obtained from juniper by distillation, which seems to be the part on which the virtues of the berry depend. Oil of juniper is an excellent carminative and diuretic : the dose is from one dram to two. It is generally highly adulterated with oil of turpentine, but this admixture does not in. jure. it materially; oil of turpentine being very similar to it, in its medical qualities, though not so powerful.

KALI. This is the new name which the London college of physicians has given to pure vegetable alkali, or potash. (See Potash.)

KERMES MINERAL. A red powder prepared from antimony, nearly the same as the golden sulphur of antimony, and re. commended as an alterative in doses from one to two drams. (See Antimony, and Golden Sulphur of Antimony.)

KINO. A resinous substance, possessing a strong astringent quality : a good remedy in diarrhœas which depend on relaxation of the intestines.

The dose is from two to four drams. 
LAC. A resin of a dark colour, deposited by an insect of the East Indies on the small branches of trees. It is now employed only in the composition of sealing wax and varnishes.

LADANUM. A resinous substance brought from Candia. It has been recommended as a pectoral medicine, but probably does not possess any quality of that kind, as it is now tised only as an ingredient in a warm stimulating plaster, wilich is of no use in veterinary practice.

LAUDANUM. A popular term for tincture of opium. (See Opizm.)

LAVENDER. A plant whose distilled water and fragrant oil are employed in medi. cine, but not in the reterinary practice.

LAUREL, or Bay. The leaves of bay are used only in fomentations. (See Pharm.)

LEAD. Many useful preparations are made from this metal, among which are litharge, Goulard's extract, sugar of lead, and the following.

LEAD, RED, or Minium. This is a red powder, made by keeping lead in a high degree of heat : it is used in the composition of plasters. 
IFAD, WHITE, is commonly made by exposing thin sheets of lead to the vapour of vinegar, by which it is converted into a white powder. White lead is often employed in the composition of healing and suftening ointment, for horses that are subject to cracked heels.

LEOPARD's BANE. This plant has been recommended as a febrifuge, but is never employed in reterirary medicine.

LIME is sometines used as a caustic in that disease of the horse's foot termed can$\mathrm{ker}$; it is preferred for this purpose on account of its absorbing the moisture wisich forms upois the diseased parts, and which is thought to be inimical to the cure. Limewater is recommended in the disease termed diabetes, which consists in a profuse discharge of limpiu urine, causing weakness, emaciation, and hectic fever.

I have seen it used, however, in two cases without success. Lime-water is male by mixing lime with a lar e proportion of boling water, stirring the mixture for some time, and afterwards pouring off the transparest liquor, which is to be carefully excluded rom the air. During the wholc pro. 
cess, indeed, there should be as little exposure to air as possible.

LINIMENT. A term given to external applications of the oily kind, but of a consistence rather thicker than oil.

LINSEED. These seeds abound with oil and mucilage, and are well adapted to the composition of those emollient drinks that are so useful in inflammations of the bladder and bowels, or conplaints of the urinary passages. A strong mucilaginous drink may be made without bruising the seeds, either by decoction, or infusion. (See Emollients and Pectorals, Pharm.)

LIQUORICE. An extract made from liquorice root, and supposed to be of use in relieving cough. In the horse it is not applicable to this purpose, as its good effect depends upon its gradual solution in the mouth, so as to be constantly lubricating the throat. Many writers, however, recommend liquorice in their pectoral and cordial drenches, probably with a view to render them more palatable.

LITHARGE. A calx of lead employed in making Goulard's extract, and diachylon plaster. 
LOGWOOD. An extract is made from logwood which possesses a considerable astringent power: it is often employed by medical practitioners in diarrhœa depending upon relaxation of the bowels, and though it has not yet been introduced into veterinary practice, it would probably be found an useful medicine in similar complaints of the horse, and deserves a trial in cases which have resisted the common remedies.

It may be given in doses from two to three drams. Alum, opium, and some aromatic, such as cassia, are often joined with the $e x$ tract, and sometimes chalk.

MACE. A pleasant aromatic spice, too expensive for veterinary purposes; nor is there any complaint in which it is particularly required, as cassia, cardamoms, carraway, and anise seed, are more effectual, and considerably cheaper.

MADDER. This root was formerly used in medicine as a remedy for jaundice. Farriers still employ it for the same complaint, which they term the yellows, both in horses aorned cattle: in the former, the se most commonly arises from increasction, or inflammation of the liver. Litreliance is to be placed on madder 
The dose is about one ounce. (Sce Compendium.)

MAGNESIA. A white powder, so estremely light, that a sufficient dose couhi not be given to a horse without great inconvenience. It is a very useful absorbent in the human body, and well calculated to remove heart-burm, by destroying any acidity that may exist in the stomach; it has alsn the advantage of acting as a gentle laxative. But, in the horse, chalk, or either of the fixed alkalies, answers the purpose equally well; and if a laxative effect is required, a small dose of aloes may be acided. (See $A b$ sorbents, Pharm. See Alkali, Mal. Med.)

MAIUEN HAIR. A old remedy for coughs, but not proper for veterinary practice.

NALACCA BEAN. The acrid matter which renders this bean useful, is contained between two membranes, which cover the kerncl. The Malays employ it for destioying fungous, or prond flesh; and, from its corrosive quality, it would probably be found very serviceable as an extcrual application in horses.

MidLLOWS. This plant is sseful in the 
composition of emollient drinks, from the mucilage it contains; fomentations, glysters, and poultices, may also be made with it. (See Pharm.)

MALT is very serviceable to horses that are recovering from fever; it is useful, also, when the system is weakened by large abscesses, winch discharge copiously, and in almost every case depending on debility.

It appears to be easy of digestion, and very nutritious, though not so stimulating as oats. Green malt has been recommended for improving the condition of horses, and giving them a smooth, glossy coat. Infusion of malt is sometimes given with advantage to sick horses; but they generally require to be drenched with it, which is a great inconvenience. It is always adviseable to employ malt that is broken, as it is more readily digested, and requires less mastication in that state; and if a horse can be induced to eat in the form of a mash, it is still better. (See Mushes.)

MANNA, a gentle laxative, but nerer usad in the diseases of horses

MilluORAM. An agreeable aromatic herb, whose essential oil possesses marly the 
same propertics as the oil of origanum; a remedy much used by farriers in strains, bruises, \&c. but always mixed with other oils or spirits, such as oil of elder, camphorated spirit, \&c.

MARSH MALLOW. This plant contains rather more mucilage than common mallows, and is therefore better calculated for making mucilaginous or emollient drinks, glysters, or fomentations.

The root is the best part, which, if carefully dried, may be kept a long time. These mucilaginous drinks are very useful when the bowels or bladder are inflamed or irritated by too strong physic, or when there is any pain or obstruction in the urinary passages. They should be given frequently in the course of the day, and may occasionally be made the vehicle of more active medicines. Any thing which contains mucilage in sufficient quantity may be employed for the purpose of making emollient cirinks. (See Emollients, Pharm.)

MARUM, or Syrian Herb Mastich.This plant, when dry, is extremely stinulating, and excites violent sileezing when applied to the membrane of the nostrils, for 
*hich purpose it is employed by medical practitioners: it is inapplicable to any purpose in the veterinary practice.

MASHES. A kind of medicated diet, and generally composed either of bran or malt. Bran mashes are made by pouring boiling water on fresh, sweet bran, in a pail, so that the mixture, when stirred, may be about the consisterce of a soft poultice; it is then to be corered orer, and not given to the horse until sufficiently cold. When it is thought necessary to steam the head, as it is termed, that is, for the horse to inhale the vapour as it arises, the mash is put into the manger while hot, and some even put it into a nose-bag, and secure it to the head, which is a bad practice, as it impedes respiration. 'Steaming the head is recommend. ed in strangles, colds, and sore throats.

BRAN MASHES form a very proper diet A) fever, and all inflammatory complaints; they are useful, also, as a preparative to physic, serving to remove any indurated fieces there may be in the bowels, whereby the operation of the medicine is rendered more safe and effectual. Mashes are a necessary diet also while the physic is operat- 
ing. In making malt mashes, the water should be considerably below the boiling point, otherwise the malt would clot, and be spoiled. These are given for the purpose of recruiting strength, when a horse is debilitated from fever, or any other cause. (See Malt.)

MASTICH. A resin, used only in the composition of varnishes.

MEADOW SAFFRON. The root of this plant is a powerful diuretic in the human system, but its effect on the horse is not known.

MECHOACAN. The root was employed as a purgative before jalap was known. It is much weaker than jalap, nor does it pos. sess a single quality which can recommend it as a horse medicine.

MELILOT. This plant was sometimes employed in the composition of glysters, and a plaster, but is now seldom applied to any medical purpose.

MERCURIALS. Preparations of quicksilver.

Mercurial. Ointment. This is made by rabbing together, in a mortar, quicksilver and hog's larl, in various proportions, ac. 
cording to the strength required, until the former disappears, and the mixture assumes a dark biue, or lead colour.

In the strongest mercurial ointment of the shops, there are equal parts of quicksilver and lard; these are the best proportions in which it can be made, as it is easily made weaker afterwards, by the addition of lard. In medical practice this ointment is employed chiefly for the parpose of introducing the quicksilver into the system, which is done by rubbing it for some time on the skin: this is said to be the most safe and effectual method of cuing the venereal disease; but in the horse, consilerable diffculty and inconvenience attend this operation, though it may be made to affect the system. Thus, if we wish to introduce mercury into the circulation, it is better to give some preparation internally. (See ¿nicksiver.)

Mercurial Ointment, however, is often employed in veterinary practice, as an application to callons swellings, or enlarged juints; it may be mixed with camphor with adrantage in those cases; and is certainly ntuch more effucions when con rerted into 
a blister, by the addition of cantharides, or: Spanish flies. In this state it is a good remedy for bog spavin, or other swellings of the hock joint.

Mercurial Ointment is said to be an effec-" tual remedy for the scab in sheep, and is often an ingredient in ointments for the mange. In making mercurial ointment the operation is considerably expedited by using a small quantity of old suet, or tallow that is rancid.

Persons unacquainted with pharmacy commonly prefer mexcurial ointment that has been recently prepared. It is said, however, that old and rather rancid ointment is more powerful, particularly if rubbed for a short time in a mortar before used.

Mercury. 2uicksilver is commonly distinguished by this rame ; the various preparations of which will be described in their proper places. (See Calomel, Sublimate, Cinnabar, LEthiops Mineral, Turpeth Mineral, Red and White Precipitate, Calx of Quicksituer, Mercurib Ointment, and Quicksilier.)

MEZEREON. A root much used in medicine, $\vdots$ venereal and rheumatic coin. 
plaints, but not calculated for reterinary purposes.

MILLIPEDES, or Hog's Lice. These were formerly employed by medical practitioners as a diuretic; but now quite disregarded.

MINDERUS'S SPIRIT. A neutral mixture, formed by the combination of ammo)mia, with acetous acid, or distilled vinegar. It is much used by medical practitioners as a diaphoretic, and though rarely used by veterinarians, I think I have seen it do good in febrile complaints, by relaxing the skin; in one case it occasioned sensible perspiration.

The dose is from eight to ten ounces. MINERAL WATERS are too weak for veterinary purposes. It has been remarked by experienced persons, that waters impregnated with saline bodies, which are commonly said to be braclish, are generally injurious to horses; and I have observed that horses seldom do well on the coast, where the greater part of the water is in this state. This may arise from their not drinking a sufficient quantity for the purposes of digestion, on account of its disagreeable tast:; 
for they often receive much benefit when at grass, in such situations.

MINT. This is a valuable herb, and grows rery abundantly. There are two kinds used in medicine, viz. Spearmint, and Peppermint. The former is an excellent carninative, and generally affords relief in flatulency of the stomach and bowels, and that complaint which arises from it, termed gripes, fret, or fiatulent cholic.

Peppermint, however, is considerably stronger, and I think more certain in its effect; all the virtues of mint reside in an oil, which it affords plentifully by distillation; and this is the only convenient form in which it can be employed for veterinary purposes, but it requires to be highly diluted with water, with which it mixes very readily, if previously disiolved in a small proportion of rectified spirit, or rubbed in a mortar with mucilage and susar.

The dose of vil of peppermint is from twenty drops to half a drans: of spearmint, from forty drops to one dram.

This is general!y fon id a sufficient quan$i \therefore$, but may be increased if it prove in $f-$ fectual. 
It is necessary to distinguish carefully between those pains of the stomach and bowels, which arise from infammation, and such as are caused by spasm, or flatulency. In the former, mint is very pernicious, in the latter, an excellent remedy. (See the Compendium of the Vet. Art.)

MITHRIDATE. The name of an elaborate and absurd preparation, of which opium was the principal ingredient. The London college have substituted for it, a much neater and more efficacious formula, which they tcrm oniate confection.

MOSAIC GOLD. $\Lambda$ combination of tin and sulphur, of a metallic appearance, though soft, and of a golden colour: it is not used in medicine.

MOXA. A light fibrous substance, somewhat like very fiuc tow. In eastern countries it is employed to remove deep seated pains, being set on fire on the affected part so as to burn and produce an eschar; it is therefore nothing more than the actual cautery, which is much more conveniently applied in reterinary practice, by means of the hot iron. (See Firin.)

MURIATES. Combinations of muriatic G 5 
acid, with allialies, earths or metals. Mruriotic Acid. (See Aeid Muriatic) Muriate of Antimony. (See Butter of Antimony.) Muriate of Quicksilver. (See Sublimate.) Muriate of Soda. (See Salt.)

MUSK. An animal substance, remarkable for its powerful odour: in medicine it is employed as an antispasmodic, but its extravagant price has prevented veterinarians from giving it a trial.

MUSTARD. Though chiefly employed for culinary purposes, it deserves to rank sather high in our Materia Medica, particularly as an external application. When flour of mustard is made into a thin paste with water, and carefully rubbed on the skin for some time, it excites considerable inflammation and swelling. This property renders it extremely useful in cases of internal inflammation, particularly when the bowels or lungs are affected. This paste is rendered stronger by the addition of oil of rurpentine. (See Embrocations, Pharm.)

MUstard may be given internally with good effect, in cases which require strong stimulants.

MXRRH. \& gummy resinous substance, 
of a pleasant smell, and a bitter pungent taste: it is much used in medical practice, as a tonic and stimulant, and I think I have seen a good effect from it in horses; in weakness of stomach, diminished appetite, and imperfect digestion; in such cases I have given it with about tiro drams of aloes and a little soap; a little ginger also has been occasionally added: it is often joined with preparations of steel or iron.

There is a simple and a compound tincture of nyrrh, sold by druggists: the former is not used in veterinary practice, but the latter is a favourite remedy with grooms, and farriers, for recent wounds.

The dose of myrrh, is from two to four drams.

NAPCOTICS. Medicines that stupify and procure sleep; such as opium, \&c.

NATRON. (See S'oda.)

NIGHTSHADE. (See Deadly Nightshade.)

NITRE, Saltpetre or Nitrated Kali, or Potash. A nentral salt, formed by the combination of nitrous acid and potash, or kali. This is a medicine of great utility in veterinary practice, and highly esteemed both by 
farriers and reterinarians. It possess es cooling and diuretic property, which renders it extremely useful in fevers, and all inflanmatory complaints; joined with camphor, it is an excellent remedy for suppres. sion of urine or stranguary, provided it does not arise from inflammation of the kidneys. (See Compendium.)

In fevers, it is often joined with emetic tartar, or antimonial powder, with good effect. In catarh or cold, nitre is the best remedy, and in troublesome coughs, it often gives relief, if mixed with some emollient irink and a little boney.

(See Emollients, pharm.)

The medium close of nitre is about one - ounce, though farriers often give double that quantity, or more; but in such large doses it is apt to irritate the stomach and do mischief; therefore, in urgent cases, one ounce may be given every fourth hour, in which way, there will be no danger of its producing that effect, particularly if it be given in a mucilagrinous drink, or in watergruel. If nitre be given in the form of a ball, it is adviseable to offer some water immediately before or after, or to wash it down with a horr-full of water-gruel. 
Nitre, as we have already observed, acts as a diuretic ; but this effect is remarkably expedited by the addition of camphor, about two drams of the latter to one ounce of nitre.

NITROUS ACID. A strong liquid caustic, which, when diluted, with a large proportion of water, forms a good detergent wash. (See Detergents, Pharm.)

Quicksilver is readily dissolved in this acid, and forms with it an excellent caustic, which is an infallible remedy for the footrot in sheep. This solution may be mixed with melted lard, so as to form a strong detergent ointment, or with water in any proportion. (See Acid, Nitrous.)

NUTMEG. This well-known spice is a good stimulant and cordial medicine, but not preferable to many others that are much less expensive. (See Cordials, Pharm.)

OAK BARK. A decoction of oak bark is a good renicle for tonic and astringent medicines. When finely powdered and made into balls with ginger, and a little oil of carraway, it may be of service in those complaints, the continuance of which depend upon debility. It is said, however, to be much less efficacious than Perutian 
bark, yet, when that cannot be procured, it may be found an useful substitute. The dose is about two ounces.

OILS. Oils are either fixed or voiatile. The former are procured from various animal and vegetable substances, generally by means of pressure, from which circumstance they have been named also expressed oils; and are termed fixed, because they do not evaporate, except at a very high temperature, when they are decomposed. Tolatile oils, on the contrary, evaporate very readily, and are generally obtained from regetables, by distillation, and as they commonly contain all the essential qualities of the substance they are procured froin, they have been named also, Essential oils.

The numerous officinal oils, directed in the old dispensatories, are still highly esteemed by farriers, among which are, oil of swallows, earthworms, johnswort, spike, petre, \&c. and we frequently meet with receipts for "strain or bruise oils," in which more than a dozen different kinds of oils are ordered! Perhaps it may be an acceptable piece of information to those who place any confidence in these oils, that only three 
kinds are kept in the shops, from which this great variety is furnished; which are, oil of elder, oil of turpentine, and Barbadoes tar. Oil of spike is made by colouring oil of turpentine with alkanet ront: oil of petre, by dissolving Barbadoes tar in the same oil: for all the other kinds, oil of elder is sold; and this is often made by colouring common oil with verdigris.

OIl of Elder. (See Elder.)

OIL of BAY. This is more like oint- . "ment, than an oil, of a light green colour, and smells like bay berries, from which it is procured. It is used chiefly as an external application in cutaneous complaints, such as the mange. Oil of bay is sometimes substi. tuted for hog's lard in making mercurial ointment, and is supposed to render it more active. When to this mixture is added cantharides, and oil of origanum, a strong blister is formed, which is warmly recommended for the removal of splents and spavins. (Fee Blisters. Pharm.)

Oll of Castor. An useful laxative.

- The dose is about a pint. (See Castor Oil.)

Oil. of Almonds. A very sweet and. 
pure oil, obtained ei her from sweet or bitter almouds, by expression.

It is used in coughs, and as a laxative for children, in medical practice, but is never required for veierinary purposes, olive oil being equally efficacious, and similar in its medical properties.

Orl of Olive. This also is a very pure and sweet oil; and in the dose of a pint generally operates as a laxative. IVhen castor oil cannot be easily procured, this may, with great propricty, be substituted for it.

Oil of Linseed. This also has a laxative quality, but is not so certain in its effect as the castof o: olive oil. It is employed as a remedy for coughs, and on such occasions the cold drawn oil is prefurred; $i$. $e$. that which is expressed from the seed without the assistance of heat. Farriers, ever averse to the use of simple medicines, invented the following absurd receipt for an epidemic cough, which prevailed a few years ago. " Cold drawn linscil oil four ounces, Barbadoes tar fotr cunces, baj:am. of sulphur four ounces, honey four ounces, liquorice powder six ounces, elecampane powder three ounces." When we reficet 
OLIBANUM-OPIATE CONFECTION. I37

that all the medicines used by farriers consists, like the above, of a great number of heterogeneous substances, it will not appear astonishing that the veterinary art made so little progress while in their hands.

Orl. of Palm, or Palm Oil. This, though terned an oil, is of the consistence of hog's lard, and very sinilar to it in its medical qualities. It is of a yellow colour, and has ratier an agreeable smell.

OLIBANU \$. A gummy resinous substance, somet ines used in medicine as a stimulat.ng expectorant, but scarcely known in retemary pactice.

ONONS. These possess a diuretic power in the horse, but are seldum used. In sup, ression of urine, a peeled onion is sometimes placed within the sheath, or prepuce of a horse, or ragina of a mare, with a view to excite staling. It is said to succeed now and then, but in difficult cases it is certainly an inadequate remedy, and when the blad.. der is inflamed may do much injury.

OPIATE CONFECTION, is composed of opium, long pepper, and other stimulants. One ounce of the confection does not contain more than fourteen or fiftecn grains of opium: it may, therefore, be 
given in doses from one to two ounces, though in this quantity it would be a powerful stimulant.

OPIUM. One of the most important ar. ticles of the Materia Medica:

It is classed among the narcotic sedatives, of which it is undoubtedly the most useful.

The anodyne quality which renders opium so valuable in human medicine, is not so manifest when given to the horse; this I attribute to the griat difference there is between the diseases of men and horses.

If injudiciously given, opiun frequently aggravates the disease, and does much injury; and I have several times seen it increase pain, when it has been improperly given as an anodyne. In spasmodic complaints of the bowels it is an excellent remedy, particularly if joined with aromatic powder, ginger, or some other stimulant. In diarrhoa it is an effectual remedy, but must be given cautiously. In diabetes I have found it very beneficial, when joined with bark and ginger. Sometimes it is given with cmetic tartar, and some cordial composition, with good effect, and in this way it prowes a good diaphoretic. 
I have often given opium and squill, in obstinate coughs, with success ; but the effect is not always permanent.

Opium is very apt to produce costiveness in horses, but this tendency may be, in a great measure, counteracted by cxercise; when it does take place, it may be removed by glisters, bran mashes, or a laxative ball.

'The medium dose of opium is one dram, but if given in the form of glyster, which it sometimes is with the best effect, two drams will not be too much.

In human medicine, opium is frequently used in the form of a tincture; in veterinary practice it is most convenient in a solid form. Should a liquid form be at any time necessary, a watery solution (using the sediment as well as the clear part) is preferable to the tincture.

OPOPONAX. A guin resin, nearly resembling galbanum in its medical qualities, though so much inferior that it does not merit any notice as a veterinary medicine.

OPODELDOC is made by dissolving soap and Camphor in spirit of rosemary. It is either liquid or solid; according to the proportion of soap. In the solid state, it 
secmis to be the same as the celebrateo Sieer's's Opodcldoc. (See Pharm. article Embrocutions.)

It is a popular remedy for strains and bruises, and is a very proper application when the inflammation, which always accompanies those complaints at first, has subsided, or have been removed by other remedies. (See the Compendium.)

ORIGANUM. The essential oil of this plant is much used by farriers, as an ingredient in their strain oils, or mixtures for bruises. It is a very powerful stimulant, and capable of doing much good in those complaints: it is sometimes mixed with mercurial ointment, oil of bay, and cantharides, to form strong blisters. (See Pharm.)

ORPIMENT. (See Arsenic, ye!low.)

OYSTER EHELL, when burnt and levigated, is cmployed as an absorbent.

The dose is al oout one ounce.

OXIGEN. A constituent part of atmospheric air, without which it would be unfit for respiration. In breathing, we deprive the air of this pure and vital principle; it is therefore unfit for the purpose a second time; and if an arinal be confuned in air 
that has been once respired, life is almost instantly extinguished. Hence may be inferred the necessity of rentilating stables: for although in close stables the air is not wholly deprived of this principle, yet its proportion is considerably diminished : and it is well known, that when there is adeficiency of this animating principle, the system is debilitated, and all its functions imperfectly performed; whence arise cough, brokell-wind, diseased eyes, \&c. \&c. Perhaps future observation may enable us to add glanders to the list of discases caused by foul air.

OXYD. The calxes of metals are now termed oxyds, on account of their containing a certain proportion of oxigen (the acidifying principle;) but not sufficient to give them the properies of an acid. The term oxyd, signifying an imperfect acid. But this subject more properly belongs to a cliemical work.

\section{PALM OIL. (See Oil of Palm.)}

PELLITORY OF SPAIN, the ròot. This is used chicfly to relieve the tooth-ache, and pain abont the jaws; which it does by caus. ing a copious discharge of saliva, when kept 
in the mouth a short time. It is not necessary in veterinary practice.

PECTORALS. Medicines that relieve cough, and disorders of the lungs. (See Pharm.)

PENNYROYAL. The essential oil of this herb possesses a carminative power, but is rery inferior to that of peppermint.

PEPPER, BLACK. This is often used by farriers in the cholic, but is by no means an eligible remedy, and is often given very improperly. I once saw a farrier give two ounces, in half a pint of Daffy's Elixir, to a mail horse, that was said to be attacked with gripes, and he condescended to give me the following scientific explanation of the manner in which it was to act. "The Pepper is to break the wind, and the Dafy's Elixir is to drive it out." I remonstrated, and endearoured to rescue the poor animal, who suffered from ingammation of the bowels, but to no purpose; the poisonous drench was given, and in the evening the horse died. I mention this circumstance as a caution to those who are too fond of giving those very hot remedies in pains of the bowels, without inquiring into the nature 
of the complaint. There are cases no doubt, in which pepper may be given with advantage, particularly in flatuleit com-plaints; but these must be carefully distinguished from such as are inflammatory, for in these, pepper is absolutely poisonous. (See the Compendium, in which are plain directions for distinguishing between flatu.. lent and inflammatory cholic.)

The dose of black pepper is from half an ounce to an ounce.

PEPPER, CAYENNE. (Sce Cuyenne Pepper.)

PEPPER, LONG. Is rather stronger than black pepper.

PEPPER, JAMAICA. (See Jamaica Pepper, or Allspice.)

PEPPERMINT. (See Mint.)

PHOSPHORUS. $\Lambda$ very combustible substance, made either from bones or urine. Experiments have been made at the Veterinary College to ascertain its medical qualities ; it proved to be a very dangerous medicine, inflaning the stomach in small doses.

PINK ROOT. (See Indian Pink.)

PITCH. A black and impure resinous 
substance, used by farriers in making charges. (Śee Burgundy Pitch.)

PONEGRANATE. The dried fruit is a moderately strong astringent, and is somctimes cmployed in diarhoa, particularly in horned cattle.

The dose is from half an ounce to an ounce.

It may be joined with alum, ginger, and other auxiliaries, and occasionaliy with opium.

POPPY. The hearls of poppy dried make a good fomentation for wounds and tumours that are in a painful and irritable state; for which purpose they are to be broken in picces, and boiled in water, so as to make a strong decuction. This decoction proves vcry serviceable in imiability of the bladder, if used as a glyster, the bowels having been previously emptied; for this purpose the decoction should be male stronger, by boiling it for some time.

It secms very probable that the good offect of this decoction depends in a great measure upon the opium which is extracted from the poppy heads; it may be better, thercfore, to dissolve in water-gruel a proger dose of opium, when an anodyne glyster 
is required, as we cannot be accurate in $r e$. spect to quantity when the decoction of Poppies is employed.

POTASH, Carbonate of, Prepared Kali, or the Vegetalle Alkali. The potash of commerce is in a rery impure state, and not applicable to chemical or medical purposes. When properly purified, it is joined with purgatives and tonics with advantage. In those cases which require the use of tonics, there is generally an acidity in the stomach, which potash corrects; and it renders purgative medicines more easy of solution. Given alone it generally acts as a diuretic. When neutralized with acids, it has a laxative property, but requires to be given in large doses. With vitriolic acid it forms vitriolated tartar, or sal polychrest (vitriolated kali); with nitrons acid, that very usefill medicine termed nitre, (nitrated kali), which, contrary to what we have just observcd, is a diuretic in a moderate dose (See Vitre); and with rinegar, or acetous acid, it makes soluble tartar (tartarized kali.) The purified potash is named in the shops prepared liali; but formeriy salt of tartar, or rormwood. When potash is deprived of 
the carbonic acid with which it is naturally combined, it becomes a strong caustic; and when diluted is sometimes employed as a wash for the mange. In this state it is termed pure kali, and is seldom used internally. (See Alkalies.)

PRECIPITATE, RED, or Red Nitrated 2uicksilver. This is extremely useful as a mild caustic or detergent, and has an excellent effect in foul ulcers. It may be used either alone, being finely powdered and sprinkled on the affected part, or mixed with various ointments. (See Detergents.) It is made from quicksilver and nitrous acid, but is considerably weaker than a solution of that metal in nitrous acid. It becomes, however, a strong and very efficacious caustic when dissolved in nitrous acid; in which state, by proper management, it readily cures fistula, poll evil, and canker. This solution may also be mixed with unctuous substances, forming with them good detergent ointments; or it may be diluted with water so as to form a detergent lotion of considerable efficacy.

PREPARED KALI. (See Potush.)

PUFFBALL. The dust of puff-ball is 
PRECIPITATE, RED-QUICKSILVER. 147 sometimes used to stop bleeding; but nothing of this sort should be depended upon when the bleeding is considerable. Pressure being much more effectual.

QUASSIA. A powerful bitter, and a good medicine in cases of weakness of the stomach. It is generally given in powder in doses from two to three drams, joined with ginger, or some other stimulant, and a small quantity of soda or potash.

QUICKLIME. (See Lime.)

QUICKSILVER, or Mercury. The most useful of all the metals for medical purposes. In its metallic state, it is inert, but when combined with orygen, or any of the acids, it becomes extremely active; and though one of the most valuable articles of the $\mathrm{Ma}$ teria Medica, requires considerable skill and experience to be employed with advantage. The most simple preparations of quicksilver are, mercurial ointment, Ethiop's mineral, and cinnabar. These may be employed with little danger: they seem, indeed, to be of very little use as hor'se medicines, except the ointment, which is a good external application; and in human medicine a very valuable preparation. The more active 
mercurials are, sublimate (muriated quicksilver), red precipitate (red nitrated quicksilver), turpeth mineral (vitriolated quick. silver) and calomel, each of which is described in its proper place.

Quichsilver oxydated, or Culcined Mercury. A reddish powder, into which quicksilver is converted by being kept in a certain degree of heat a sufficient length of time, and in a ressel aclapted to the purpose. It is an active mercurial, but rarely employed in veterinary practice.

The dose is from half a dram to one dram.

RATTLESNAKE ROOT. This is now neglected by medical practitioners, and inapplicable to veterinary purposes.

RAKING. A term employed by farriers for an operation which consists in introducing the hand into the horse's rectum, and drawing out any hardened excrement that may lodged there. This may generally be effected inore to the purpose, and with greater ease to the animal, by means of glysters.

REALGAR. A natural combination of sulphtir and arsenic, not used as a medicine. (See Arsenic.) 
RECTIFIED SPIRIT. Alkohol, or Spirit of Wine. This is obtained in a dilute state, from fermented liquors by distillation, and is afterwards rectified or concentrated, by repeating the operation two or three times. Rectified spirit is the basis of many useful embrocations, for strains, bruises, \&c. It dissolves camphor, and all the resins very readily; hence we have camphorated spirit, opodeldoc, Fryar's balsam, \&c. Mixed with an equal quantity of water it forms what is termed proof spirit, which is the liquid generally einployed for making tinctures. Reclified Spirit is often used alone as an embrocation for strains; and, when the injury is deeply seated, is very serviceable. I think, however, it is rendered mure efficacious by the addition of camphor, or oil of rosemary. Rectified spirit is never employed as an internal remedy in the horse; though fermented liquors, such as beer, porter, or wine, have been often given with great advantage, in cases which required cordials. I have often seen horses, that have been so fatigued with a long chase or jour$\mathrm{n} e \mathrm{y}$, as to refuse their food and appear quite exhausted, wonderfully refreshed by taking 
a cordial ball in a pint or more of beer, and feed soon after with great alacrity : the advantage thus derived is not merely temporary, as they are by this treatment rendered adequate to another chase or journey much quicker than they would otherwise be. (See Cordials, Pharm.) I have known wine given in obstinate diarrhœa with good effect.

It may be asked, why diluted alkohol, or rectified spirit, is not equally useful, since it is the essential principle of all fermented liquors. The reason is this : when rectified spirit is diluted with water to any degree, the combination is so weak, that the heat of the stomach readily separates the former, which from its volatility attaches itself to all the superior parts of the stomach, acting on them as rectified spirit; whereas in fermented liquors, the spirit and water are so firmly united, that the heat of the stomach is not sufficient to separate them. This may be proved by experiments out of the body, and sufficiently accounts for the difference we observe between the action of diluted spirit, and fermented liquors in the human stomach: but in the horse great part of this 
REGULUS OF ANTIMONY-RESINS. 151

organ is covered by an insensible membrane; and as spirit has never been fairly tried on this animal, it is worth while to make some experiments on the subject.

I once gave six ounces of brandy, diluted, with the best effect, to a horse that was once done up in a journey; it enabled him to continue it, without any apparent inconvenience,

REGULUS OF ANTIMONY. Common or crude antimony, deprived of its sulphur, and brought to a metallic state. It is never used as a horse medicine. In the human body it is said to cperate with great violence.

REPELLENTS. $\Lambda$ term employed by the old school, for medicines that were supposed to have the power of causing tumours or eruptions to recede from the surface of the body. The term is founded upon a false theory, and has been the cause of much mischief in practice.

To be convinced of this, the reader may consult modern works on physiology.

RESINSare distinguished by theirinflammability, and by combining readily with rectified spirit and oils. They are generally solid, and immixable with water. 
RESOLVENTS. Medicines that dispere sumours, either external or internal.

ROBORANTS. Medicines that strengthen the system.

ROSIN, yellow and black. The former is a weak diuretic, and sometimes given with advantage to horses that are subject to swelling of the legrs. The dose is about one ounce, which may be powdered and mixed with the corn: it is necessary to continue this medicine for sereral days, or until its diuretic effect is considerable. Black rosin is not used in medicine.

ROWELLING. An operation ofien performed in veterinary practice. It consists in making an incision in the skin, about an inch in length, with a pair of short and strong bladed scissars. The finger is then introduced in order to separate the skin from the subjacent parts all round the incision that the cavity may contain a circulat piece of leather about an inch and a half or two inches in breadth: before this leather is iritroduced, a hole is made in the centre about half an inch in diameter; it is then covered with tow (the hole being left open), and smeared with digestive ointment: when 
the rowel is put in, the hole in the middle of the leather is plugged up with a little tow.

In this sitution it is left until matterforms, whic! general'y happens in two or thee days; the plug of to:v is then withdrawn, an l the matter suffered oflow out, in which state it remains as long as is thought necessary. Thus we sed that a rowel is an artificial abscess, the lea her first causing infammati.n, which ends in suppuration or the formation of matter; and the matter continu's to be forsel aslong as the extraneous boily of leather remains under the skin.

The inten:inn of ruselling is to divert infam nation from any important organ or part of the boly. Thus, when the lungs are inflamed, the animal certainly dies, unless it is put a stop to; but the skin may be inflamed to a considerable extent without danger, we therefore put a rowel in the chest, which, though not sufficient of itself to stop the inflammation of the lunga, contributes very materially to it, and with the other necessary remedies often effects a cure. In large swellings of the hind legs

H. 5 
and obstinate cases of grease, rowels in the thighs are good remedies.

In shoulder strains, a rowel may be put in the chest with good effect. In short, whenever inflammation attacks an essential and important part of the system, much benefit will be derived from inserting a rowel in some contiguous part that is of little importance. When a rowel is removed, the part generally heals of itself; if not, a little Fryar's balsam may be applied.

ROSEMARY. The essential oil of rosemary forms an excellent embrocation for strains and bruises, if mixed with rectified spirit and soap. This mixture is nearly the same as the celebrated opodeldoc; and by the addition of camphor becomes the same thing. Oil of rosemary has been given in the flatulent cholic or gripes with good effect, but requires considerable dilution.

The dose is from half a dram to one dram, or more.

RUE. This plant has been recommended as an anthelmintic ; but whatever its virtues may be in the human body, it has certainly no effect of this kind on the horse ; and may 
ROSEMARY-ST, JOHN'S-WORT. 155

with great propriety be dismissed from our Materia Medica. Farriers sometimes use it in making fomentations.

SACCHARUM SATURNI. (See Sugar af Lead.)

SAFFRON was formerly thought a good cordial medicine, and frequently employed as such; but at this time medical practitioners are agreed in thinking it destitute of any medical virtues. It is still retained, however in their Pharmacopœia, probably on account of its elcgant yellow colour and fragrant smell. As a horse medicine it is certainly not worth notice.

SAGAPENUM. A gum resin, similar to but weaker than assaforida.

SAGE. A plant not used in veterinary practice.

SAGO. A farinacious substance, which, when boiled in water, is a pruper driik for sick horses that are incapable of feeding.-

ST. JOHN'S-WORT. A plant not used in medicine, though formerly supposed to possess many virtues. The oil of St. Joinn's wort sold by druggists, is nothing more than the common green oil which is sold under a variety of names. (See Oils.)

H 6 . 
SAL AMMONIAC, or Muriate of Ammonia. A neutral salt, which when dissolved in vinegar and water, forms a good embrocation for strains and bruises.

SAL INDUS. A saline substance of a reddish colour and rery unpleasant smell, lately brought from the East Indies, and strongly recommended as a remedy for that species of worm called botts: I have not found it however capable of destroying those worms or expelling them ; though, if given in large doses, it will sometimes discharge common worms, particularly if assisted by iloes. The dose is from two to four ounces. It appears to differ from common salt only in being combined with a small proportion of liver of sulphur, or sulphurated potash.

SAL VOLATILE. This term is promiscuously applied to compound spirit of ammonia, and prepared ammonia or smelling salts; but the former is oft'n distinguished by the name "spirit of salvolatile."

SALTS. There are three kinds of salt, viz. the acid, the alkaline, and that which is formed by the combination of these, i. e. the nentral. (Sec Acids, Alkalies, and Neu= trals.) 
Salt Common, or Sea Salt. This is the most useful of all neutral salts for veterinary purposes, nitre excepted.

In doses from four to six ounces, it generally operates as an easy and effectual laxative; and when there are worms, if assisted by a small dose of aloes, it frequently expels them.

It is extremely useful in laxative glysters, (See Pharm.) and considerably promotes the operation of castor oil. (See Laxatives, Pharm.) In chronic inflamınation of the eye, I have often applied it to that organ in fine powder, with the best effect.

\section{Salt Perre. (See Nitre.)}

Salt of STE:L, or Vitriolated Iron. A combination of vitriolic acid and iron. This is by no meaus so remirkable for its tonic power in the horse, as in the human subject, but it is said to possess this quality, and is often given in doses from four to six drams. I have several times employed it in cases that appeared to require tonic remedies, but with very little effec.. (Sce Iron.)

Salt of Tartar. (See Potash and Alkalies.)

SALT of WORMWOOd. (See the same.) 
SARSAPARILLA. A root not used in veterinary medicine.

SASSAFRAS. The only part of sassafras that can be of use in veterinary practice, is the essential oil, which is an aromatic stimulant of considerable power.

SAVIN. Farriers often employ the leaves of this shrub in a green state as an anthelmintic, but I have never seen it do any good.

SCAMMONY. A gum resin, strongly purgative, but never necessary in veterinary practice when aloes can be procured.*

SCORDIUM. The leaves of scordium were formerly considered as an astringent and corroborant; and there is still an electuary of scordium or diascordium kept by druggists for the accommodation of farriers, who are often attached to useless medicines.

SEA WATER. Some horses will drink a sufficient quantity of sea-water to excite purgation. Should such horses be affected

* I have lately tried scammony in various doses: it produced scarcely any effect until six drams were given at one dose, which was followed by moderate purging. 
with swollen heels, inflamed eyes, or other inflammatory complaints, it would be found an useful remedy.

SENNA. The leaves are an effectual purgative in the human body; but in the horse it is an inconvenient medicine, on account of the large quantity requisite to produce this effect. . Some writers on farriery have recommended a strong infusion of senna, with Glauber's salt, as an expeditious laxative. I have given senna in considerable doses without the least effect. I tried also the following mixture so strongly recommended by many writers on farriery which did not affect the bowels in the slightest degree.

Senna three ounces, infused in a quart of boiling water, and kept in a warm situation about an hour; the infusion was then strained off, and the remainder forced off by considerable pressure. In this infusion we dissolved four ounces of Glauber's salt, and gave the whole to a horse at one dose.

SIALOGOGUES. Medicines that cause an increased secretion of saliva, the principal of which are the preparations of mercury.

SILVER. The only preparation this 
metal affords is the lunar caustic or nitrated silver, an application of great inportance in surgery, whether human or veterinary. (See Causics, Pharm. and Mat Med):

SNAKE ROOT. Th' idea that this root counteracts the bites of serpents, is now disregarded; but it is consilered an useful medicine in cases of weakness, and may be employed with advantage in veterinary practice, particularly in ill-conditioned wound, in which there appears a tendency to mortification.

The dose is from half an ounce to an ounce, and is generally given with prepared ammoniac, or alt of harishorn, camplicr and bark; in some cases opium is added. (See Tonics, and sintiseptics, Pharm.)

SOAP. The various kinds of soap have all a strong diuretic quality; but the purer 'kincis only should be employed as internal remedies, and these are Castile, Spanish, and pure white soap. Soap is an useful ingredient in purgative, as well as diuretic preparations.

The dose is from two drams to half an ounce, but it is sometimes given in larger doses. 
Soft soap is very useful in cleansing foul heels; and when mixed with oil of turpentine and spirit of wine. forms a good embrocation for strains, bruises, and indurated tumours.

SODA. Natron, or the Mineral Alkuli. This is procured chielly from the ashes of marine plants. Its niedical properties are nearly the same as potash, but the prepared natron or soda is sometimes preferred as an ingredient in purgative and tonic medicines.

The dose is from two to four drams.

SOUTHERNWOOD. A fragrant shrub, directed by the London College as an ingredient in fomentations.

SPANISH FLIES. (See Cantharides.)

SPEARMINT. (See Mint.)

SPI.RMACETI. An unctuous substance, procured from the head of a certain species of whale. In medical practice it is often employed as a demulcent, to allay irritation, as in cough, but is rarely employed in veterinary practice, and appears to differ very little in its medical properties from hog's lard or suet. It has been lately discovered that the muscular parts of all animals may be converted into a substance re- 
sembiing spermaceti, by maceration in water.

SPIKE, a species of lavender. An oil of spike is kept in the shops and much used by farriers; it appears, however, to be nothing more than oil of turpentine, coloured with alkanet root.

\section{SPIRITS. (See Rectified Spirit.)}

By the term spirit is commonly understood alkohol, either pure or diluted, and mixed with various substances. Spirit may be obtained from fermented liquids in a diluted state; when concentrated and purified, it is termed rectified spirit, or alkohol. An equal quantity of water being mixed with alkhol, forms proof spirit. There are various kinds of spirits used in medicine, such as spirit of nutmeg, spirit of juniper, \&c. which are made by distiling the medical substance with dilute spirit.

SPONGE. Burnt sponge is sometimes used by medical practitioners in scropliulous complaints, but it is never employed in veterinary practice.

SQUILL, or Sea Onion. A large bulbous root resembling the onion, and a nedicine of considerable value. The best prepara- 
tion of squill for veterinary purposes is the powder of the dried root; which, in the dose of one dram or more, is an excellent expectorant, and very efficacious in chronic cough; in larger doses it generally acts as a diuretic, but is not a desirable medicine for that purpose, there being many diuretics more certain in their effect. Gum Ammoniacum is an eligible addition to squill; and $I$ have sometimes seen camphor and opium joined to it with good effect. One dram of the dried squill is equal to about five drams in its fresh state. There are three other preparations of squill made, viz. the spirituous and acetous tincture, and the oxymel; but these are not well calculated for veterinary purposes.

STARCH. Starch glysters with opium are sometimes employed in obstinate diarrhœas or irritation of the rectum. In no other way is it useful in veterinary practice, while the cheaper mucilages, such as linseed, marshmallow, \&c. can be procured; but when these are wanting, it is capable of making a good mucilaginous drink. (See. Pharm. Emollients and Demulcents.)

STAVESACRE. The seeds of Stavesacre 
are recommended as a topical application in cutaneous complaints, and for destroying those animalcules which are sometimes generated upon the horse's skin. They are used either in the form of a decoction, or finely powdered and mixed with train oil, 'turpentine, \&c.

STEEL. The medical properties of steel are not supposed to differ from those of iron. (See Iron.)

STORAX. The common and the strained storax are the only kinds kept in the shops. The former is in the form of saw dust, inter-mixed with resinous matter of an agreeable odour : the latter is extracted from this dust, and is far more pure; indeed it is the only kind that can be employed for medical purposes. In its medical properties it nearly resembles balsam of tolu, and may be given in obstinate coughs with squill, opium, and soap.

The dose is about two drams.

STYPICS are medicines which constringe the blood ressels when wounded, so as to stop an effusion of blood. Many preparations have been recommended for this purpose : but when the size of the wounded 
vessel is at all considerable, an adequate degree of pressure by means of holsters and bandages is alone to be depended upon; and wisen tliat cannot be done, the vessel must be tied up above the wound and below, by which the hleeding will be effectually suppressed. No danger is to be apprehended from slight bleedings in the horse, as they always cease spontaneouly.

The styptics commonily employed are oil of turpeutine, diluted ritriolic acid, muriate of iron, absorbent earths and flour.

SUBLINATE. Coirosive Sublimate of Mercury, or Muriate of Zuicksilier. For reterinary purposes this is the most useful of the mercurial preparations, both for external and internal use. Though a violent remedy in the human body, and given only in very minute doses (from the eighth to a quarter of a grain), it is comparatively innocent in the horse. I have often employed it to the extent of two clrams at one dose, without producing much effect upon the animal; it is adrisable, however, to begin with a much smaller q!antity, 10 grains for example, which may be gradually increased if necessary. I helieve it to be the 
best remedy we know for the farcy, and more likely than any other medicine, if properly managed, to cure the glanders. I have often given it in obstinate cutaneous complaints, with emetic tartar, and generally with good effect. It commonly acts as a diuretic, and ver̀y seldom salivates, though given daily for two or three weeks. Sometimes it irritates the bowels and stomach, in which case opium becomes necessary.

When the use of sublimate is continued three or four weeks, it is necessary to watch its effect carefully, and to counteract its debilitating quality, by a nutritious diet, moderately warm clothing, and a stable properly ventilated.

The groom must be particularly attentive, fiequently rubbing the legs, giving moderate exercise and warm water. When sublimate has been employed in large doses, and continued a considerable time, I have seen it produce a dangerous degree of debility, from which the horse was with great difficulty recovered; but this arose, in great measure, from the inattention of the groom. In short, sublimate is either an excellent remedy, or a dangerous poison, according 
to the judgment of the person who employs it. In the hands of those illiterate, conceited fellows, who think themselves profoundly skilled in medicine, and are more dangerous in a stable than an epidemic fever, it is liable to do great mischief, and should never be entrusted to them; but I repeat, when used by a judicious practitioner, it becomes in his hands an invaluable medicine. I have frequently and successfully employed it, generally beginning with a dose of 10 or 15 grains, which was gradually increased, according to the effect it appeared to produce. It should be finely powdered and mixed with a small quantity of cordial ball.

As an external application, it is also highly necessary; it may be dissolved in rectified spirit, proof spirit, or distilled water, but it dissolves more readily if first rubbed in a mortar with a few drops of spirit of salt, or muriatic acid. It is an excellent application to foul ulcers, particularly those of the knees, when the ligaments are wounded (See Detergents, Pharm.) It is capablealso of destroying those animacules which sometimes infest the skin of horses, and of curing the mange. 
SULPHUR. (See Flowers of Sulphur.)

TANSY. This plant grows abundantly about the borders of fields; it has a strong bitter taste, and rather a pleasant odour. It may be employed in the form of a decoction as a vehicle for tonic or stomachic medicines. It has been said to possess an anthelmintic quality, but I believe there is no foundation for this opinion.

TAR. This is a good remedy for thrushes, and other diseases of the frog. It appears to promote the growth of hom, by gently stimulating the secretory vessels of that part.

The rotten parts of the frog having been carefully removed with a knife, and the rest well cleaned, the tar is to be nelted and poured into the cleft or cavity: a pledget of tow is then to be laid on the part, and confined by some proper contrivance. In bad cases, a small proportion of vitriolic acid should be carefully mixed with the tar; and when a thrush has degenerated into the disease termed canker, a larger proportion of the acid should be employed. (See Liniments, Phurm.)

Tar, mixed with oil of turpentine, and cantharides, forms a strong blister. Farricrs 
sometimes employ tar as a remedy for cough, but it more frequently aggravates than rejieves the complaint. (See also, Barbadoes Tar.)

TARTAR. An acid substance, found about the sides and bottoms of casks in which wine is fermented, when purified, it is termed chrystals, or cream of tartar. Farriers generally employ it in their purging medicines, upon the authority of some old writers, who supposed it to have the property of correcting aloes, but in the horse it is a very inert medicine, and in my opinion, of very little use.

TARTAR EMETIC. (See Emetic T artar.) TARTARIZED ANTIMONI. (SEe Emetic Tartar.)

TARTAR SOLLBIE, or Tartarised Fali. A neutral salt, not used in veterinary medicine.

TARTAR, VITRIOLATED. A neutral salt, not adapted to veterina:y purposes.

TIN. This metal is a good antirelmintic in dogs, and though not employed in reterinary practice, appears to be worth a trial. I have seen great numbers of worms cischarged from dogs, by giving filings or scrapings 
of pewter, which is composed principally of tin and lead.

TOBACCO. This is sometimes given to horses by grooms, for the purpose of keeping their legs fine; it generally acts as a diuretic.*

TORMENTIL. The root is a powerful astringent, and is sometimes employed in the diarrhcas of horses and horned cattle, with good effect.

One ounce, or one ounce and a half, being boiled in three pints of water, to one pint and a half, with a little cassia, and caraway seeds, makes one dose, which may be repeated if necessary.

TRAGACANTH, or Gum Dragon. This gum makes a strong mucilage, and may be employed in making emollient drinks.

TURBITH MINERAL, Yellow Mercurial Emetic, or Vitriolated 2uicksilier. This mercurial preparation is seldom used in veterinary practice, being apt to irritate the sto.

* A short time since an infusion of about two ounces of tobacco in a quart of beer was given to a horse nerely for the purpose of keeping his heets fine. He died immediately after taking it. 
mach and bowels, and bring on violent purging; but it has been recommended a: a remedy for farcy.

The dose is from half a dram to a dram.

It is a good emetic for dogs, when they have swallowed any poisonous substance, or at the commencement of the distemper.

TURMERICK. This root, though formerly employed, and still highly esteemed, by farriers, as a remedy for the jaundice, or yellows, does not appear to differ from other aromatic stimulants, which quality it possesses in a moderate degree.

The close is about one ounce.

TURNIPS. Boiled tumips make an excellent poultice for the hecls when affected with grease.

TURPENTINE. This term is applied to the resinous juices of certain trees. There are four kinds, viz. Chio, Strasburgh, Venice, and common turpentine, the two last only, are employed in veterinary medicine. They are effectual diuretics, and possess a considerable carminative power. Common turpentine is a principal ingredient in digestive and deterghent ointments. By distillation we obtain from it the oil, or as it is 
sometimestermed, the spirit, of turpentine, a medicine of great utility: In doses from one ounce to two ounces, it frequently cures the flatulent cholic, or gripes, and when combined with camphor, and other stimulants, makes a goorl embrocation for indurated swellings, strains, and bruises. When properly mixed with mustard, it forms an embrocation, that has been found serviceable in counteracting internal infiammation. I have seen it applied to obstinate ulcers with good effect. It is an useful ingredient in blistering ointment, and liniments.

I enice Turpentine is generally made by mixing the oil with the common turpentine, which is easily done when the latter is meited.

Venice Turpentine is sometimes employed as an ingredient in cough medicines. The dose is about half an ounce, But if given as a remedy for flatulent cholic, or as a diuretic, a larger quantity is necessary. It makes an excellent detergent ointment, if mixed with about a fourth or a third part of red precipitate, finely powdered.

TUTTY. $\Lambda$ grey earthy substanco, not used in reterinary practice. 
VALERIAN. The dried root is employed by medical practitionces, in spasmodic and nervous complaint, but there is no disease in the horse in which it is likely to be serviceable.

VERDIGRIS. The rust of Copper. It is made in wine countries, by burying thin copper-plates in the refuse parts of the grape, after the juice has been pressed out. It is employed externally as a mild caustic, or detergent, and is frequently mixed with common tuipentine, or ointments, for the same purpose. (See Detergents, Pharm.)

When verdigris is dissolved in distilled vinegar, and chrystallized, it becomes considerably stronger, and will be found an excellent remedy for quittors. (See the Compendium.) In this state it is called chrystallized, or distilled verdigris. Common verdigris has been recommencleci as a remedy for the farcy; but I have neverseen it do any good in that complaint, though I have several times given it a trial.

It has been fairly tried in the glanders: half an ounce was given daily for a consideable time, but it had no effect on the disease, nor did it occasion any inconrenience to the 
anima.?. This is rather reinarkable, verdigris being considered as a poison in the human Fody, and is the sustance which causes the deleterious efrects which copper vessels, when employed for culinary purposes, hare sometimes occasioned.

VERMILION. This is prepared nearly in the same way as cimabar, but as a little arsenic is sometimes employed to heighten its colour, it is never used for medical purposes.

VESICATORIES. A term synonimous with blisters.

VINEGAR. Though medical practitioners prefer distilled vinegar, yet, for veterinary purposes, the best undistilled vinegar is just as proper. In makes an useful embrocation with about a tenth part of sal ammoniac or muriate of ammonia, for inflamed swellinus; and when neutralized wirh prepared ammonia, or sa!t of hartshorn, forms a preparation sometimes enployed in fevers, and termed Minderus's spirit.

Vinegar is sometimes used alone as an embrocation for strains, bruises, or inflamed swellings of any kind, and often with success; it may be made more effectual, how- 
ever, by the addition of sal ammoniac anc proof spirit, or by being mixed with a small quantity of sugar of lead and water, according to the circumstances of the case. $\Lambda$ solution of honey in vinegur is termed an oxymel, and is sometimes used as a remedy for coughs; this is said to be nearly the same preparation as Godbold's vegetable syrup, which has been sometimes recommended by farriers, to cure "Groken wind," an incurable disease!

VIPERS' FAT, is similar in its medical qualities to common fat ; though formerly supposed to be a remedy for the bite of the viper, and other venomous reptiles.

VITRIOL, a term commonly applied to those salts of which vitriolic acid is a constituent part; the London college, however, gives names expressive of their composition, thus, white vitrio!, which is composed of vitriolic acid and zinc, is named ritriolated zinc.

VITRIOLIC ACID. (See Acid Vitriolic.)

VITRIOLATED COPPER. (See Blue Vitriol.)

VITRIOLATED IRON, Green Fitriol, or 
Copperas, this resembles salt of steel, in its medical qualities. (See Sult of Steel.)

VITRIOLATED KALI, or Vitrioluted Tartar, not used in veterinary medicine. VITRIOLATED NATRON, or Soda. (See Glauber's Sal:.)

VITRIOLATED QUICKSILVER. (See Turbeth Mineral.)

VITRIOLA TED ZINC, White Vitriol,or Copperas. This has been recommended as a tonic remedy, in doses from half an ounce to six drams. But I have seen it given to the extent of twelve ounces at one dose, to a glandered horse, by way of experiment, without producing much inconvenience: the only effect produced, was upon the urinary organs, occasioning a frequency and a little difficulty in staling. It is a good application to indolent ulcers, and in the latter stages of grease. (See Astringent, and Tonics, Pharm.) A weak solution of white vitriol is often employed as an eye water.

WAX. Bees wax is used only in the composition of ointments and plasters.

WINE. Port wine has been strongly recommended in obstinate diarrhœas, accompanied with debility. A little cassia, or 
ginger, is generally added to it, and on some occasions, opium. It is certainly a powerful cordial, and may be advantageously employed when such remedies are required. It has been given in the diarrhoea of horned cattle with good effect. The dose is about half a pint; but a horse accustomed to cordials will take more.

WINTER'S BARK. A pleasant stimulant; and though not commonly used in veterinary practice, may be given with good effect in cuses of indigestion, and weakness of stomach.

The dose one ounce, every morning.

WOLF'S BANE, or Aconite. A dangerous meadicine in the horse, and nerer employed, its effect having been ascertained upon glandered horses.

WOP.I SEED. Not used in veterinary medicine.

WORMWOOD, a strong aromatic bitter, but rarely employed as an internal remedy. It is a principal ingredient in fomentations. Its essential oil is very strong, and is sometimes added to worm-balls, but 
it does not appear to possess any peculiar qualities.

WORT. An infusion of malt, and a very useful drink in the decline of fevers, being nutritious and easy of digestion.

ZEDOARY. The root is a pleasant aromatic stimulant, not unlike turmerick, but stronger. It has been recommended in jaundice, or yellows, but can be serviceable only, by counteracting the debilitating effects of that disorder.

ZINC. This metal affords only two medicinal preparations, viz. vitriolated zinc and flowers of zinc. The former we have already noticed: the other is scarcely ever employed in veterinary practice, but may be serviceable, as an application to ulcers, to promote their healing, or cicatrization, as it is termed. 


\title{
THE VETERINARY \\ PHARMACOPEIA;
}

\author{
OR, \\ INSTRUCTIONS
}

FOR

COMPOUNDING HORSE MEDICINES,

AND

PREPARING THE VARIOUS SLBSTANCES

EMPLOYED IN VETERINARY PRACTICE,

In the most Conzenient and Eflicacious Manner;

WITH

A LARGE COLLECTION OF VALUABLE RECEIPTS, OF ESTADEISHED EFFICACY. 



\section{INTRODUCTION.}

IN describing the various substances used in medicine, it was thought adviseable to adopt an alphabetical order, in preference to those more scientific modes of arrangement which have been recommended by medical writers, as not only more simple, but better adapted to the general reader. In this part of our work, however, it will be necessary to bring the compositions or formulæ under certain classes; the receipts for Physic, for example, will come under the head Cathartics; but these classes will be placed alphabetically.

In the MATERIa Medica, all the simple vegctable medicines have been faithfully described, their particular effects upon the horse pointed out, and the different doses in which they may be giren with safety and advantage, accurately roticed; at the same time, such observations have been introduced respecting the diseases in which the medicines are applicable, as app-ared requisite; all those chemical preparations which are employed in the practice of medicine are likewise fully des. cribed. 
The Pharmacopera contains instructions for compounding or mixing those simple medicines and preparations in such a way, that they may mutualiy assist each other in their $c$ ir atıe operation; and sometimes produce effects that cannot be obtained from either of them individually. Many of those persons who undertake to compound horse medicine, are unacquainted with chemistry, and not aware, that by improper mixtures, the original qualities of the ingredients may be destroyed; thus, by mixing vitriolic acid, or oil of vitriol, with pure soda, both of which are powerful caustics, we produce that innocent compound, termed Glauber's sult. Mistakes of this kind are very common in books of farriery, which therefore can seldom be depended upon.

Another very common error in those books, as well as in the recipes of farriers in general, is, that instead of mixing medicines that are similar in their nature, and capable of co-operating in the removal of diseases, they frequently direct the most heterogeneous mixtures, uniting medicines of opposite qualities in the same ball or drencl.

In our Pharmacopæeia we have endeavoured to avoid those errors: the compounds are directed according to the principles of chemistry; and such only are recommended as bave been found effica. cious in practice. 


\section{PHARMACOPCEIA.}

Abluents. Medicines that were supposed to purify the blood, by carrying off any noxious matter that may be mixed with it.

It has been proved that noxious matter does sometimes exist in the blood*, but we do not know any medicine that has the power of roashing it away, or expelling it, as the term abluent implies. The glanders of horses seems to arise from the introduction of a peculiar poison into the mass of blood, like the venereal disease, but the effect of this poison is produced upon the solids: the blooci serving merely as a vehicle for it. It is generally known that mercury is a remedy

* The blood of a glandered horse was transfused into the jugular vein of a healthy ass, by Mr. Coleman; after a short time the ass was completely glandered. 
for the venereal disease, but it does not appear to produce its beneficial effects, by expelling the venereal poison from the system, or by rniting with it, and changing its poisonous quality ; it is more probable that it renders the solids unsusceptible of the venereal action; and that by continuing the use of it a sufficient Jength of tirne, the poison will be evicuated from the sistem, like all other extraneous or noxious matter which may happen to get into it; an opinion which I believe originated with the late Mir. John Hunter.

Is it not probable that the glanders (a disease which has hitherto proved incurable), may at some future period be successfully treated, by keeping this opinion in view ?

This idea is thrown out as a hint to those who may wish to investigate the Glanders, and endeavour to find out a remedy for so destructive a discase.

ABSORBENTS. Medicines that $n_{-}$utralize or dustroy any acid matter that may happen to be in the stomach; which in the licrse is indicated by a disposition to eat Jitter or dirt in preference to hay.

It is probable that this condition of the 
stomach depends upon debility, and imperfect secretion of the gastric juice, or an unhealthy action of the liver; it will be adviseable, therefore, to give tonics and stimulants with the absorbent medicines; and these I have always found more efficacious if preceded by a laxative.

\section{ABSORBENTS.}

No. 1. Prepared chalk six drams. Powdered gentian, two drams. Aromatic powder, one dram and half No. 2. Prepared kali, one dranı and half. Powdered quassia, two drans. Powdered ginger, two drams. Oil of carraway, tivelve drops.-Mix. No. 3. Prepared natron, or Soda, two drams. Powdered columba, three drams.

Cassia, powdered, one dram,-Mix.

These medicines may be made into balls with a little flour and syrup, or honey. One ball should be given every moruing.

ALEXIPHARMICS. It was formerly supposed that certain compositions possessed the specific power of expelling poisons of all kinds from the system; of this kind were Venice treacle, and Andromachus's treacle, which were termed Alexipharmics. 
In modern practice those medicines are never used, nor is any credit given to the opinion, so that the term is become obsolete.

ALTERATIVES. Medicines that gradually change the system from a diseased to a healthy state; the medicines commonly used as alteratives, are given in very small doses, so that their effect is scarcely perceptible ; nor do they prevent a horse from continuing his usual work, or render it necessary to make any alteration in his diet. In the $M a-$ teria Medica, we endeavoured to shew the propriety of dividing alteratives into three classes, viz. laxative, diuretic, and diaphorretic, which plan we shall now follow.

\section{LAXATIVE ALTERATIVES.}

No. 1. Barbadoes aloes, ten drams.

Castile soap, one ounce.

Aniseed powdered, one ounce and a half.

Oil of cloves, 20 drops.

Syrup enough to form the mass for four balls, one to be given every morning until the bowels are moderately opened. No. 2. Barbadoes aloes one ounce. Calomel, one dram and a half. 
Golden sulphur of antimony, half an ounce.

Powdered carraway seeds, one ounce.

Syrup enough to form the mass, to be divided into four balls, and given like the preceding No. 1.

No. 3. Flower of sulphur, six ounces.

Tartarized antimony, six drams.

Mix for six doses.

This may be given in the form of powder, daily ; few horses will refuse it in their corn, which should be previously moistened. No. 4. Liver of antimony, three ounces.

Cream of tartar, four ounces.

Mix for six doses, one to be given daily, or until the bowels are opened.

DIURETIC ALTERATIVES.

No. 1. Yellow rosin, powdered, six drams.

Nitre, half an ounce.

Mix for one dose to be given daily.

No. 2. Flower of sulphur and liver of antimony, of each half an ounce.

Nitre, three drams.

Mix for one dose, to be given daily.

No. 3. Prepared natron, or soda (reduced to powder by exposure to the air,

one ounce.

Castile soap, six drams. 
Powdered resin, two ounces.

Liquorice powder, half an ounce.

Barbadoes tar, enough to form a mass for six balls, one to be given daily.

DIAPHORETIC AI,TERATIVES.

No. 1. Antimony, finely levigated,oneounce.

To be given daily in the horse's corn. No. 2. Unwashed calx of antimony, three drams.

Powdered anise seed, one ounce and ahalf.

Mix for two doses, one to be given daily. No. 3. Tartarized antimony, one dram. Strong muriate of quicksilver, twelve grains.

Arrow root, prepared, half an ounce. Grains of paradise, two drams. Oil of carraway, ten drops.

Syrup enough to form the ball for one dose.

Remaik-This is an excellent remedy in obstinate cutaneous complaints, as surfeit, farcy, \&c. The quantity of muriate of quicksilver should be gra ually incrensed; (See Sublimate, Mat. Med.) but if it occasion sickness, griping, or purging, or if it makes the moutb sore, it must be discon- 
tinued a short time, and afterwards given in diminished doses. This remark applies to all the preparations of mercury, when given as alteratives.

ANALEPTICS. Medicines that recruit the strength. (See Restoratives, Cordials, and Tonics.)

The celebrated James's Analeptic Pills, appear to be composed principally of aloes and James's powder. (See Febrifuges.)

ANODYNES. Medicines that relieve pain; of which opium is the most powerful. When pain is occasioned by infammation it is seldom proper to employ opium, or any medicine of that kind, but when it depends upon spasm, or irritation, no medicines are so beneficial. In inflammation of the bowels, for example, opium would certainly do much injury, but in the flatulent or spasmodic cholic it selciom fuils of giving relief. (See Arodynes, Mutcria Medica.)

$$
\text { ANODYNES. }
$$

No. 1. Opium, ose dram. Castile soap, two drams.

Powdered aniseed, half an ounce.

To be made into a ball with syrup, for one dose. 
No. 2. Opium and balsam of tolu, of each one dram.

Camphor, one dram and a half.

Castile soap, twe drams.

To be made into a ball for one dose.

No. 3. Opium, two scruples,

Russia castor, two drams.

To be mixed with peppermint water, eight ounces.

To this add expeditiously, of ether, six drams.

This drench must be given with great expedition, as the ether evaporates in the common temperature of the atmosphere. The effects of henbane, hemlock, and other narcotics are very uncertain, and cannot be depended upon.

ANTISEPTICS. This term is applied to medicines that correct or prevent putridity.

The only occasion, nearly, on which they are required in veterinary practice is, when wounds or bruises shew a tendency to gangrene, ormortification, discharging an offensive, ill-looking matter. (See Antiseptics, Materia Medica.)

Antiseptics are employed also externally. (See Poulitice and Fomentation.) 
ANTISEPTIC MIXTURE, for gangrene or mortification of the external parts. No. 1. Take of Peruvian bark, one ounce. Powdered ginger, two drams. Opium, one dram.-Mix for one dose.

No. 2. Powdered snake root, one ounce. Salt of hartshorn, one dram. Cassia, powdered, one dram and a half.-Mix for one dose.

No. 3. Opium and salt of hartshorn, of each one dram.

Camphor, one drain and a half. Aromatic powder, two drams.

Mix for one dose.

No. 4. Colombo roct powdered, one ounce. Capsicum, one dram and a half. Oil of carraway, fifteen drops.

Remarl-These receipts may be given either in form of balls or drenches, but I think the latter preferable, as we can employ a vehicle that will contribute considerably to the effect of the medicine. The best liquid for this purpose is port wine; porter, or good strong beer, will, however generally answer the purpose very well. The arench should be given once or twice in 
twenty-four hours, according to the effect produced, and the nature of the case. $\Lambda$ strong decoction of oak bark is not a bad rehicle for those medicines. We have before observed; that opium is liable to produce costiveness. When this effect is obserred from it, a glyster of water-gruel will be useful. The dose of bark and snake-root may be increased, when the quantity prescribed does not produce the desired effect.

A small addition nay be also made to the doses of salt of hartshorn, and camphor, should it be thought necessary. We have not recommended any receipt for internal gangrene, or mortification, because it is always fatal in the horse, and they are not subject to those disorders termed putrid, or typhus, ferers so dangerous in the human subject. But in cases of external mortification, the above receipts will be found extremely. serviceable; they should be assisted, however, by a proper diet, consisting of such food as is mutritious and casy of digestion; such as bruised oats and malt, with a moderate quantity of carrot. When the horse is off his food, he should be drenched with good water-gruel, or arrow root, and sweet wort. 
Great attention is required in the groom, as well as frequent and assiduous application of proper fomentations, \&c.

ANTISPASMODICS. Medicines that cure, or relieve spasmodic diseases. (See Materia Medica.)

ANTISPASMODIC MIXTURE, for flatulent cholic.

No. 1. Oil of turpentine, two ounces.

Cold water-gruel, one pint.

Mix for one dose.

Remark-To an inexperienced person, this might appear a very formidable remedy; but it is not only very safe, but seldom fails of giving relief : many practitioners give it in much larger doses; indeed, I have often known four ounces given at a dose, with the best effect. No. 2. Camphor, one dram and a half.

Ether, six drams.

Essence of peppermint, from one to two drams.

Water, one pint.-Mix for one dose,

Essence of peppermint is made by dissolving one part of oil of peppermint in five of rectified spirit.

The bottle must be well shaken, in order 
to mix the ether with the other ingredients, and the camphor should be first dissolved in the essence of peppermint.

No. 3. Tincture of opium one ounce.

Oil of juniper, two drams,

Sweet spirit of nitre, one ounce.

Water a pint.-Mix for one dose.

No. 4. Opium, one dram.

Camphor, one dram and a half.

Powdered ginger, two drams.

Castile soap, three drams.

To be made into a ball with syrup, for one dose.

Remark - The flatulent, or spasmodic cholic, must be carefully distinguished from the inflammatory, and fiom that which depends upon costiveness. It is alreays necessary to empty the bowels by means of glysters; and, should the horse have appeared clull and heavy, previous to the attack, it will be adviseable to bleed. If costiveness attends it, give a laxative drench after the paroxysm, which will prevent its return.

Those who travel with crib-biting horses, or one that is often attacked with this complaint, should always have a remedy at hand, for which purpose No. 4. is recommended. 
It may be easily dissolved in stroug beer, or peppermint water, and given as a drench. To distinguish the inflammatory cholic the Compendium may be consulted. antispasmodic Mixtures, for locked jaw. No. 1. Opium one dram and a half.

Camphor, two drams.

Ginger, three drams.

To be made into a ball with syrup, for one dose, or mixed with some stimulating fluid (such as strong brandy and water, about eight ounces; or eight ounces of spiritlious peppermint water), and given as a drench. No. 2. Ether, one ounce.

Compound tincture of cardamoms, four ounces.

Peppermint water six ounces.

Mix for one dose.

It is necessary to observe, that the locked jaw generally proves fatal to horses; but it is worth while, when the jaws are not so firmly closed as to prevent the exhibition of medicine, to try the above. I have known one case in which camphor and opium succeeded; it was necessary, however, to give it in considerable doses, beginning with that which we have prescribed, and gradual- 
ly increasing it. Some practitioners recommend blisters, and others fomentations, to the jaws; stimulating glysters and the cold bath have also been advised. Strong blisters to the spine, from the withers to the tail, have been recommended as the best remedy.

ANTISPASMODIC MIXTURES, for old or chronic cough.

No. 1. Assafœtida, half an ounce.

Powdered squill, one dram.

Castile soap and Venice turpentine, of each, two drams. Mix for one dose.

No. 2. Gum ammoniacum, half an ounce. Balsam of tolu, two drams.

Liquorice powder, and powdered squills, of each one dram.

Oil of anise seed, twenty drops.

Balsam of sulphur, enough to form the ball, for one dose.

No. 3. Powdered squill, and camphor, of each, one dram.

Powdered opium, half a dram.

Castile soap, two drams. Strained storax, one dram and a half. 
To be made into a ball with syrup, for one dose.

Remark-I have generally found the above receipts more efficacious, when preceded by a laxative ball, or a course of the laxative alteratives.

They are to be given every morning until the desired effect is produced, unless, in the mean time, they should take off the appetite, or occasion profuse staling, in which case they should be discoritinued for a few days. When any appearance of fulness, or plethora, accompanies those coughs, bleeding is advisable; and whenever costiveness occurs, a laxative ball should be given.

Coughs which arise from irritation about the throat, are distinguished by their almost constantly harrassing the animal; and these are often relieved by emollient drinks, and the following:

No. 4. Opium, one dram.

Castile soap, two drams.

Camphor, one dram and a half.

Oil of anıseed, twenty drops.

To be made into a ball, with syrup, for one dose.

In speaking of the modus operandi of exr. 3 
pectorants, we observed, that the most effec. tual medicines of that class, possessed a diuretic quality, and that probably, by carrying off some of the watery parts of the blocd by the kidneys, they produced their peculiar effect upon the lungs, diminishing the secre. tion of thin mucus in the branches of that organ, and removing the cough, which an abundant secretion had occasioned. Most of the medicines we have here recommended for chronic cough, possess a diuretic quality, and it is probable, that their good defects depend more upon this, than upon their anizspasmodic power.

Some of the medicines, however, are certainly antispasmodics, and as the greater part are commonly said to act in that way, wc have brought them under that head. (Siee Expectorants.)

ANTISPASMOdic MATUREs, for suppression of urine, or pain and difficulty in void-

$$
\text { ing it. }
$$

No. 1. Purified nitre, one ounce.

Camphor, two drams.

liemark-This nay be made into a ball with mucilage of gum arabic, and a little fonr, or mixed with linsced infusion, ow any 
smucilagrinous vehicle, and given as a drench. This medicine has proved so unifornly successful, that I shall not add any other formulæ, but must observe that an emollient glyster is often a necessary assistant, and when the horse appears to be of a full habit, or plethoric, bleeding is also advisable. If the complaint returns in a short time, give a laxative drench after repeating the above medicine*.

It is the opinion of many practitioners that the staggers sometimes depend upon a diseased condition of the stomach, and that certain antispasmodics are the best remedies. I am satisfied, however, that copious and timely bleeding is almost always necessary in this conplaint, but do not dispute the

- The author is aware that pain and difficulty in voiding urine, frequently in the human body, depend on inflammation of the bladder, in which case Nitre would be an improper medicine. This is sometimes the case in the Horse, but the symp. toms most commonly arise from a cause which the above medicine speedily removes; and which may be distinguished from an inflammatory affection, by its not being accompanied by quick pulse, loss of appetite and other symptoms of fever, and inflam. mation of tbe bladder. (See the Author's first Vol.) K 4 
occasional utility of those medicines, particularly the following: Since this was written the author has met with many cases of staggers, which were caused by obstruction in the stomach or bowels; in these cases strong purgatives with stinulants were the only effectual remedies. See Vol. I. eighth edition.

No. 1. Volatile tincture of valerian, one ounce.

Powdered valerian, one ounce and a half.

Peppermint water; eight ounces.

Mix for one dose.

No. 2. Fœtid spirit of ammonia, one ounce Camphor, one dram.

Ether, half an ounce.

Mint water, eight ounces.

Mix for one dose.

No. 3. Salt of hartshorn, one dram and a half.

Assafœtida, six drams.

Oil of peppermint, ten drops.

To be made into a ball, for one dose, by meani of a little syrup and flour.

Rernark-I have seen a good effect from the following cathartic drench. 
CATHARTIC DRENCH,

Barbadoes aloes, six drams to one ounce.

Calomel, one dram to three drains. Myrrh, in powder, two drams.

Ginger, ditto, one dram and a half.

Syrup enough to form the ball, for one dose.

Remurk-In staggers the bowels are generally rather torpid, and, in some cases, are not affected by the stru nyst purgatives. The above dose, therefore, will, in general, operate only as a mild laxative: for a large draft horse, one ounce or ten drams of aloes will not be too much.

ASTRINGENTS. Medicines that suppress unnatural or increased evacuations, such as diarrhoca, diabetes, and profuse sweating. It is comaonly supposed that astringents act mechanicaily, by constringing or condensing the solids. This opinion, hovever, does not appear to be well founded, since opium, which is, in many cases, the most powerful remedy in morbid evacinations, does not possess those principles which are said to constitute astringency, which are the gallic acid, and tannin. 
Medical writers generally clas s the preparations of iron, copper, zinc, and lead, with astringents; these, however, have not been found very useful as internal remedies in the horse ; and whenever they prove serviceable it is in cases of debility, in which tonics are required.

ASTRINGEN's, for diarrhœa.

No. 1. Opium, one dram.

Ginger, one dram and a half.

Prepared chalk, six drams.

Mix into a ball with treacle, syrup, or sıoney, for one dose.

No. 2. Gum kinn, two drams.

Alum, half an ounce.

Aromatic powder, one dram and a half.

Castile soap, two drams.

Honey enough to form the ball, for one dose.-Mix.

No. 3. Powdered rhubarb, one ounce.

Prepared natron, two drams.

Cassia, powdered, one dram and a half.

Oil of mint, twenty drops.

To be mixed as above for one dose. Remark-I have often seen mischief done 
by giving astringents in diarrhea too hastily; and think it advisable, in general, to give in the first place, a laxative. There are external applications, termed astringents, which are, those which dry up sores, or diminish their discharge.

ASTRINGENT BALL, for diabetcs.

Opium, one dram.

Powdered ginger, two drams.

Powdered oak bark, one ounce.

To be given in a pint of oak bark decoc.. tion.

EXTERNAL ASTRINGENTS.

No. 1. Powdered alum, four ounces.

Armenian bole, one ounce-Mix.

No. 2. White vitriol, four ounces.

Flowers of zinc, one ounce.-Mix..

No. 3. A strong goulard mixture.

No. 4. $\Lambda$ solution of blue vitriol.

No. 5. Muriate of iron, one ounce.

Water, eight ounces.-Mix. .

No. 6. Flowers of Zinc (alone.)

ASPRINGEN'T OINTMENTS.

No. 1. Venice turpentine, four ounces..

Hog's lard, six ounces. .

To be melted over a slow fire; and when rather cool, but while it is liquid, add sugar : 
of lead, finely powdered, two ounces. Stir the mixture until it is cold.

No. 2. Hog's lard, four ounces.

Oil of rosemary, two drams.

Finely powdered white lead, an ounce and a half.-Mix.

Remark-The astringent powders and ointments, are designed chiefly as remedies for the grease, after the inflammation of the part has been in great measure removed by proper poultices : but the ointment is applicable only to those ulcerations or cracks, which are so often an effect of that disease.

ATTENUANTS. Medicines that were supposed to attenuate or thin the blood, many diseases being thought at that time to depend upon a preternatural thickness, or viscidity of that fluid. This doctrine, how. ever, is now known to be erroneous, and the term of course not used. The medicines thus named were, soap, nitre, and other neutral salts, and water.

BALLS. We have made some observations on this subject in the Materia Medica : but it it necessary to add in this place, that whenever a ball is found to exceed the proper size, which is that of a middle sized egg, 
it is advisable to divide it, as much injury has been done by those large balls, which are made by farriers, particularly when they have been kept so long as to become dry. In making balls, the dry ingredients should be finely powdered, and well mixed; the liquid for forming them into balls, must be adapted to the nature of the other ingredients. If they are of a resinous kind, such as gum guaiacum, \&c. balsam of peru, balsam of capivy, or Venice turpentine, are the proper substances to form the ball; but if they consist of roots, bark, or wood, \&c. syrup, treacle, or honey, may be used for the purpose. When the ingredients are difficult of cohesion, which is the case with nitre, golden sulphur of antimony, and many others: the best thing for uniting them into a ball is mucilage of gum arabic. This will answer the purpose more effectually, if a little starch or flour be first mixed with the powders. When a ball contains any very stimulating, or acrid ingredient, such as essential oil, Cayenne pepper, \&c. and particularly if there be arsenic, or sublimate in it, the stomach should not be empty 
when it is given; and some water or watergruel should be given immediately after.

It is generally necessary to give balls wrapt in paper; but for this purpose the thinnest tissue should be preferred.

BLISTERS. Applications which inflame the skin, and cause watery bladders to form upon it.

They are used on various occasions, and form a very important class of remedies.

MILD BLISTER OINTMENT.

No. 1. Hog's lard, four ounces.

Venice turpentine, one ounce.

Powdered cantharides, six drams.Mix.

No. 2. Oil of bay, three ounces.

Oil of origanum, two drams.

Powdered cantharides, half an ounce.

Mix.

STRONGER BLISTER, OINTMENT.

No. 1. Oil of turpentine, one ounce.

Vitriolic acid by measure, two drams.

Mix carefully, in a chimney or open place, and add of hog's lard four ounces.

Powdered cantharides, one ounce. Mix.

No. 2. Mercurial ointment, and oil of bay? 
of each two ounces.

Barbadoes tar, one ounce.

Oil of rosemary, two drams.

Cantharides, powdered, one ounce.Mix.

No. 3. Common tar, four ounces. Vitriolic acid, three drams.

Mix carefully, previously melting the tar. Oil of turpentine, half an ounce.

Hog's lard, two ounces.

Cantharides, powdered, one ouncc and a half.-Mix.

STRONGEST BLISTER.

No. 1. Strong mercurial ointment, four ounces.

Oil of origanum, half an ounce.

Finely powdered euphorbium, three drams.

Powdered cantharides, half an ounce Mix.

No.2, Strong mercurial ointment, two ounces.

Oil of origanum, two drams.

Sublimate finely powdered, two drams.

Cantharides porwdered, six drams. Mix. 
Remark-The strong blisters, particularly the last, is a good remedy for splents and bone sparins, but they must be used with caution. The last is apt to destroy the hair, an inconvenience that must often be submitted to in curing a bone spavin or splent. Blister's are the most effectual applications for removing those swellings and lamenesses, which are the consequences of strains, bruises, and hard work; but they should nerer be applied while the inflammation is consilerable. When blisters are employed for the removal of bog or blood spavins, curbs, or windgalls, they generally require to be repeated two or three times. Blisters are often employed to remove internal inflammation, particularly when the lungs are attacked, for this purpose I think the following mustard blister hy far the best.

MUSTARD BLISTER.

Best flour of mustard, eight ounces.

Water enough to make it into a paste.

To this, add oil of turpentine, two ounces, water of pure ammonia, one ounce. To be well mixed, and rubbed into the sides with the hand; if the bowels are affected, it should be rubbed all over the belly; and if 
the kidneys, upon the loins. The friction should be continued for some time, and the parts afterwards covered. After a short time, swelling and inflammation will take place, and sometimes in a considerable degree; but it will greatly diminish the internal inflammation, and often preserve the animal's life. (See Bowels, Materia Medica.)

BACK OINTMENT. (See Ointment, Liniments, and Lotions for Sore Backs.).

BITES. (See Ointments for Bites and Stings.)

BOTTS. We have already observed that there is no medicine with which we are acquainted, that is capable of destroying and discharging botts from the body, though they often pass off spontaneously about the spring of the year, and generally one at a time. But a saline substance has been lately brought from the East Indies, under the name of sal indus, which is said to possess this property: I believe, however, that other worms have been mistaken for, botts; for if given in doses sufficient to purge the horse, it sometimes discharges common worms. (See Mat. Med. Sal Indus, and the Compendium.) 
The most eligible mode of employing sal indus, as a remedy for worms, is the following : let the horse fast for four or five hours very early in the morning, then give a quart of sweet wort, with a little honey; and about half an hour after, the following drench:

Sal indus, four ounces.

Barbadoes aloes, two or three drams. Water, about a pint.

First dissolve the aloes in hot water, and then add the salt.

This will generally act as a brisk purgative, therefore the horse will require the same atterition and management as if he were under physic.

CARMINATIVES. Remedies for the flatulent cholic, commonly termed fret or gripes. (See Antispasmodics, page 191, where several receipts are given for the purpose.) We shall add, in this place, a few domestic remedies, which may be employed, when medicines cannot be procured in time. 1st. $\Lambda$ pint of strong peppermint water, with about four ounces of gin, and any kind of spice. 2 d. A pint of port wine, with spice or ginger. 3d. Half a pint of gin diluted with four ounces of water, and a 
intle gringer. I have seen the complaint removed by warm beer and ginger, or a cordial ball, mixed with warm beer.

It may not be amiss to repeat the caution we have given, respecting the necessity of distinguishing the flutulent from the inflammatory cholic; as in the latter, the above remedies would be highly pernicious : for this purpose, the reader may consult the Compendium of the Veterinary Art; in which both diseases are fully described.

CATHARTICS. Merlicines that excite purging. The preparations employed for this purpose are commonly termed physic.

MILD PHYSIC.

No. 1. Barbadoes aloes, half an ounce. Prepared natron, one dram and a half. Powdered cassia, one dram. Oil of aniseed, twenty five drops.

To be made into a ball with honey for one dose.

No.2. Barbadoes alocs, half an ounce.

Calomel, half a dram.

Ginger, one dram.

Castile soap, three drams.

Oil of aniseed, twenty drops. 
Syrup enough to form the ball for one dose.

\section{STRUNG PHYSIC.}

No. 1. Barbadoes aloes, six drams.

Almond soap, three drams.

Oil of carraway, twenty drops.

Aromatic confection enough to form the ball for one dose.

No. 2. Barbadoes aloes, six drams.

Calomel, one dram.

Almond soap, three drams.

Aromatic confection enough to form the ball for one dose.

Remark-The strength of the above balls may be varied by increasing or diminishing the quantity of aloes. A cathartic may be given in the form of a drench when a speedy effect is required; for this purpose dissolve one of the balls in warm watergruel.

There is a wonderful difference in horses with respect to the quantity of pur ative medicine necessary to produce a proper effect; and as rioient purgation, or too strong physic, often does much injury, and sometimes proves destructive, it is always advisable to give a moderate dose to a horse whose 
strength and constitution we are not acquainted with. I have often met with horses that were effectually purged by half an ounce of aloes, while to others I have given an ounce, without any effect. On the other hand, again, I have frequently seen the same dose do much injury; in one case, a horse was nearly destroyed by taking half an ounce of aloes, and half a dram of calomel. I lately met with an instance of a horse being evidently killed by taking one ounce. Some, nay several, have been destroyed by the doses recommended in books of farriery, in which aloes have been prescribed in the dose of one ounce and a half. At the same time, it must be acknowledged, that these accidents are not very frequent, and that hundreds of horses take those strong doses apparently with impunity. Still there is one bad effect which must result from violent purgation, of which few people are aware. The debility thus produced lays a foundation for many diseases; and I have known even blindness produced by it: the whole system is rendered more irritable, and consequently more susceptible of disease. 


\section{CARDIACS. (See Cordials.)}

CAUSTICS. Substances which burn of destroy any part of the body to which they are applied. They are of great use in veterinary practice, for destroying unnatural excrescences, cleansing foul ulcers and sinuses, so as to bring them to a healthy state, and curable by more simple applications. Caustics may be divided into liquid and solid, strong and mild. The mild caustics are called also escharotics, and are more useful than the stronger caustics, which are too violent in their action in many cases, and often require to be diluted with water, spirit, or unctuous substances, according to the nature of the case.

solid caustics, strong.

No. 1. The red hot iron.

(See Firing, Materia Medica.)

No. 2. Pure kali with lime.

No. 3. Nitrated silver, or lunar caustic.

No. 4. Nitrated copper.

mild caustics, solid.

No. 1. Acetated copper, or distilled verdi. gris.

No.2. Vitriolated copper, or blue vitriol. 
No. 3. Red nitrated quicksilver, or red precipitate.

No. 4. Burnt alum.

No. 5. Common verdigris.

Remark-The strong caustics are generally sold in a convenient form for application ; but the mild require to be finely powdered and sprinkled on the ulcer: they are sometimes mixed with digestive ointments to increase their power.

\section{STRONG CAUS'TICS, LIQUID.}

No. 1. The vitriolic and nitrous acids, which are very powerful, and must be used cautiously; they may be diluted with different proportions of water, so as to be applicable to many purposes.

No. 2. Nitrous acid, one onnce.

Quicksilver, half an ounce.

Place them in a large gally-pot, or open phial, and take care to avoid the noxious fumes which arise. When the quicksilver is perfectly dissolved, and the mixture cold, it may be put into a smaller phial and corked.

Remark-This is a strong and efficacious caustic ; it is a certain remedly for the foot- 
rot in sheep, and often effectual in canker of the horse's foot, provided these complaints are properly managed in other respects. It is sometimes mixed with melted hog's lard to form a strong detergent ointment.

No. 3. Nitrous acid, one ounce.

Copper filings, half an ounce.-Mix.

The copper is to be dissolved like the former, the fumes being equally hurtful. This caustic is very little, if at all, inferior to the former, and applicable to the same purposes.

No. 4. Muriate of antimony, or butter of antimony.

No. 5. Muriate of quicksilver, or sublimate, one dram.

Muriated acid, two drams.

Remark-This is a very powerful caustic, and generally requires dilution.

MILD CAUSTICS, LIQUid.

No. 1. Solution of blue vitriol.

No. 2. Any of the stronger caustics, except butter of antimony, diluted with an equal quantity, or more, of water.

No. 3. Muriatic acid.

No. 4. Muriate of iron. 
CHARGES. Adhesive plasters which are softened or liquified in a ladle by a gentle heat, and then applied to the legs, from the knee and hock joints, to the foot, as are. medy for windgalls and old lamenesses, arising from strains or hard work.

As soon as the plaster is applied, the part is covered with short tow, and the horse sent to grass.

\section{A CHARGe.}

Burgundy pitch, four ounces.

Barivadoes tar, six ounces.

Bees' wax, two ounces.

Red lead, four ounces.

The three first are to be melted together, and then the latter is to be added. The mix ture is to be constantly stirred until sufficiently cold to be applied; and if it prore too thick when cold, it may be sofiened with a little oil or lard.

Farricrs generally mix Dragon's Blood (as it is commonly called) from an idea that it has a strengthening quality, others recum. mend bole armenic. It appears, however, that charges act as a bandage only; con. pressing equally, and for a considerable tine, the joints, tendons, \&c. 
CONDITION. This term implies, that a horse enjoys the highest degree of health and vigour of which he is capable. $\Lambda$ horse may be fat and sleek, but unfit for those exertions which are so often required from him. This subject has been fully treated of in the "Compendium;" and we have only to observe in this place, that many horses are destroyed, and numerous diseases produced, by forcing them to exertions, to which they are unequal; wherefore, it is of great importance, that their condition should be brought to perfection, before they are empioyed in any severe exercise, such as racing, hunting, quick travelling, or heavy draught. In getting horses into condition, great advantage will be derived from the occasional use of laxatives and diuretics, in the form of alteratives: but regular exercise, proportioned, and adapted in point of duration, and pace, to their feed, the kind of employment for which they are required, and the state of their health, is of the last importance.

CORDIAĹs. Medicines which cause a temporaiy augmentation of strength and spirits; and if employed properly, are, on 
some occasions, capable of producing permanently good effects. 'They are more beneficial in general to old horses than to young; more particularly to those that have been worked hard, and accustomed to such medicines, as well as to high feeding and warm stables. Cordials become remarkably serviceable to draught horses, when they work hard, and have but indifferent forage. They gently stimulate the stomach, and increase its digestive power; whereby they are capable, I apprehend, of preventing, on many occasions, that fatal disease, the stuggers.

Cordials have an excellent effect, when the animal has been fatigued with a long run, or a severe journey, refusing his food, and seemingly exhausted. A good cordial preparation at such times restores the appetite, promotes digestion, and renovates the strength and spirits. I do not mean, however, that the cordial balls commonly made up, have this useful property. On the contrary, they often do harm, but most commonly they are quite inert; for example, Bracken's cordial, which is the receipt generally used, has a considerable proportion of 
sulphur, and other useless drugs, in its composition.

CORDIAL BAILS.

No. 1. Powdered carraway seeds, six drams. Ginger, two diams. Oil of cloves, twenty drops.

Honey or treacle enough to form the ball for one dose.

No. 2. Powdered aniseed, six drams.

- cardamoms, two drams. cassia, one dram.

Oil of carraway, tiventy drops.

To be made into a ball with honey, for one dose.

No. 3. Powdered carraway seeds, half an ounce.

Graius of paradise, three drams. Aromatic powder, one dran.

Essential oil of cummin seed, twenty drops.

To be made into a ball with honey, for one dose.

No. 4. Powdered aniseeds, half an ounce.

Ginger, three drams.

Oil of carraway, 15 drops.

To be made into a ball for one dose.

Remaik-The above receipts afford a 
sufficient variety of preparations. The strength may be easily increased or diminished, when found necessary. They are all of a very stimulating nature, and not to be employed but on the occasions we have pointed out. An indiscriminate and frequent use of cordials, does great mischief, and is the cause of many diseases; though, as we have before observed, when judiciously employed, they are extremely beneficial. We shall now give some receipts for pectoral cordicils, which differ from the foregoing, by being less stimulating, and containing ingredients that promote expectoration, and alleviate or cure old coughs, which are accompanied with some degree of debility flatulency, and indigestion: when costiveness occurs during their use, it is to be removed by a gentle laxative. (See Laxatives.)

PECTORAL CORDIAL BALLS.

No. 1. Powdered aniseed, half an ounce. squill, one dram. myrrh, one dram and a

half.

Balsam of. Peru, enough to form the ball for one dose. 
No. 2. Liquorice powder, half an ounce. Gum ammoniacum, three drams. Balsam of tolı, one dram and a half. Powdered squill, one dram.

Anisated balsam of sulphur, enough to form the ball for one dose.

No. 3. Elecampane porder, half an ounce. Ginger, one dram and a half.

Powdered squill, one dram.

Oil of aniseed, twenty drops.

Syrup of tolis, enough to form the ball for one dose. (See Antispasmodic Minares for (hronic Coughs.)

Medicines are sometimes named stomathic and tonic cordials: for these we reftit the reader to the artisle 'Tonic's and stomachics.

CORROSIVES. (See Caustics.)

DECOCTIONS. These are made by boiling medicines in water until the latter has extracted all its virtues. This operation, it is obrious, is not suited to those substances, whose medical qualities depend on a volatile, or eraporable principle.

DEMULCENTS. Medicines which shcathe parts, so as to defend them from the sction of any irritating substance. The best medicines of this kind are, a solution of gnm 
arabic, decoction of linseed or marshmallows, or any thing that is oily and mucilaginous. They are employed chiefly in ir* ritation of the bowels, kidneys, and bladder; also in coughs and irritation of the luings.

DEOBSTRUENTS. Medicines that are supposed to be capable of removing obstructions. Obstinate coughs and asthmas have been attributed to this cause; and the most ponderous medicines were recommended for their removal, at a time when many diseases and functions of animals were explained upon mechanical principles. Thus we find ciunabar of antimony, Fathiop's mineral, \&e. Mrescribed on those occasions. The theory has been found erroneous, and of course the practice built upon it must be imperfect. It is necessary, however, to observe, that certain medicines, termed Deobstruent, such as calomel, have been sometimes found useful in those diseases of the liver which are said to arise from obstruction.

DETERGENTS. A name given to applications which have the property of cleansing foul ulcers, and bringing them to a healthy state, so that they may be cured by . 
more simple remedies. The term has been applied also to internal remedies, which were supposed to heal ulceration of the lungs, kidneys, \&c. but we shall confine it to externalapplications, being unacquainted with any medicine that has the power of curing ulcerated lungs or kidneys.

DETERGENT OINTMENT.

No. 1. Mutton suet, four ounces.

Venice turpentine, six ounces.

Red precipitate, finely powdered, two ounces.-Mix.

Melt the suet and turpcutine orer a slow fire, and when nearly cold stir in the powder; continue stirring until cold.

No. 2. Hog's lard, four ounces.

Olive oil, one ounce.

Strong liquid caustic, No. 2. one ounce.

Melt the oil and lard; and while the mixture is liquid, but rather cool, add the caus. tic, and continue stirring with a reoden instrui...ent unil it is quite cold.

\section{'DETERGGNT LINIMENT.}

No. 1. Oil of turpentine, one ounce, Vitriclic acid, by measure, two drams. 
Mix cautiously, in a large gally-pot, or open phial, and in a situation where you may avoid the suffocating fumes which arise. When the mixture is complete and cool, add of linseed oil two ounces. No. 2. Red precipitate, half an ounce, finely

$$
\text { powdered. }
$$

Linseed oil, half an ounce.

Mix well in a mortar, and add, of oil of origanum two drams.

No. 3. Chrystallized rerdigris, finely powdered, one ounce,

Olive cil, one ounce.

To be well mixed in a mortar ; then add of Venice turpentine, half an ounce.

\section{DETERGENT LOTIONS.}

No. 1. Vitriolated copper, one ounce. Vitriolic acid, twelve drops. Water, four ounces.-Mix.

No. 2, Nitrous acid, one ounce.

Vitriolated copper, half an ounce.

Water, eight ounces.-Mix.

DIAPHORETICS. Medicines that increase the insensible perspiration.

In veterinary medicine it is necessary to divide diaphoretics into two kinds, which may be called, antispasmodic and stimulating.

\section{ᄂ 5}


The former kind is applicable in fevers, and receipts, or compositions of that kind, will be found under the head, febrifuges. The stimulating cliophoretics are calculated for horses that are hide-bound, and have rough, unhealthy looking coats, without any other appearance of disease.

STINULATING DIAPHORETICS.

No. 1. Emetic tartar, one dram and a half.

Camphor, half a dram.

Ginger, two drams.

Opium, one scruple.

Oil of carraways, fifteen drops.

Honey, enough to form the ball for one dose.

No. 2. Powdered carraway seeds, six drams. Antimonial powder, two drams.

Ginger one dram.

Oil of aniseed, twenty drops.

Honey, enough to form the ball for one dose.

No. 3. Unwashed calx of antimony, two drams.

Ginger, and salt of hartshorn, of each one dram.

Opium, two scruples.

Powdered aniseed, half an ounce. 


\section{Oil of carraway, fifteen drops.}

Syrup, enough to form the ball for one dose.

Remark-It is essentially necessary to assist the above remedies by regular exercise (at least two hours every day), which may be carried so far as to excite moderate sweating; but the greatest attention must be paid as soon as the horse gets into the stable, nor should the groom discontinue wisping until he is perfectly dry.

DIGESTIVES. Applications which pro- mote suppuration in wounds or ulcers.

DIGESTIVE OINTMENT.

No. 1. Hog's lard, four ounces.

Bees' wax, one ounce.

Venice turpentine, three ounces.

Red nitrated quicksilver, finely pow--

dered, two ounces.

Melt the three first over a slow fire, and while the mixture is liquid, but nearly cold, stir in the powder.

Powdered verdigris is sometimes used instead of the nitrated quicksilver, but the latter is certainly preferable. We find in some books very elaborate compositions recommonded as digestives, in .which are frank- 
1 ncense, gum elemi, balsam of tolu, conmon resin, and various other substances; but the formula, or receipt, we have given, will be found adequate to every purpose for which digestives are wanted, as it may be rendered more or less stimulating, by rarying the proportion of red nitrated quicksilver or, as it is more commonly called red precipitate. Oil of turpentine, also, will render it more stimulating.

DILUENTS. Medicines which dilute the blood. If any thing has this power, it must be water, which may be medicated according to the judgment of the practitioner.

DIURETICS. Medicines that stimulate the kidneys, and increase the evacuation of urine.

These are much used in veterinary practice, in cases of grease, swelling of the legs, and other parts, they are employed, also, as a preventive in horses that are subject to those complaints, and with great advantage. They are given either in the form of ball or powder, and are very convenient remedies, as they do not prevent a horse from working moderately.

DIURETIC BALL.

No. 1, Castile soap. 
Powdered resin, of each three drams. Sal prunella powdered, four drams. Oil of juniper one dram.

Mix for one dose.

First beat the soap and oil of juniper in a mortar, until they become a soft, uniform mass, then add the powders, having previously mix them well.

Should any addition be necessary to form the ball, use mucilage of gum arabic, ho:tey, or flour.

No. 2. Camphor, and oil of juniper, of each one dran.

Powdered nitre, half an ounce.

Castile soap, three drams.

Mix for one dose.

First mix the camphor and oil, then add the soap, and beat the mixture well, lastly the nitre, and as much flour as will give it a proper consistence.

DIURETIC POWDERS.

No. 1. Resin and nitre, of each half an ounce.

Mix for one dose.

No. 2. Nitre, six drans.

Camphor, one dram and a half.

Mix for one dose. 
DRENCHES. (See Muteria Medica.)

EMBROCATIONS. External applications are often so named. The term seems to imply, that it is to be well rubbed on the affected part, with the hand, since its effect will be considerably promoted by friction of this kind.

MUSTARD EMBROCATION:

Take of the best flour of mustard, . four ounces.

Water of ammonia, one ounce.

Oil of rosemary, or oil of turpentine, one ounce.

Water, a sufficient quantity to form a thin paste, which is to be well rubbed on the af- fected part.

EMBROCATION, for strains and bruises. No. 1. Soft soap, two ounces.

Oil of bay, one ounce.

Water of pure ammonia, one ounce and a half.

Oil of origanum, half an ounce.

Camphorated spirit of wine, two Ounces.-Mix.

No. 2. Camphor, half an ounce.

Oil of turpentine, one ounce and half.

Spirit of wine, two ounces.-Mix. 
No. 3. Soap liniment, two ounces.

Water of pure ammonia, half an ounce.-Mix.

EMBROCATION, for callous swelling; or bog-spavins, windgalls, enlarged joints, \&c.

Strong mercurial ointment, two ounces.

Camphor, half an ounce.

Oil of rosemary, two drams.

Oil of turpentine, one ounce.

BLISTERING EMBROCATION.

Strong mercurial ointment, two ounces.

Oil of bay, one ounce.

Oil of origanum, half an ounce.

Powdered cantharides, half an ounce. Mix.

EMOLLIENTS. Medicines that soothe and allay irritation; they are employed both internally and externally. Like demulcents, they defend parts from irritation, by their mucilaginous quality, but they take off irritation in another way, that is by diluting, or weakening the irritating substance. (See Materia Medica.)

When the bowels, kidneys, or bladder, are inflamed or irritated emollient liquids 
are extremely useful, these are nade by boiling nucliaginous and oily seeds, or vegetaibles in water, or, simply, by dissolving gum in water; in extemal inflammation, or irritation, warm water is the best emollient; but it is commonly supposed, that the addition of nucilaginous vegetables renders it more efficaciuus; I do not believe, however, that this opinion is well founded, nor do I think that any kind of unctuous application is proper in cases where emollients are wanted, though we frequently hear various linds of ointment extolled for their emollient virtues.

EMOLLIENT DRENCH, for coughs.

No. 1. Linseed, four ounces.

Boiling water, three pints.

Let them stand togetherseveral hours, then strain off the liquid, and add four ounces of honey, for two doses.

No. 2. Marshmallow root, bruised, four ounces.

Water, one quart.

Let them simmer over the fire a short time, then strain off the liquor and add four ounces of honey, two ounces of linseed oil, and one ourice of powdered gum arabic. This is sufficient for two doses. 
Many practitioners add to every dose of these drenches, four or six diams of nitre, which on some occasions, I believe is serviceable, but we have omitted it here, as nitre cannot be considered at an emollient.

EMOLTIENT FOMENTATIONS.

No, 1. Marshmallow root, eight ounces.

To be boiled in three quarts of water for an hour or two. The strained liquor makes the fomentation,

Tt is only necessary to add, that every kind of mucilagrinous vegetable is supposed to impart to water an emollient quality, and rendder it fit for an emollient fomentation. (See Fomentutions) Ointment of elder, and marsh-mallows, are used by farriers as emollients.

E.MULSIONS. Mixtures of oil and water, by means of an alkali, or a mucilage.

Eimulsions are used principally in coughs, either alone, or as a vehicle for other medicine.

SIMPLE EMULSION.

Linseed oil, two ounces.

Honey, three onnces.

Soft or distilled water, one pint.

Prepared kali, one dram. 
Dissolve the honey and kali in the water, and afterwards add the linseed oil, the mix. ture is then to be well sliaken, and it will assume a milky appearance.

PECTORAL EMUISION, for conghs. No. 1. Simple emulsion eight ounces. Camphor, one dram. Opium, powdered, half a dram. Oil of aniseed, thirty drops.

Let the camphor be powdered, and rubbed in a mortar with a little sugar, the wil of aniseed, and the opium, then add the emul. sion gradually.

ERRHINES. Medicines that excite sneezing when applied to the internal purts of the nose. For this purpose, commor. snuif, which a little powdered hellebore, may be exployed. It has been recommended in the gutta serena, or that kind of blindness, in which the eye, to a common observer, appears sound, and which is caused by a palsy of the optic nerve. Errhines are sometimes applied to the noses of glandered horses; the sneezing it occasions, causes all the matter that is formed to be tbrown off; the nose bejng then carefully wiped with a cloth, the horse is sold as sound, there bcing 
no appearance of a discharge for two or three hours afterwards. This abominable fraud is only practised at country fairs, by the lowest order of horse dealers, who have no reputation to lose.

ESCHAROTICS. This term is applied io the mild caustics, such as red precipitate and verdigris. (See Caustics.)

EXPECTORANTS. Medicines that excite or promote a discharge from the lungs, and thereby remove or alleviate coughs and thickness of wind.

There is another way in which it is probable expectorants relieve cough, \&c. These complants may ametimes be occ asioned by a redundant secretion in the branches of the windpipe; in such cases, medicines that diminish the quantity of fluid in the whole system, by increasing the secretion of urine, or perspiration, will of course relieve the complaint, by lessening the quantity of fluid in the branches of the windpipe: hence we may explain the operation of the balsams, turpentines, and rarious other me. dicines that are employed as expectorants with good effect, and which manifestly possess a diuretic quuality. 
EXPECTORANT BALLLS.

No. 1. Gum ammoniacum, half an ounce;

Powdered squill, one diram.

Castile soap, two drams.

Honey enough to form the ball for one dose.

No. 2. Assafotida, three drams.

Galbanum, one dam.

Salt of hartshern, half a dian.

Ginger, one dram and a half.

Honey, enough to form the ball for one dose.

No. 3. Aromatic powder, two drams.

Camphor one dram and a half.

Powdered squill, and balsam of tolu, of each one dram.

Honcy enough to form the ball for one dose.

EXTRACTS are marle by infusing any substance in a liquid that is capable of dis. solving and extracting its essential principle, so that it may be pricured, free from the other useless parts. When the essential principle is of a resinous nature, we imploy rectified spirit to extrac it; if it be a compound of gum and resin, proof spirit is better adapted. 
By evaporation, we procure the extract in a solid state.

EYE-WATER. This term is applied to liquids that remove inflammation from the eye, or that are employed for that purpose. No 1. Extract of saturn, one tea-spoon-full. Camphorated spirit, two teit-spoonsfull.

Elder hower water, half a pint.-Mix. No. 2. Vitriolated ainc, one dram.

. Water, one pint,-Mix.

No. 3. Vitrislated zinc, and acetated lead, of each one cirain. Water, twelve ounces.

No. 4. Opium, one dram.

Water, four onnces....Mix.

FEERIFUGES. Medicines that tend to relieve or remove ferer.

$$
\text { pEVER BALLS. }
$$

No. 1. Camphor one dram and half.

Nitre, four dram:

Calomel and opium, of each twenty graius.

Syrup enough to form the ball for one dose.

No. 2. Univashed calx of antimony, two drams. 
Camplior, one dram.

Opium, half a dram.

Compound powder of tragacanth, two drams.

Honey enough to form the ball for one dose.

No. 3. Emetic tartar, one dram and a half, or two drams.

Compound powder of tragacanth, two drams.

Syrup enough to form the ball for one dose.

No. 4. Camphor, two drams.

Nitre, one ounce.-Mix for one dose.

The above balls are to be given every day, or oftener if the symptoms require it. No. 4. generally acts as a diuretic, and therefore must not be persevered in toolong, as it may occasion so pròfuse an evacuation of urine as to injure the animal. It is proper to observe here, that no medicine will avail much in fever, if bleeding is neglected; and if the fever is violent, external inflammation. should be raised by means of row els in the chest and belly; and the mustard blister applied to the sides.

FOMENTATIONS. This term is ap- 
plied to various kinds of decostions, or medicated liquids, which are employed externally to bathe or foment any inflamed or painful part, oi to improve the condition of wounds when they are very imritable, and discharge unhealthy, offensive matter, approaching to a state of gangrene or mortifi. cation. Fomentations are therefore divided in the following kinds, viz. emollient, an. tisepici, and anodyne.

EMIOLIENT FOMENTATION.

No. 1. (See Emollients.)

Boil marshmallows in water for some time, then strain off the liquor, and bathe the affected parts with it while warm.

. ANTISEPTIC FOMENTATION.

No. 1. Emollient fomentation, one gailon. Muriate of ammonia, four ounces.

Camphorated spirit, six ounces.

No. 2. Stale beer grounds and yeast, mixed with hot water and applied immediately.

ANODYNE FOMENTATION. -

No. 1. White poppy heads broken, two dozen.

Hemlock, two handsful. 
Boil for two hours gently in six quarts of water.

No. 2. Wormwood dried, and chamomile flowers, of each four ounces.

Rue, three ounces.

Bay leares two ounces.

Boil them for one hour in a gallon of wa.. ter.

Remark-The efficacy of a fomentation depends on its being properly applied, the refore we have to observe, that the liquid should be as hor as the hand can bear; or to be more accurote, a thermometer may be used, and then the proper temperature will be about 120. Large flannel cloths are to be dipped into the fomentation, then lightly wrung out, and spread over the arrected part; by the time this gets a littie cool, another cloth should be got ready, and applied in the same manner: this operation ought to be continued for half an hour at least, a:d repeated three or four times a day. The emollient fomentation is adapted to inflamed swellings, from whatever cause they may arise; and when it camnot be procured, warm water alone will be found an useful substitute. 'The anodyne fomenta- 
tion, No. 1 , is of great serrice in wotnds or swellings, which are accompanied with great pain and intability. The antisepic fomentation tonits to comect putridity and gan. grene, in larger wr):lnds of the lacerated hind, where the mater is thin, ill-coloured, and offensive : but in such cases, the assistance of interual remedies cannot be dispensed with. (Sec Compendium.)

FUMIGATIONS. These consist of substances which emit fumes or vapours by the application of heat, or other means. They are generally employed to destroy contagion; and though the fumigations recom. mended in books of furriery, as well as those in common use, arc inadequate to that purpose, yet there are certainly some, which may be productive of great advantage. Fumigations are cimployed to prevent the spreading of epidenic distempers, or to destroy the contagion of glunders: for the former purpose I cannot from experience, recommend any thing, though it is not in.. probable that the nitious fumirat in of $\mathrm{D}_{\mathrm{i}}$. C. Smith, or the following, may be found useful; butwlien a stable is contaminated with glanders, I can reconmend them with 
confidence, provided the other means I ar about to propose are carefully employed. These are, in the first place, to remove every jarticle of litter, hay, dust, \&c. from the stable; as well as the pail, collar, and every thing which belonged, or was used for the infected horse. The rack, manger, and every thing on which the glandered horse could possibly have rubbed his nose, are to be well scraped, and afterwards washed with hot water and soft soap, or potash and line in water ; which has a strong cieansing quality, and if not sufficiently dilsted will injure the operator's hands.

After this wash has been employed, the manger, \&c. should be well washed with water; for should any potash remain, it might leave a dampuess in the stable, from its property of attracting moisture from the atmosphere. The floor or pavement of the stall is also to be carefully washed and swept. After this, the whole is to be whitewashed with whiting and a solution of glue. Before any sound horses are ainnitted into the stable, the following fumigation should be employed. The number of pans in 
which the materials are placed being adapted to the size of the stable.

Take of common salt, eight ounces.

Manganese, powdered, six ounces.

Let these be well mixed and placed in an earthen dish, then pour on the mixture gradually, of vitriolic acid, four ounces. As soon as the latter is added, the operator should leave the stable, shutting both the door and the windows. The fumes which arise from this mixture are highly injurious to the lungs, and must be carefully avoided; therefore this fumigation can only be per.. formed in an empty stable. During the whole day, the stable door and windows are to be kept shut; but at night they may be thrown open, that there may be no danger in entering the stable the next morning. I believe this to be the most efficacious of all the fumigations, haring found that when glanderous matter is exposed to it a short time, it is rendered ; erfectly harmless. The fumes which are generated by pouring oil of virriol, or vitriolic acid, on pordered nitre, are said to be very effectual in destroying human contagion; how far it may be serviceable in veterinary practice, remains 
to be ascertained: but as the fever's of horses do not appear to be infectious, there is no great probability of its proving useful.

FIRING. We have noticed this subject in the Materia Medica, but it remains to be observed, that unless this operation is performed with good instruments, and by a skilful hand, an indelible blemish will generally be the consequence. Many farriers pretend to do it while a horse is standing; but this should never be attempted, as it is impossible in this way to perform the operation correctly, and there is always danger of doing mischief. The horse should always be thrown down, and properiy secured. 'The edge of the firing iron is to be rather hinner than the back of a small pen-knife, and of a round form. The back part of the instruns.nt must be very sub itantial, that the heat may be retained a sufficient length of time. It is to be applied, when of a dull red heat, which in the day time is scarcely perceptible. The operator is to draw it rather quickiy orer the skin in perpendicular lines; ; but as the iron gets a littie cooler,

* At present, practitioners generally prefér drawing the instrument in an oblique direction. 
the motion of the hand is to be slower. It may be known when the instrument is applied sufficiently hot, by its leaving a whttish or scorched line upon the skin, but on no occasion should the skin be penetrated of divided by the iron. Several irons should be employed, that the operator may be constantly supplied with one sufficiently hot. When this operation is properly performed, the absorbent ressels have their action considerably increased, and are thereby enabled to remove any c.llous or boney substances which may haye been formed about the joints or tendons, in consequence of strains or hard ivork. It is said also to contract the skin so as to make it act as a bandage to the subjacent parts. The day after the operation, it is advisable to apply a mild blister to the part. Firing, though a severe and painful operation, is often very efficacious, and the only one we are acymanted with for remoring callous or boney swellings, whichoccasion lameness by impeding the action of joints or tendons; but is too frequently made use of when milder remedies may be employed with success. The pracice of firing colts, with a view is 113 
strengthen their joints and tendons, is strongly to be reprobated.

It is always necessary to allow the horse a long run at grass, or rest, in a large loose stable, after he has recovered from the operation; and as long as the inflammation which firing occasions continues, the hors should be treated as have directed, after blistering.

GALVANISM. It has been discovered within these few years, that an effect, somewhat like electricity, may be produced on the body by the application of different metals in a certain way; and that a short time after death, the muscles may be excited to action by the same means, producing the most curious phanomenon. From the name of its discoverer, Galvani, it is termed $\mathrm{Gal}$ ranism. It has lately been employed for the cure of certain diseases, and it is said with considerable success ; therefore it may be worth a trial in those disorders of the horse, for which at present we have no remedy, such as locked jaw, gutta serena, and other diseases of the eye. (See IVilkinson's Elements of Galvanism.)

GLYSTERS. Glysters are composed 
difierently, according to the effect they are intended to produce. The simpie opening glyster, which is designed merely to remove the contents of the lower parts of the belly, consists of water-gruel, and a little sweet oil; about one gallon of the former, and a pint of the latter. When water-gruel cannot be procured, warm water may be used, and linseed oil may be substituted for sweet oil ; but I have often employed warm water alone with very good effect. The heat of the water should not exceed (or very little) that of the body, which is about 96 by the thermoincter, or what is commonly termed blood heut.

This kind of glyster is extremely useful in the first stage of fevers, as it effectually removes any inclurated frees that may be lodged in the large intestines, without danger of creating debility. It is highly serviceable also in inflammation of the bowels, when accompanied with costiveness, and when the bladder is inflamed or irritable, which is indicated by pain and difficulty in staling, the horse voiding only very small quantities apparently mixed with matter, and that frequently; nothing relieves the 
animal nore speedily than the simple giys ter, if it be assiste:! by other appropriate rumedies. The next glyster we have to descritse is the anodyne, which consists of water made highly mucilaginous by means of starch ol arrow root, and about two drams of opilum dissolved in it. The quantily of licuid should not exceed three pints, or two cluarts at most. This glyster acts aIso as an - stringent in very obstinate diarrhœas. The last glyster we have to notice is the cathartic, which may be cumposed merely of one galWn of water and eight ounces of common wilt; but when the bowels are very turpid, which is often the case in staggers, one ounce and a half of aloes may be adided.

GRUEL. Water-gruel is extrenely useful on many occasions. When medicines are given in the form of drenches, it makes the best vehicle, more particularly if the medicines be of an acrimonious nature, the mucilaginious quality of the gruel teirding to prevent any umpleasant effect upon the stomach: for the same reason it is acivisuble to give gruel immeliately after the exhibition of any strong mineral preparation, sucis as sublimate, arsenic, \&c. Nothing is more 
useful as an article of diet for sick, or co:3valescent horses than water-gruel, provided it is properly made; and as this is seldom done, we shall give the best method of making it. Take of fine and swcet oatmeal, four ounces, water, two quarts. Put the water over a slow clear fire to boil, and mix the oatmeal gradually with as much cold water as will make the mixture quite liquid. Add this to the water over the fire, befure it gets very hot, and continue to stir the whole until it boils. The gruel is then made, but may be improved by letting it simmer some time longer over a slow, clear fire, for horses are very nice, and perhaps would not touch it, if in the least smoaky. Should the gruel be too thick, add warm water.

HYDRAGOGUES. Medicines that purge violently, and produce thin watery stools. Of this kind are elaterium and gamboge. It is a class of medicines of little or no use in veterinary practice.

LAX $\Lambda$ TIVES. Medicines that purge very gently, and wishout irritating the system. They are employed chiefly in febrile complaints, accompanied with costiveness, in which cases the strongest purgatives would. 
be injurious. They are useful also in slight cases of grease, swelling of the heels, and all cases of external inflammation, when the horse is too weak to bear any considerable evacuation. On those occasions aloes is the best laxative, but in fevers, castor oil, with small doses of neutral salts, is most proper, being less liable to irritate the system.

\section{LAXATIVE BALL.}

No. 1. Succotrine aloes, five drains.

Venice soap, three drams.

Oil of caraway, twenty drops.

No. 2. Barbadoes aloes, four drams.

Salt of tartar, one dram and a half.

Compound powder of tragacanth, two drams.

Syrup, enaugh to form the ball.

Remark-These balls always operate more effectually when assisted by exercise, and bran mashes, than when the horse is suffered to stand in the stable without receiving any attention.

laXATIVE DiRENCH, for fevers, \&c.

No. 1. The best castor oil, one pint.

For one dose.

No. 2. Cummon salt, three or four ounces.

Water-gruel, enough to dissolve it per- 
fectly; add to, this, of linseed oil, eight ounces, for one dose.

Remurk-Though we have in No. 2. prescribed linseed oil, there is no doubt that castor oil is preferable; but this cannot always be procured rearlily, and as many may object to the expence of it, where the disorder is but trifling, linseed oil may on such occasions be substituted. Sallad oil is still better. We have recommended common salt in preference to Glauber's and Epsom salt, because it is more certain in its effect, and may be given in much smaller doses.

LINIMENTS. A term for certain external applications, generally of an oily kind, between the consistence of an ointment and oil.

LINIMENT, for thiushes.

Barbadoes tar, one ounce.

Oil of turpentine, one ounce and a half.

Vitriolic acid, one dram.

First mix the acid and turpentine very carefully, then add the tar. This is a good. application for thrushes, and rottenness of the frog; the ragged part being first reM 6 
moved with a knife, and the part well clean. ed and dried.

LINIMENT, for sore backs.

Extract of saturn, half an ounce.

Vinegar one ounce.

Olive oil, two ounces.

To be incorporated weli, by shaking. LINIMENT, for old strains.

No. 1. Camphor, one ounce.

Oil of rosemary, half an ounce.

Oil of turpentine, two ounces.

Olive oil, four ounces.-Mix.

No. 2. Camphor, half an ounce.

Oil of origanum, two diams.

Soft soap, two ounces.

Spirit of wine, four ourices.-Mix.

Remurk-The liniments for strains, may be applied also to incipient spavins, windgalls, indurated swellings, and to parts affected with rheumatic pain ; by the addition of powdered cantharides, they may be converted into blistering liniments, and flower of mustard renders them highly stimulating. We have given a few receipts under the head, embrocations, though nearly every thing that can be useful, in that way, is comprehended in the present subject. 
LOTIONS. Liquids to wash diseased parts, they are employed chiefly in cases of external inflammation, or in cutaneous diseases.

Lo'Tion, for inflamed eyes.

No. 1. Extract of saturn, one dram. Spirit of wine, two drams. Water, eight ounces.-Mix.

No. 2. Vitriolated copper, half a dianr. Water, eight ounces.-Mix.

No. 3. Vitriolated zinc, one dram. Acetated lead, one dram. Water, twelve ounces.-Mix.

No. 4. Extract of henbane, one dram. Water, eight ounces.-Mix.

No. 5. Tincture of opium, two drams.

Water, six ounces.-Mix.

(See Eye Waters.)

COOLING LUTION, for external inflammation.

No. 1. Extract of saturu, one ounce. Vinegar, two ounces.

Camphorated spirit of wine, three ounces.

Water, eighteen ounces.-Mix.

No. 2. Crude sal ammoniac, one ounce.

Vinegar, four ounces. 
Spirit of wine, two ounces.

Water, eight ounces.-Mix.

These are remarkably useful in sadule galls, and inflamed tumours, which it is proper to disperse.

LOTION, for foul ulcers.

No. 1. Vitriolated copper, one ounce.

Nitrous acid, half an ounce.

Water, six ounces.-Mix.

No. 2. Nitrous acid, one ounce.

Quicksilver, half an ounce.

Dissolve in an open place, and in a large phial, or gally-pot, cautiously. When the solution is complete, add eight ounces of water.

OINTMENTS. External applications for wounds, \&c. (See Digestives, Detergents, and Blisters. See also Emollients, and Caustics.)

OINTISENT, for mange.

No. 1. Oil of turpentine, one ounce.

Vitriolic acid, two drams.

Mix cautiously in a large gally-pot, and avoid the fumes which arise. While this mixture is hot, add of hog's lard, four ounces. Sulphur vivum, finely powdered, two ounces.-Mix. 
No. 2. Hog's lard, four ounces.

Train oil, two ounces.

Oil of turpentine, one ounce.

Sulphur vivum, four ounces.-Mix.

Remark-These are effectual remedies for the mange, both in dogs, and horses. OINTMENT, for sore-backs, from saddlegalls, \&c.

No. 1. Ointment of althea, four ounces. Extract of saturn, or goulard, one ounce.-Mix.

No. 2. Camphor, two drams.

Oil of rosemary, one dram.

Oil of elder, or hoy's lard, three ounces.-Mix.

To these may be added ointments for fistula, poll-evil, and canker, but the remedies for those complaints have been already noticed under the articles, digestives, detergents, and caustics.

olNTMENr, for spavins, and wind-galls, Strong mercurial ointment, four ounces.

Camphor, half an ounce.

Oil of rosemary, two drams.

SOFTENING AND COOLING OINTMENT, for painful cracks, or ulcers of the heels. 
No. 1. Spermaceti ointment, four ounces. Olive oil, one ounce.

- Sugar of lead, two drams.

Flowers of zinc, one ounce.-Mix.

No. 2. Ointment of althea, four ounces. Extract of saturn, three drams. Oil of elder, half an ounce. Lapis calaminaris, finely levigated, one ounce.-Mix.

SATURNINE OINTMENT.

Spermaceti ointment, four cunces. Cold drawn linseed oil, one ounce.

Melt them slowly, by placing the gallypot in boiling water, and when the mixture is cooling, add of Goulard's extract, one ounce. Continue stirring until the mixture is cold.

Remark-There are various other ointments used by farriers, but the formulæ, or receipts we have given here, and in other places, will answer every jurpose. There is an ointment termed reyptiacum, much used by farriers, which is made by simmering over a slow fire, four ounces powdered verdigris, four ounces of honey, and eight ounces of strong vinegar; this is a detergent ointment, and the receipts we have given. 
under this head are, I think, more efficacious.

OXYMELS. Nixtures of honey and vinegar. (See Materia Medica.)

They have been recommended in obstinate coughs, and as a gargle in sore throats. I do not believe they are beneficial in either of those complaints. There is an oxymel of squills kept, which is made by infusing fresh squills in vinegar for several days, then straining off the liquid, and adding to it as much honey, as will, by boiling gently, and taking off the scum which arises, give it the' consistence of syrup.

This preparation is certainly much better adapted as a remedy to old coughs, than the simple oxymel.

The dose is three or four ounces.

PECTORALS. Medicines that cure or relieve diseases of the lungs. (See Expectorants, and Cordials, Pectoral.) Demulcents are also useful as pectorals, in some cases, $_{2}$ and may be given in the form of emulsions, which see. Emollients also are useful in certain complaints of the lung», particularly the linseed decoction, with a little honey dissolved in it Pectoral drintss have been 
recommended in diseases of the lungy, which are generally composed of liquorice, figs, and marshmallows, boiled in water.

POWDERS. This sometimes is a very convenient form for giving medicines, as many horses will take them in their corn without reluctance. It is by no means pro. per, however, for such as have a delicate appetite, and are remarkably nice in feeding; for alihough they may after some time cat their food, yet the reluctance with which it is taken would prevent its being readily digested, or proving so nutritious as it would do, were it not so medicated.

Some horses, however, eat their corn very readily when mixed with powder, and to such, it may be given without inconvenience. There is another objection to this mode of giving medicine, which is, the difficulty of ascertaining whether the whole or not, or how much of the powder, that is mixed with the corn, is taken. But this may, in a great measure, be dune away, by sprinkling the corn with water, and mixing the powder with it very carefully. As we have before ubserved, whenever a horse appears unwilling to eat his corn, thus medi- 
cated, the medicine should be given in some other form. The medicines best suited to this purpose are antimony, sulphur, resin, emetic tartar, nitre, aniseeds, \&c. Medicines toat are given in the form of powder, should be finely sifted, or levigated, and when kept in that form, a well corked bottle is most proper for the purpose.

RELAXANTS. Medicines that are supposed to relax the fibres of the body; or such as diminish the capacity for motion in the living fibres. It is generally, however, applied to those which lessen or stop unnatural or increased motions, as in convulsion and spasm. The principal remedies of this class, are antimonials, blecding, warm bathing, and opium.

REFRIGERANTS. Medicines which take off unnatural heat from the body, such as takes place in fevers.

The best remedies of this kind, are nitie, and other neutral salts. (See Materia Medica), cold water, and bleeding.

RESOLVENTS. This terin is applied to those applications, which are said to disperse inflamed tumours, or swellings, or ta 
subdue inflanmation of any kind. (See tinflammation.)

RESTRINGENTS. Medicines which restrain increased or unnatural evacuations. (See Astringents, Anodynes, and Styptics.)

ROBORANTS. (See Tonics.)

RUBEFACIENTS. A term used in medicine, for applications which excite redness upon the skin, and which are employed for the purpose of removing deeply seated pain or inflammation. The principal medicines of this kind are mustard and oil of turpentine. (See Embrocations, and Liniments.)

SEDATIVES. Medicines that allay or liminish spasmodic or painful motion in the living fibres of the body.

SIALOGUES. Medicines that cause an increased secretion of saliva, or a saliration; such as the preparations of mercury.

STIMULANTS. A term of very extensive signification, and may with propriety be applied to the greater part of the articles of the Matcria Nedica. Accorling to the celebrated Dr. John Brown, every medicine was considered as a stimu'ant : but it is probable that some, particularly the nareotics, have an opposite effect, particularly the dis- 
cilled laurel water. The term stimilant, is generally applied to those substances, which perceptibly increase the motion of the heart and arteries. And under this head a great variety of remedies are included, both internal and cxternal; among the former are cordials, cathartirs, diuretics, \&c. ; the latter consists of embrecations, ointments, liniments, \&c. It would fill a volume to treat properly of this subject, therefore we s'iall dismiss it without any further observation.

If the reader is desirous to obtain informa. tion on this head, he may consult Cullen's Materia Medica, Murray's Elements of Materia Medica, Brown's Elements of Medicine, and Darwin's Zoonomia.

STOMACHICs. Medicines that strengthen the stomac! and excite appetite.

The term is nearly synonimous with cordials in veteritary medicise; thoug! from stomachics we generally expect a more permanent effect than from those preparations denominated cordial, as they approach more to the nature of tonics. $\Lambda$ lew recripts will be girea under this head, which are intended for horses that feed bally, without any apparent cause, and such as are subject 
to flatulent cholic and indigestion. Horses of this description are generally lean snd in bad condition.

STOMACHIC BALL.

No. 1. Powdered gentian, half an ounce.

Powdered ginger, one dram and a half.

Prepared natron or soda, one dram.

" Treacle, enough to form the ball for one dose.

No. 2. Cascarilla, powdered, one ounce.

Myrrh, one dram and a half.

Cistile soap, one dram.

Syrup, enough to form the ball for one dose.

No. 3. Powdered quassia, two drams.

Aromatic powder, one dram and a half.

Salt of tartar, one dram.

Treacle, enough to form the ball for one dose.

No. 4. Powdered colombo root, half an ounce.

Powdered cassia, one dram.

Powdered rhubarb, two drams.

Syrup, enough to form the ball for one dose. 
STYPTICS. Applications which suppress hemorrhages or bleeding. It is sometimes applied also to those internal remedies which cure bleeding from the kidneys, or red water, and bleeding from the lungs. When any considerable blood vessel is wounded in the horse, styptics are not to be depended upon; and when the bleeding is so inconsiderable as to submit to those applications, there is little reason to doubt, that it would cease after a short time without their use. (See Mut. Med. Styptics.)

TEMPERATURE. This subject is very seldom attencied io in the management of horses, and it is very probable that many of their diseases arise from this omission. Horses that have been long accustomed to warm stahles, generally receive injury by being put suddenly into such as are cold, particularly when they are exposed to a current of air: and it is a well known fact, that many formidable diseases are produced by putting a horse that has been accurstomed to live in the open air, too suddenly into a warm stable. To this cause may be attributed the various diseases to which horses are subject when taken from grass or camp. 
In a well construcied stable, some mithod may easily be found for regulating the temperature of the air, and making it either cold or warm; for this purpose a thermometer should always be employed. Old horses that have been accustomed to warm stables, become lean and unfit for work if placed in a colder situation, though their allowance of corn be increased. External warmth is guite a cordial to them, and gives them health and spirits; but on no occasion do we recoumend those hot, close stables, so highly valued by grooms, though a very prolific source of disease. 'The stable should be always properly rentilater, and the body kept warm by clothing, adapted to the season of the year, and the temperature of the air.

TONICA. Medicines that augment the vigour of the boly permanently, and are therefore useful in all cases arising from debility.

\section{TONICS.}

No. 1. Powdered bark, one ounce.

Ginger, two drams.

Salt of tartar, half a dran. 
Form them into a ball with syrup. No. 2. Salt of steel, half an ounce. Aromatic powder, two drams.

Mucilage, enough to form the ball for one dose.

No. 3. Arsenic, ten grains.

Ginger, one dram.

Powdered aniseed, half an ounce.

Compound powder of tragacanth, two drams.

Syrup, to form the ball for one dose.

UNGUENTS. (See Ointments.)

URINE BALLS. (See Diuretics.)

WATER. Much has been written respecting the different qualities of water, some having been considered as very injurious to horses, while others have been said to promote health and condition. Dr. Bracken thought hard or pump water liable to produce the gravel or stone; and other authors have had still more whimsical notions on this subject. It appears probable that transparent and sweet water, that is, such as is most grateful to man, is most wholesome for horses, whether it be taken from a well, or from any other situation. The ill effects that hav sometimes resulted. 
from drinking certain kinds of water, may depend upon its being drank too largely, or at too cold a temperature, at a time when the stomach was not in a condition for receiving so much, or, upon its being so ill tasted, that the horse does not take a sufficient quantity for the purposes of digestion; or if he does, it may create that degree of nausea, which prores injurious to the stomach, and iiispedes its functions. In the former way we may explain the production of cholic or gripes, by drinking largely of pump water in summer, when the body is heated too much; and in the latter we can account for that loss of condition and staring coat, so remarkable in horses that are kept on the coast where the water is brackish.

$$
\text { FI N } 1 \mathrm{~S} \text {, }
$$

H. Bryer, Printer, Bridge Street, Blachfriars. 






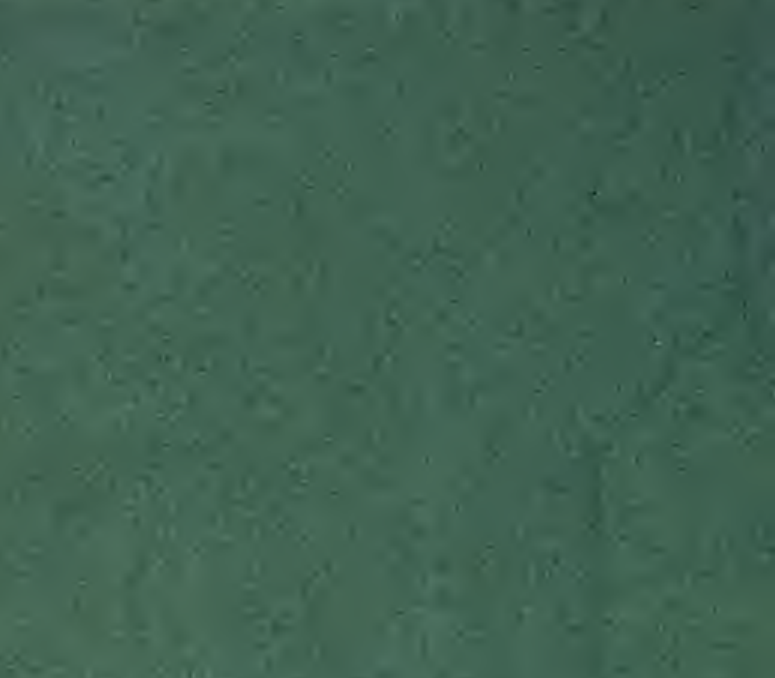

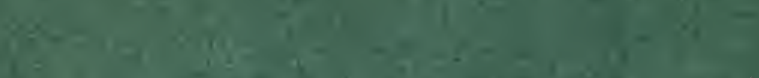
(2)

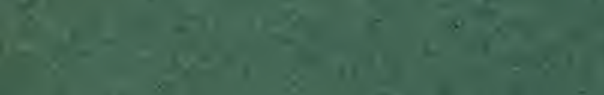

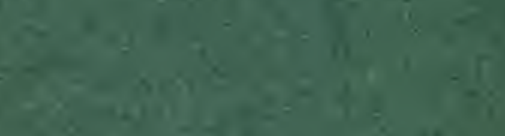

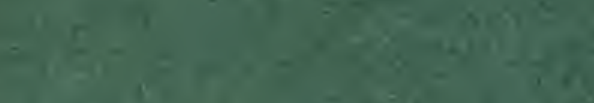

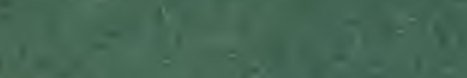

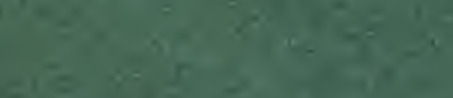
$-2+8$

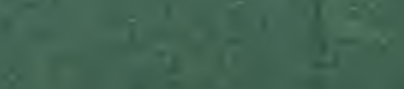

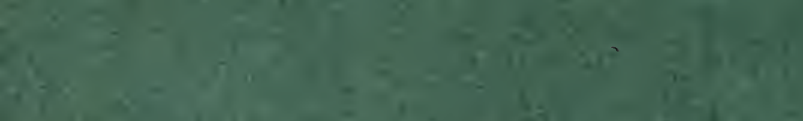

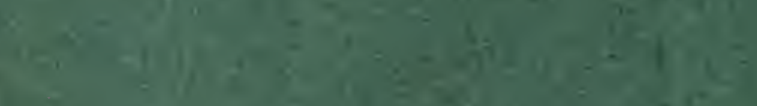

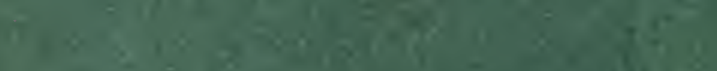

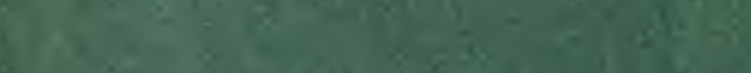

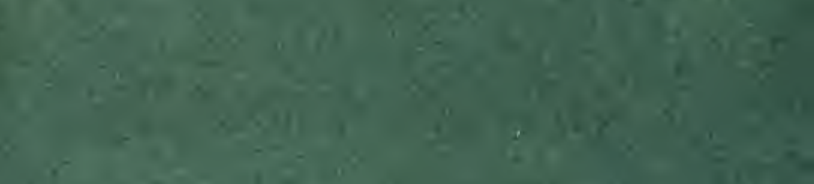




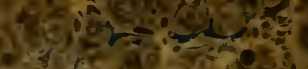

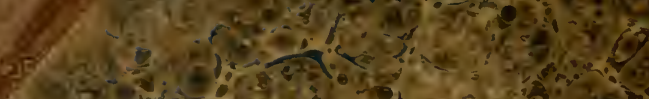

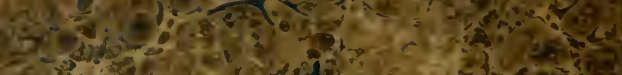

E.

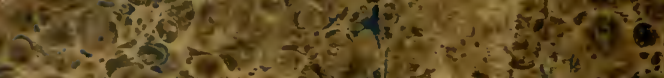

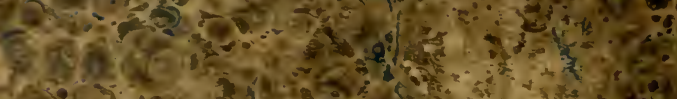

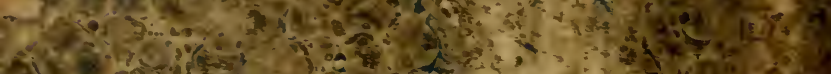

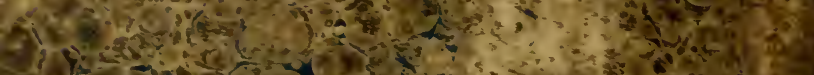

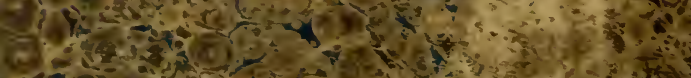

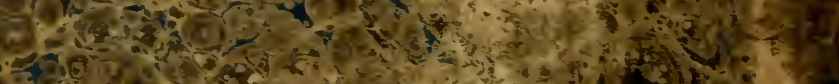

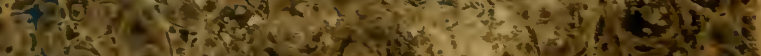

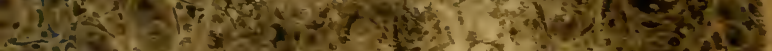

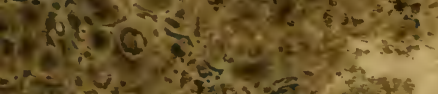

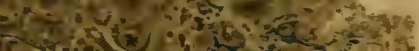
r. $\therefore$ C.

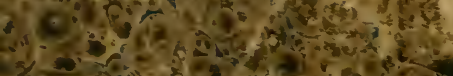

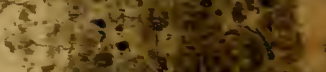

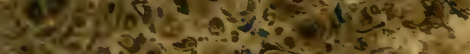

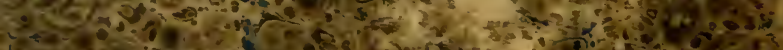

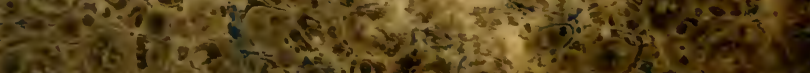

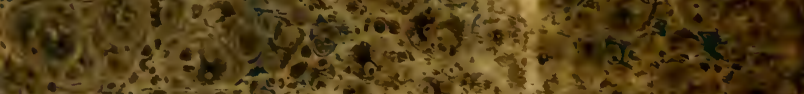

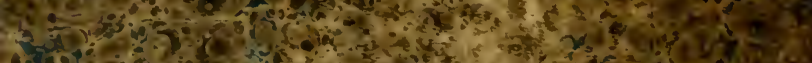

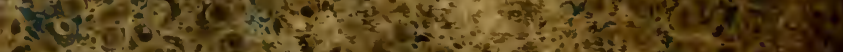

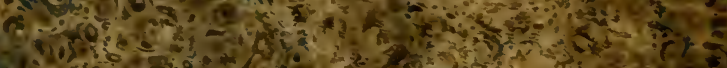
20130 9.

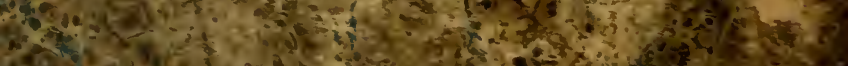

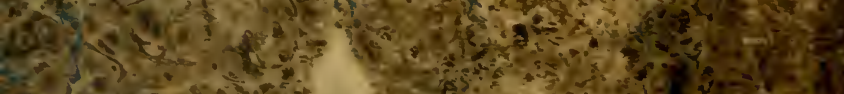

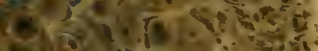

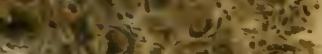

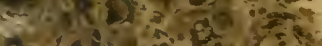

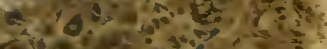

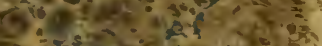

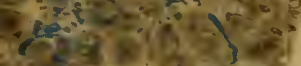

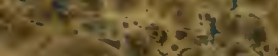

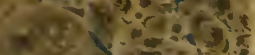

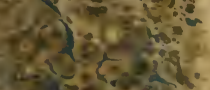

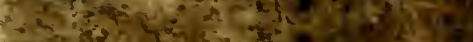

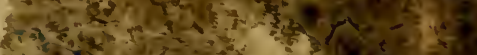

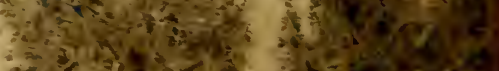

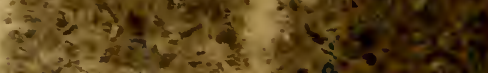

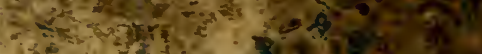

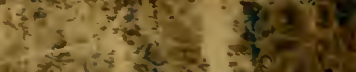

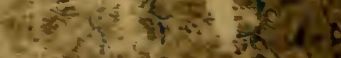

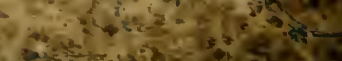

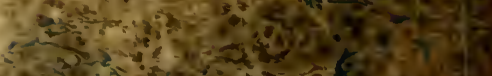
0 